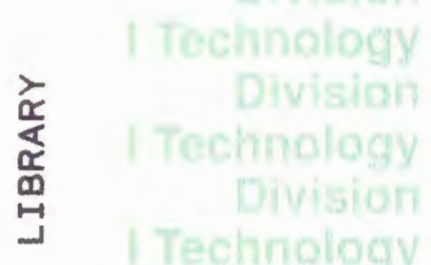

Division

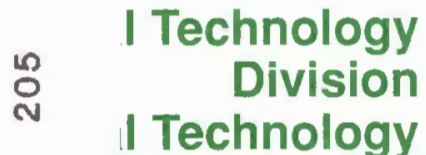

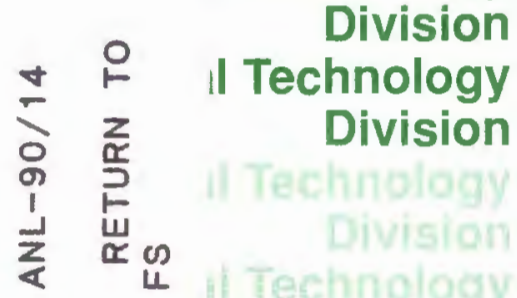

Division

Chemical Technology

Division

Chemical Technology

Division

Chemical Technolocy

Division

Chemical Technology

Orvision

Chemical Technology

Division

Chemical Technology

Division

Chemical Technology

Division

Chemical Technology

Division
Radiolysis and Hydrolysis of TRUEX-NPH Solvent

by N. Simonzadeh, A. M. Crabtree, L. E. Trevorrow, and G. F. Vandegrift

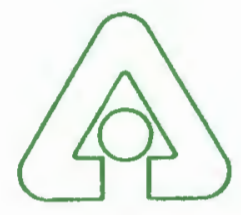

Argonne National Laboratory, Argonne, Illinois 60439

operated by The University of Chicago

for the United States Department of Energy under Contract W-31-109-Eng-38 
Argonne National Laboratory, with facilities in the states of Illinois and Idaho, is owned by the United States government, and operated by The University of Chicago under the provisions of a contract with the Department of Energy.

\section{DISCLAIMER}

This report was prepared as an account of work sponsored by an agency of the United States Government. Neither the United States Government nor any agency thereof, nor any of their employees, makes any warranty, express or implied, or assumes any legal liability or responsibility for the accuracy, completeness, or usefulness of any information, apparatus, product, or process disclosed, or represents that its use would not infringe privately owned rights. Reference herein to any specific commercial product, process, or service by trade name, trademark, manufacturer, or otherwise, does not necessarily constitute or imply its endorsement, recommendation, or favoring by the United States Government or any agency thereof. The views and opinions of authors expressed herein do not necessarily state or reflect those of the United States Government or any agency thereof.

Reproduced from the best available copy.

Available to DOE and DOE contractors from the Office of Scientific and Technical Information P.O. Box 62

Oak Ridge, TN 37831

Prices available from (615) 576-8401

Available to the public from the National Technical Information Service

U.S. Department of Commerce 5285 Port Royal Road Springfield, VA 22161 
Distribution Category:

Defense Waste Management (UC-721)

ANL-90/14

ARGONNE NATIONAL LABORATORY

9700 South Cass Avenue

Argonne, IL 60439-4801

RADIOLYSIS AND HYDROLYSIS OF TRUEX-NPH SOLVENT

by

N. Simonzadeh, ${ }^{*}$ A. M. Crabtree, ${ }^{* *}$ L. E. Trevorrow, and G. F. Vandegrift

Chemical Technology Division

July 1992

"Abbott Laboratories, 1401 Sheridan Road, North Chicago, IL.

**Graduate Student, Iowa State University, Ames, IA. 



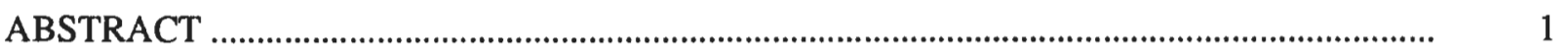

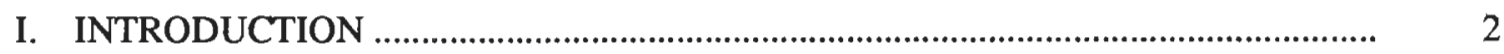

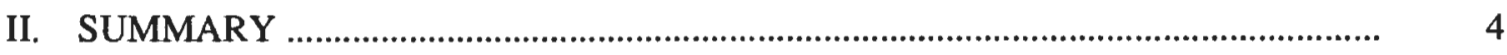

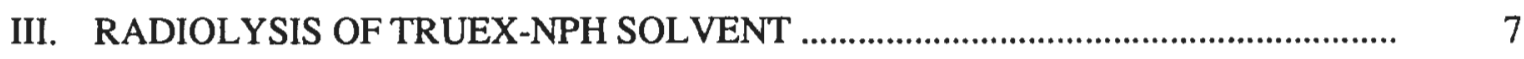

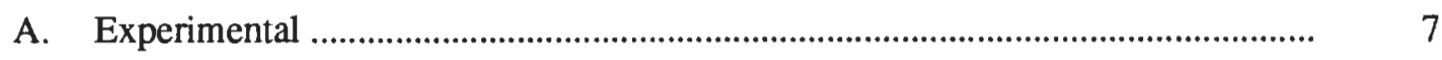

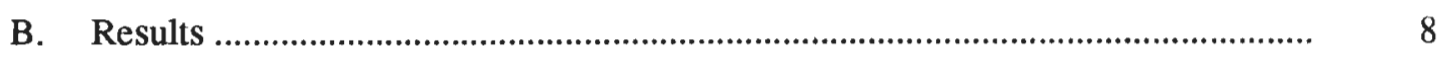

C. Mathematical Expressions of $\mathrm{D}_{\mathrm{Am}}$ as a Function of Dose …............................. 11

1. Expression of $\mathrm{D}_{\mathrm{Am}}^{.01}$ as Function of Dose ............................................... 11

2. Expression of $\mathrm{D}_{\mathrm{Am}}^{\mathrm{Am}} .05$ as Function of Dose ..................................................... 12

3. Expression of $\mathrm{D}_{\mathrm{Am}}^{2.0}$ and Calculation of Radiation Chemical Yield for CMPO Destruction ................................................................. 12

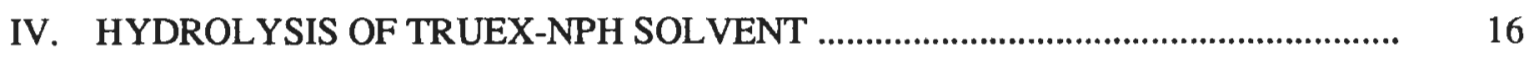

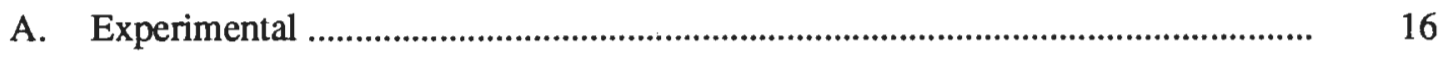

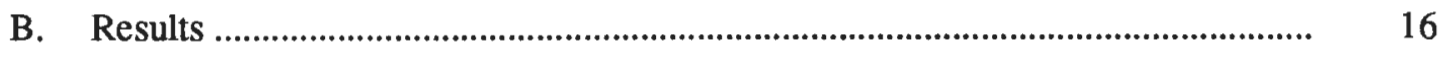

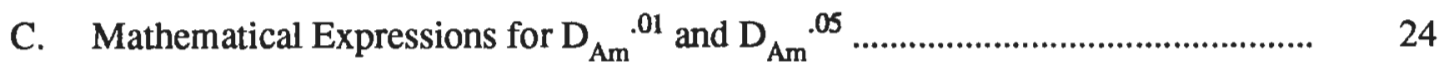

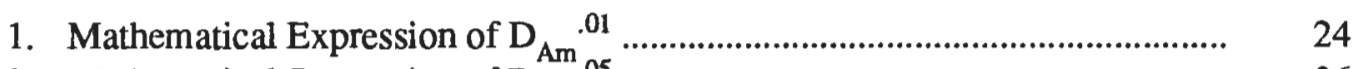

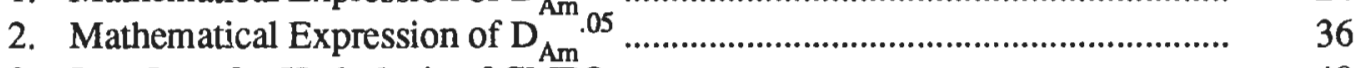

3. Rate Law for Hydrolysis of CMPO ............................................................... 48

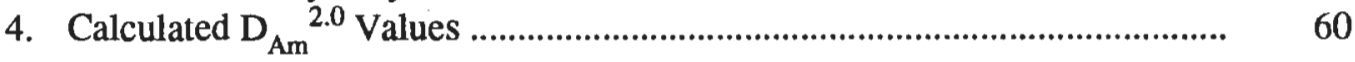

V. APPLICATION OF EXPRESSIONS FOR RADIOLYSIS AND HYDROLYSIS TO PROCESSING SYSTEMS .......................................................................... 61

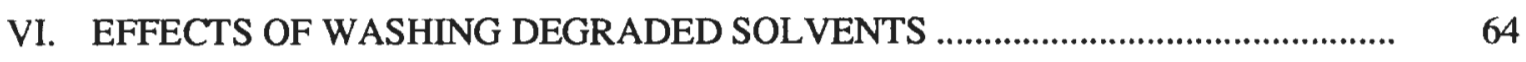

VII. CHANGE OF ACIDITY ACCOMPANYING RADIOLYSIS AND HYDROLYSIS

A. Changes in Acidity of Aqueous Phase in Contact with TRUEX-NPH Solvent During Radiolysis 
TABLE OF CONTENTS (contd)

Page

B. Changes in Acidity of Organic Phase During Hydrolysis ................................. 67

VIII. EFFECTS OF SOLVENT DEGRADATION ON DISTRIBUTION BEHAVIOR

OF NONTRANSURANIC ELEMENTS

REFERENCES

70

APPENDIX A. REAGENTS

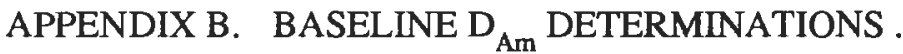

APPENDIX C. CALCULATIONS OF CMPO CONCENTRATIONS IN PROCESSING SYSTEMS

APPENDIX D. EXPRESSIONS FOR VARIATION OF D ${ }_{\mathrm{Am}}^{.01}$ and $\mathrm{D}_{\mathrm{Am}}^{.05} \mathrm{WITH}$ RADIOLYSIS AND HYDROLYSIS APPLIED TO PROCESS SYSTEMS

APPENDIX E. SOLVENT WASHING DATA

APPENDIX F. ACIDITY OF ORGANIC AND AQUEOUS PHASES

97

APPENDIX G. ANALYSIS OF NONTRANSURANIC ELEMENTS IN DEGRADED SOLVENT EQUILIBRATED WITH SYNTHETIC WASTE SOLUTIONS 


\section{LIST OF FIGURES}

No.

Title

$\underline{\text { Page }}$

III-1. Dependence of $\mathrm{D}_{\mathrm{Am}}{ }^{.01}, \mathrm{D}_{\mathrm{Am}}{ }^{.05}$, and $\mathrm{D}_{\mathrm{Am}}{ }^{2.0}$ on Dose

Received by Solvent during Previous Irradiation

at $50^{\circ} \mathrm{C}$ in Contact with $0.25 \underline{\mathrm{M}} \mathrm{HNO}_{3}$

III-2. Dependence of $\mathrm{D}_{\mathrm{Am}}{ }^{.01}, \mathrm{D}_{\mathrm{Am}}{ }^{.05}$, and $\mathrm{D}_{\mathrm{Am}}{ }^{2.0}$ on Dose

Received by Solvent during Previous Irradiation

at $50^{\circ} \mathrm{C}$ in Contact with $2.5 \underline{\mathrm{M}} \mathrm{HNO}_{3}$

III-3. Dependence of $\mathrm{D}_{\mathrm{Am}}{ }^{.01}, \mathrm{D}_{\mathrm{Am}}{ }^{.05}$, and $\mathrm{D}_{\mathrm{Am}}{ }^{2.0}$ on Dose

Received by Solvent during Previous Irradiation

at $50^{\circ} \mathrm{C}$ in Contact with $6.0 \mathrm{M} \mathrm{HNO}_{3}$

III-4. Dependence of $\mathrm{D}_{\mathrm{Am}}{ }^{.01}, \mathrm{D}_{\mathrm{Am}}{ }^{.05}$, and $\mathrm{D}_{\mathrm{Am}}{ }^{2.0}$ on Dose Received by Solvent during Previous Irradiation at $50^{\circ} \mathrm{C}$ in Contact with Simulated

CAW Containing 1.6 $\mathrm{MNO}_{3}$

III-5. Dependence of $\mathrm{D}_{\mathrm{Am}}{ }^{.01}, \mathrm{D}_{\mathrm{Am}}{ }^{.05}$, and $\mathrm{D}_{\mathrm{Am}}{ }^{2.0}$ on Dose Received by Solvent during Previous Irradiation at $50^{\circ} \mathrm{C}$ in Contact with Simulated

CAW Containing $2.6 \underline{\mathrm{M}} \mathrm{HNO}_{3}$

III-6. $\quad \mathrm{D}_{\mathrm{Am}}^{.01}$ as Function of Dose Received by Solvent

III-7. $\quad \mathrm{D}_{\mathrm{Am}}{ }^{.05}$ as Function of Dose Received by Solvent

III-8. $\quad\left(D_{\mathrm{Am}}{ }^{2.0}\right)^{1 / 3}$ as Function of Dose Received by Solvent

III-9. Radiation Chemical Yield for the Radiolysis of CMPO in

TRUEX-NPH Solvent for Five Values of $n$

IV-1. Dependence of $\mathrm{D}_{\mathrm{Am}}{ }^{.01}, \mathrm{D}_{\mathrm{Am}}{ }^{.05}$, and $\mathrm{D}_{\mathrm{Am}}{ }^{2.0}$ on Hydrolysis Time for TRUEX-NPH Solvent Previously Hydrolyzed by $0.25 \underline{\mathrm{M}} \mathrm{HNO}_{3}$ at $50^{\circ} \mathrm{C}$

IV-2. Dependence of $\mathrm{D}_{\mathrm{Am}}{ }^{.01}, \mathrm{D}_{\mathrm{Am}}{ }^{.05}$, and $\mathrm{D}_{\mathrm{Am}}{ }^{2.0}$ on Hydrolysis Time for TRUEX-NPH Solvent Previously Hydrolyzed by $2.5 \underline{\mathrm{M} \mathrm{HNO}_{3}}$ at $50^{\circ} \mathrm{C}$

IV-3. Dependence of $\mathrm{D}_{\mathrm{Am}}{ }^{.01}, \mathrm{D}_{\mathrm{Am}}{ }^{.05}$, and $\mathrm{D}_{\mathrm{Am}}{ }^{2.0}$ on Hydrolysis Time for TRUEX-NPH Solvent Previously Hydrolyzed by $6.0 \underline{\mathrm{M}} \mathrm{HNO}_{3}$ at $50^{\circ} \mathrm{C}$

IV-4. Dependence of $\mathrm{D}_{\mathrm{Am}}{ }^{.01}, \mathrm{D}_{\mathrm{Am}}{ }^{.05}$, and $\mathrm{D}_{\mathrm{Am}}{ }^{2.0}$ on Hydrolysis Time for TRUEX-NPH Solvent Previously Hydrolyzed by Simulated CAW Containing $1.6 \mathrm{M} \mathrm{HNO}_{3}$ at $50^{\circ} \mathrm{C}$ 


\section{LIST OF FIGURES (contd)}

No.

IV-5. Dependence of $\mathrm{D}_{\mathrm{Am}}{ }^{.01}, \mathrm{D}_{\mathrm{Am}}{ }^{.05}$, and $\mathrm{D}_{\mathrm{Am}}{ }^{2.0}$ on Hydrolysis Time for TRUEX-NPH Solvent Previously Hydrolyzed by Simulated CAW Containing $2.6 \mathrm{M} \mathrm{HNO}_{3}$ at $50^{\circ} \mathrm{C}$

IV-6. Dependence of $\mathrm{D}_{\mathrm{Am}}{ }^{.01}, \mathrm{D}_{\mathrm{Am}}{ }^{.05}$, and $\mathrm{D}_{\mathrm{Am}}{ }^{2.0}$ on Hydrolysis Time for TRUEX-NPH Solvent Previously Hydrolyzed by $0.25 \underline{\mathrm{M}} \mathrm{HNO}_{3}$ at $70^{\circ} \mathrm{C}$

IV-7. Dependence of $\mathrm{D}_{\mathrm{Am}}{ }^{.01}, \mathrm{D}_{\mathrm{Am}}{ }^{.05}$, and $\mathrm{D}_{\mathrm{Am}}{ }^{2.0}$ on Hydrolysis Time for TRUEX-NPH Solvent Previously Hydrolyzed by $2.5 \underline{\mathrm{M}} \mathrm{HNO}_{3}$ at $70^{\circ} \mathrm{C}$

IV-8. Dependence of $\mathrm{D}_{\mathrm{Am}}{ }^{.01}, \mathrm{D}_{\mathrm{Am}}{ }^{.05}$, and $\mathrm{D}_{\mathrm{Am}}{ }^{2.0}$ on Hydrolysis Time for TRUEX-NPH Solvent Previously Hydrolyzed by $6.0 \mathrm{M} \mathrm{HNO}_{3}$ at $70^{\circ} \mathrm{C}$

IV-9. Dependence of $\mathrm{D}_{\mathrm{Am}}{ }^{.01}, \mathrm{D}_{\mathrm{Am}}{ }^{.05}$, and $\mathrm{D}_{\mathrm{Am}}{ }^{2.0}$ on Hydrolysis Time for TRUEX-NPH Solvent Previously Hydrolyzed by Simulated CAW Containing 1.6ㅆ $\mathrm{HNO}_{3}$ at $70^{\circ} \mathrm{C}$

IV-10. Dependence of $\mathrm{D}_{\mathrm{Am}}{ }^{.01}, \mathrm{D}_{\mathrm{Am}}{ }^{.05}$, and $\mathrm{D}_{\mathrm{Am}}{ }^{2.0}$ on Hydrolysis Time for TRUEX-NPH Solvent Previously Hydrolyzed by Simulated CAW Containing 2.6M $\mathrm{HNO}_{3}$ at $70^{\circ} \mathrm{C}$

IV-11. Dependence of $\mathrm{D}_{\mathrm{Am}}^{.01}, \mathrm{D}_{\mathrm{Am}}^{.05}$, and $\mathrm{D}_{\mathrm{Am}}{ }^{2.0}$ on Hydrolysis Time for TRUEX-NPH Solvent Previously Hydrolyzed by $0.25 \mathrm{M} \mathrm{HNO}_{3}$ at $95^{\circ} \mathrm{C}$

IV-12. Dependence of $\mathrm{D}_{\mathrm{Am}}{ }^{.01}, \mathrm{D}_{\mathrm{Am}}{ }^{.05}$, and $\mathrm{D}_{\mathrm{Am}}{ }^{2.0}$ on Hydrolysis Time for TRUEX-NPH Solvent Previously Hydrolyzed by $2.5 \mathrm{M} \mathrm{HNO}_{3}$ at $95^{\circ} \mathrm{C}$

IV-13. Dependence of $\mathrm{D}_{\mathrm{Am}}{ }^{.01}, \mathrm{D}_{\mathrm{Am}}{ }^{.05}$, and $\mathrm{D}_{\mathrm{Amn}}{ }^{2.0}$ on Hydrolysis Time for TRUEX-NPH Solvent Previously Hydrolyzed by $6.0 \mathrm{M} \mathrm{HNO}_{3}$ at $95^{\circ} \mathrm{C}$

IV-14. Dependence of $\mathrm{D}_{\mathrm{Am}}{ }^{.01}, \mathrm{D}_{\mathrm{Am}}{ }^{.05}$, and $\mathrm{D}_{\mathrm{Am}}{ }^{2.0}$ on Hydrolysis Time for TRUEX-NPH Solvent Previously Hydrolyzed by Simulated $\mathrm{CAW}$ Containing 1.6 $\mathrm{MNO}_{3}$ at $95^{\circ} \mathrm{C}$.

IV-15. Dependence of $\mathrm{D}_{\mathrm{Am}}{ }^{.01}, \mathrm{D}_{\mathrm{Am}}{ }^{.05}$, and $\mathrm{D}_{\mathrm{Am}}{ }^{2.0}$ on Hydrolysis Time for TRUEX-NPH Solvent Previously Hydrolyzed by Simulated $\mathrm{CAW}$ Containing $2.6 \mathrm{M} \mathrm{HNO}_{3}$ at $95^{\circ} \mathrm{C}$

IV-16. Graph of $\mathrm{D}_{\mathrm{Am}}{ }^{.01}$ versus Hydrolysis Time Using $0.25 \underline{\mathrm{M}} \mathrm{HNO}_{3}$ at $50^{\circ} \mathrm{C}$ 


\section{LIST OF FIGURES (contd)}

No.

Title

$\underline{\text { Page }}$

IV-17. Graph of $\mathrm{D}_{\mathrm{Am}}{ }^{.01}$ versus Hydrolysis Time Using $2.5 \mathrm{M} \mathrm{HNO}_{3}$

at $50^{\circ} \mathrm{C}$

IV-18. Graph of $\mathrm{D}_{\mathrm{Am}}{ }^{.01}$ versus Hydrolysis Time Using $6.0 \mathrm{M} \mathrm{HNO}_{3}$ at $50^{\circ} \mathrm{C}$

IV-19. Graph of $\mathrm{D}_{\mathrm{Am}}{ }^{.01}$ versus Hydrolysis Time Using Simulated CAW

Containing $1.6 \underline{\mathrm{M} \mathrm{HNO}} \mathrm{H}_{3}$ at $50^{\circ} \mathrm{C}$.

IV-20. Graph of $\mathrm{D}_{\mathrm{Am}}^{.01}$ versus Hydrolysis Time Using Simulated CAW

Containing 2.6ㅉ $\mathrm{HNO}_{3}$ at $50^{\circ} \mathrm{C}$

IV-21. Graph of $\mathrm{D}_{\mathrm{Am}}^{.01}$ versus Hydrolysis Time Using $0.25 \underline{\mathrm{M}} \mathrm{HNO}_{3}$

at $70^{\circ} \mathrm{C}$

IV-22. Graph of $\mathrm{D}_{\mathrm{Am}}{ }^{.01}$ versus Hydrolysis Time Using $2.5 \underline{\mathrm{M}} \mathrm{HNO}_{3}$

at $70^{\circ} \mathrm{C}$

IV-23. Graph of $\mathrm{D}_{\mathrm{Am}}{ }^{.01}$ versus Hydrolysis Time Using $6.0 \mathrm{M} \mathrm{HNO}_{3}$

at $70^{\circ} \mathrm{C}$

IV-24. Graph of $\mathrm{D}_{\mathrm{Am}}{ }^{.01}$ versus Hydrolysis Time Using Simulated CAW

Containing $1.6 \mathrm{M} \mathrm{HNO}_{3}$ at $70^{\circ} \mathrm{C}$

IV-25. Graph of $\mathrm{D}_{\mathrm{Am}}{ }^{.01}$ versus Hydrolysis Time Using Simulated CAW

Containing 2.6ㅆ $\mathrm{HNO}_{3}$ at $70^{\circ} \mathrm{C}$

IV-26. Graph of $\mathrm{D}_{\mathrm{Am}}^{.01}$ versus Hydrolysis Time Using $0.25 \underline{\mathrm{M}} \mathrm{HNO}_{3}$ at $95^{\circ} \mathrm{C}$

IV-27. Graph of $\mathrm{D}_{\mathrm{Am}} .01$ versus Hydrolysis Time Using $2.5 \underline{\mathrm{M}} \mathrm{HNO}_{3}$ at $95^{\circ} \mathrm{C}$

IV-28. Graph of $\mathrm{D}_{\mathrm{Am}}^{.01}$ versus Hydrolysis Time Using 6.0 $\underline{\mathrm{M}} \mathrm{HNO}_{3}$ at $95^{\circ} \mathrm{C}$

IV-29. Graph of $\mathrm{D}_{\mathrm{Am}}^{.01}$ versus Hydrolysis Time Using Simulated CAW

Containing $1.6 \mathrm{M} \mathrm{HNO} \mathrm{HN}_{3}$ at $95^{\circ} \mathrm{C}$

IV-30. Graph of $\mathrm{D}_{\mathrm{Am}}{ }^{.01}$ versus Hydrolysis Time Using Simulated CAW Containing $2.6 \underline{\mathrm{M} \mathrm{HNO}} \mathrm{HN}_{3}$ at $95^{\circ} \mathrm{C}$

IV-31. Graph of $\mathrm{k}_{\mathrm{h}}{ }^{.01}$ versus Activity of $\mathrm{HNO}_{3}$ in Aqueous Solution Used as Hydrolytic Agent at $50^{\circ} \mathrm{C}$ 


\section{LIST OF FIGURES (contd)}

No.

Title

$\underline{\text { Page }}$

IV-32. Graph of $\mathrm{k}_{\mathrm{h}}{ }^{.01}$ versus Activity of $\mathrm{HNO}_{3}$ in Aqueous Solution

Used as Hydrolytic Agent at $70^{\circ} \mathrm{C}$

IV-33. Graph of $\mathrm{k}_{\mathrm{h}}{ }^{.01}$ versus Activity of $\mathrm{HNO}_{3}$ in Aqueous Solution

Used as Hydrolytic Agent at $95^{\circ} \mathrm{C}$

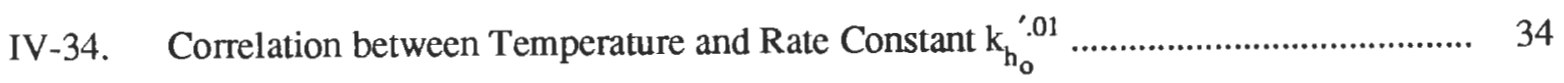

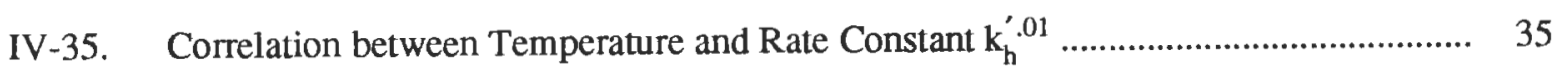

IV-36. Comparison of Calculated Values for $\mathrm{D}_{\mathrm{Am}}{ }^{.01}$ with Observed Values

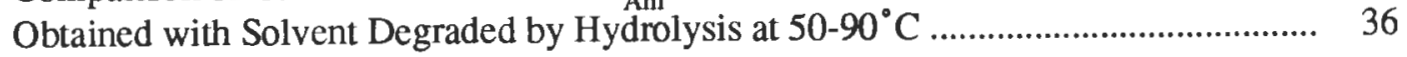

IV-37. Graph of $\mathrm{D}_{\mathrm{Am}}^{.05}$ versus Hydrolysis Time at $50^{\circ} \mathrm{C}$ with $0.25 \underline{\mathrm{M}} \mathrm{HNO}_{3} \ldots \ldots \ldots \ldots \ldots \ldots \ldots . . . . . . . . . .37$

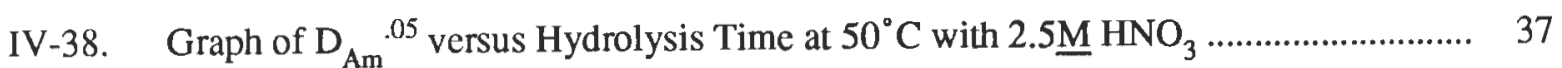

IV-39. Graph of $\mathrm{D}_{\mathrm{Am}}^{.05}$ versus Hydrolysis Time at $50^{\circ} \mathrm{C}$ with $6.0 \mathrm{M} \mathrm{HNO}_{3} \ldots \ldots \ldots \ldots \ldots \ldots \ldots \ldots . . . . . . . . . . . .38$

IV-40. Graph of $\mathrm{D}_{\mathrm{Am}}^{.05}$ versus Hydrolysis Time at $50^{\circ} \mathrm{C}$ with Simulated

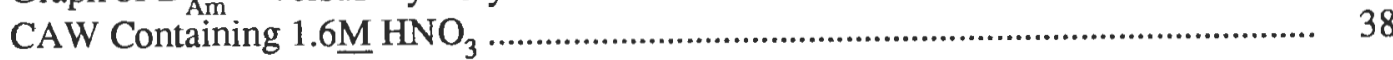

IV-41. Graph of $\mathrm{D}_{\mathrm{Am}}^{.05}$ versus Hydrolysis Time at $50^{\circ} \mathrm{C}$ with Simulated

CAW Containing $2.6 \underline{\mathrm{M} \mathrm{HNO}} 3$

IV-42. Graph of $\mathrm{D}_{\mathrm{Am}}{ }^{.05}$ versus Hydrolysis Time at $70^{\circ} \mathrm{C}$ with $0.25 \underline{\mathrm{M}} \mathrm{HNO}_{3} \ldots \ldots \ldots \ldots \ldots \ldots \ldots . . . . . . . . . . .39$

IV-43. Graph of $\mathrm{D}_{\mathrm{Am}}{ }^{.05}$ versus Hydrolysis Time at $70^{\circ} \mathrm{C}$ with $2.5 \underline{\mathrm{M}} \mathrm{HNO}_{3} \ldots \ldots \ldots \ldots \ldots \ldots \ldots \ldots . . . . . . . . . . .40$

IV-44. Graph of $\mathrm{D}_{\mathrm{Am}}^{.05}$ versus Hydrolysis Time at $70^{\circ} \mathrm{C}$ with $6.0 \mathrm{M} \mathrm{HNO}_{3} \ldots \ldots \ldots \ldots \ldots \ldots \ldots . . . . . . . . . . .40$

IV-45. Graph of $\mathrm{D}_{\mathrm{Am}}^{.05}$ versus Hydrolysis Time at $70^{\circ} \mathrm{C}$ with Simulated

CAW Containing 1.6ㅆ $\mathrm{HNO}_{3}$

IV-46. Graph of $\mathrm{D}_{\mathrm{Am}}^{.05}$ versus Hydrolysis Time at $70^{\circ} \mathrm{C}$ with Simulated

CAW Containing 2.6ㅆ $\mathrm{HNO}_{3}$

IV-47. Graph of $\mathrm{D}_{\mathrm{Am}}{ }^{.05}$ versus Hydrolysis Time at $95^{\circ} \mathrm{C}$ with $0.25 \underline{\mathrm{M}} \mathrm{HNO}_{3} \ldots \ldots \ldots \ldots \ldots \ldots \ldots . . . . . . . . .42$

IV-48. Graph of $\mathrm{D}_{\mathrm{Am}}^{.05}$ versus Hydrolysis Time at $95^{\circ} \mathrm{C}$ with $2.5 \underline{\mathrm{M}} \mathrm{HNO}_{3} \ldots \ldots \ldots \ldots \ldots \ldots \ldots \ldots . . . . . . . . . . . .42$

IV-49. Graph of $\mathrm{D}_{\mathrm{Am}}{ }^{.05}$ versus Hydrolysis Time at $95^{\circ} \mathrm{C}$ with $6.0 \underline{\mathrm{M}} \mathrm{HNO}_{3} \ldots \ldots \ldots \ldots \ldots \ldots \ldots \ldots . . . . . . . . . . . . .43$

IV-50. Graph of $\mathrm{D}_{\mathrm{Am}}^{.05}$ versus Hydrolysis Time at $95^{\circ} \mathrm{C}$ with Simulated

$\mathrm{CAW}$ Containing $1.6 \underline{\mathrm{M}} \mathrm{HNO}_{3}$ 


\section{LIST OF FIGURES (contd)}

No.

Title

$\underline{\text { Page }}$

IV-51. Graph of $\mathrm{D}_{\mathrm{Am}}^{.05}$ versus Hydrolysis Time at $95^{\circ} \mathrm{C}$ with Simulated

CAW Containing 2.6 $\mathrm{MNO}_{3}$

IV-52. Graph of $\mathrm{k}_{\mathrm{h}}{ }^{.05}$ versus Activity of Hydrogen Ion in Aqueous Solution

Used as Hydrolytic Agent at $50^{\circ} \mathrm{C}$

IV-53. Graph of $k_{b}{ }^{.05}$ versus Activity of Hydrogen Ion in Aqueous Solution

Used as Hydrolytic Agent at $70^{\circ} \mathrm{C}$

IV-54. Graph of $k_{b}{ }^{.05}$ versus Activity of Hydrogen Ion in Aqueous Solution

Used as Hydrolytic Agent at $95^{\circ} \mathrm{C}$

IV-55. Correlation between Temperature and Rate Constant $\mathrm{k}_{\mathrm{h}_{\mathrm{o}}} .05$

IV-56. Comparison of Calculated Values for $\mathrm{D}_{\text {Am }}^{.05}$ with Observed Values

Obtained with Solvent Degraded by Hydrolysis at $50-95^{\circ} \mathrm{C}$

IV-57. Graph of $\mathrm{D}_{\mathrm{Am}}{ }^{2.0}$ versus Hydrolysis Time at $50^{\circ} \mathrm{C}$ with $0.25 \underline{\mathrm{M}} \mathrm{HNO}_{3} \ldots \ldots \ldots \ldots \ldots \ldots \ldots . . . . . . . . . . .49$

IV-58. Graph of $\mathrm{D}_{\mathrm{Am}}{ }^{2.0}$ versus Hydrolysis Time at $50^{\circ} \mathrm{C}$ with $2.5 \underline{\mathrm{M}} \mathrm{HNO}_{3} \ldots \ldots \ldots \ldots \ldots \ldots \ldots \ldots . . . . . . . . . . . .50$

IV-59. Graph of $\mathrm{D}_{\mathrm{Am}}{ }^{2.0}$ versus Hydrolysis Time at $50^{\circ} \mathrm{C}$ with $6.0 \mathrm{M} \mathrm{HNO}_{3} \ldots \ldots \ldots \ldots \ldots \ldots \ldots \ldots . . . . . . . . . . .50$

IV-60. Graph of $\mathrm{D}_{\mathrm{Am}}{ }^{2.0}$ versus Hydrolysis Time at $50^{\circ} \mathrm{C}$ with Simulated CAW Containing 1.6ㅆ $\mathrm{HNO}_{3}$

IV-61. Graph of $\mathrm{D}_{\mathrm{Am}}{ }^{2.0}$ versus Hydrolysis Time at $50^{\circ} \mathrm{C}$ with Simulated CAW Containing 2.6 $\underline{\mathrm{M}} \mathrm{HNO}_{3}$

IV-62. Graph of $\mathrm{D}_{\mathrm{Am}}{ }^{2.0}$ versus Hydrolysis Time at $70^{\circ} \mathrm{C}$ with $0.25 \underline{\mathrm{M}} \mathrm{HNO}_{3} \ldots \ldots \ldots \ldots \ldots \ldots \ldots . . . . . . . . . .52$

IV-63. Graph of $\mathrm{D}_{\mathrm{Am}}{ }^{2.0}$ versus Hydrolysis Time at $70^{\circ} \mathrm{C}$ with $2.5 \underline{\mathrm{M}} \mathrm{HNO}_{3} \ldots \ldots \ldots \ldots \ldots \ldots \ldots \ldots . . . . . . . . . . .52$

IV-64. Graph of $\mathrm{D}_{\mathrm{Am}}{ }^{2.0}$ versus Hydrolysis Time at $70^{\circ} \mathrm{C}$ with $6.0 \underline{\mathrm{M}} \mathrm{HNO}_{3} \ldots \ldots \ldots \ldots \ldots \ldots \ldots \ldots \ldots . . . . . . . . . . .53$

IV-65. Graph of $\mathrm{D}_{\mathrm{Am}}^{2.0}$ versus Hydrolysis Time at $70^{\circ} \mathrm{C}$ with Simulated CAW Containing 1.6ㅆ $\mathrm{HNO}_{3}$

IV-66. Graph of $\mathrm{D}_{\mathrm{Am}}{ }^{2.0}$ versus Hydrolysis Time at $70^{\circ} \mathrm{C}$ with Simulated CAW Containing 2.6 $\underline{\mathrm{M}} \mathrm{HNO}_{3}$

IV-67. Graph of $\mathrm{D}_{\mathrm{Am}}{ }^{2.0}$ versus Hydrolysis Time at $95^{\circ} \mathrm{C}$ with $0.25 \underline{\mathrm{M}} \mathrm{HNO}_{3} \ldots \ldots \ldots \ldots \ldots \ldots \ldots . . . . . . . . . .54$

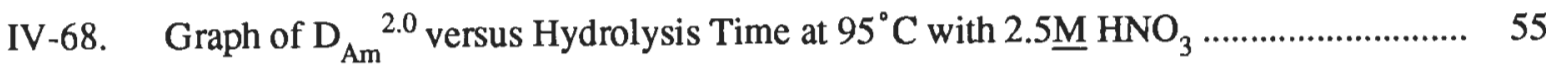




\section{LIST OF FIGURES (contd)}

No.

IV-69. Graph of $\mathrm{D}_{\mathrm{Am}}{ }^{2.0}$ versus Hydrolysis Time at $95^{\circ} \mathrm{C}$ with $6.0 \mathrm{M} \mathrm{HNO}_{3}$

IV-70. Graph of $\mathrm{D}_{\mathrm{Am}}^{2.0}$ versus Hydrolysis Time at $95^{\circ} \mathrm{C}$ with Simulated

CAW Containing 1.6ㅆ $\mathrm{HNO}_{3}$

IV-71. Graph of $\mathrm{D}_{\mathrm{Am}}^{2.0}$ versus Hydrolysis Time at $95^{\circ} \mathrm{C}$ with Simulated

CAW Containing 2.6 $\mathrm{MNO}_{3}$

IV-72. Rate Constant, $\mathrm{nk}_{\mathrm{h}}$, for Hydrolysis of CMPO at $50^{\circ} \mathrm{C}$

IV-73. Rate Constant, $\mathrm{nk}_{\mathrm{h}}$, for Hydrolysis of CMPO at $70^{\circ} \mathrm{C}$

IV-74. Rate Constant, $\mathrm{nk}_{\mathrm{h}}$, for Hydrolysis of CMPO at $95^{\circ} \mathrm{C}$

IV-75. Correlation between Temperature and $\ln n \mathrm{k}_{\mathrm{h}}$ Used to Determine

$\mathrm{A}$ and $\mathrm{E}$ for $\mathrm{Eq}$. IV-27

IV-76. Comparison of Calculated Values for $\mathrm{D}_{\mathrm{Am}}^{2.0}$ with Observed Values

Obtained for Solvent Degraded by Hydrolysis at $50-95^{\circ} \mathrm{C}$

VI-1. Graph of $\mathrm{D}_{\mathrm{Am}}{ }^{.01}$ as Function of Dose and Concentration

of Acid in Contact with Solvent during Irradiation

VI-2. Graph of $\mathrm{D}_{\mathrm{Am}}^{.05}$ as Function of Dose and Concentration

of Acid in Contact with Solvent during Irradiation

C-1. Fraction of CMPO Decomposed as Function of Number of

Process Cycles

D-1. Calculated Values of $\mathrm{D}_{\mathrm{Am}}{ }^{.01}$ versus Number of Process Cycles

D-2 Calculated Values of $\mathrm{D}_{\mathrm{Am}}{ }^{.05}$ versus Number of Process Cycles

E-1. $\mathrm{D}_{\mathrm{Am}}{ }^{.01}$ as a Function of Dose Absorbed by Solvent Irradiated in Contact with $0.25 \underline{\mathrm{M}} \mathrm{HNO}_{3}$

E-2. $\quad \mathrm{D}_{\mathrm{Am}}{ }^{.05}$ as a Function of Dose Absorbed by Solvent Irradiated in Contact with $0.25 \underline{\mathrm{M}} \mathrm{HNO}_{3}$

E-3. $\mathrm{D}_{\mathrm{Am}}{ }^{.01}$ as a Function of Dose Absorbed by Solvent Irradiated in Contact with $2.5 \underline{\mathrm{M}} \mathrm{HNO}_{3}$

E-4. $\quad \mathrm{D}_{\mathrm{Am}}{ }^{.05}$ as a Function of Dose Absorbed by Solvent Irradiated in Contact with $2.5 \underline{\mathrm{M}} \mathrm{HNO}_{3}$ 


\section{LIST OF FIGURES (contd)}

No.

Title

$\underline{\text { Page }}$

E-5. $\mathrm{D}_{\mathrm{Am}}{ }^{.01}$ as a Function of Dose Absorbed by Solvent Irradiated in Contact with 6.0 $\mathrm{MNO}_{3}$

E-6. $\mathrm{D}_{\mathrm{Am}} .05$ as a Function of Dose Absorbed by Solvent Irradiated in Contact with 6.0 $\underline{\mathrm{M}} \mathrm{HNO}_{3}$

E-7. $\mathrm{D}_{\mathrm{Am}}{ }^{.01}$ as a Function of Reaction Time for Hydrolysis of Solvent by $2.5 \underline{\mathrm{M} \mathrm{HNO}} 3$ at $50^{\circ} \mathrm{C}$

E-8. $\quad \mathrm{D}_{\mathrm{Am}} .05$ as a Function of Reaction Time for Hydrolysis

of Solvent by $2.5 \mathrm{M} \mathrm{HNO}$ at $50^{\circ} \mathrm{C}$

E-9. $\mathrm{D}_{\mathrm{Am}}{ }^{.01}$ as a Function of Reaction Time for Hydrolysis

of Solvent by $2.5 \underline{\mathrm{M}} \mathrm{HNO}_{3}$ at $70^{\circ} \mathrm{C}$

E-10. $\quad \mathrm{D}_{\mathrm{Am}}{ }^{.05}$ as a Function of Reaction Time for Hydrolysis

of Solvent by $2.5 \mathrm{M} \mathrm{HNO}_{3}$ at $70^{\circ} \mathrm{C}$

E-11. $\quad \mathrm{D}_{\mathrm{Am}}{ }^{.01}$ as a Function of Reaction Time for Hydrolysis

of Solvent by $6.0 \mathrm{M} \mathrm{HNO}_{3}$ at $70^{\circ} \mathrm{C}$

E-12. $\mathrm{D}_{\mathrm{Am}}{ }^{.05}$ as a Function of Reaction Time for Hydrolysis

of Solvent by $6.0 \underline{\mathrm{M} \mathrm{HNO}} \mathrm{HN}_{3}$ at $70^{\circ} \mathrm{C}$

E-13. $\mathrm{D}_{\mathrm{Am}}{ }^{.01}$ as a Function of Reaction Time for Hydrolysis of

Solvent by Simulated CAW Containing $1.6 \underline{\mathrm{M}} \mathrm{HNO}_{3}$ at $70^{\circ} \mathrm{C}$

E-14. $\mathrm{D}_{\mathrm{Am}}{ }^{.05}$ as a Function of Reaction Time for Hydrolysis of

Solvent by Simulated CAW Containing $1.6 \mathrm{M} \mathrm{HNO}_{3}$ at $70^{\circ} \mathrm{C}$

F-1. Acidity of the Aqueous Phase, Initially $0.25 \underline{M} \mathrm{HNO}_{3}$, in Contact

with TRUEX-NPH Solvent versus Radiation Dose Absorbed

by the Solvent

F-2. Acidity of the Aqueous Phase, Initially 6.0 $\mathrm{M} \mathrm{HNO}_{3}$, in Contact with TRUEX-NPH Solvent versus Radiation Dose Absorbed by the Solvent

F-3. Change of Acidity in TRUEX-NPH Solvent versus Reaction Time at 50,70 , and $95^{\circ} \mathrm{C}$ in Contact with an Aqueous Phase That Was Initially $0.25 \underline{\mathrm{M}} \mathrm{HNO}_{3}$

F-4. Change of Acidity in TRUEX-NPH Solvent versus Reaction Time at 50,70 , and $95^{\circ} \mathrm{C}$ in Contact with an Aqueous Phase That Was Initially $2.5 \underline{\mathrm{M}} \mathrm{HNO}_{3}$ 


\section{LIST OF FIGURES (contd)}

No. $\underline{\text { Title }}$

$\underline{\text { Page }}$

F-5. Change of Acidity in TRUEX-NPH Solvent versus Reaction Time at 50,70 , and $95^{\circ} \mathrm{C}$ in Contact with an Aqueous Phase That Was Initially 6.0 $\underline{\mathrm{M}} \mathrm{HNO}_{3}$ 100

G-1. Concentration of Yttrium in TRUEX-NPH Solvent Degraded by Hydrolysis at 50,70 , or $95^{\circ} \mathrm{C}$ in Contact with Simulated CAW Containing 1.6 or $2.6 \underline{\mathrm{M} \mathrm{H}} \mathrm{H}^{+}$

G-2. Concentration of Yttrium in TRUEX-NPH Solvent Degraded by

Radiolysis at $50^{\circ} \mathrm{C}$ in Contact with Simulated CAW

Containing 1.6 or $2.6 \underline{\mathrm{M} \mathrm{H}} \mathrm{H}^{+}$

G-3. Concentration of Lanthanum in TRUEX-NPH Solvent Degraded by Hydrolysis at 50,70 , or $95^{\circ} \mathrm{C}$ in Contact with Simulated CAW Containing 1.6 or $2.6 \mathrm{M} \mathrm{H}^{+}$

G-4. Concentration of Lanthanum in TRUEX-NPH Solvent Degraded by

Radiolysis at $50^{\circ} \mathrm{C}$ in Contact with Simulated CAW

Containing 1.6 or $2.6 \underline{\mathrm{M}} \mathrm{H}^{+}$

G-5. Concentration of Cerium in TRUEX-NPH Solvent Degraded by Hydrolysis at 50,70 , or $95^{\circ} \mathrm{C}$ in Contact with Simulated CAW Containing 1.6 or $2.6 \underline{\mathrm{M} \mathrm{H}} \mathrm{H}^{+}$

G-6. Concentration of Cerium in TRUEX-NPH Solvent Degraded by Radiolysis at $50^{\circ} \mathrm{C}$ in Contact with Simulated CAW Containing 1.6 or $2.6 \underline{\mathrm{M} \mathrm{H}} \mathrm{H}^{+}$

G-7. Concentration of Praseodymium in TRUEX-NPH Solvent Degraded by Hydrolysis at 50,70 , or $95^{\circ} \mathrm{C}$ in Contact with Simulated CAW Containing 1.6 or $2.6 \mathrm{M} \mathrm{H}^{+}$

G-8. Concentration of Praseodymium in TRUEX-NPH Solvent Degraded by Radiolysis at $50^{\circ} \mathrm{C}$ in Contact with Simulated CAW Containing 1.6 or $2.6 \underline{\mathrm{M} \mathrm{H}} \mathrm{H}^{+}$

G-9. Concentration of Samarium in TRUEX-NPH Solvent Degraded by Hydrolysis at 50,70 , or $95^{\circ} \mathrm{C}$ in Contact with Simulated CAW Containing 1.6 or $2.6 \mathrm{M} \mathrm{H}^{+}$

G-10. Concentration of Samarium in TRUEX-NPH Solvent Degraded by Radiolysis at $50^{\circ} \mathrm{C}$ in Contact with Simulated CAW 


\section{LIST OF FIGURES (contd)}

No.

$\underline{\text { Title }}$

$\underline{\text { Page }}$

G-11. Concentration of Europium in TRUEX-NPH Solvent Degraded by

Hydrolysis at 50,70 , or $95^{\circ} \mathrm{C}$ in Contact with Simulated

CAW Containing 1.6 or $2.6 \underline{\mathrm{M}} \mathrm{H}^{+}$

106

G-12. Concentration of Europium in TRUEX-NPH Solvent Degraded by

Radiolysis at $50^{\circ} \mathrm{C}$ in Contact with Simulated CAW

Containing 1.6 or $2.6 \underline{\mathrm{M} \mathrm{H}} \mathrm{H}^{+}$

107

G-13. Concentration of Aluminum in TRUEX-NPH Solvent Degraded by

Hydrolysis at 50,70 , or $95^{\circ} \mathrm{C}$ in Contact with Simulated

CAW Containing 1.6 or $2.6 \underline{\mathrm{M}} \mathrm{H}^{+}$

G-14. Concentration of Aluminum in TRUEX-NPH Solvent Degraded by

Radiolysis at $50^{\circ} \mathrm{C}$ in Contact with Simulated CAW

Containing 1.6 or $2.6 \underline{\mathrm{M}} \mathrm{H}^{+}$

G-15. Concentration of Iron in TRUEX-NPH Solvent Degraded by

Hydrolysis at 50,70 , or $95^{\circ} \mathrm{C}$ in Contact with Simulated

CAW Containing 1.6 or $2.6 \underline{\mathrm{M}} \mathrm{H}^{+}$

G-16. Concentration of Iron in TRUEX-NPH Solvent Degraded by

Radiolysis at $50^{\circ} \mathrm{C}$ in Contact with Simulated CAW

Containing 1.6 or $2.6 \underline{\mathrm{M}} \mathrm{H}^{+}$

G-17. Concentration of Zirconium in TRUEX-NPH Solvent Degraded by

Hydrolysis at 50,70 , or $95^{\circ} \mathrm{C}$ in Contact with Simulated

CAW Containing 1.6 or $2.6 \mathrm{M} \mathrm{H}^{+}$

G-18. Concentration of Zirconium in TRUEX-NPH Solvent Degraded by

Radiolysis at $50^{\circ} \mathrm{C}$ in Contact with Simulated CAW

Containing 1.6 or $2.6 \underline{\mathrm{M} \mathrm{H}^{+}}$

G-19. Maximum Concentration of NonTRU Elements in TRUEX-NPH

Solvent Degraded in Contact with Simulated CAW by

Hydrolysis at 50,70 , or $95^{\circ} \mathrm{C}$ and by Radiolysis at $50^{\circ} \mathrm{C}$ 


\section{LIST OF TABLES}

No.

Title

Page

A-1. Preparation of 20-L, Doubly Concentrated Synthetic

CAW Feed Solution

71

A-2. Mineral Acids Added to Doubly Concentrated

Synthetic CAW

73

B-1. Distribution of Am Between Fresh TRUEX-NPH Solvent

and Aqueous Nitric Acid.

74 


\section{GLOSSARY}

CAW

CMPO

$\mathrm{D}_{\mathrm{Am}}$

Degradation

FPs

G Value

HLW

ICP

PUREX

TBP

TRU

Transuranium

Radionuclide

Transuranic Waste
Current Acid Waste, the name given to the high-level waste streams produced at the Hanford site from concentration by evaporation of the raffinate from PUREX processing of irradiated nuclear fuel. In this work, a synthetic CAW solution, prepared from a mixture of salts and sulfuric, nitric, and oxalic acids, was used to observe its effect in radiolysis and hydrolysis of TRUEXNPH solvent.

Octyl (phenyl)-N,N-diisobutylcarbamoylmethylphosphine oxide.

Distribution coefficient of americium, i.e., the ratio of its concentration in the organic solvent to its concentration in the aqueous nitric acid phase, or $[\mathrm{Am}]_{\mathrm{org}} /[\mathrm{Am}]_{\mathrm{aq}}$ at $25^{\circ} \mathrm{C}$. The concentration of nitric acid in the equilibrated aqueous phase is indicated as a superscript, e.g., $\mathrm{D}_{\mathrm{Am}}{ }^{.01}$ represents the distribution coefficient of americium between solvent and $0.01 \underline{\mathrm{M}} \mathrm{HNO}_{3}$.

Decomposition of the components of the extraction solvent by radiolysis or hydrolysis.

Fission products.

An expression of radiochemical yield, units of $\mathrm{mol} \cdot \mathrm{J}^{-1}$ or molecules $/ 100 \mathrm{eV}$.

Hydrogen ion activity in the aqueous phase being contacted.

High-level waste.

Inductively Coupled Plasma Atomic Emission Spectroscopy, an analytical method.

A solvent-extraction process for recovering uranium and plutonium from irradiated nuclear fuel and separating them from the fission products contained in the fuel. One of the most important applications of the TRUEX process is separation of transuranic elements from the high-level waste that is a by-product of the PUREX process.

Tributyl phosphate.

Transuranic. Refers to elements with atomic numbers greater than 92 . Material classified as TRU contains $>100 \mathrm{nCi} / \mathrm{g}$ of total activity emitted by transuranic elements.

Any radionuclide having an atomic number greater than 92 .

Without regard to source or form, waste that is contaminated with alphaemitting transuranium radionuclides with half-lives greater than 20 years and concentrations greater than $100 \mathrm{nCi} / \mathrm{g}$ at the time of assay. Heads of DOE 
Field Elements can determine that other alpha contaminated wastes, peculiar to a specific site, must be managed as transuranic waste.

TRUEX

A process for removing transuranic elements from high-level liquid waste by solvent extraction.

TRUEX-NPH Solvent

A solution consisting of $0.2 \underline{\mathrm{M}} \mathrm{CMPO}$ and $1.4 \underline{\mathrm{M}} \mathrm{TBP}$ in the normal paraffinic hydrocarbon mixture Conoco $\mathrm{C}_{12}-\mathrm{C}_{14}$. 


\title{
RADIOLYSIS AND HYDROLYSIS OF TRUEX-NPH SOLVENT
}

by

N. Simonzadeh, A. M. Crabtree, L. E. Trevorrow, and G. F.Vandegrift

\begin{abstract}
The TRUEX solvent extraction process separates transuranic (TRU) elements from aqueous nitrate and chloride solutions. During contact with high-level wastes, which may be highly radioactive and highly acidic, the radiolysis and hydrolysis of TRUEX-NPH solvent can affect the process not only by destroying the extractant CMPO in the solvent, but also by generating products of CMPO destruction, some of which are powerful extractants at low acidities and can prevent the stripping of $\mathrm{Am}$ and $\mathrm{Pu}$ from solvent that is to be recycled.

To provide an experimental basis from which mathematical expressions of these effects could be derived, samples of solvent were degraded by radiolysis and hydrolysis while in contact with acidic aqueous solutions. Following this treatment, the distribution of americium between degraded solvent and aqueous $\mathrm{HNO}_{3}$ was used as a measure of the extent of degradation. Mathematical expressions were derived to represent the distribution coefficient, $\mathrm{D}_{\mathrm{Am}}$, as a function of hydrolysis time and/or radiation dose. Assumptions about the dependence of $\mathrm{D}_{\mathrm{Am}}$ on CMPO concentration were used to derive expressions for the hydrolysis rate for CMPO and also to calculate values of radiation chemical yield for CMPO radiolysis. Also experimentally investigated were changes in acidity of both the aqueous and organic phases as functions of contact time, the effects of a carbonate wash in removing acidic degradation products that function as extractants at low acidities, and changes in compositions of some of the aqueous and organic phases during contact.
\end{abstract}




\section{INTRODUCTION}

The TRUEX solvent extraction process separates transuranic (TRU) elements from aqueous nitric acid solutions. In this process, the TRU elements are extracted into an organic phase that typically consists of the extractant octyl (phenyl)-N,N diisobutylcarbamoylmethylphosphine oxide (CMPO), synthesized specifically for this application [HORWITZ], tributyl phosphate (TBP), and an organic diluent such as a normal paraffinic hydrocarbon (NPH) or tetrachloroethylene. Most other constituents of the original nitric acid solution are not extracted and leave this process in the aqueous raffinate.

The TRUEX process was developed [VANDEGRIFT] to separate high-level waste (HLW) or TRU waste, such as that now stored at some Department of Energy (DOE) reservations, into two fractions: a relatively small volume containing the TRU elements and a relatively large volume of raffinate. Depending on the value of their constituents, the TRU extracts could be recycled for recovery or disposed of as a much-decreased volume of TRU waste. The raffinate, with concentrations of TRU elements totaling less than $3.7 \times 10^{6} \mathrm{~Bq} \mathrm{~kg}^{-1}$ (100 nCi/g), could reasonably be expected to qualify as a low-level waste [TREVORROW]. This would permit a major fraction of the original waste volume to be managed using waste forms and disposal facilities less costly than those normally planned for HLW.

If the organic phase is contacted with aqueous high-level wastes previously generated in the application of the PUREX process on irradiated fuel, the solvent will undergo radiolysis. Also, because of contact with nitric acid at above-ambient temperatures during these treatment operations, the solvent will undergo hydrolysis. As a result of these radiolytic and hydrolytic reactions, a fraction of the extractant, CMPO, will be converted to other chemical species.

The radiolysis and hydrolysis of solvent have been commonly referred to as "degradation," and the resulting species as "degradation products." These degradation processes affect the operation of the TRUEX process, not only through decreasing concentration of CMPO, but also through increasing concentration of acidic degradation products, some of which are powerful extractants in low acid solutions. Thus, radiolysis and hydrolysis can be expected to change the extracting capacity of the organic phase, not only through the decrease in the CMPO concentration, but also through the buildup of strongly extracting acidic degradation products. The presence of strong acidic extractants can inhibit the stripping of actinides and lanthanides from solvent to be recycled.

Studies of the hydrolysis and radiolysis of various solvents used in the extraction of transuranics were carried out previously. Some of them focused on the performance of diluents, such as carbon tetrachloride [CHIARIZIA, VANDEGRIFT], decalin [CHIARIZIA], and tetrachloroethylene [NASH]. The present study, however, is concerned specifically with the TRUEX-NPH solvent whose composition is $0.2 \mathrm{M}$ CMPO, 1.4M TBP in Conoco $\mathrm{C}_{12-14}$. The important products of solvent degradation have generally proved to be acidic compounds that can be partially removed from degraded solvent by contact with aqueous carbonate solutions. It has been reported [CHIARIZIA, NASH] that the degradation of CMPO also results in some neutral products and some acidic products.

The objectives of the present study were to (1) derive expressions for the change in the extraction properties of the TRUEX-NPH solvent resulting from radiolysis and hydrolysis, (2) determine the effectiveness of removing the products of these reactions from the solvent by aqueous sodium carbonate washes, (3) investigate the change of acidity of the aqueous and organic phases accompanying the degradation of solvent in contact with aqueous nitric acid solutions, and (4) determine the effect of solvent degradation on the extraction behavior of components in the simulated waste solution. 
In the present work, samples of the TRUEX-NPH solvent were subjected to radiolysis or hydrolysis followed by tests of extraction performance. The extraction performance was used as an analytical tool to make inferences about the concentration of CMPO remaining in the degraded solvent. For radiolysis, samples of TRUEX-NPH solvent, while in contact with nitric acid solutions of five different concentrations, were exposed at a constant temperature of $50^{\circ} \mathrm{C}$ to a Co- 60 gamma source. The same concentrations of nitric acid were used to hydrolyze solvent samples at 50,70 , and $95^{\circ} \mathrm{C}$. After partial radiolysis or hydrolysis, the solvent samples were divided into three groups for treatments, as follows: (1) no washing, (2) washing with water, and (3) washing with aqueous $0.25 \underline{\mathrm{M}}$ sodium carbonate.

The distribution ratios of americium $\left(\mathrm{D}_{\mathrm{Am}}\right)^{*}$ between these degraded solvent samples and nitric acid solutions of three concentrations $(0.01,0.05$, and $2.0 \mathrm{M})$ were obtained at $25^{\circ} \mathrm{C}$. Testing the distribution of americium between $0.05 \mathrm{M} \mathrm{HNO}_{3}$ and solvent is especially relevant to the TRUEX process because this concentration is close to that of the $0.04 \underline{\mathrm{M}} \mathrm{HNO}_{3}$ typically used in the process for stripping americium away from the solvent. The distribution ratios were used as indicators of the effects on the solvent of radiolysis, hydrolysis, and washing. Because acidic extractants would be even more powerful when the solvent is in contact with $0.01 \underline{\mathrm{M}} \mathrm{HNO}_{3}$, the $\mathrm{D}_{\mathrm{Am}}$ value at this low acidity is a more sensitive indicator of their presence. In some cases, the distribution ratios were used to derive concentrations of CMPO remaining in degraded solvent. These concentrations were then used to develop mathematical expressions for the change of CMPO concentration per unit radiation dose and thus to derive $\mathrm{G}$ values. Concentrations of CMPO derived from measurements of $\mathrm{D}_{\mathrm{Am}}$ were also used to calculate hydrolysis rates for CMPO.

Either radiolysis or hydrolysis of the TRUEX-NPH solvent in contact with aqueous nitric acid is accompanied by changes in the acidities of both the organic and the aqueous phases. This phenomenon was investigated in this effort by measuring the acidities of the solvent and the acid phase that had been in contact with it. These data were obtained from titration of samples of the aqueous phases and samples of water washes of the nitric-acid-loaded TRUEX-NPH solvent.

The HLW to which the TRUEX process will be applied contains a number of nonTRU elements. The effect of solvent degradation on the extraction behavior of these elements was briefly investigated in the present study. Samples of solvent degraded to varying extents during contact with a simulated aqueous HLW solution, CAW, were analyzed for several nonTRU elements initially present in the CAW. The composition and the preparation method for this solution are described in Appendix A.

"The values of $D_{A m}$ used in this discussion are the ratios of the concentration of americium in the organic phase to its concentration in the aqueous phase. 


\section{SUMMARY}

During operations to extract TRU elements from aqueous HLW, TRUEX-NPH solvent will undergo radiolysis and hydrolysis. These reactions could affect operation of the TRUEX process in two general ways. (1) The concentration of CMPO will decrease, causing a decrease in the extractive ability of the TRUEX-NPH solvent. (2) If the acidic degradation products are not removed, their strong extractive properties at low aqueous-phase acidities would prevent the stripping of the traces of Am and $\mathrm{Pu}$ from the solvent that is to be recycled. The effects of these reactions on the extraction performance of the solvent have been studied in laboratory-scale tests.

Samples of solvent were degraded by radiolysis or hydrolysis while in contact with aqueous solutions. Subsequent measurements of distribution ratios of americium between degraded solvent and aqueous $2 \mathrm{M} \mathrm{HNO}_{3}$ were used as an analytical tool for determining the extent of solvent degradation.

Hydrolyzed solvent samples were prepared by exposing solvent to aqueous solutions of several different compositions at 50,70 , and $95^{\circ} \mathrm{C}$ for times up to $800 \mathrm{~h}$. The aqueous solutions included 0.25 , 2.5, and 6.0 $\mathrm{M} \mathrm{HNO}_{3}$, as well as two solutions simulating a Hanford waste stream and containing a mixture of metal ions and nitric acid concentrations of 1.6 and 2.6M (CAW). Radiolyzed solvent samples were prepared by exposing them to gamma radiation while in contact with the same set of aqueous solutions at a constant temperature of $50^{\circ} \mathrm{C}$.

In the measurements of $\mathrm{D}_{\mathrm{Am}}$ between degraded solvent and nitric acid, three acid concentrations were used: $0.01,0.05$, and $2.0 \mathrm{M}$. At the highest acid concentration, distributions were apparently controlled by CMPO. Therefore, distribution ratios at $2.0 \mathrm{M} \mathrm{HNO}_{3}$ were used to follow the CMPO concentration as a function of dose absorbed by the solvent.

The effects of solvent radiolysis are expressed by representing $\mathrm{D}_{\mathrm{Am}}$ as a function of absorbed radiation dose and by deriving a radiation chemical yield ( $\mathrm{G}$ value) for the radiolytic destruction of CMPO. Values of $\mathrm{D}_{\mathrm{Am}}$ for solvent degraded by radiolysis at $\mathrm{HNO}_{3}$ concentrations of $0.01,0.05$, and 2.0M are mathematically represented as a function of absorbent dose.

Derived from the assumed relation of $\mathrm{D}_{\mathrm{Am}}^{2.0}$ to $\mathrm{CMPO}$ concentration, $\mathrm{G}$ values for radiolytic destruction of CMPO can be represented as a function of $n$, the exponent used in relating $D_{A m}$ to the nth power of the CMPO concentration: $G=1.86 \mathrm{n}^{-0.823}$ molecules $/ 100 \mathrm{eV}=1.94 \times 10^{-7} \mathrm{n}^{-0.823} \mathrm{~mol} \mathrm{~J}^{-1}$. If $\mathrm{D}_{\mathrm{Am}}{ }^{2.0}$ is assumed to be proportional to the third power of the CMPO concentration, then the $\mathrm{G}$ value derived from these data is 0.76 molecules $/ 100 \mathrm{eV}\left(7.9 \times 10^{-8} \mathrm{~mol} \mathrm{~J}^{-1}\right)$. The effects of solvent hydrolysis are mathematically represented by $\mathrm{D}_{\mathrm{Am}}$ as a function of Kelvin temperature, time, and aqueous hydrogen ion activity, as well as by a rate law for the hydrolytic destruction of CMPO. The expressions for radiolysis and hydrolysis have been combined to give expressions for CMPO concentration in the degraded solvent and also for the $\mathrm{D}_{\mathrm{Am}}$ that would be obtained with the degraded solvent as a function of the number of process stages and the parameters used in describing radiolysis and hydrolysis.

Sample calculations were completed using typical process parameters and the expressions derived for calculating values of $\mathrm{D}_{\mathrm{Am}}$ and CMPO concentration. The results indicate that the value of $\mathrm{D}_{\mathrm{Am}} .05$ increases about $1 \%$ during one process cycle (i.e., extraction, scrub, strip, and rinse). The much larger change of about $30 \%$ obtained in similar calculations for $\mathrm{D}_{\mathrm{Am}}{ }^{.01}$ is consistent with the fact that the acidic products of CMPO degradation are more powerful at low acidities. Similar calculations indicate that the fraction of CMPO decomposed at the end of 100 cycles, corresponding to about one year of processing, is $8.6 \times 10^{-4}$. 
The effectiveness of removing the products of CMPO degradation from TRUEX-NPH solvent by washing was tested on samples of solvent that had been exposed to radiolysis or hydrolysis. The americium distribution ratios when the solvent is equilibrated with $0.01 \underline{\mathrm{M}}\left(\mathrm{D}_{\mathrm{Am}}{ }^{.01}\right)$ and $0.05 \underline{\mathrm{M}}\left(\mathrm{D}_{\mathrm{Am}}{ }^{.05}\right.$ ) $\mathrm{HNO}_{3}$, generally increase with the extent of degradation, presumably from the formation of acidic degradation products that are powerful extractants. Washing the degraded solvent with aqueous carbonate generally decreases the $\mathrm{D}_{\mathrm{Am}}$ values obtained with solvent that has been subjected to hydrolysis or radiolysis. For systems hydrolyzed at $50^{\circ} \mathrm{C}$, the $\mathrm{D}_{\mathrm{Am}}$ shows little dependence on hydrolysis time, regardless of whether the degraded solvent was washed with carbonate or not. This behavior is expected since the rate of hydrolysis is low at $50^{\circ} \mathrm{C}$. In many cases, the final values of $\mathrm{D}_{\mathrm{Am}}{ }^{.05}$ are not much greater than the initial $\mathrm{D}_{\mathrm{Am}}{ }^{.05}$ value. The $\mathrm{D}_{\mathrm{Am}}{ }^{.01}$ values, which are more sensitive indicators of the presence of acidic extractants, are lowered by carbonate washing, but they are still greater than the corresponding initial $\mathrm{D}_{\mathrm{Am}}{ }^{.01}$ value. Thus, carbonate washing is generally not $100 \%$ effective. For radiolysis of solvent in contact with $0.25 \underline{\mathrm{M}} \mathrm{HNO}_{3}$, washing with carbonate solution is more effective in restoring $\mathrm{D}_{\mathrm{Am}}$ to the value characteristic of nondegraded solvent (i.e., $\mathrm{D}_{\mathrm{Am}_{\mathrm{O}}}$ ) than for radiolysis of solvent in contact with 2.5 or $6.0 \mathrm{M} \mathrm{HNO}_{3}$. For dose rates greater than about $30 \mathrm{Wh} / \mathrm{L}, \mathrm{D}_{\mathrm{Am}}{ }^{.01}$ values depend on the concentration of acid in contact with solvent during irradiation in the order $6.0>2.5>0.25 \underline{\mathrm{M}}$ acid. Values for $\mathrm{D}_{\mathrm{Am}}{ }^{.05}$ show similar behavior.

As the degradation of TRUEX-NPH solvent in contact with aqueous solution proceeds, the acidities of both phases also change. Several organic-aqueous pairs were subjected to radiolysis or hydrolysis, and the acidity changes were measured. For radiolysis, the hydrogen ion concentration in aqueous $\mathrm{HNO}_{3}, 2.5$ or $6 \mathrm{M}$ before equilibration with the solvent, increases with dose absorbed by the solvent. This increase can be expressed as a $\mathrm{G}$ value of $6.1 \times 10^{16}$ hydrogen ions $\mathrm{J}^{-1}(0.98$ hydrogen ions $/ 100 \mathrm{eV}$ ). For hydrolysis, the hydrogen ion concentration in solvent contacting aqueous $\mathrm{HNO}_{3}$ decreases with hydrolysis time. This behavior has not been represented mathematically, but two trends are evident: (1) the hydrogen ion concentration in the solvent decreases to a level that remains approximately constant after about $200 \mathrm{~h}$, and (2) the final concentrations are inversely related to temperature.

For some of the TRUEX-NPH samples that were degraded in the presence of simulated CAW, the organic phase was analyzed to provide observations of the effect of solvent degradation on extraction behavior of the nonTRU elements in wastes. The concentrations of nonTRU elements in the organic phase were graphically correlated with hydrolysis time (i.e., the extent of solvent degradation). It was found that the elements present in the simulated CAW solutions fell into two general types: either the concentrations are measurable and can be represented as a function of hydrolysis time, or they are so low as to permit their expression only as maximum values that do not vary with hydrolysis time and do not depend regularly on temperature.

Elements that have measurable concentrations in CAW solutions include several rare earths: Y, La, $\mathrm{Ce}, \mathrm{Pr}, \mathrm{Sm}$, and Eu. Some generalities can be expressed: (1) their concentrations are inversely dependent on hydrolysis temperature, (2) at a constant hydrolysis temperature, their concentrations are inversely dependent on acid concentration, with the solutions hydrolyzed by $1.6 \underline{\mathrm{M}}$ acid showing greater concentration values than those hydrolyzed by $2.6 \mathrm{M}$ acid, and (3) the concentrations are little affected by solvent degradation, declining slightly as hydrolysis time (extent of solvent degradation) increases. The elements $\mathrm{Al}, \mathrm{Fe}$, and $\mathrm{Zr}$ have measurable concentrations, but the shapes of the graphs of concentration versus time differ from those of the rare earths; generalities are not obvious.

Elements that have very low concentrations include $\mathrm{Ag}, \mathrm{Ca}, \mathrm{Mg}, \mathrm{Rh}, \mathrm{Ru}, \mathrm{Cr}, \mathrm{Ni}, \mathrm{Sr}, \mathrm{Mn}, \mathrm{Be}, \mathrm{Cd}$, $\mathrm{Pd}, \mathrm{Cu}, \mathrm{Mo}, \mathrm{Ba}$, and $\mathrm{Ti}$. The values are generally about the same for $1.6 \underline{\mathrm{M}}$ as for $2.6 \mathrm{M}$ acid, and 
considering the limitations of the analysis for these elements, small differences should not be considered significant. These maximum concentrations range from about $1 \times 10^{-5}$ to about $2 \times 10^{-3} \mathrm{M}$. 


\section{RADIOLYSIS OF TRUEX-NPH SOLVENT}

To determine the effects of radiolysis on TRUEX-NPH solvent, samples of it in contact with aqueous solutions of five different compositions were exposed to gamma radiation at $50^{\circ} \mathrm{C}$. After receiving doses of about $3.0 \times 10^{-4}$ to $8.5 \times 10^{5} \mathrm{~Gy}(7$ to $200 \mathrm{Wh} / \mathrm{L})$, solvent samples were then used to measure the distribution of Am-241 (III) at $25^{\circ} \mathrm{C}$ between degraded solvent and aqueous nitric acid solutions of three concentrations: $0.01,0.05$, and $2.0 \mathrm{M}$. The resulting values of $\mathrm{D}_{\mathrm{Am}}{ }^{.01}, \mathrm{D}_{\mathrm{Am}}{ }^{.05}$, and $\mathrm{D}_{\mathrm{Am}}{ }^{2.0}$ were used as indicators of the effects of solvent degradation.

\section{A. Experimental}

The solutions in contact with solvent samples during irradiation included five different

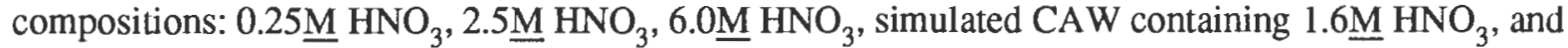
simulated $\mathrm{CAW}$ containing $2.6 \mathrm{M} \mathrm{HNO}_{3}$. The $\mathrm{CAW}$ used here, prepared from a number of salts and acids, simulates an actual HLW stream at the Hanford site. Its composition is described in Appendix A.

Radiolysis of TRUEX-NPH solvent in contact with aqueous solutions was carried out by exposure to a Co-60 source in a hot cell. During irradiation, the solutions were contained in thermostated beakers fitted with water condensers and clad in jackets that provided a constant temperature of $50^{\circ} \mathrm{C}$. Each vessel contained equal volumes of the TRUEX solvent and an aqueous solution, which were mixed vigorously during the irradiation. The organic solutions were not pre-equilibrated before contact with the aqueous solution. Samples of both aqueous and organic solutions were removed from the flask periodically during exposure, after the source had been shut down and the hot cell entered. Samples $(2 \mathrm{~mL})$ of the organic solvent were washed twice with distilled water (organic/aqueous volume ratio equal to 1) and pre-equilibrated with the appropriate acid solution three times at an O/A ratio of $1 / 3$. An equal volume of the appropriate acid solution was contacted with the solvent, and a spike ( $5 \mu \mathrm{L})$ of Am-241 was added. Before being separated, the solutions were given three 20-s contacts, with 2-min temperature equilibrations in between. Aliquots of the solutions were counted with a sodium iodide detector for the $59.5 \mathrm{keV}$ Am-241 gamma.

Solvent samples were exposed to doses of $3.0 \times 10^{-4}$ to $8.5 \times 10^{5} \mathrm{~Gy}$ ( 7 to $200 \mathrm{Wh} / \mathrm{L}$ ). The dose was measured by glass dosimetry. The glass dosimeters had been calibrated against a Fricke dosimeter to indicate absorbed dose rates in erg/g $\mathrm{H}_{2} \mathrm{O}$. A glass dosimeter was located at the outer surface of the wall for each of four vessels holding the solutions during irradiation. In each case, the dosimeter was on the wall facing the radiation source; it was thus located between the source and the vessel. The dose rates indicated by these four dosimeters ranged from $6.1 \times 10^{-1}$ to $7.5 \times 10^{-1} \mathrm{~Gy} \mathrm{~s}^{-1}$ ( 2.2 to $2.7 \times 10^{5} \mathrm{rad} / \mathrm{h}$ ), with an average of $6.9 \times 10^{-1} \mathrm{~Gy} \mathrm{~s}^{-1}\left(2.5 \times 10^{5} \mathrm{rad} / \mathrm{h}\right)$. That average, however, may be somewhat higher than the actual dose, considering attenuation by the vessel wall and the solution.

On one of the vessels, dosimeters were placed at the wall facing the source and also at the opposite wall. The dosimeter at the wall facing the source read $6.1 \times 10^{-1} \mathrm{~Gy} \mathrm{~s}^{-1}\left(2.2 \times 10^{5} \mathrm{rad} / \mathrm{h}\right)$, while the dosimeter at the opposite wall, measuring radiation that had traversed both walls and the solution, read $2.4 \times 10^{-1} \mathrm{~Gy} \mathrm{~s}^{-1}\left(0.87 \times 10^{5} \mathrm{rad} / \mathrm{h}\right)$. From this difference, it is estimated that the actual absorbed dose rate for the solutions could be 20 to $30 \%$ less than the average reading at the walls facing the source. The calculation of the dose absorbed by the solvent takes into account the difference in electron concentrations of the aqueous and organic phases. Thus, the energy absorbed per gram of solvent per rad is derived from the ratio of electron concentration of the TRUEX-NPH to that of water. That is, 


$$
\begin{aligned}
& 100 \mathrm{erg} / \mathrm{g}\left(\mathrm{H}_{2} \mathrm{O}\right)-\mathrm{rad} \times(477 / 555)= \\
& 85.9(\mathrm{erg})(\mathrm{g} \text { solvent })^{-1}(\mathrm{rad})^{-1}
\end{aligned}
$$

Furthermore, the density of the solvent, $0.845 \mathrm{~g} / \mathrm{mL}$, rather than the average density of the organic and aqueous phases, was used for the dose calculation. Therefore, the absorbed dose rate during these irradiations was

$$
\begin{aligned}
\left(2.5 \times 10^{5} \mathrm{rad} / \mathrm{h}\right) \times(85.9 \mathrm{erg} / \mathrm{g} \text { solvent-rad }) \times\left(1 \times 10^{-7} \mathrm{~W}-\mathrm{s} / \mathrm{erg}\right) \times(\mathrm{h} / 3600 \mathrm{~s}) \\
\times(0.854 \mathrm{~g} / \mathrm{mL}) \times\left(10^{3} \mathrm{~mL} / \mathrm{L}\right)=8.0 \times 10^{-1} \mathrm{~Gy} \mathrm{~s}^{-1}\left(0.51 \mathrm{~W} \mathrm{~L}^{-1}\right) \\
(\text { III-2) }
\end{aligned}
$$

\section{B. Results}

The results of these observations are presented in the form of $\mathrm{D}_{\mathrm{Am}}$ as a function of absorbed dose. Figure III-1 shows, as a function of dose received, coefficients for distribution of Am between aqueous nitric acid of the three concentrations and samples of TRUEX-NPH solvent that had received varying doses of gamma radiation while in contact with $0.25 \underline{\mathrm{M}} \mathrm{HNO}_{3}$. Similar representations of $\mathrm{D}_{\mathrm{Am}}$ as a function of dose received by solvent are given for solvent radiolyzed in contact with $2.5 \underline{\mathrm{M}} \mathrm{HNO}_{3}$ (Fig. III-2), 6.0 $\mathrm{M} \mathrm{HNO}_{3}$ (Fig. III-3), simulated CAW containing 1.6M $\mathrm{HNO}_{3}$ (Fig. III-4), and CAW containing $2.6 \mathrm{M} \mathrm{HNO}_{3}$ (Fig. III-5). These figures indicate that increases in dose received by the solvent cause $\mathrm{D}_{\mathrm{Am}}$ to increase in subsequent distribution tests involving $0.01 \underline{\mathrm{M}} \mathrm{HNO}_{3}$ and $0.05 \underline{\mathrm{M}} \mathrm{HNO}_{3}$. In contrast, for distributions involving $2.0 \mathrm{M} \mathrm{HNO}_{3}$, increasing the dose over the same range decreases $\mathrm{D}_{\mathrm{Am}}$.

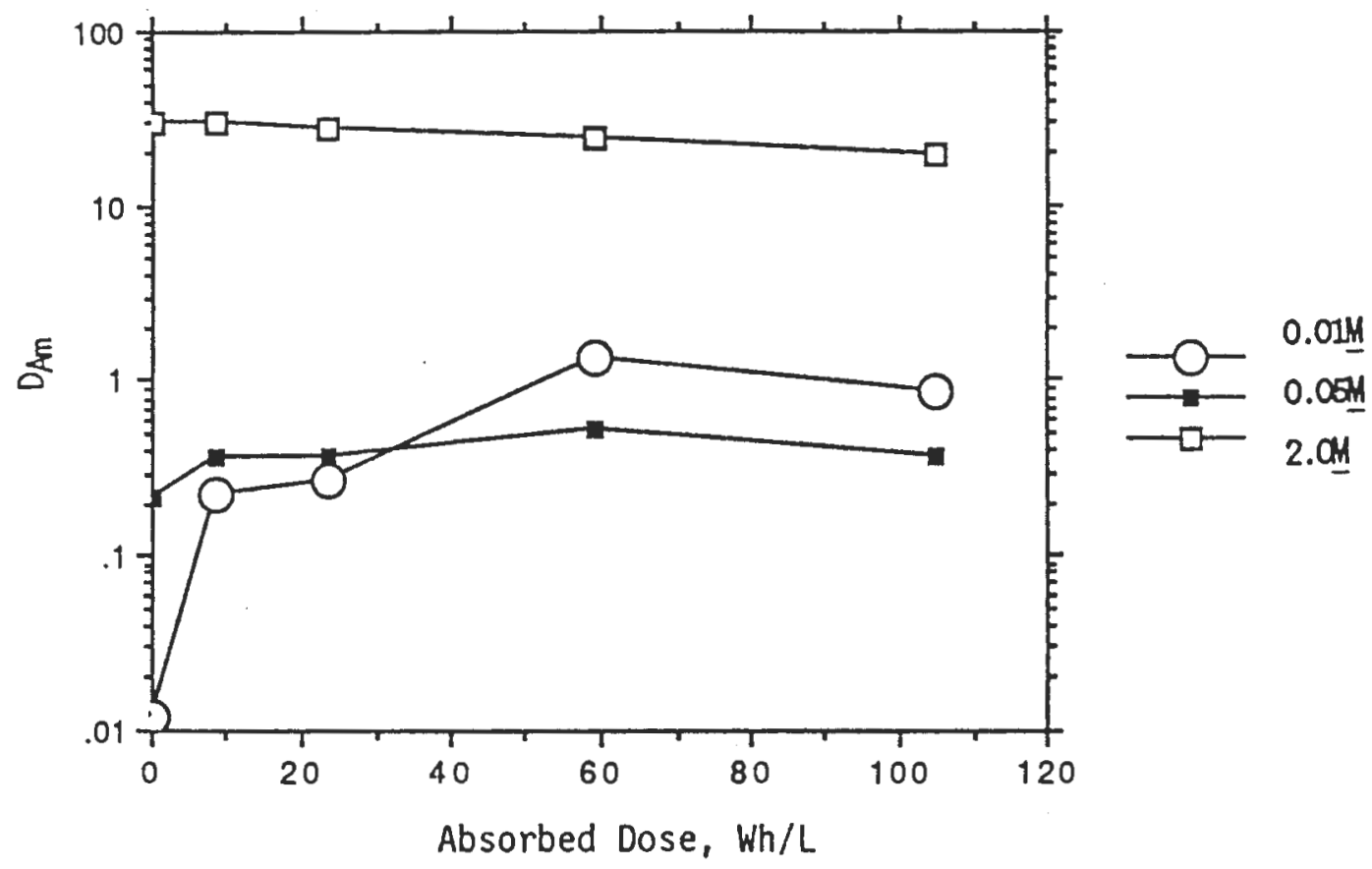

Fig. III-1. Dependence of $\mathrm{D}_{\text {Arm }}{ }^{.01}, \mathrm{D}_{\mathrm{Am}}{ }^{.05}$, and $\mathrm{D}_{\mathrm{Am}}{ }^{2.0}$ on Dose Received by Solvent during Previous Irradiation at $50^{\circ} \mathrm{C}$ in Contact with $0.25 \underline{\mathrm{M}} \mathrm{HNO}_{3}$ 


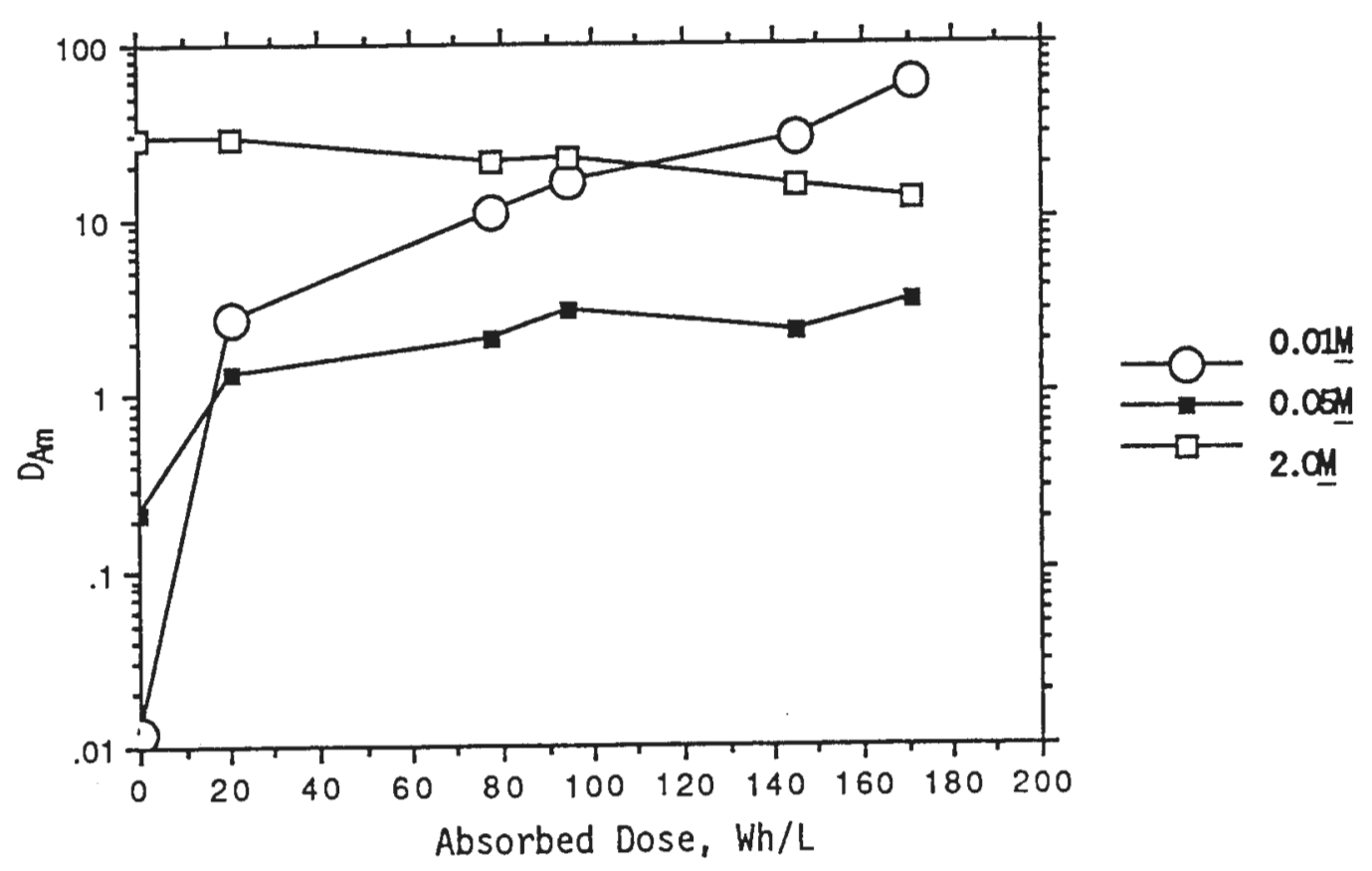

Fig. III-2. Dependence of $\mathrm{D}_{\mathrm{Am}}{ }^{.01}, \mathrm{D}_{\mathrm{Am}}{ }^{.05}$, and $\mathrm{D}_{\mathrm{Am}}{ }^{2.0}$ on Dose Received by Solvent during Previous Irradiation at $50^{\circ} \mathrm{C}$ in Contact with $2.5 \mathrm{M} \mathrm{HNO}_{3}$

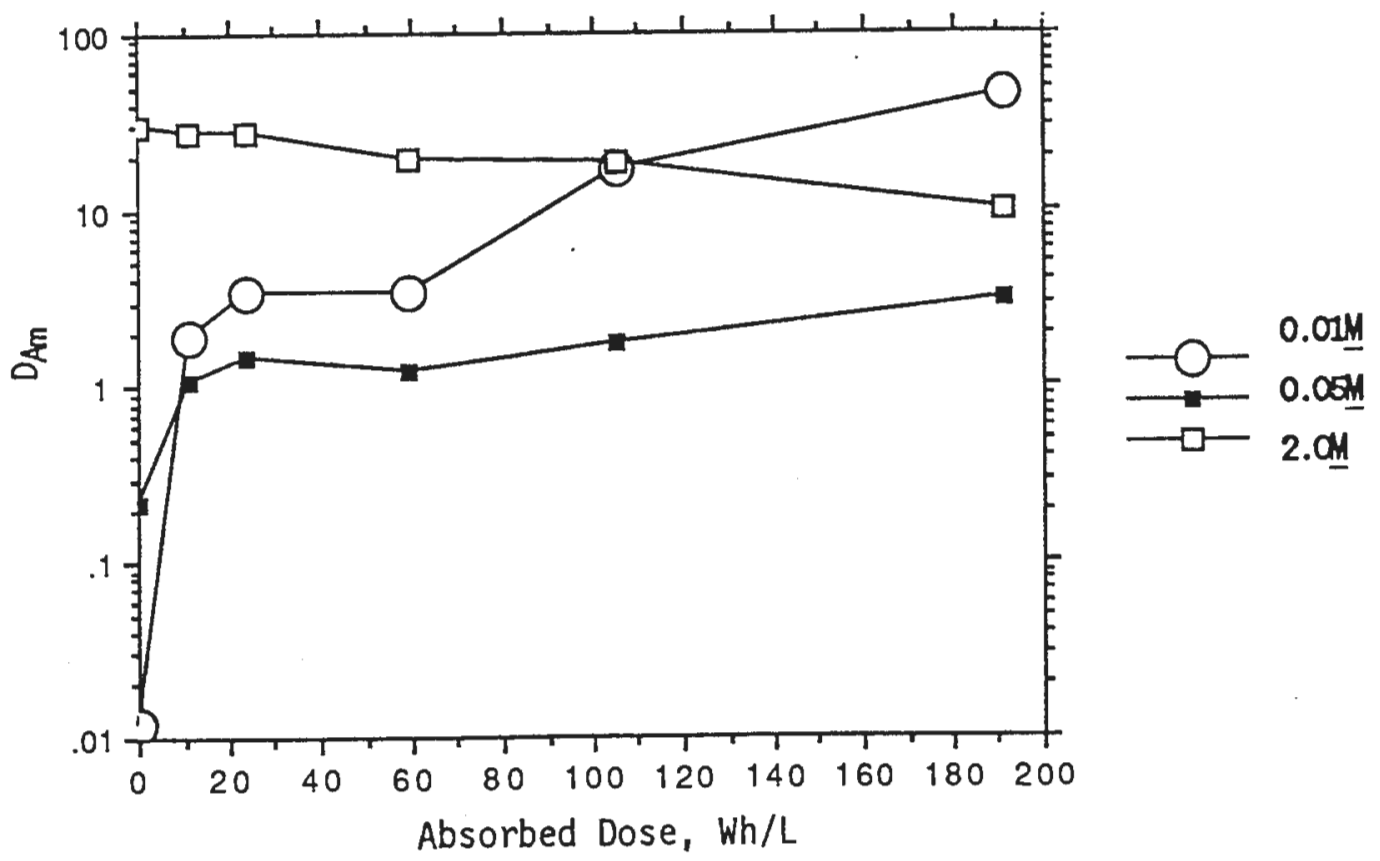

Fig. III-3. Dependence of $\mathrm{D}_{\mathrm{Am}}{ }^{.01}, \mathrm{D}_{\mathrm{Am}}{ }^{.05}$, and $\mathrm{D}_{\mathrm{Am}}{ }^{2.0}$ on Dose Received by Solvent during Previous Irradiation at $50^{\circ} \mathrm{C}$ in Contact with $6.0 \underline{\mathrm{M}} \mathrm{HNO}_{3}$ 


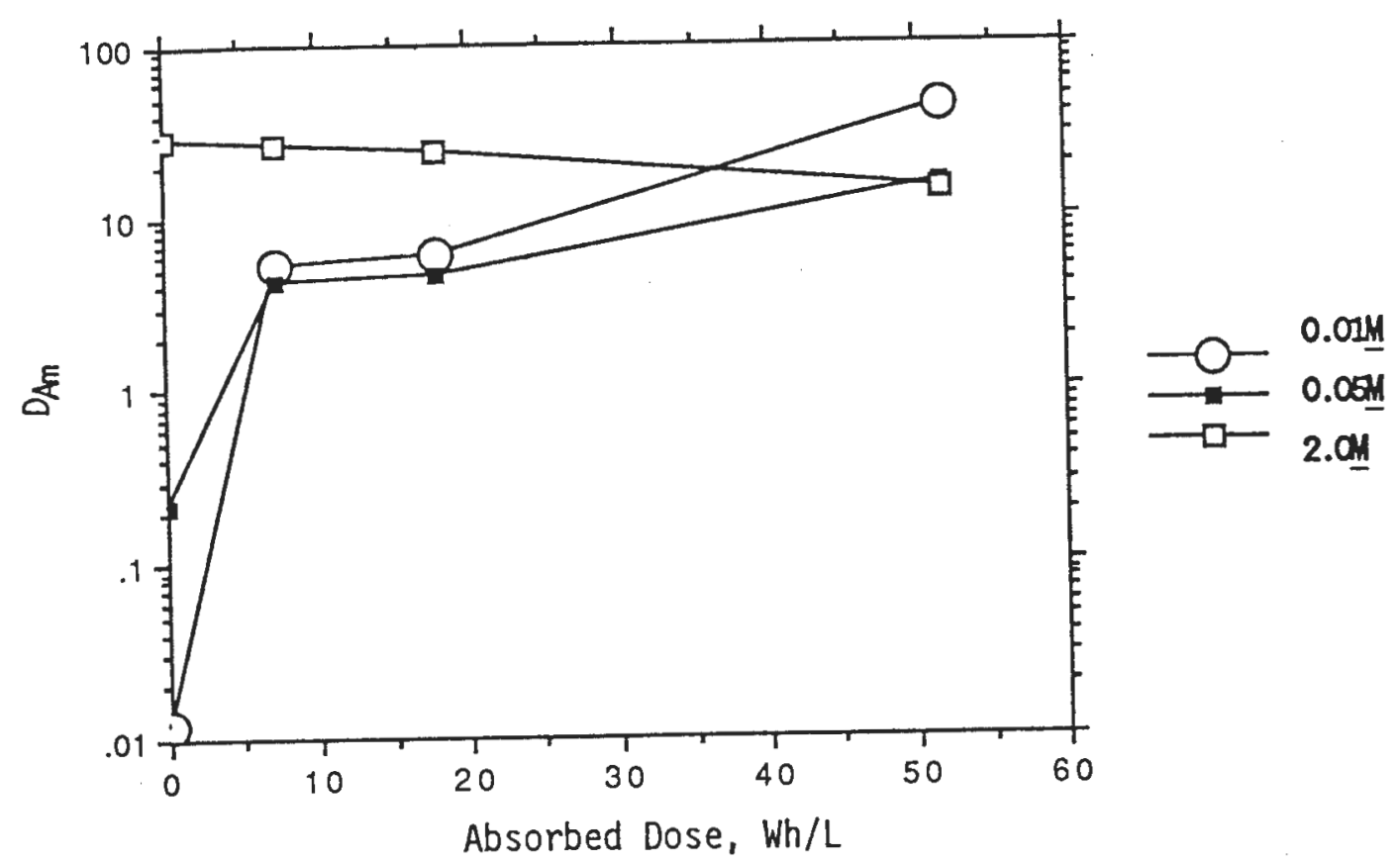

Fig. III-4. Dependence of $\mathrm{D}_{\mathrm{Am}}^{.01}, \mathrm{D}_{\mathrm{Am}}{ }^{.05}$, and $\mathrm{D}_{\mathrm{Am}}{ }^{2.0}$ on Dose Received by Solvent during Previous Irradiation at $50^{\circ} \mathrm{C}$ in Contact with Simulated CAW Containing 1.6 $\mathrm{M}_{\mathrm{HNO}}$

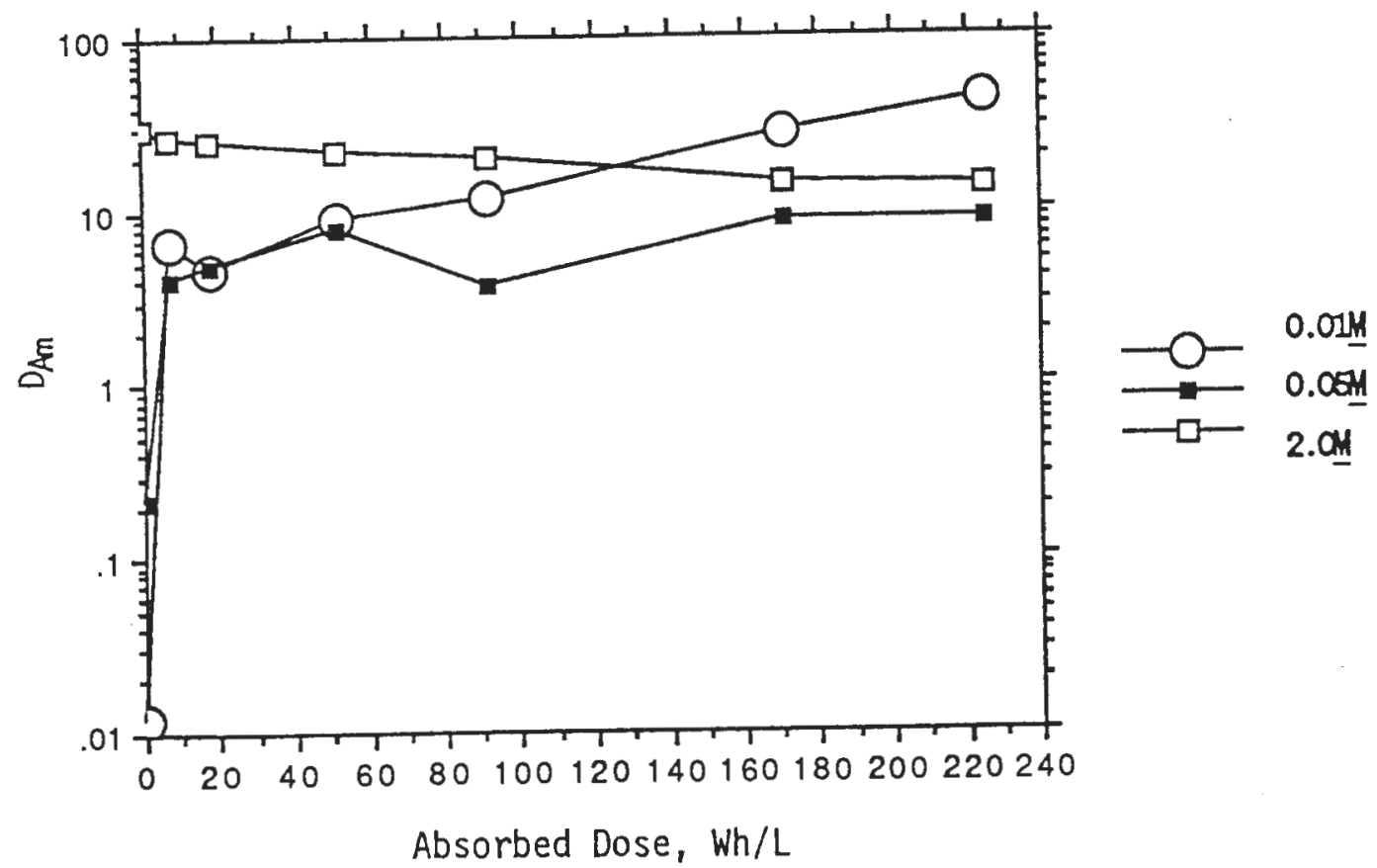

Fig. III-5. Dependence of $\mathrm{D}_{\mathrm{Am}}{ }^{.01}, \mathrm{D}_{\mathrm{Am}}{ }^{.05}$, and $\mathrm{D}_{\mathrm{Am}}{ }^{2.0}$ on Dose Received by Solvent during Previous Irradiation at $50^{\circ} \mathrm{C}$ in Contact with Simulated CAW Containing $2.6 \mathrm{M} \mathrm{HNO}_{3}$ 


\section{Mathematical Expressions for $\mathrm{D}_{\mathrm{Am}}$ as a Function of Dose}

Expressions that will permit the calculation of $D_{A m}$ for a given dose were derived by correlating the observed values of $D_{A m}$ with the measured doses. A separate expression was derived for each of the three acid concentrations $(0.01,0.05,2.0 \mathrm{M})$ used in the measurements of distribution of americium between degraded solvent and nitric acid. The $\mathrm{D}_{\mathrm{Am}}$ values for any one of these three do not show a perceptible dependence on the concentration of acids that were in contact with the solvent during irradiation.

Therefore, in deriving expressions for $\mathrm{D}_{\mathrm{Am}}{ }^{.01}$ as a function of dose, the data obtained for the five solutions containing $\mathrm{HNO}_{3}$ in contact with solvent during irradiation were combined. Similar combinations were used in deriving expressions for $\mathrm{D}_{\mathrm{Am}}{ }^{.05}$ and $\mathrm{D}_{\mathrm{Am}}{ }^{2.0}$ as a function of dose.

1. Expression for $\mathrm{D}_{\mathrm{Am}}^{.01}$ as Function of Dose

At a constant absorbed dose rate, the rate of change of the $\mathrm{D}$ value is treated as a constant as follows:

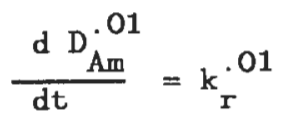

In Eq. III- $3, \mathbf{k}_{r}^{.01}=\mathbf{k}_{r}^{\prime .01}(P)$, where $P$ is the absorbed dose rate.

The integrated form of Eq. III-3 is

$$
\mathrm{D}_{\dot{A}_{0}}^{.01}=\mathrm{D}_{\mathrm{Am}}^{.01}+\mathrm{k}_{\mathrm{r}}^{.01}(\mathrm{t})
$$

By substitution,

$$
D_{A m}^{01}=D_{A_{0}}^{.01}+k_{r}^{\prime} \cdot 01 \quad(P)(t)
$$

The value of $\mathrm{D}_{\mathrm{Am}_{\mathrm{O}}}{ }^{.01}$ was obtained from the average of $\mathrm{D}_{\mathrm{Am}}{ }^{.01}$ values obtained with fresh TRUEX-NPH solvent listed in Appendix B. The value of $\mathrm{k}^{\prime} .01$ was evaluated from the dependence of measured values of $\mathrm{D}_{\mathrm{Am}}{ }^{.01}$ on absorbed dose (dose rate multiplied by time, $\mathrm{P} \cdot \mathrm{T}$ ) for samples of irradiated solvent.

The expression for distributions at $0.01 \underline{\mathrm{M}} \mathrm{HNO}_{3}$ is

$$
\mathrm{D}_{\dot{A}^{m}}^{01}=0.0115+k_{r}^{\prime} \cdot 01 \quad(P)(t)
$$

where $\mathrm{k}_{\mathrm{r}}^{\prime .01}=5.64 \times 10^{-5} \mathrm{~L} \mathrm{~W}^{-1} \mathrm{~s}^{-1}\left(0.203 \mathrm{~L} \mathrm{~W}^{-1} \mathrm{~h}^{-1}\right)$ and $\mathrm{P}=$ absorbed dose rate to solvent, $\mathrm{W} \mathrm{L}^{-1}$.

In Fig. III-6, empirical values of $\mathrm{D}_{\mathrm{Am}}{ }^{.01}$ can be compared with the line representing $\mathrm{D}_{\mathrm{Am}}{ }^{.01}$ as a function of dose calculated by Eq. III-6. 


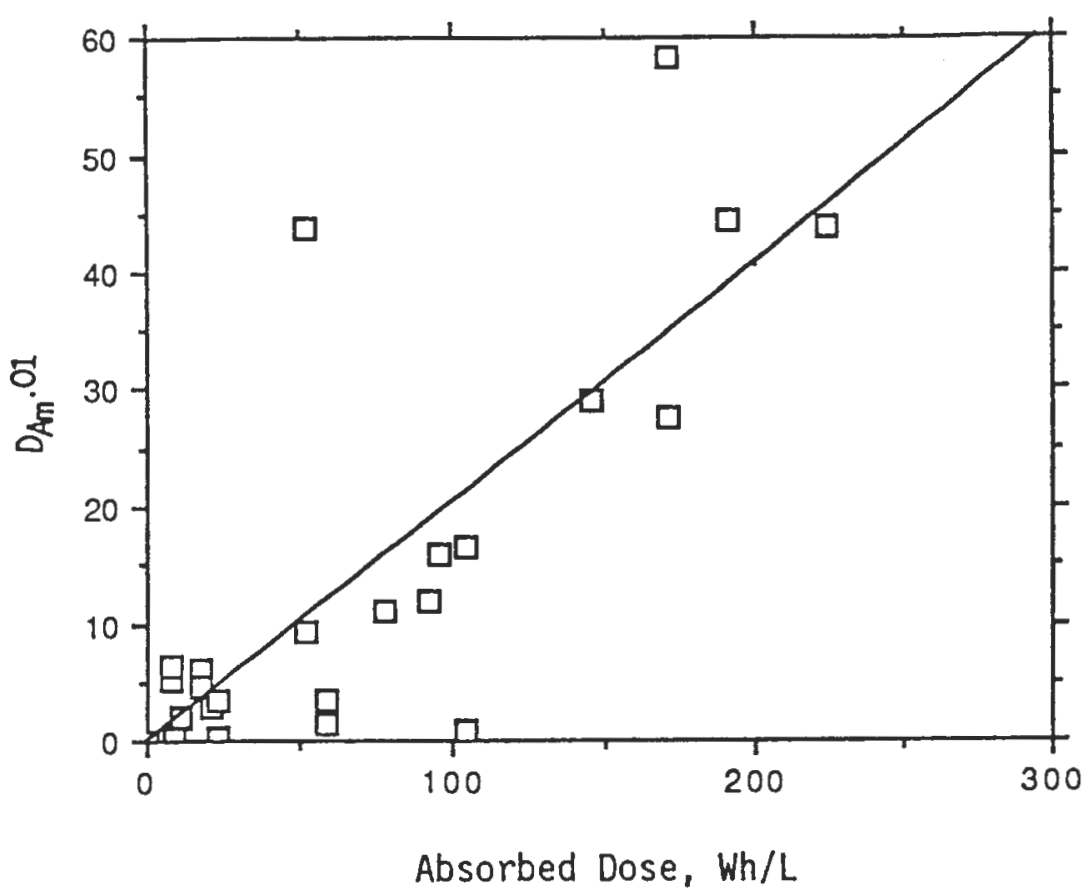

Fig. III-6. $\quad \mathrm{D}_{\mathrm{Am}}^{.01}$ as Function of Dose Received by Solvent. Comparison of calculated values represented by the line with observed values represented by points.

2. Expression for $\mathrm{D}_{\mathrm{Am}}^{.05}$ as Function of Dose is

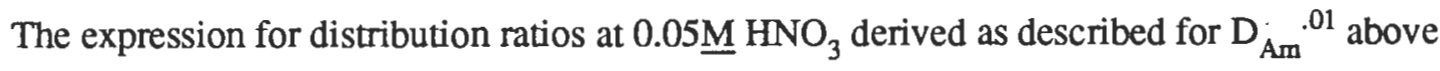

$$
D_{\dot{A m}}^{05}=0.231+k_{r}^{\prime} \cdot 05(P)(t)
$$

where $\mathrm{k}_{\mathrm{r}}^{\prime} .05=8.78 \times 10^{-6} \mathrm{~L} \mathrm{~W}^{-1} \mathrm{~s}^{-1}\left(0.0316 \mathrm{~L} \mathrm{~W}^{-1} \mathrm{~h}^{-1}\right)$.

Figure III-7 permits a comparison of empirical values of $\mathrm{D}_{\mathrm{Am}}^{.05}$ with a line representing $\mathrm{D}_{\mathrm{Am}}{ }^{.05}$ as a function of dose calculated by Eq. III-7.

3. Expression for $\mathrm{D}_{\mathrm{Am}}^{2.0}$ and Calculation of Radiation Chemical Yield for CMPO Destruction

It is assumed that irradiated solvent contains residual CMPO and degradation products, all capable of affecting the distribution of Am between degraded solvent and aqueous solution. At high acid concentration, however, the extraction capacity of the acidic products of CMPO degradation is repressed. Thus, the acid concentration of the aqueous phase determines whether CMPO or degradation products control the distribution. At high acid concentrations $(2.0 \mathrm{M}), \mathrm{D}_{\mathrm{Am}}$ decreases from its initial value as the dose absorbed by solvent increases, indicating that the distribution is controlled by an extractant, present initially, whose concentration decreases with dose absorbed by the solvent. Therefore, the distribution results at $2.0 \underline{\mathrm{MNO}_{3}} \mathrm{HNe}_{3}$ were assumed to reflect the extraction of Am by CMPO, and the $\mathrm{D}_{\mathrm{Am}}{ }^{2.0}$ values 
along with the relation between $\mathrm{D}_{\mathrm{Am}}$ and CMPO concentration were used to calculate values of radiation chemical yield ( $G$ values) for the destruction of CMPO.

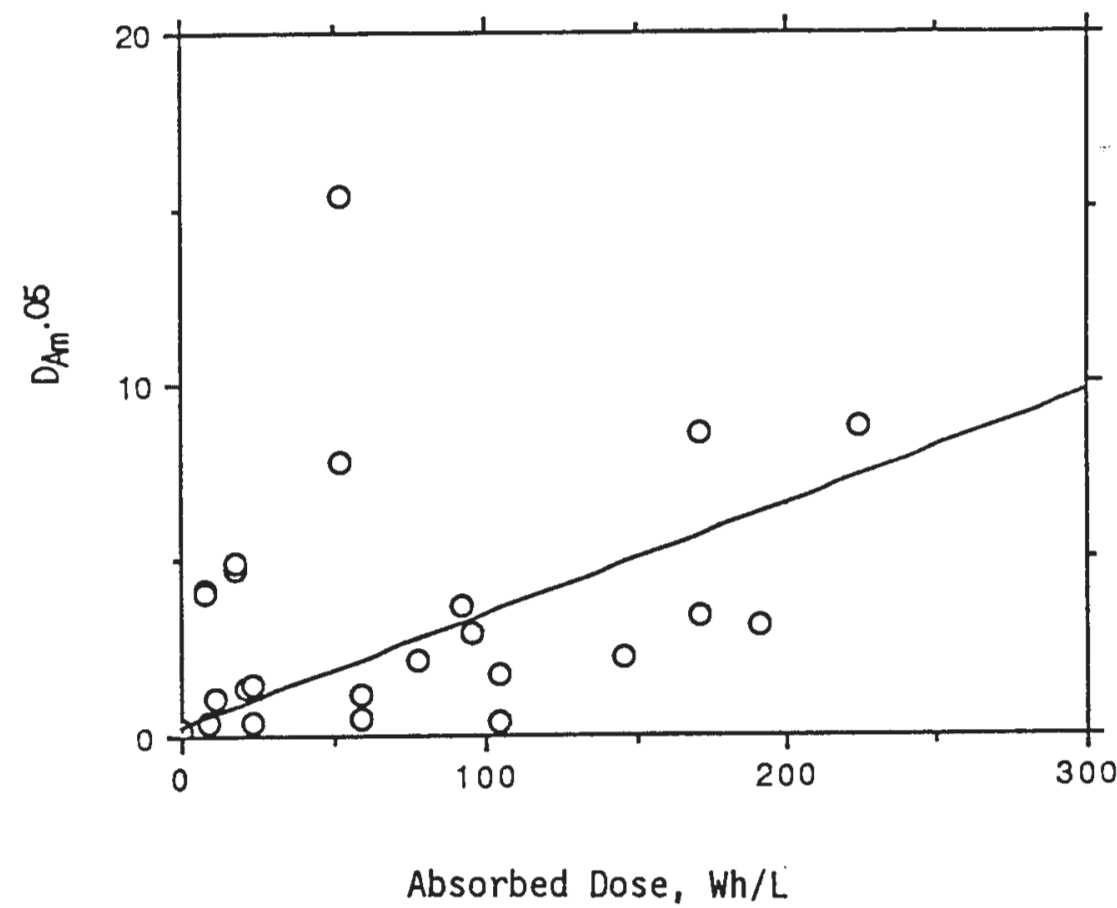

Fig. III-7. $\quad \mathrm{D}_{\mathrm{Am}}^{.05}$ as Function of Dose Received by Solvent. Comparison of calculated values represented by the line with observed values represented by points.

The $G$ value can be considered to be a component of a zero-order rate law describing the decrease of CMPO concentration with time:

$$
\frac{-d C}{d t}=\text { constant }=(G)(M)(P)
$$

$$
\text { where } \begin{aligned}
\mathrm{C} & =\text { concentration of } \mathrm{CMPO} \\
\mathrm{P} & =\text { absorbed dose rate to solvent } \\
\mathrm{t} & =\text { irradiation time } \\
\mathrm{G} & =\text { radiation chemical yield } \\
\mathrm{M} & =\text { a dimensional conversion factor }
\end{aligned}
$$

The $\mathrm{G}$ value determined in this work can be used to predict the effects of radiation on TRUEX processing by calculating the concentration of CMPO remaining in NPH solvent after it has been in contact for a given time period with high-level liquid waste that would subject the solvent to a given absorbed dose rate. Thus, from the integrated form of Eq. III-8, 


$$
C=C_{0}-(G)(M)(P)(t)
$$

(III-9)

where $\mathrm{C}_{\mathrm{o}}=$ initial concentration of $\mathrm{CMPO}$, or

$$
\frac{\mathrm{C}}{\mathrm{C}_{\mathrm{o}}}=1-\frac{(\mathrm{G})(\mathrm{M})(\mathrm{P})(\mathrm{t})}{\mathrm{C}_{\mathrm{o}}}
$$

The parameter that was measured, $\mathrm{D}_{\mathrm{Am}}$, is proportional to the $\mathrm{n}^{\text {th }}$ power of CMPO concentration. Therefore,

$$
\frac{\mathrm{C}}{\mathrm{C}_{\mathrm{O}}}=\left[\frac{\mathrm{D}_{\mathrm{Am}}}{\mathrm{D}_{\mathrm{Am}}}\right)^{1 / \mathrm{n}}=1-\frac{(\mathrm{M})(\mathrm{G})(\mathrm{P})(\mathrm{t})}{\mathrm{C}_{\mathrm{O}}}
$$

or

$$
\left(\mathrm{D}_{\mathrm{Am}}^{2.0}\right)^{1 / \mathrm{n}}=\left(\mathrm{D}_{\mathrm{Am}_{\mathrm{o}}}^{2.0}\right)^{1 / \mathrm{n}}-\frac{\left(\mathrm{D}_{\mathrm{Am}}^{2.0}\right)^{1 / \mathrm{n}}}{\mathrm{C}_{\mathrm{O}}} \quad(\mathrm{G})(\mathrm{M})(\mathrm{P})(\mathrm{t})
$$

$$
\text { where } \begin{aligned}
\mathrm{D}_{\mathrm{Am}_{\mathrm{o}}}^{2.0} & =30.7 \\
\mathrm{C}_{\mathrm{o}} & =0.2 \mathrm{~mol} \mathrm{~L}^{-1} \\
\mathrm{G} & =\text { radiation chemical yield, molecules }(100 \mathrm{eV})^{-1} \\
\mathrm{M} & =3.73 \times 10^{-4}\left(100 \mathrm{eV}^{-1} \mathrm{~W}^{-1}\right. \text { mol molecule } \\
\mathrm{P} & =\text { absorbed dose rate, } \mathrm{W} \mathrm{L}^{-1} \\
\mathrm{t} & =\text { time, } \mathrm{h} \\
\text { or } \quad \mathrm{G} & =\text { radiation chemical yield, } \mathrm{mol} \mathrm{J}^{-1} \\
\mathrm{M} & =1 \mathrm{~J} \mathrm{~W}^{-1} \mathrm{~s}^{-1} \\
\mathrm{t} & =\text { time, } \mathrm{s}
\end{aligned}
$$

Thus, $G$ values can be calculated from the linear relation between $\left(D_{A m}{ }^{2.0}\right)^{1 / n}$ and absorbed dose for any assumed value of $n$. Other studies [CHIARIZIA, NASH] have indicated that the value of $n$ is about 3 . In Fig. III-8, $\left(D_{A m}^{2.0}\right)^{1 / 3}$ is shown as a function of absorbed dose. These data can be represented by

$$
\left[D_{\mathrm{Am}}^{2.0}\right]^{1 / 3}=3.131-k_{r}^{12.0}(\mathrm{P})(\mathrm{t})
$$




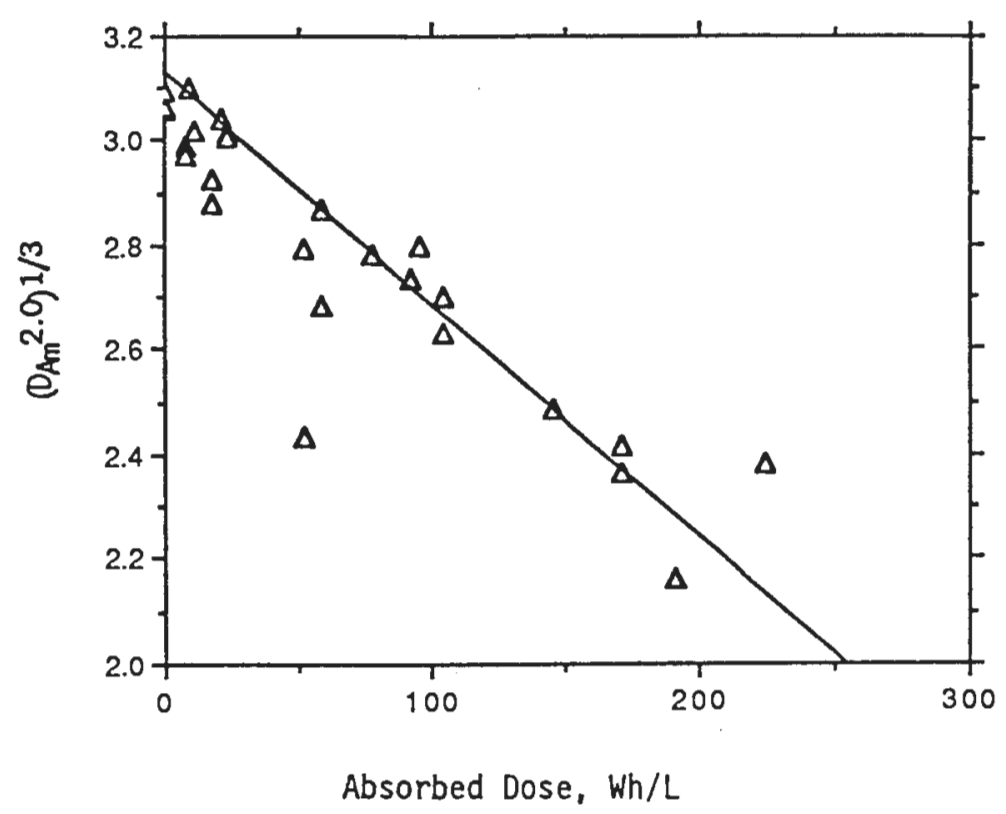

Fig. III-8. $\quad\left(\mathrm{D}_{\mathrm{Am}}{ }^{2.0}\right)^{1 / 3}$ as Function of Dose Received by Solvent. Comparison of calculated values represented by the line with observed values represented by points.

where $\mathrm{k}_{\mathrm{r}}^{2.0}=1.23 \times 10^{-6} \mathrm{~L} \mathrm{~W}^{-1} \mathrm{~s}^{-1}\left(4.438 \times 10^{-3} \mathrm{~L} \mathrm{~W}^{-1} \mathrm{~h}^{-1}\right)$.

The $G$ value associated with the slope of the line representing calculated values is $7.9 \times 10^{-8} \mathrm{~mol} \mathrm{~J}^{-1}$ $(0.76$ molecules per $100 \mathrm{eV})$. Since the value of $n$, although uncertain, is believed to be about 3 , similar calculations of the $G$ value were made for radiolytic destruction of CMPO for assumed values of $n$ ranging from 1 through 5; the calculated G values are presented in Fig. III-9.

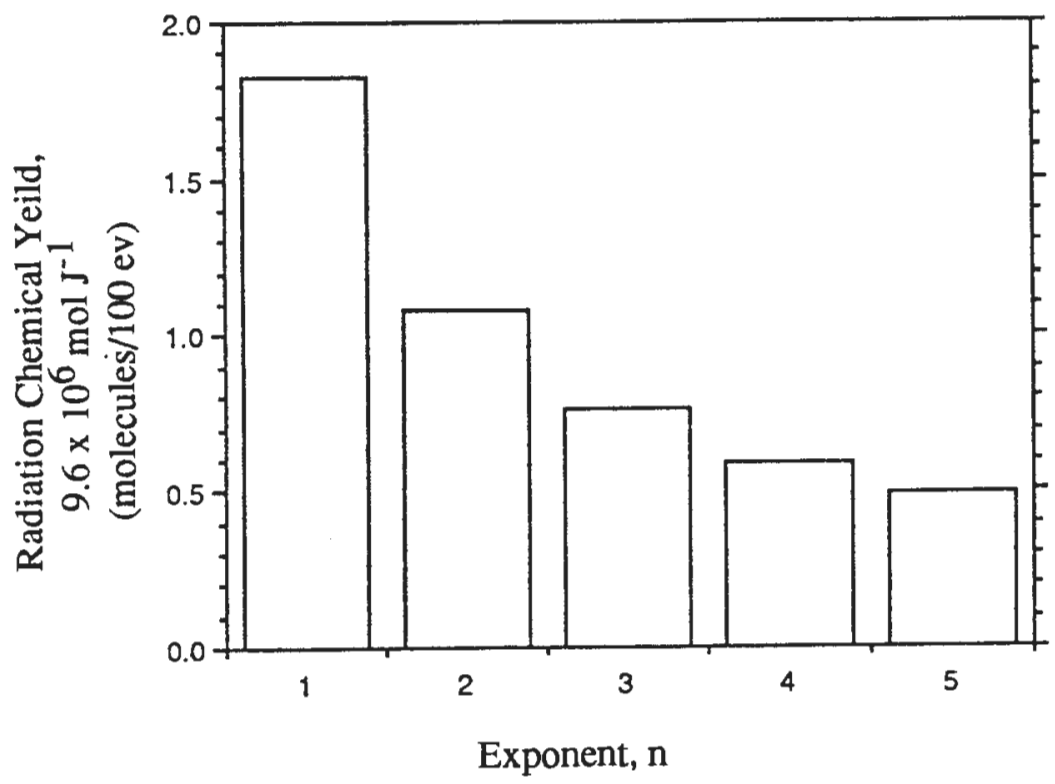

Fig. III-9. Radiation Chemical Yield for the Radiolysis of CMPO in TRUEX-NPH Solvent for Five Values of $n$ (the exponent for dependence of $\mathrm{D}_{\mathrm{Am}}$ on CMPO concentration) 


\section{HYDROLYSIS OF TRUEX-NPH SOLVENT}

The hydrolysis of TRUEX-NPH solvent was studied for the temperature range $50-95^{\circ} \mathrm{C}$. The hydrolytic agents were aqueous solutions of the same compositions as those used in the radiolysis investigations (Sec. III). As in the radiolysis studies, the effects of solvent degradation were assessed by measuring the $\mathrm{D}_{\mathrm{Am}}$ between degraded solvent and aqueous nitric acid.

\section{A. Experimental}

Samples of TRUEX-NPH solvent were stirred in contact with equal volumes of aqueous solutions at 50,70 , and $95^{\circ} \mathrm{C}$ for time periods ranging from about $24 \mathrm{~h}$ up to about $800 \mathrm{~h}$. The solutions included $0.25,2.5$, and $6.0 \underline{\mathrm{M}} \mathrm{HNO}_{3}$, plus two $\mathrm{CAW}$ solutions, with nitric acid concentrations of 1.6 and $2.6 \underline{\mathrm{M}}$. Additional details on the CAW solution are given in Appendix A. The beakers containing the solutions were water-jacketed to provide constant temperatures and were also fitted with water-cooled condensers.

Samples of solvent were removed at the end of successive time periods, and the $\mathrm{D}_{\mathrm{Am}}$ was measured at $25^{\circ} \mathrm{C}$ for hydrolyzed solvent and aqueous nitric acid of three concentrations: $0.01,0.05$, and $2.0 \mathrm{M}$. The procedures for measurement of $\mathrm{D}_{\mathrm{Am}}$ with solvent degraded by hydrolysis were the same as those described in Sec. III.A. for measuring $\mathrm{D}_{\mathrm{Am}}$ with solvent degraded by radiolysis.

\section{B. $\quad \underline{\text { Results }}$}

The $\mathrm{D}_{\mathrm{Am}}$ values obtained by distribution of Am between hydrolyzed solvent and the three aqueous nitric acid solutions are presented graphically as a function of hydrolysis time in Figs. IV-1 through IV-15. The general pattern of behavior shown in these figures is similar to that observed with radiolysis. That is, at a given temperature, $\mathrm{D}_{\mathrm{Am}}{ }^{.01}$ and $\mathrm{D}_{\mathrm{Am}}{ }^{.05}$ increase with solvent degradation, while $\mathrm{D}_{\mathrm{Am}}{ }^{2.0}$ decreases as solvent degradation proceeds.

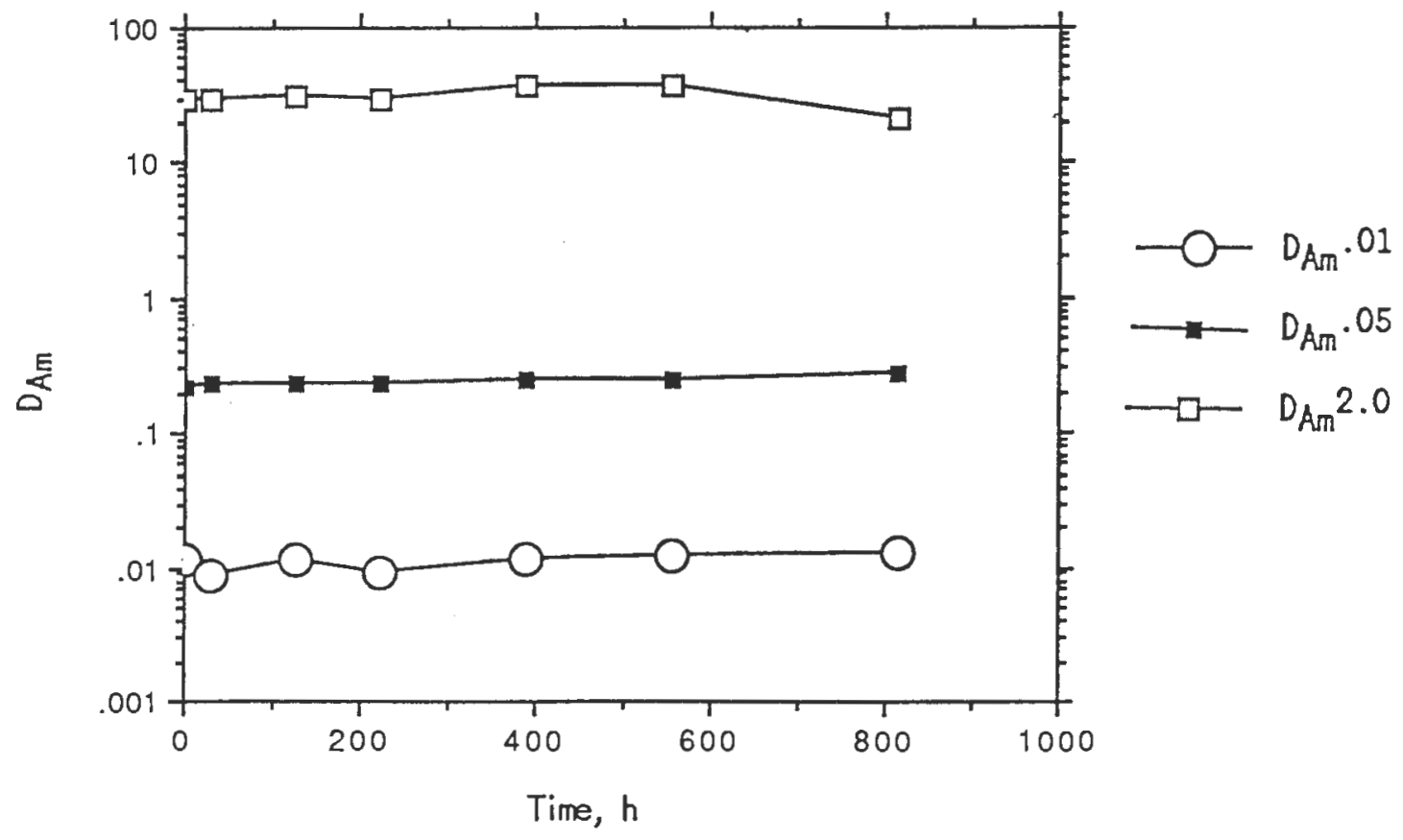

Fig. IV-1. Dependence of $\mathrm{D}_{\mathrm{Am}}{ }^{.01}, \mathrm{D}_{\mathrm{Am}}{ }^{.05}$, and $\mathrm{D}_{\mathrm{Am}}{ }^{2.0}$ on Hydrolysis Time for TRUEX-NPH Solvent Previously Hydrolyzed by $0.25 \underline{\mathrm{M}} \mathrm{HNO}_{3}$ at $50^{\circ} \mathrm{C}$ 


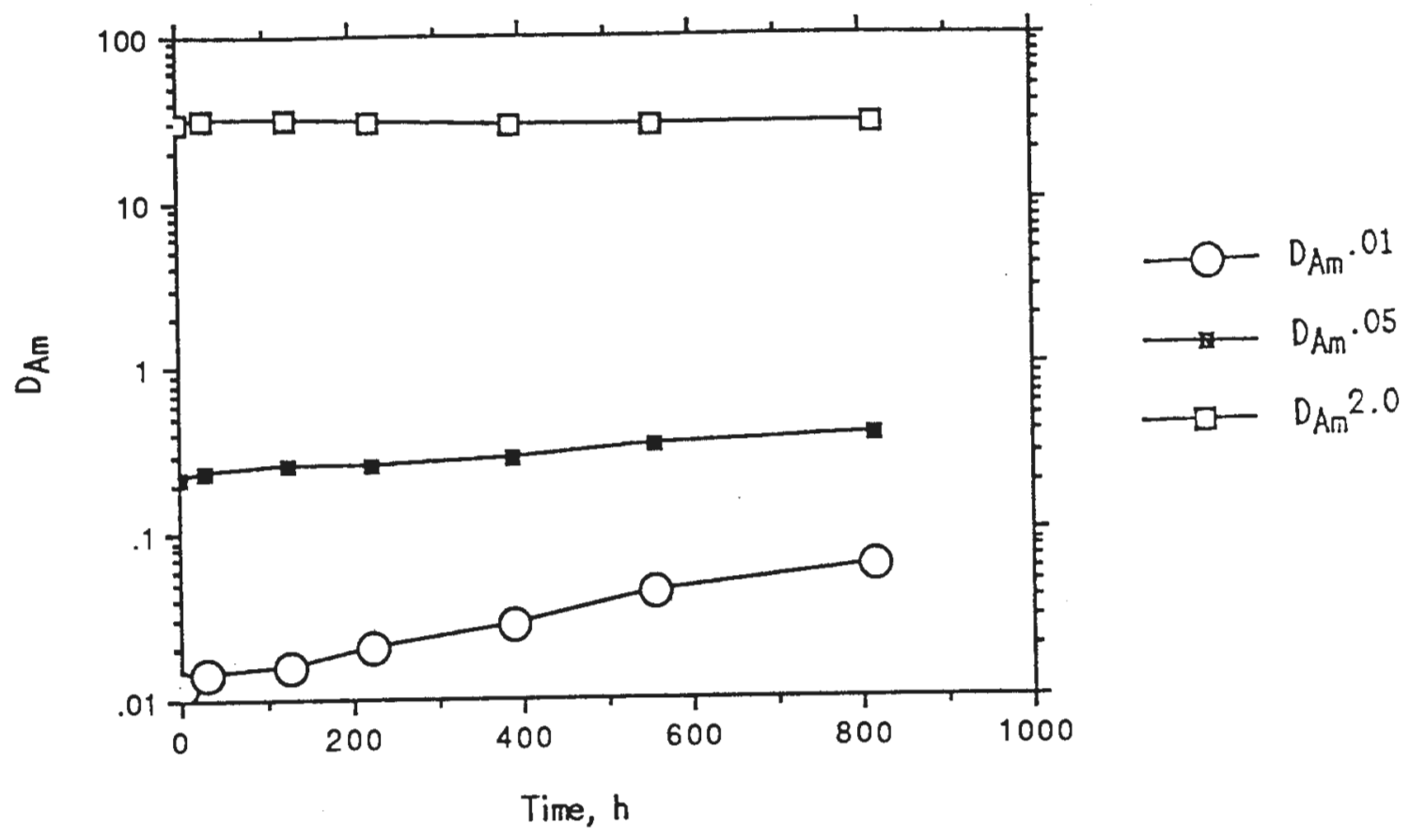

Fig. IV-2. Dependence of $\mathrm{D}_{\mathrm{Am}}{ }^{.01}, \mathrm{D}_{\mathrm{Am}}{ }^{.05}$, and $\mathrm{D}_{\mathrm{Am}}{ }^{2.0}$ on Hydrolysis Time for TRUEX-NPH Solvent Previously Hydrolyzed by $2.5 \underline{\mathrm{M}} \mathrm{HNO}_{3}$ at $50^{\circ} \mathrm{C}$

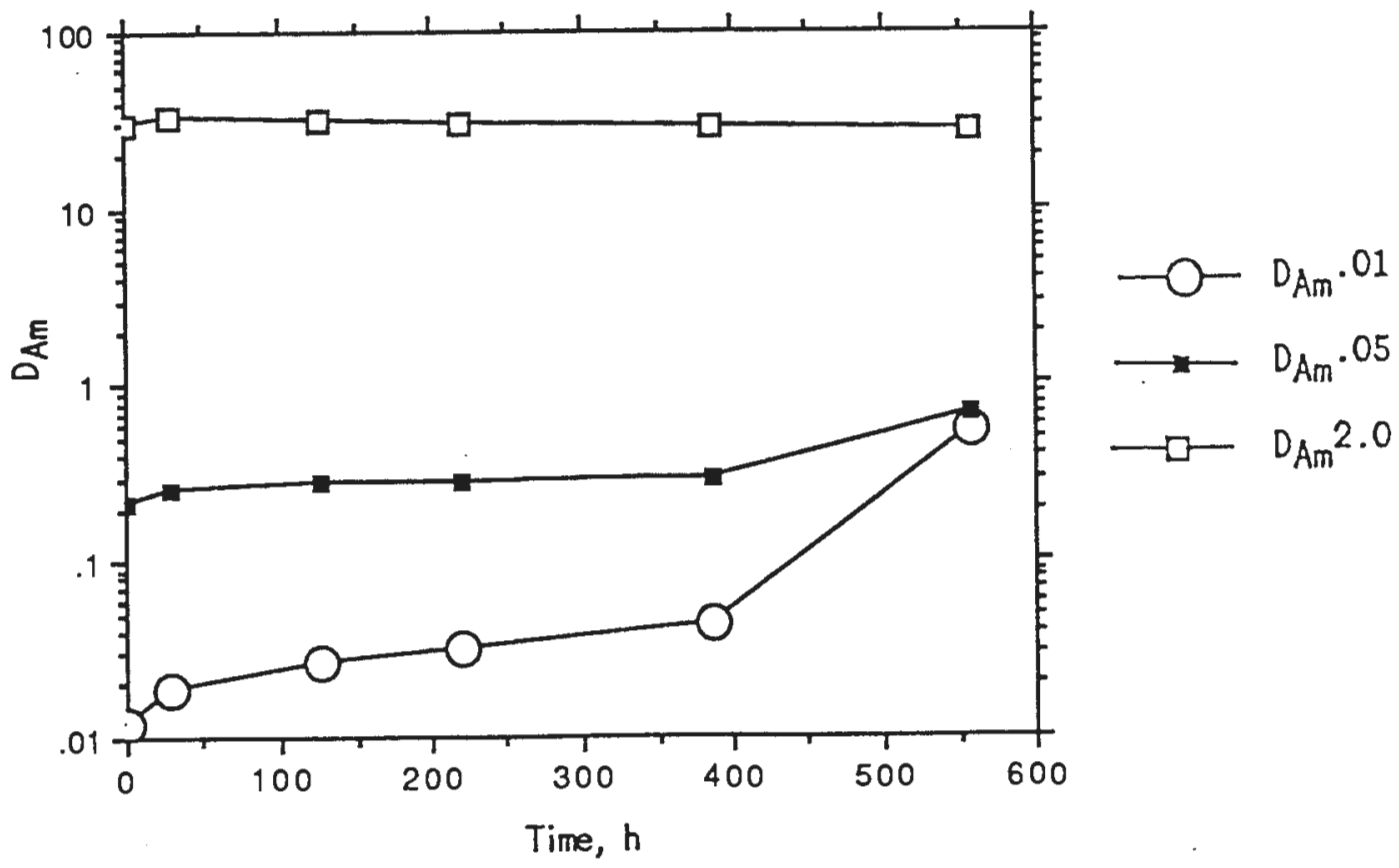

Fig. IV-3. Dependence of $\mathrm{D}_{\mathrm{Am}}{ }^{.01}, \mathrm{D}_{\mathrm{Am}}{ }^{.05}$, and $\mathrm{D}_{\mathrm{Am}}{ }^{2.0}$ on Hydrolysis Time for TRUEX-NPH Solvent Previously Hydrolyzed by $6.0 \mathrm{M} \mathrm{HNO}_{3}$ at $50^{\circ} \mathrm{C}$ 


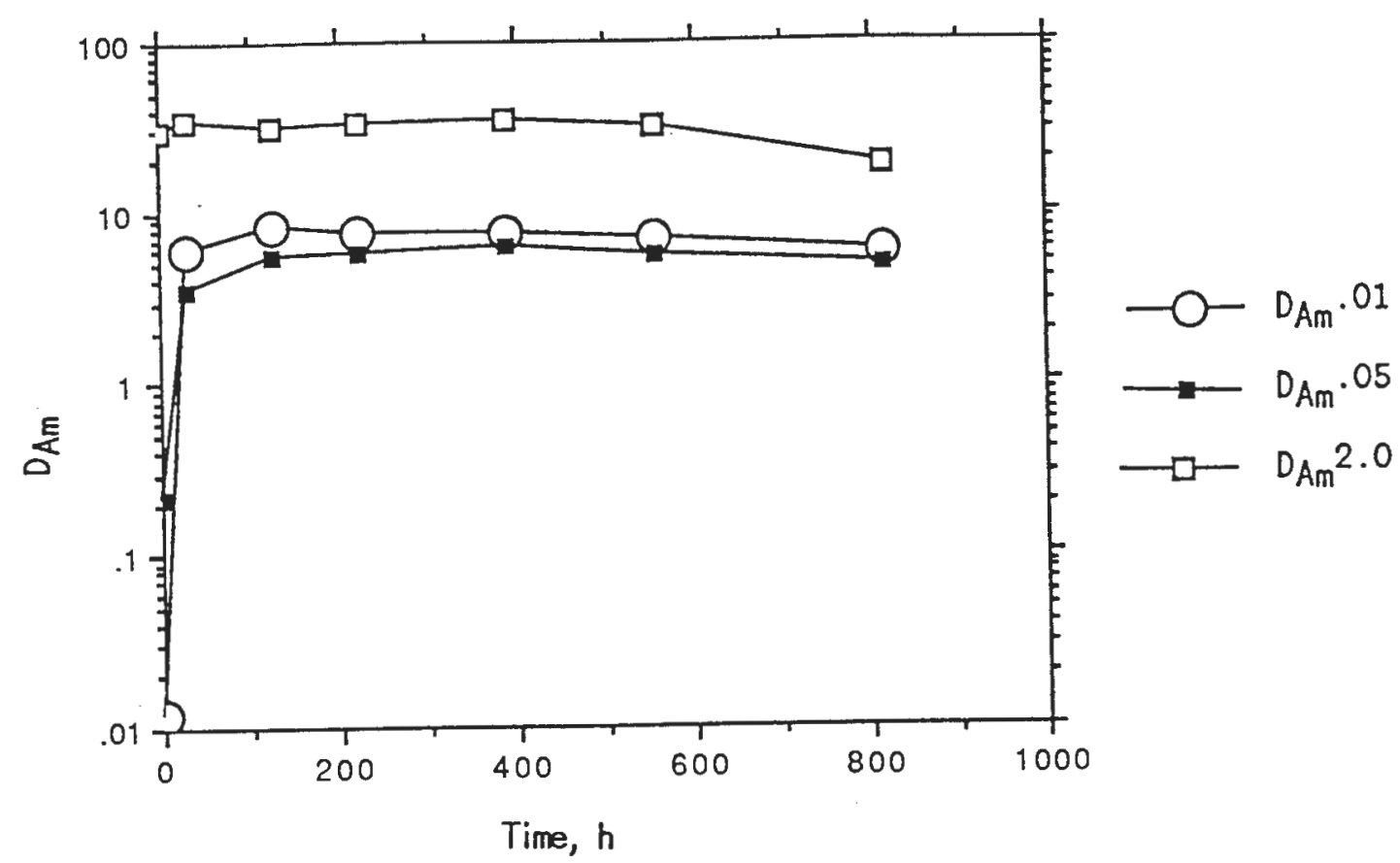

Fig. IV-4. Dependence of $\mathrm{D}_{\mathrm{Am}}{ }^{.01}, \mathrm{D}_{\mathrm{Am}}{ }^{.05}$, and $\mathrm{D}_{\mathrm{Am}}{ }^{2.0}$ on Hydrolysis Time for TRUEX-NPH Solvent Previously Hydrolyzed by Simulated CAW Containing $1.6 \mathrm{M} \mathrm{HNO}_{3}$ at $50^{\circ} \mathrm{C}$

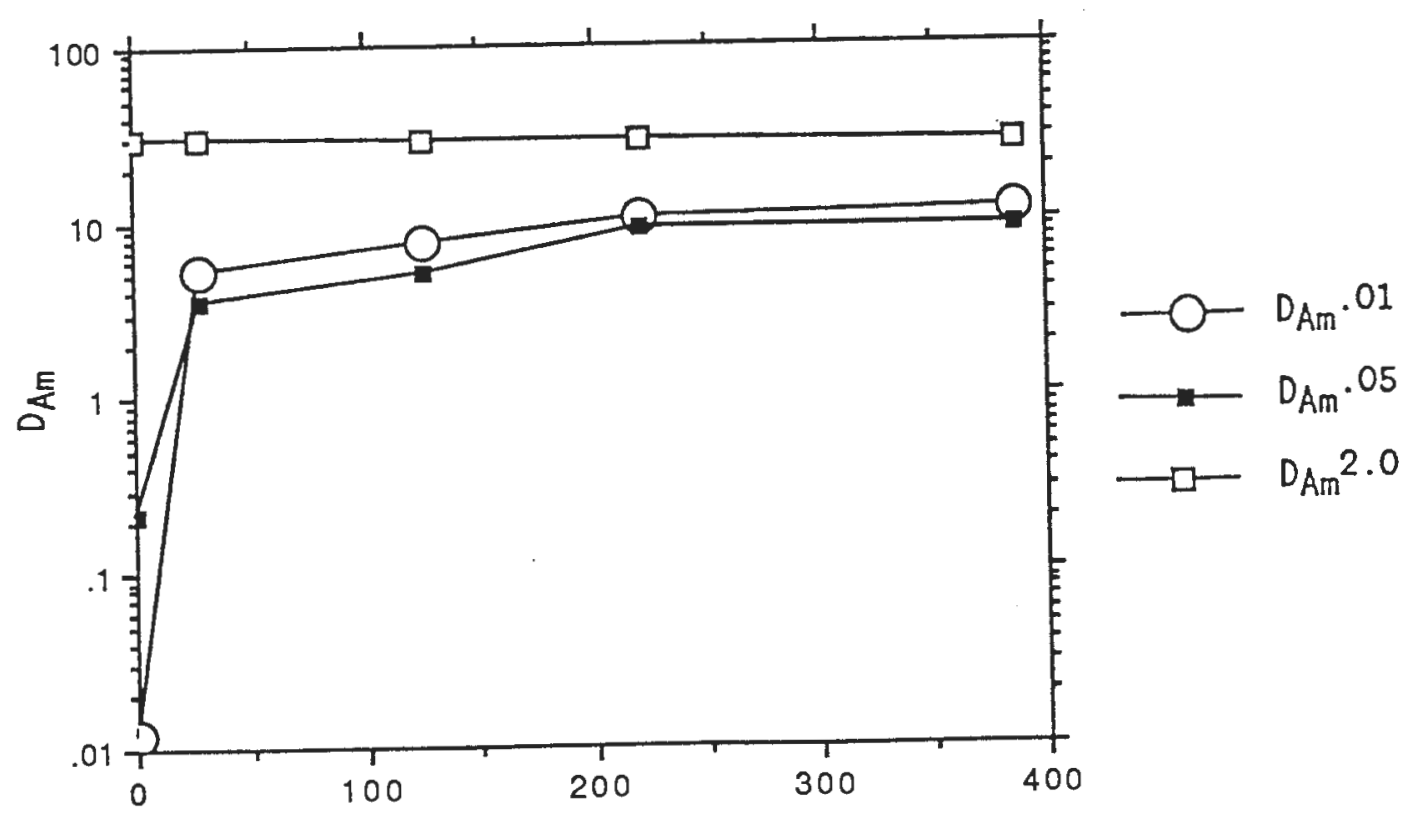

Time, $h$

Fig. IV-5. Dependence of $\mathrm{D}_{\mathrm{Am}}{ }^{.01}, \mathrm{D}_{\mathrm{Am}}{ }^{.05}$, and $\mathrm{D}_{\mathrm{Am}}{ }^{2.0}$ on Hydrolysis Time for TRUEX-NPH Solvent Previously Hydrolyzed by Simulated CAW Containing $2.6 \underline{\mathrm{M}} \mathrm{HNO}_{3}$ at $50^{\circ} \mathrm{C}$ 


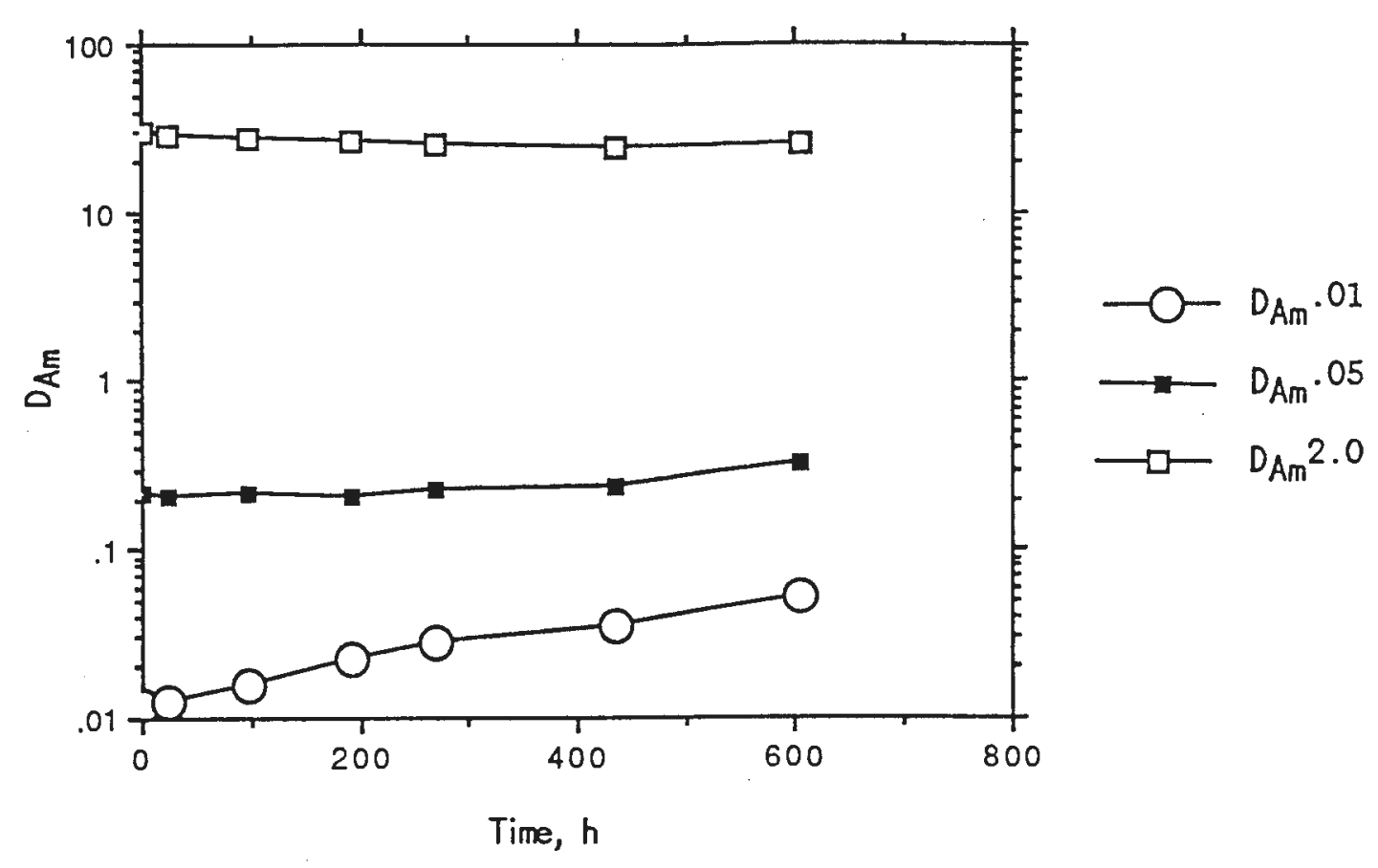

Fig. IV-6. Dependence of $\mathrm{D}_{\mathrm{Am}}{ }^{.01}, \mathrm{D}_{\mathrm{Am}}{ }^{.05}$, and $\mathrm{D}_{\mathrm{Am}}{ }^{2.0}$ on Hydrolysis Time for TRUEX-NPH Solvent Previously Hydrolyzed by $0.25 \mathrm{M} \mathrm{HNO}_{3}$ at $70^{\circ} \mathrm{C}$

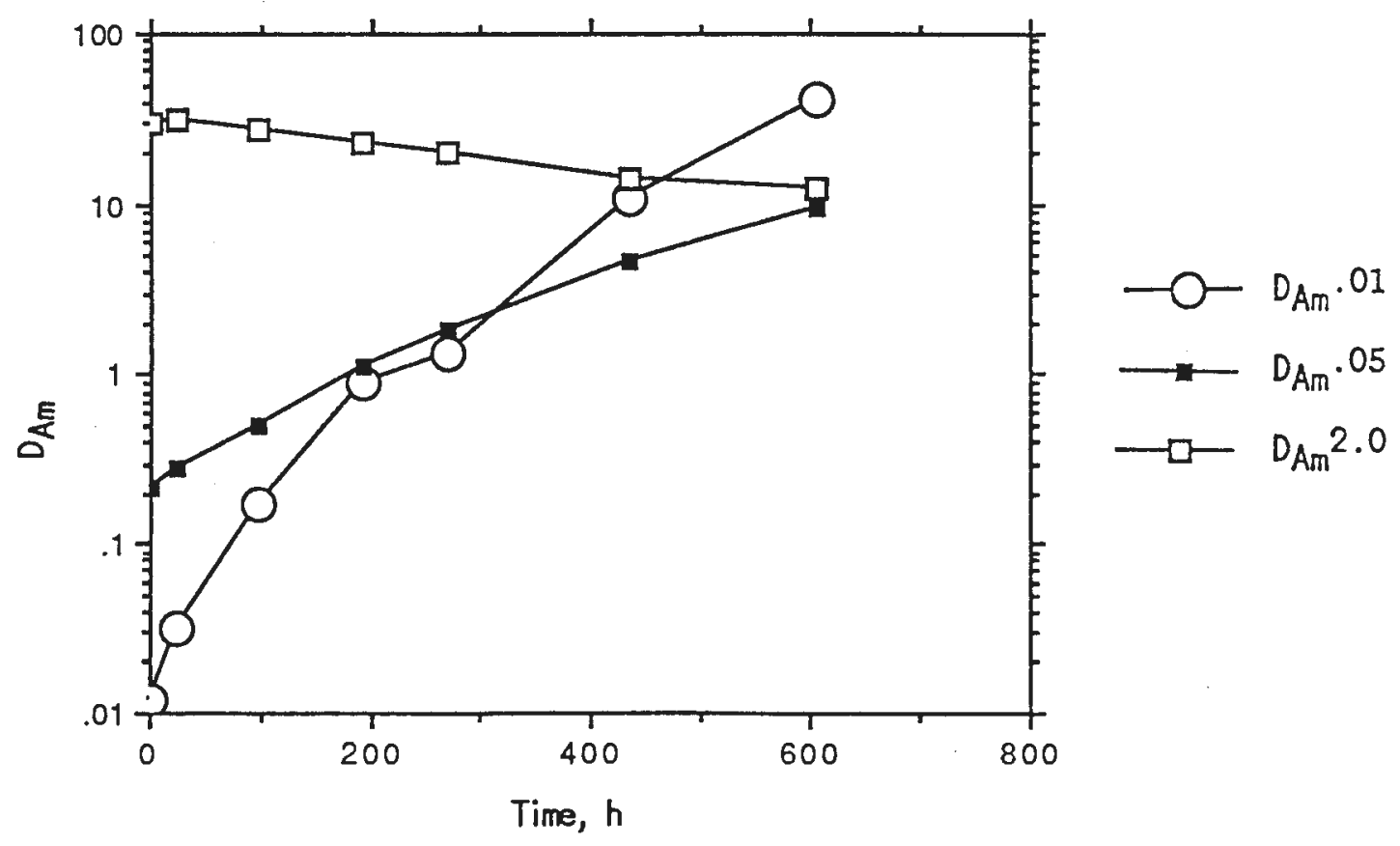

Fig. IV-7. Dependence of $D_{A m}{ }^{.01}, D_{A m}{ }^{.05}$, and $D_{A m}{ }^{2.0}$ on Hydrolysis Time for TRUEX-NPH Solvent Previously Hydrolyzed by $2.5 \underline{\mathrm{M}} \mathrm{HNO}_{3}$ at $70^{\circ} \mathrm{C}$ 


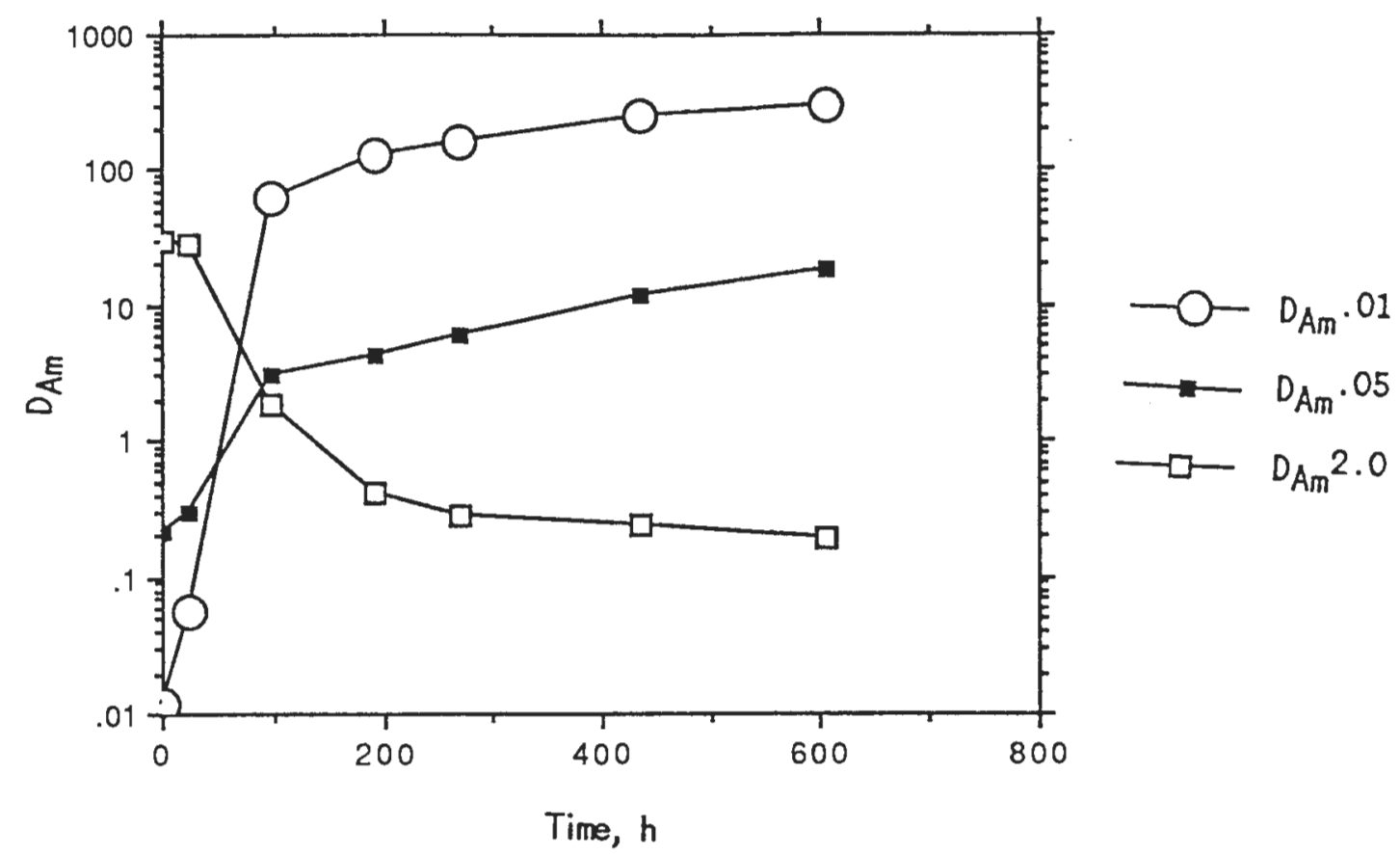

Fig. IV-8. Dependence of $D_{A m}{ }^{.01}, D_{A m}{ }^{.05}$, and $D_{A m}{ }^{2.0}$ on Hydrolysis Time for TRUEX-NPH Solvent Previously Hydrolyzed by $6.0 \mathrm{M} \mathrm{HNO}_{3}$ at $70^{\circ} \mathrm{C}$

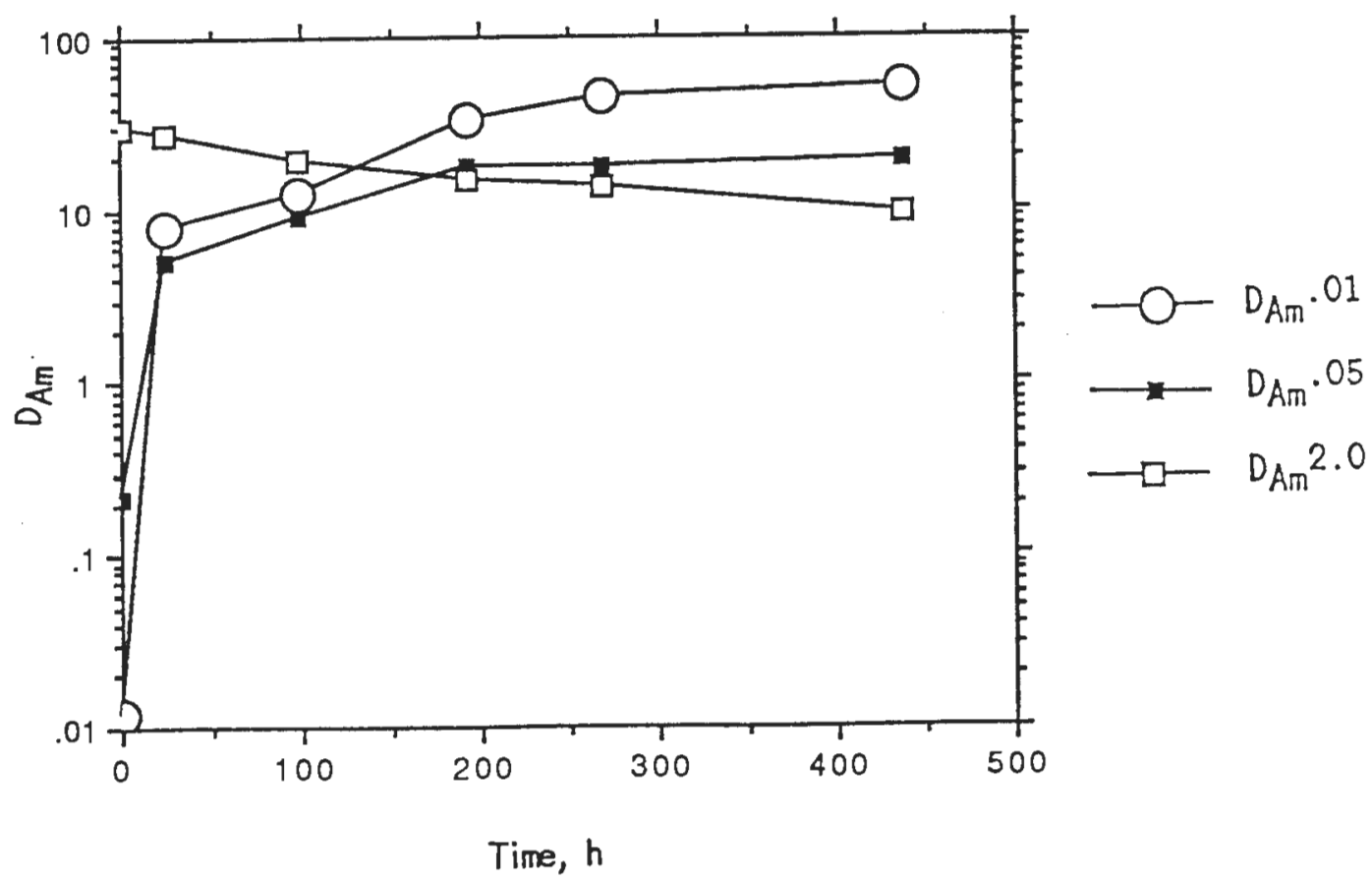

Fig. IV-9. Dependence of $\mathrm{D}_{\mathrm{Am}}{ }^{.01}, \mathrm{D}_{\mathrm{Am}}{ }^{.05}$, and $\mathrm{D}_{\mathrm{Am}}{ }^{2.0}$ on Hydrolysis Time for TRUEX-NPH Solvent Previously Hydrolyzed by Simulated CAW Containing 1.6 $\mathrm{HNO}_{3}$ at $70^{\circ} \mathrm{C}$ 


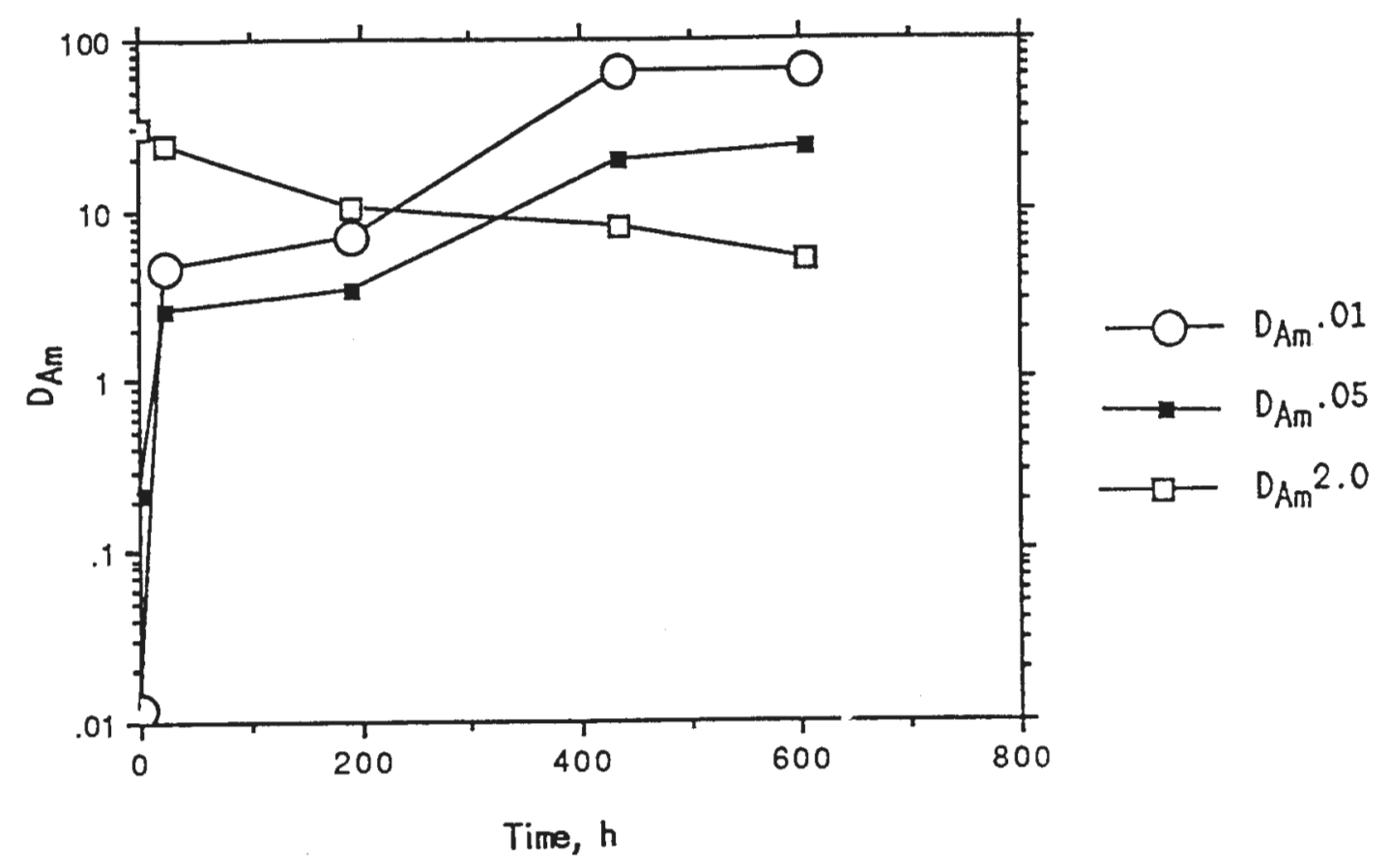

Fig. IV-10. Dependence of $\mathrm{D}_{\mathrm{Am}}{ }^{.01}, \mathrm{D}_{\mathrm{Am}}^{.05}$, and $\mathrm{D}_{\mathrm{Am}}{ }^{2.0}$ on Hydrolysis Time for TRUEX-NPH Solvent Previously Hydrolyzed by Simulated CAW Containing $2.6 \underline{\mathrm{M} \mathrm{HNO}} \mathrm{HN}_{3}$ at $70^{\circ} \mathrm{C}$

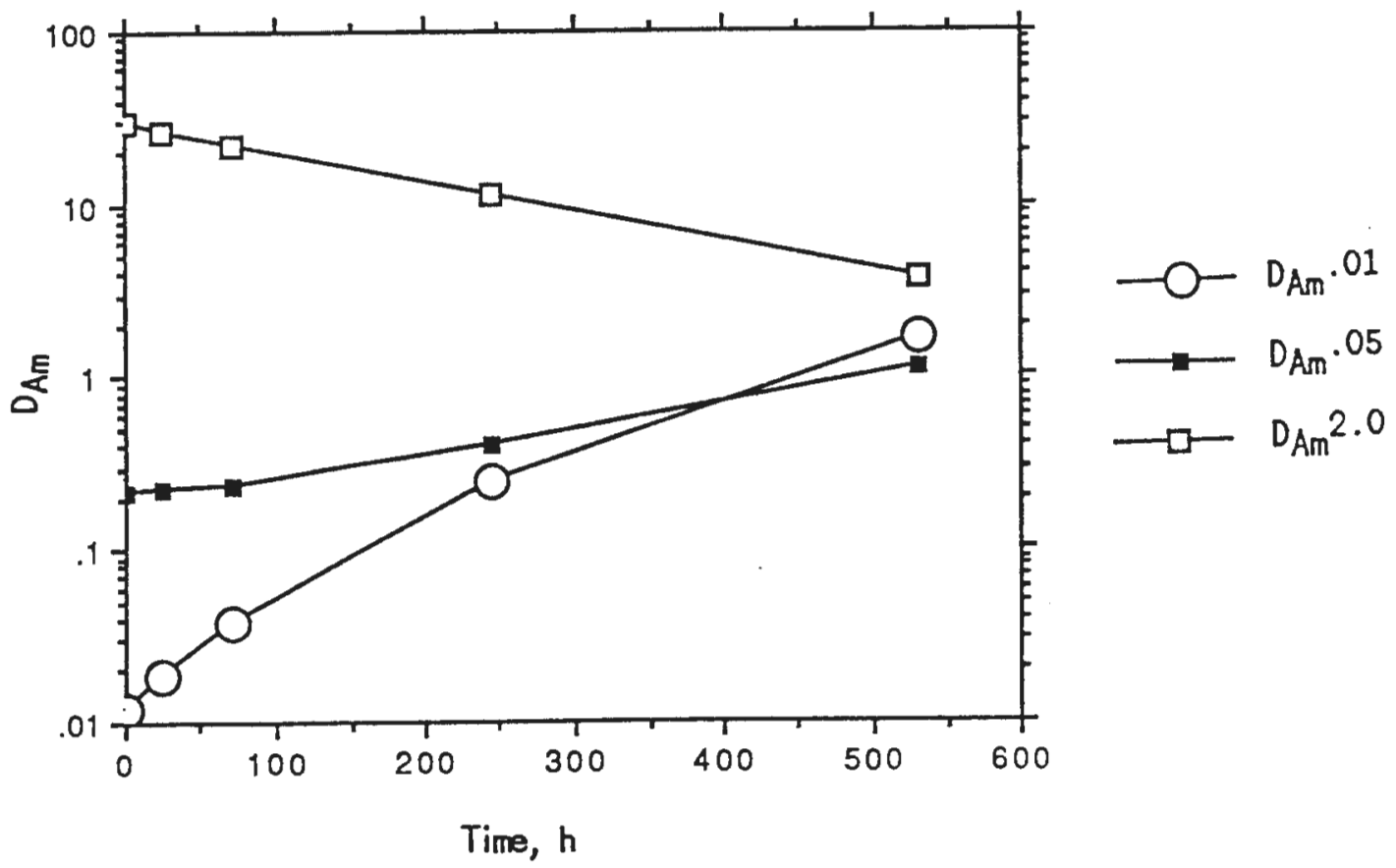

Fig. IV-11. Dependence of $\mathrm{D}_{\mathrm{Am}}{ }^{.01}, \mathrm{D}_{\mathrm{Am}}{ }^{.05}$, and $\mathrm{D}_{\mathrm{Am}}{ }^{2.0}$ on Hydrolysis Time for TRUEX-NPH Solvent Previously Hydrolyzed by $0.25 \underline{\mathrm{M}} \mathrm{HNO}_{3}$ at $95^{\circ} \mathrm{C}$ 


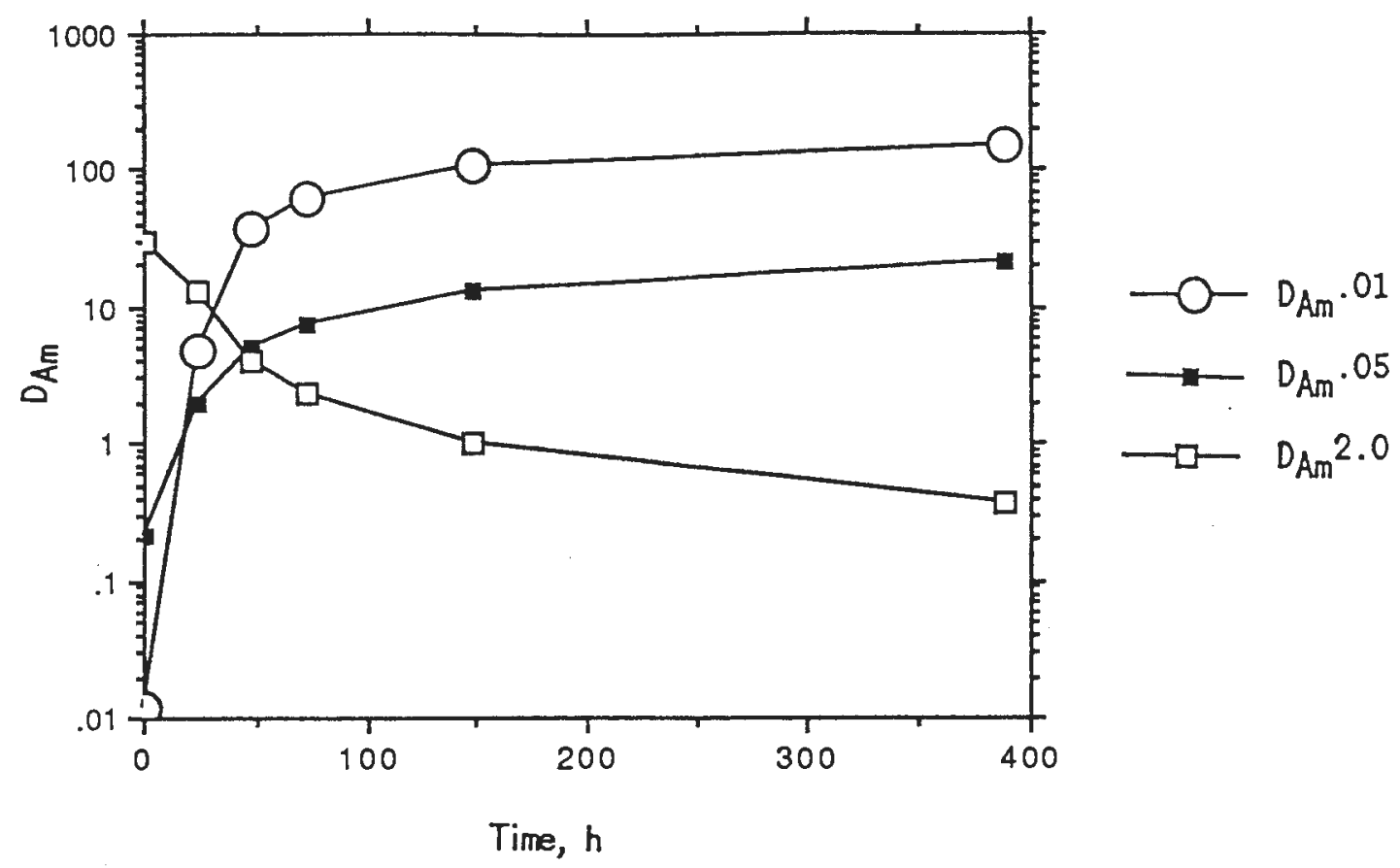

Fig. IV-12. Dependence of $\mathrm{D}_{\mathrm{Am}}^{.01}, \mathrm{D}_{\mathrm{Am}}^{.05}$, and $\mathrm{D}_{\mathrm{Am}}{ }^{2.0}$ on Hydrolysis Time for TRUEX-NPH Solvent Previously Hydrolyzed by $2.5 \underline{\mathrm{M}} \mathrm{HNO}_{3}$ at $95^{\circ} \mathrm{C}$

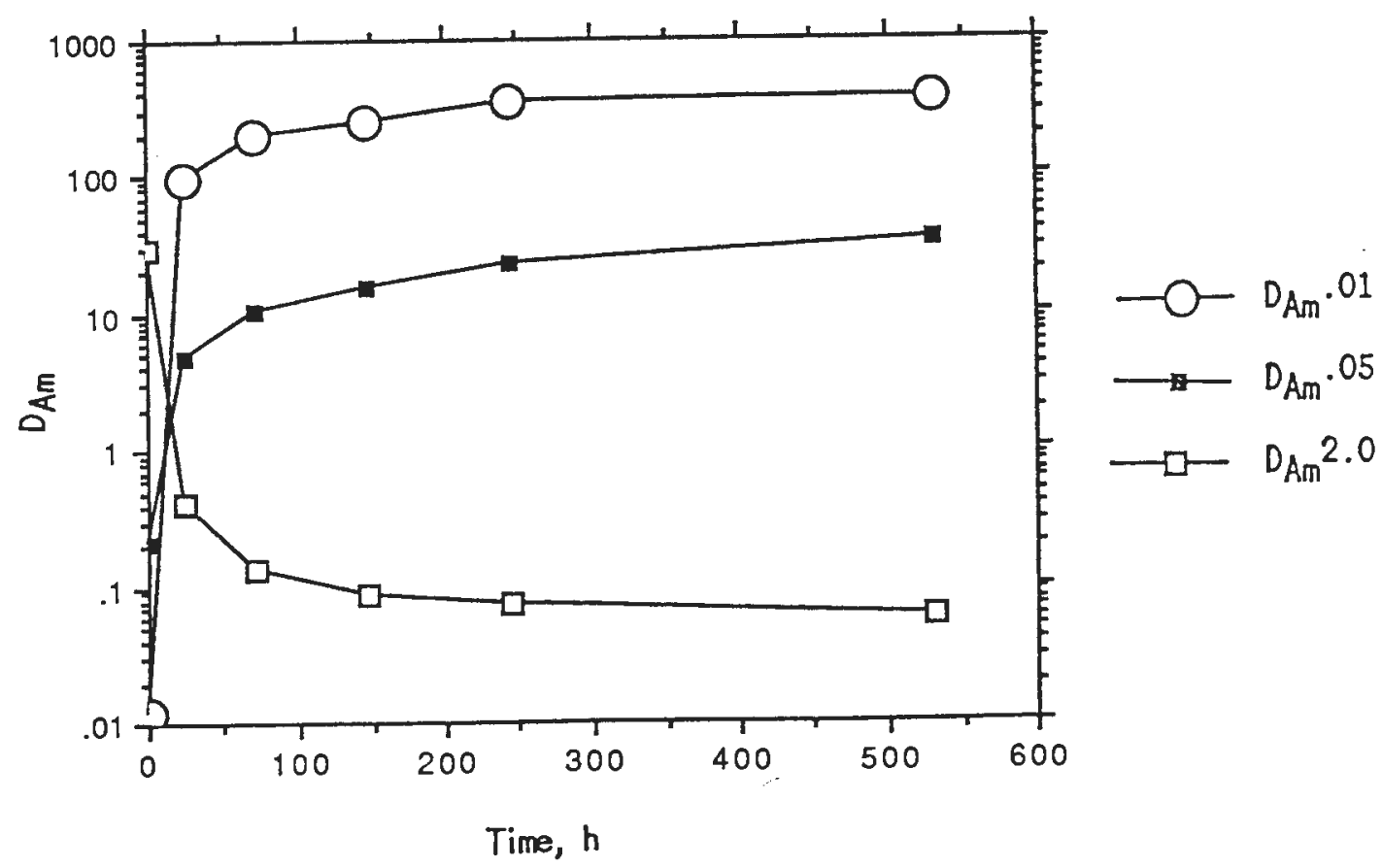

Fig. IV-13. Dependence of $\mathrm{D}_{\mathrm{Am}}^{.01}, \mathrm{D}_{\mathrm{Am}}{ }^{.05}$, and $\mathrm{D}_{\mathrm{Am}}{ }^{2.0}$ on Hydrolysis Time for TRUEX-NPH Solvent Previously Hydrolyzed by $6.0 \underline{\mathrm{M}} \mathrm{HNO}_{3}$ at $95^{\circ} \mathrm{C}$ 


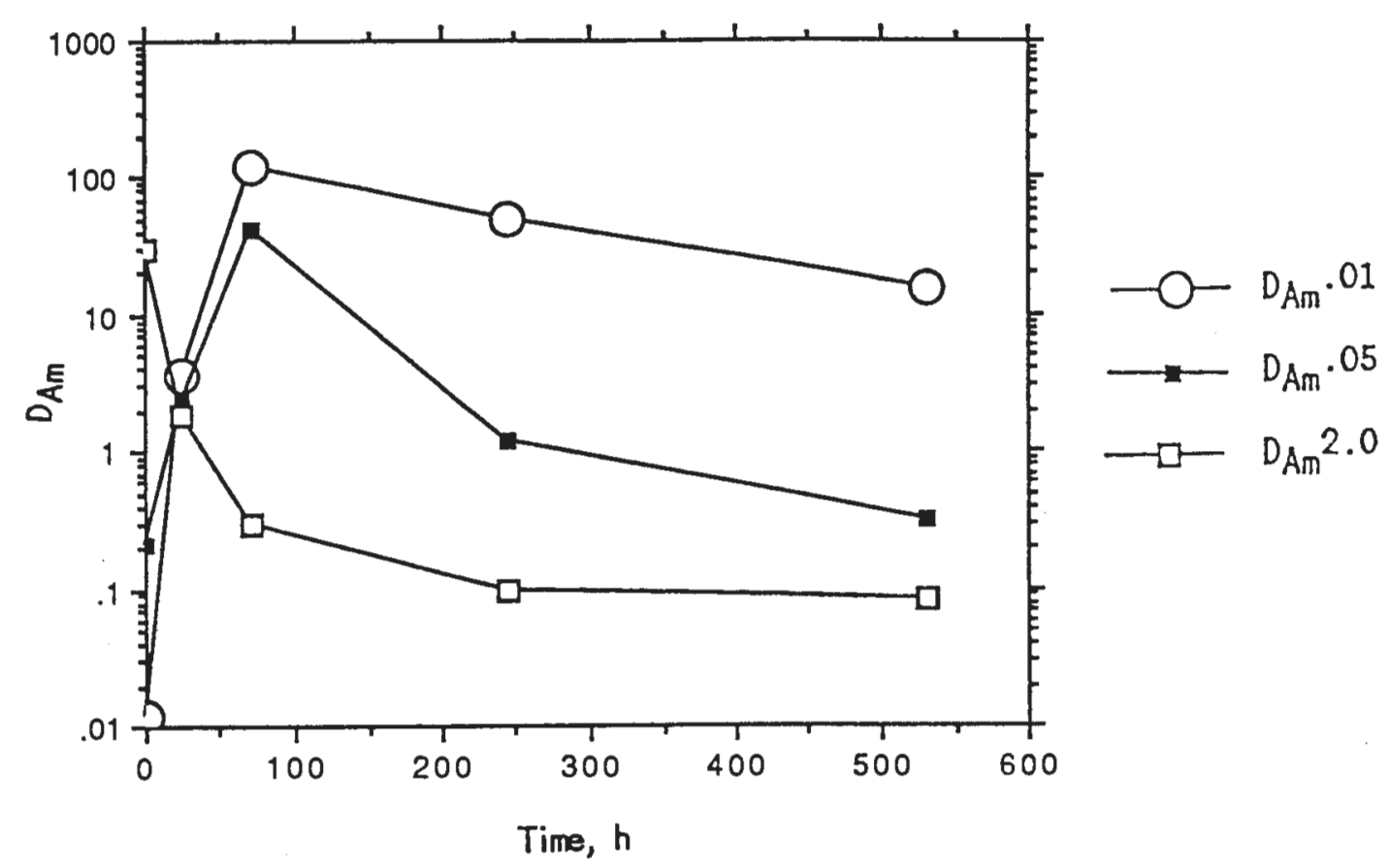

Fig. IV-14. Dependence of $\mathrm{D}_{\mathrm{Am}}{ }^{.01}, \mathrm{D}_{\mathrm{Am}}{ }^{.05}$, and $\mathrm{D}_{\mathrm{Am}}{ }^{2.0}$ on Hydrolysis Time for TRUEX-NPH Solvent Previously Hydrolyzed by Simulated CAW Containing $1.6 \mathrm{M} \mathrm{HNO} \mathrm{HN}_{3}$ at $95^{\circ} \mathrm{C}$

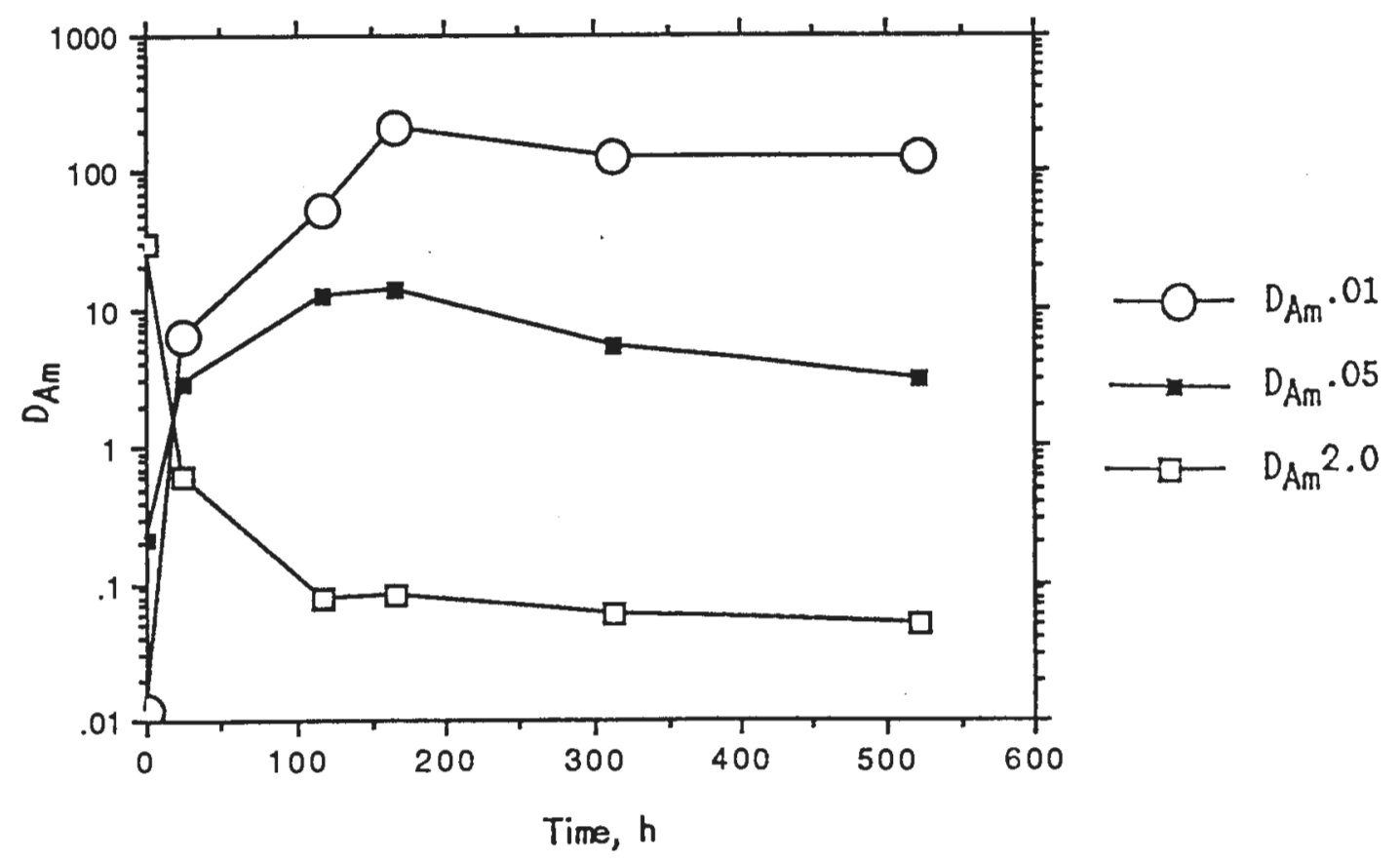

Fig. IV-15. Dependence of $\mathrm{D}_{\mathrm{Am}}{ }^{.01}, \mathrm{D}_{\mathrm{Am}}{ }^{.05}$, and $\mathrm{D}_{\mathrm{Am}}{ }^{2.0}$ on Hydrolysis Time for TRUEX-NPH Solvent Previously Hydrolyzed by Simulated CAW Containing $2.6 \underline{\mathrm{M}} \mathrm{HNO}_{3}$ at $95^{\circ} \mathrm{C}$ 
C. Mathematical Expressions for $\mathrm{D}_{\mathrm{Am}}^{.01}$ and $\mathrm{D}_{\mathrm{Am}}{ }^{.05}$

According to a previous study [NASH], the products of CMPO degradation include neutral and acidic species. The dependence of $\mathrm{D}_{\mathrm{Am}}{ }^{.01}$ and $\mathrm{D}_{\mathrm{Am}}{ }^{.05}$ on hydrolysis time cannot therefore be related to the concentration of a single extractant species.

The increase of $\mathrm{D}_{\mathrm{Am}}{ }^{.01}$ and $\mathrm{D}_{\mathrm{Am}}^{.05}$ as solvent degradation proceeds as shown in Figs. IV-1 through IV-15 is assumed to result from the increasing concentration of the acidic degradation products of CMPO, which control the extraction in the presence of 0.01 or $0.05 \underline{\mathrm{M}}$ nitric acid.

\section{Mathematical Expression for $\mathrm{D}_{\mathrm{Am}}^{.01}$}

Using the data obtained in this work, the change of $\mathrm{D}_{\mathrm{Am}}{ }^{.01}$ with time appears to be best represented by assuming that it is independent of extractant concentration at early stages of the hydrolysis for a time up to about $100 \mathrm{~h}$. This change is mathematically expressed as

$$
\frac{\mathrm{d} \mathrm{D}_{\mathrm{Am}}^{.01}}{\mathrm{dt}}=\mathrm{k}_{\mathrm{h}}^{.01}
$$

which has the integrated form

$$
\mathrm{D}_{\mathrm{Am}}^{.01}=\mathrm{D}_{\mathrm{Am}_{\mathrm{O}}}^{.01}+\mathrm{k}_{\mathrm{h}}^{.01} \mathrm{t}
$$

Therefore, values of $k_{h}{ }^{.01}$ are determined from graphs of $D_{A m}{ }^{.01}$ versus t. Figures IV-16 through IV-30 show the experimental values for $\mathrm{D}_{\mathrm{Am}}{ }^{.01}$ for a given combination of temperature and hydrolytic agent as a function of hydrolysis time. Each figure also shows the line used to represent those values, whose slope was taken to be the value of $\mathrm{k}_{\mathrm{h}}{ }^{.01}$. Because solvent will receive brief exposure to hydrolytic conditions during processing, the times shown in the figure are limited to $<150 \mathrm{~h}$. Furthermore, $\mathrm{k}_{\mathrm{h}}{ }^{01}$ is correlated with the acidity of the aqueous solution in contact with the solvent during hydrolysis:

$$
\mathrm{k}_{\mathrm{h}}^{.01}=\mathrm{k}_{\mathrm{h}_{\mathrm{o}}} .01+\mathrm{k}_{\mathrm{h}}^{\prime} .01\{\mathrm{H}\}
$$

Values of $\mathrm{k}_{\mathrm{h}_{\mathrm{o}}} \cdot 01$ and $\mathrm{k}_{\mathrm{h}}{ }^{\prime} .01$ were determined from graphs of $\mathrm{k}_{\mathrm{h}} .01$ as a function of acidity. 


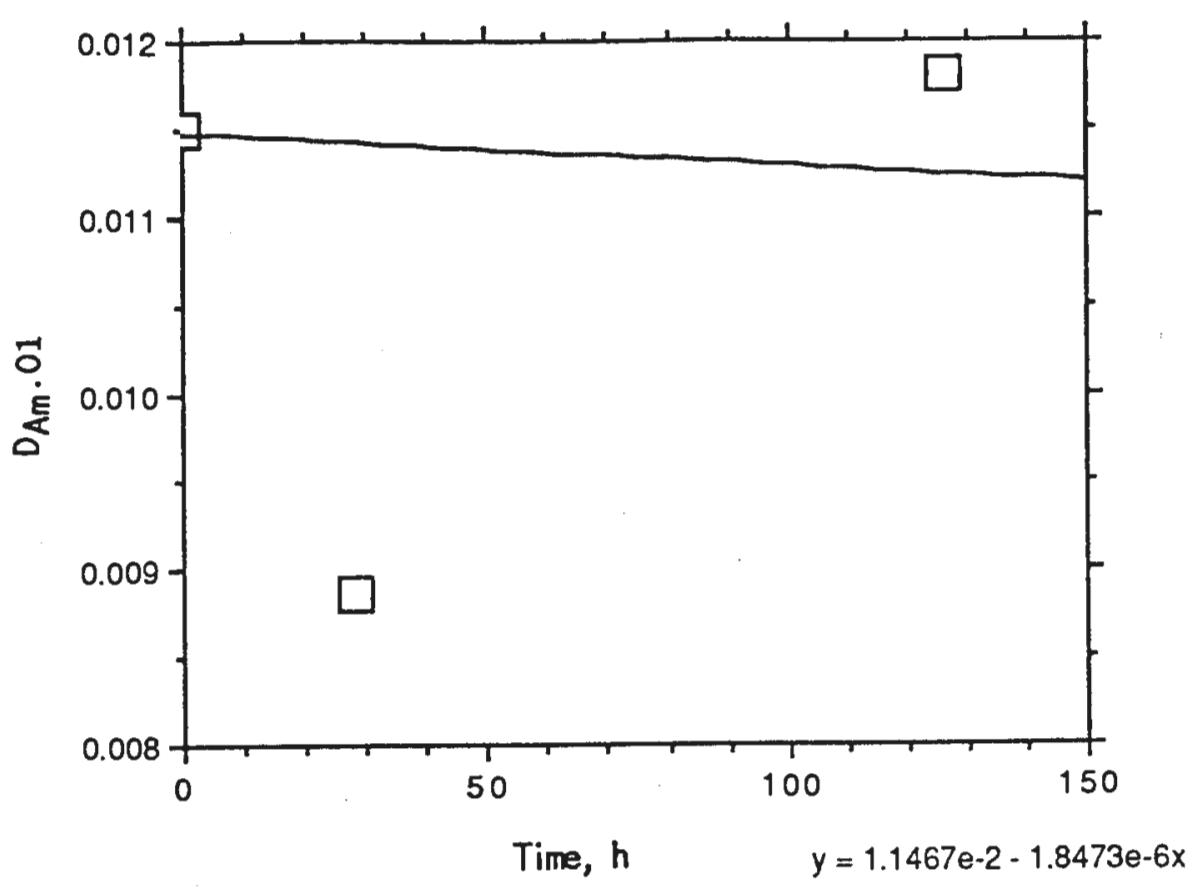

Fig. IV-16. Graph of $\mathrm{D}_{\mathrm{Am}}{ }^{.01}$ versus Hydrolysis Time Using $0.25 \mathrm{M} \mathrm{HNO}_{3}$ at $50^{\circ} \mathrm{C}$. Slope of line represents value of $k_{h} .01$ used for Eq. IV-2.

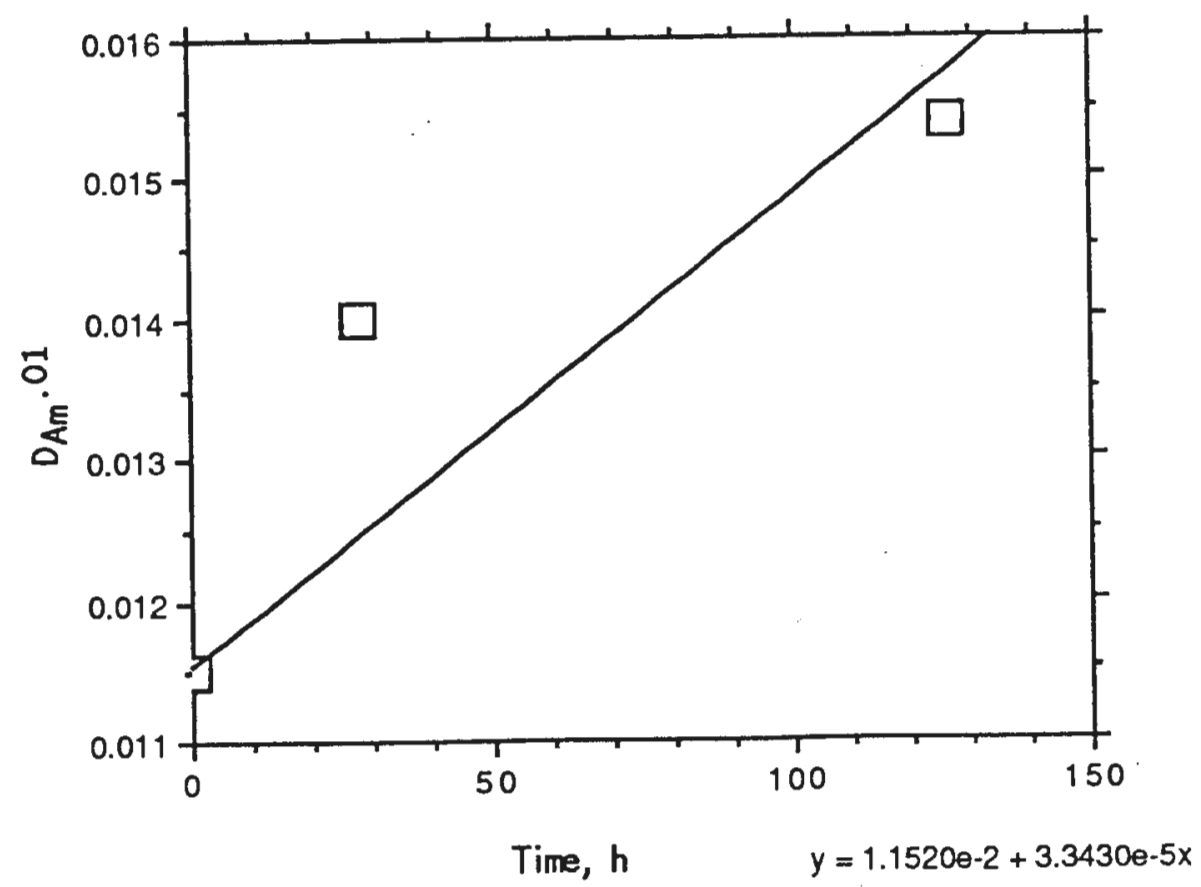

Fig. IV-17. Graph of $\mathrm{D}_{\mathrm{Am}}{ }^{.01}$ versus Hydrolysis Time Using $2.5 \mathrm{M} \mathrm{HNO}_{3}$ at $50^{\circ} \mathrm{C}$. Slope of line represents value of $\mathrm{k}_{\mathrm{h}}{ }^{.01}$ used in Eq. IV-2. 


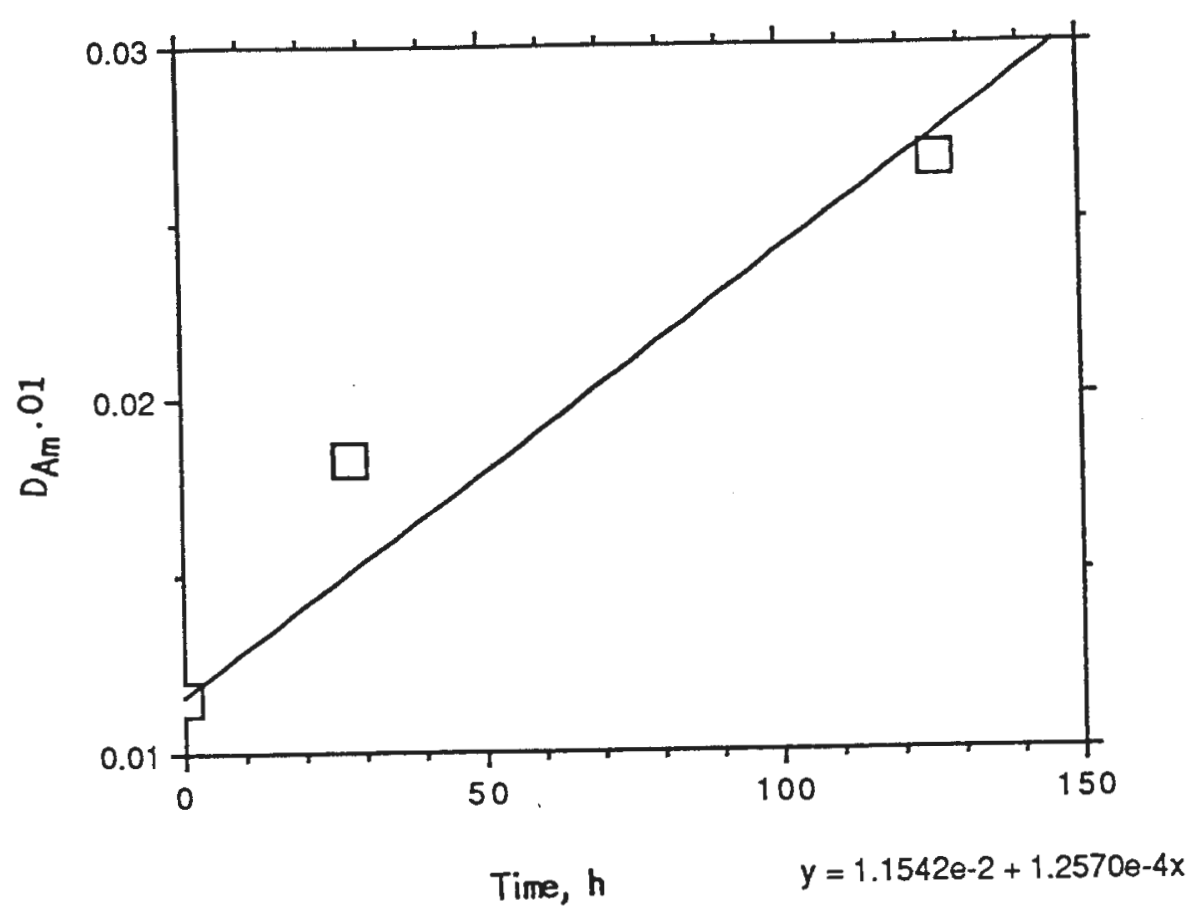

Fig. IV-18. Graph of $\mathrm{D}_{\mathrm{Am}}{ }^{.01}$ versus Hydrolysis Time Using $6.0 \mathrm{M} \mathrm{HNO}_{3}$ at $50^{\circ} \mathrm{C}$. Slope of line represents value of $\mathrm{k}_{\mathrm{h}} .01$ used in Eq. IV-2.

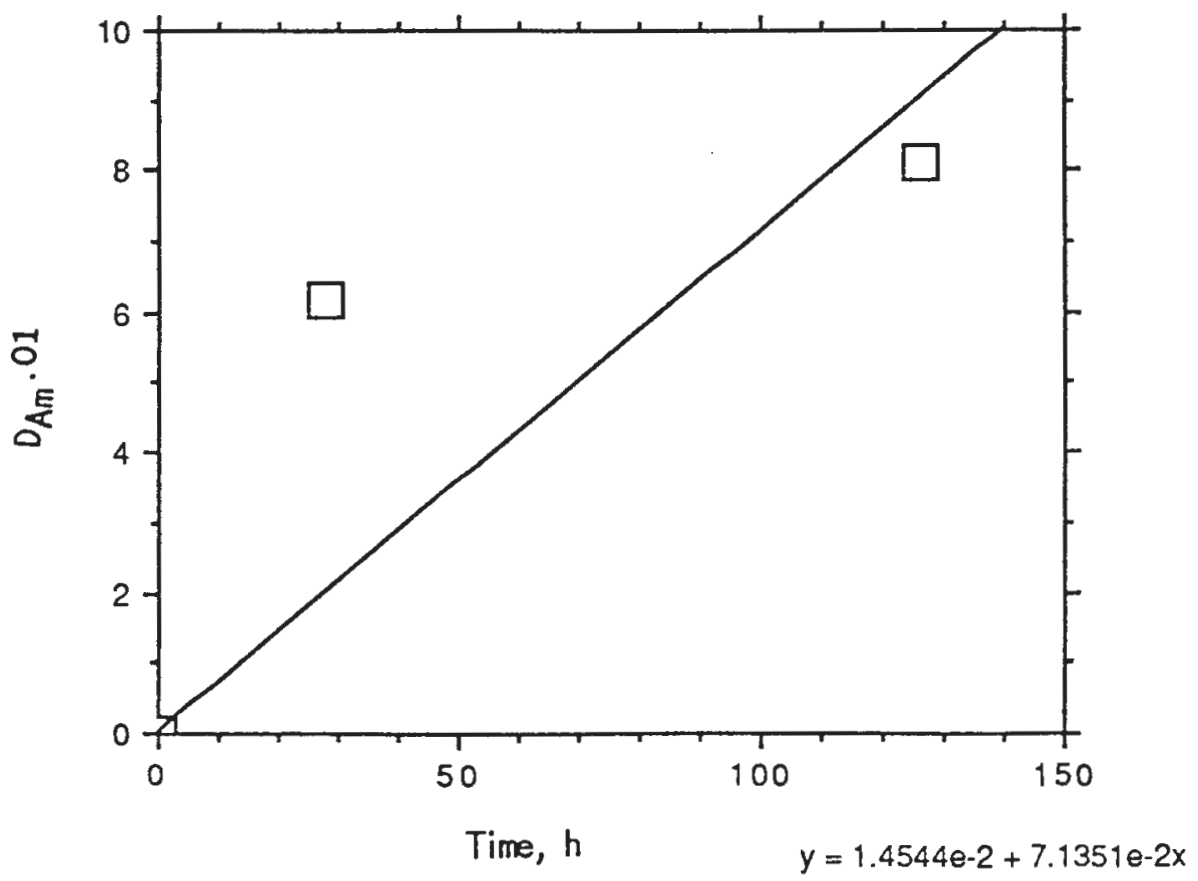

Fig. IV-19. Graph of $\mathrm{D}_{\mathrm{Am}}{ }^{.01}$ versus Hydrolysis Time Using Simulated CAW Containing $1.6 \mathrm{M} \mathrm{HNO}_{3}$ at $50^{\circ} \mathrm{C}$. Slope of line represents value of $\mathrm{k}_{\mathrm{h}}{ }^{.01}$ used in Eq. IV-2. 


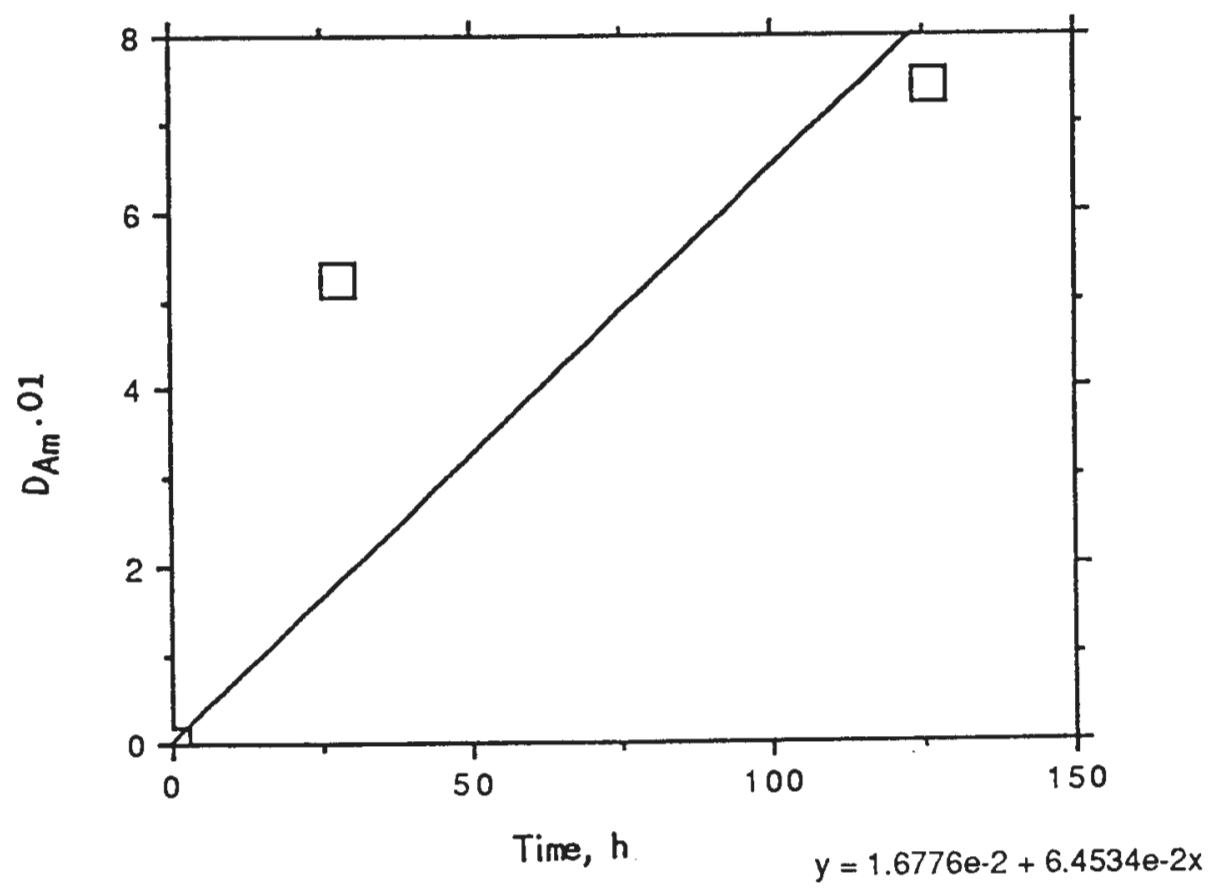

Fig. IV-20. Graph of $D_{A m}^{.01}$ versus Hydrolysis Time Using Simulated CAW Containing 2.6M $\mathrm{HNO}_{3}$ at $50^{\circ} \mathrm{C}$. Slope of line represents value of $\mathrm{k}_{\mathrm{h}}{ }^{.01}$ used in Eq. IV-2.

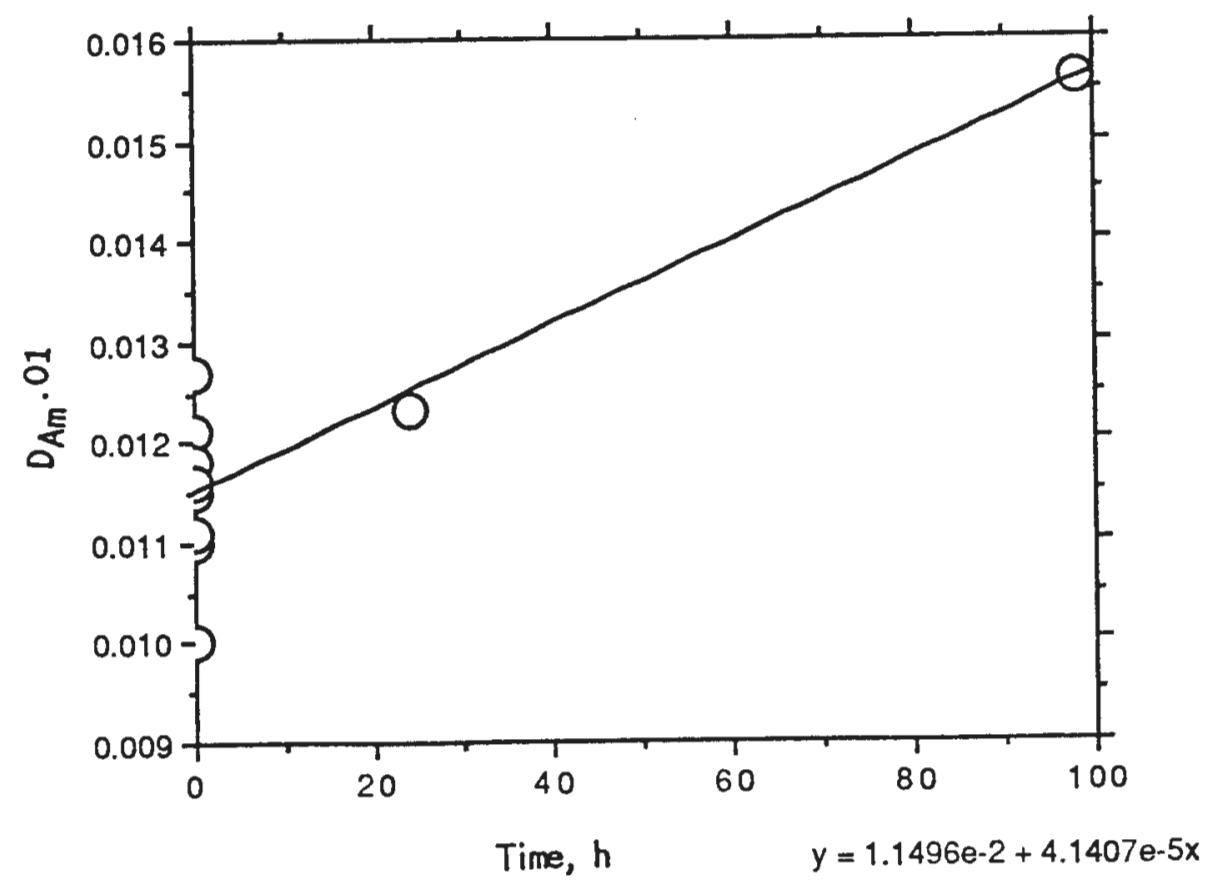

Fig. IV-21. Graph of $\mathrm{D}_{\mathrm{Am}}^{.01}$ versus Hydrolysis Time Using $0.25 \mathrm{M} \mathrm{HNO}_{3}$ at $70^{\circ} \mathrm{C}$. Slope of line represents value of $k_{h}{ }^{.01}$ used in Eq. IV-2. 


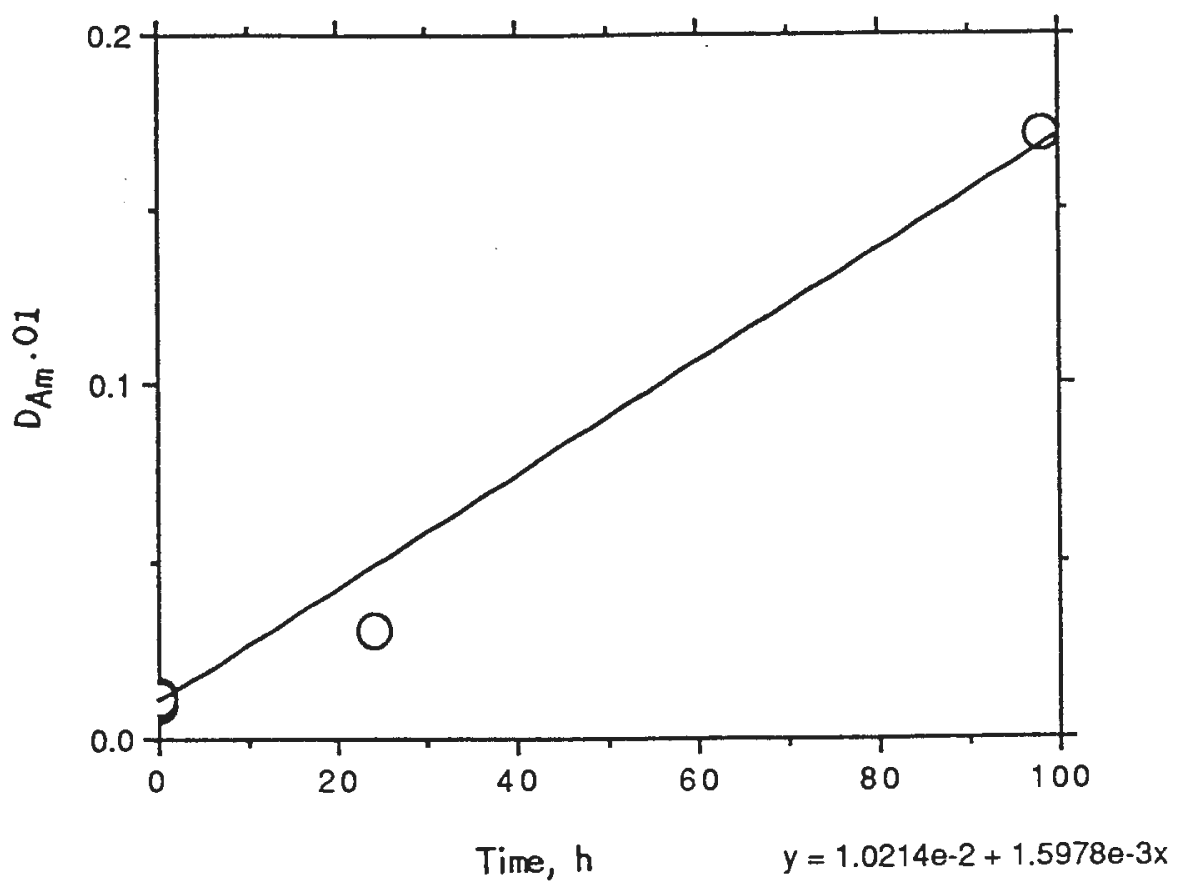

Fig. IV-22. Graph of $\mathrm{D}_{\mathrm{Am}}{ }^{.01}$ versus Hydrolysis Time Using $2.5 \mathrm{M} \mathrm{HNO}_{3}$ at $70^{\circ} \mathrm{C}$. Slope of line represents value of $\mathrm{k}_{\mathrm{h}} .01$ used in Eq. IV-2.

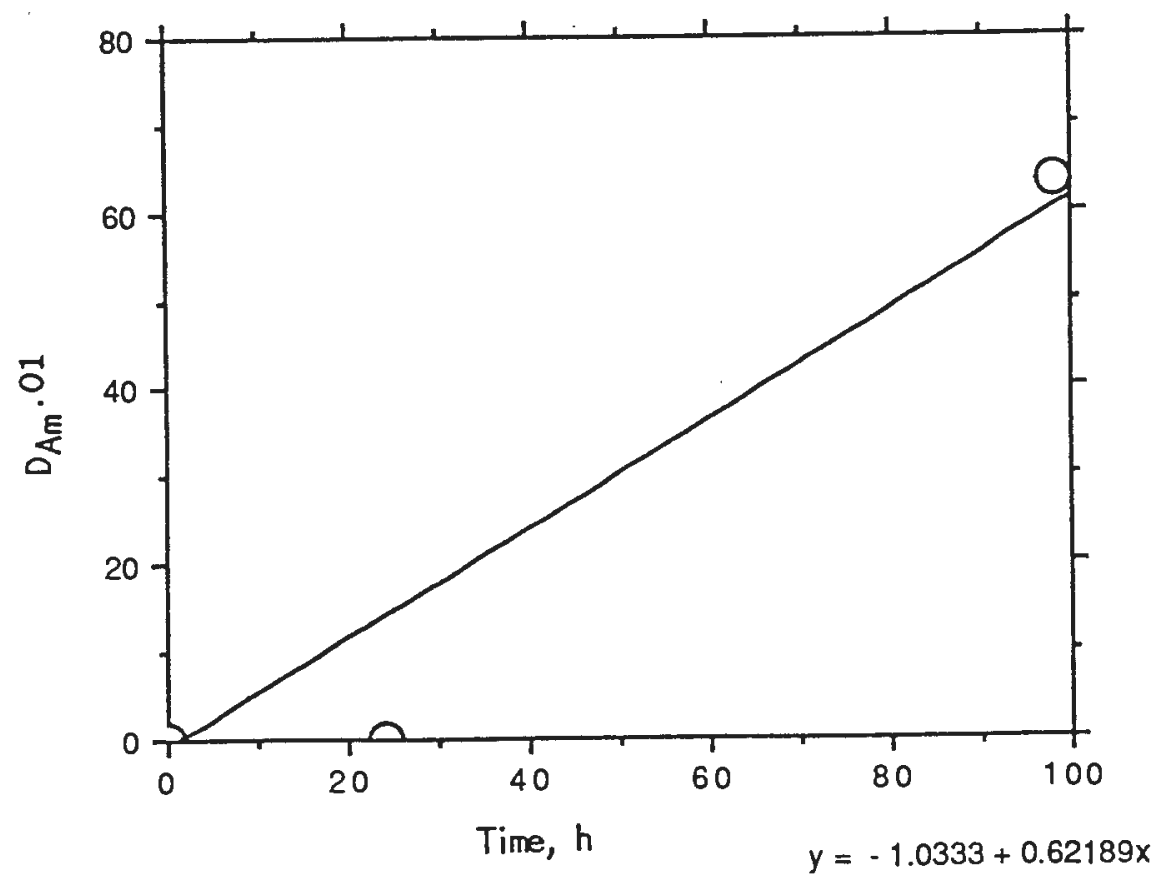

Fig. IV-23. Graph of $\mathrm{D}_{\mathrm{Am}}{ }^{.01}$ versus Hydrolysis Time Using $6.0 \mathrm{M} \mathrm{HNO}_{3}$ at $70^{\circ} \mathrm{C}$. Slope of line represents value of $\mathrm{k}_{\mathrm{h}}{ }^{.01}$ used for Eq. IV -2 . 


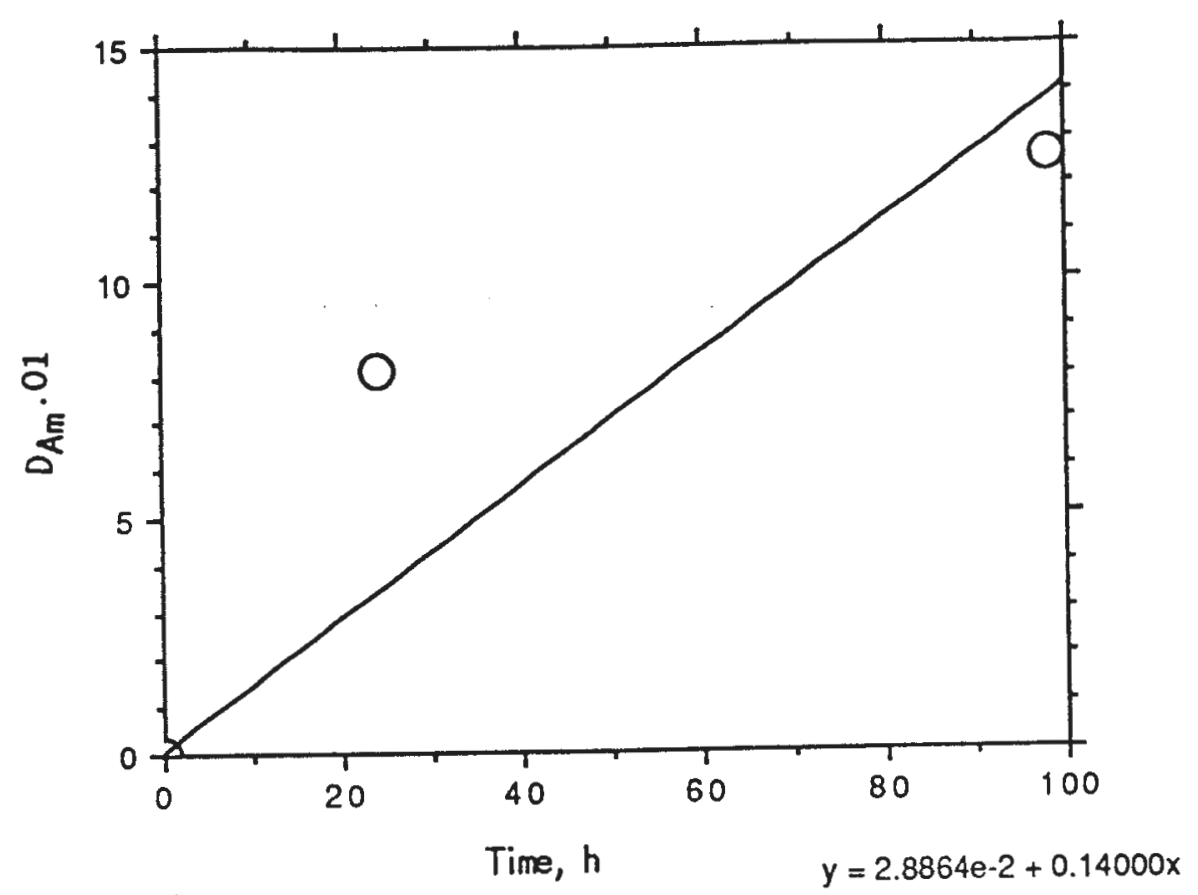

Fig. IV-24. Graph of $\mathrm{D}_{\mathrm{Am}}{ }^{.01}$ versus Hydrolysis Time Using Simulated CAW Containing 1.6 $\mathrm{M} \mathrm{HNO}_{3}$ at $70^{\circ} \mathrm{C}$. Slope of line represents value of $\mathrm{k}_{\mathrm{h}} .01$ used for Eq. IV-2.

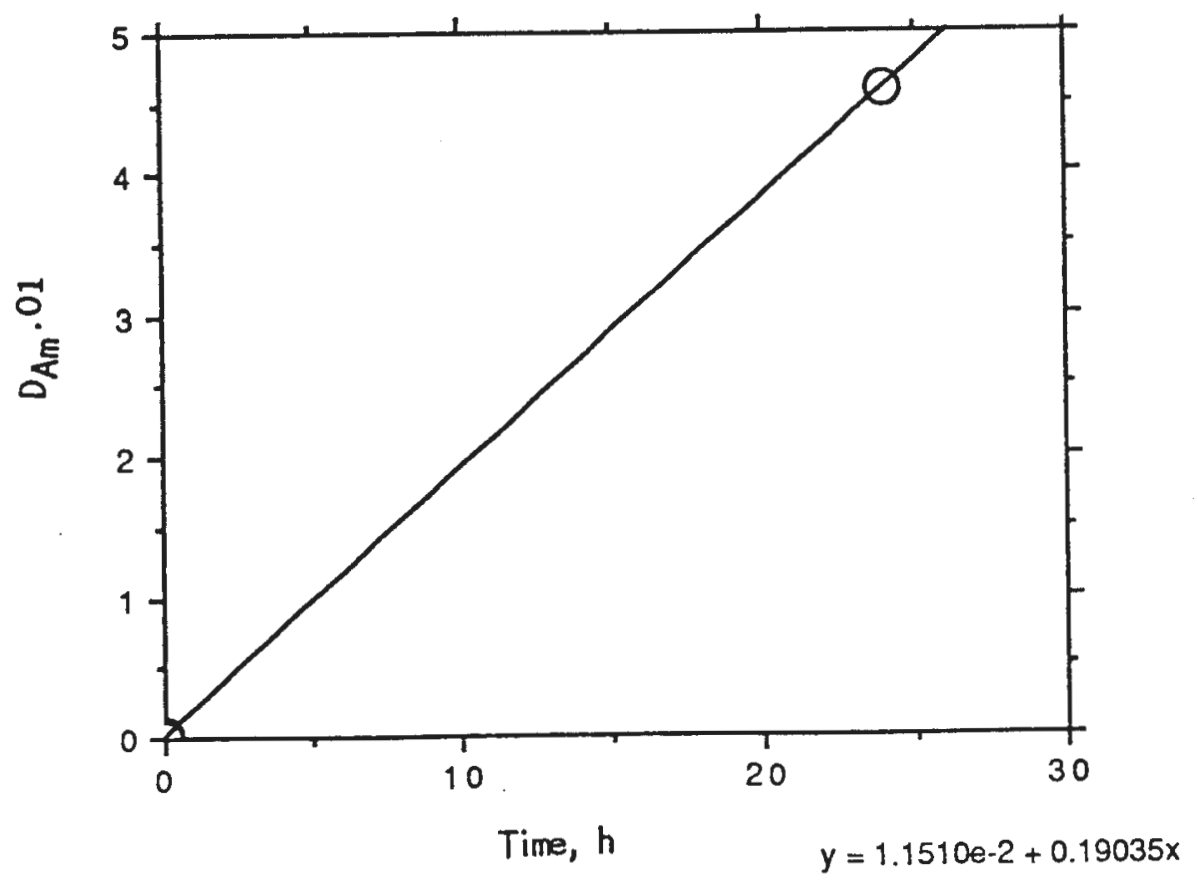

Fig. IV-25. Graph of $\mathrm{D}_{\mathrm{Am}}{ }^{.01}$ versus Hydrolysis Time Using Simulated CAW Containing $2.6 \mathrm{M} \mathrm{HNO}_{3}$ at $70^{\circ} \mathrm{C}$. Slope of line represents value of $k_{h} .01$ used for Eq. IV-2. 


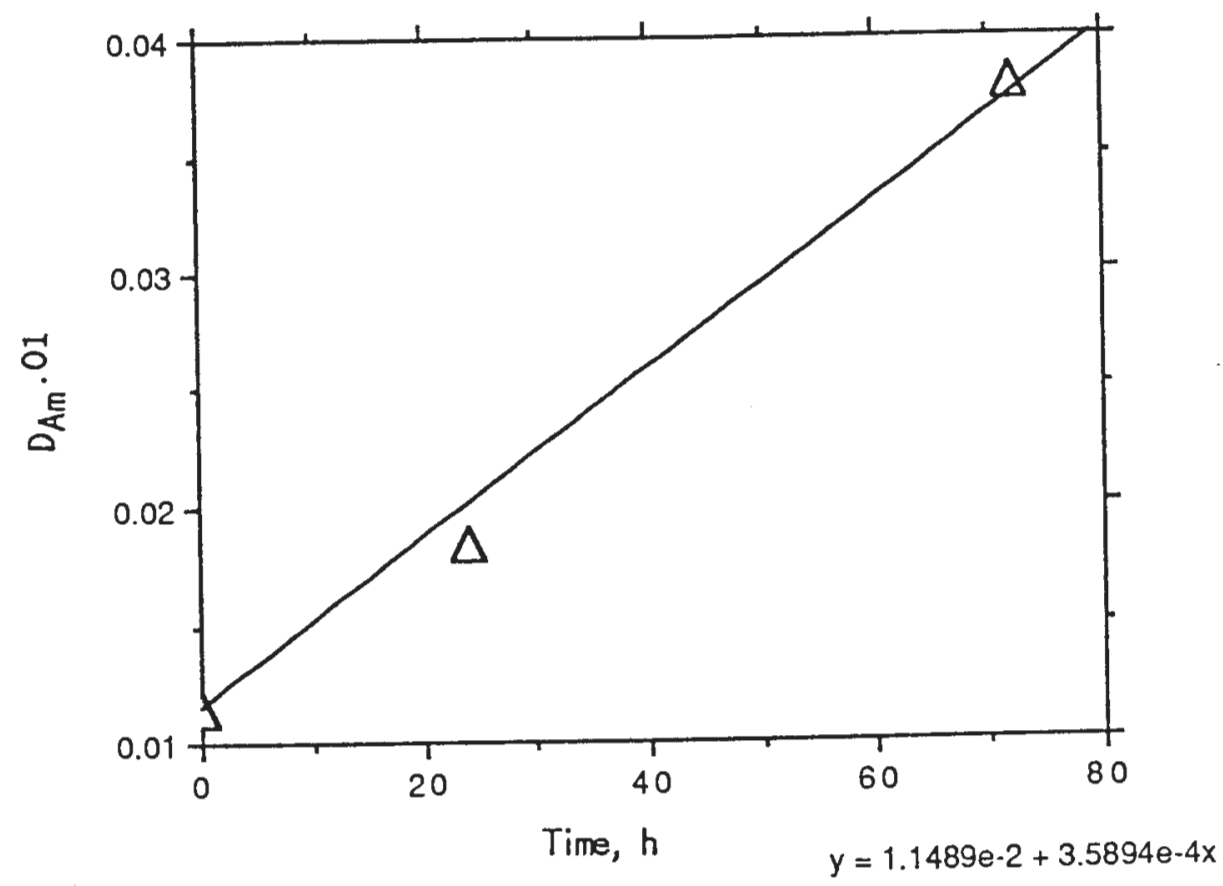

Fig. IV-26. Graph of $\mathrm{D}_{\mathrm{Am}}^{.01}$ versus Hydrolysis Time Using $0.25 \mathrm{M} \mathrm{HNO}_{3}$ at $95^{\circ} \mathrm{C}$. Slope of line represents value of $\mathrm{k}_{\mathrm{h}}{ }^{.01}$ used for Eq. IV-2.

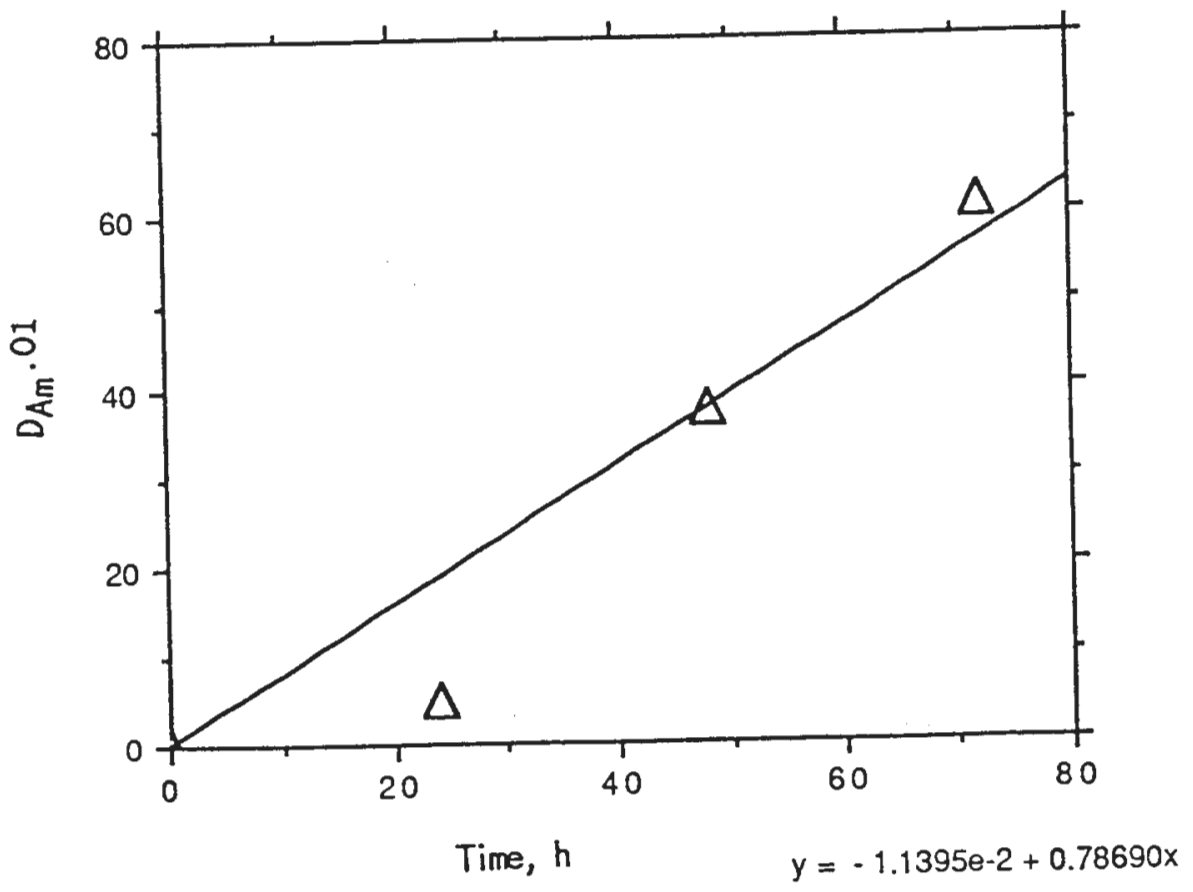

Fig. IV-27. Graph of $\mathrm{D}_{\mathrm{Am}} .01$ versus Hydrolysis Time Using $2.5 \mathrm{M}_{\mathrm{HNO}}$ at $95^{\circ} \mathrm{C}$. Slope of line represents value of $k_{b}{ }^{.01}$ used for Eq. IV -2 . 


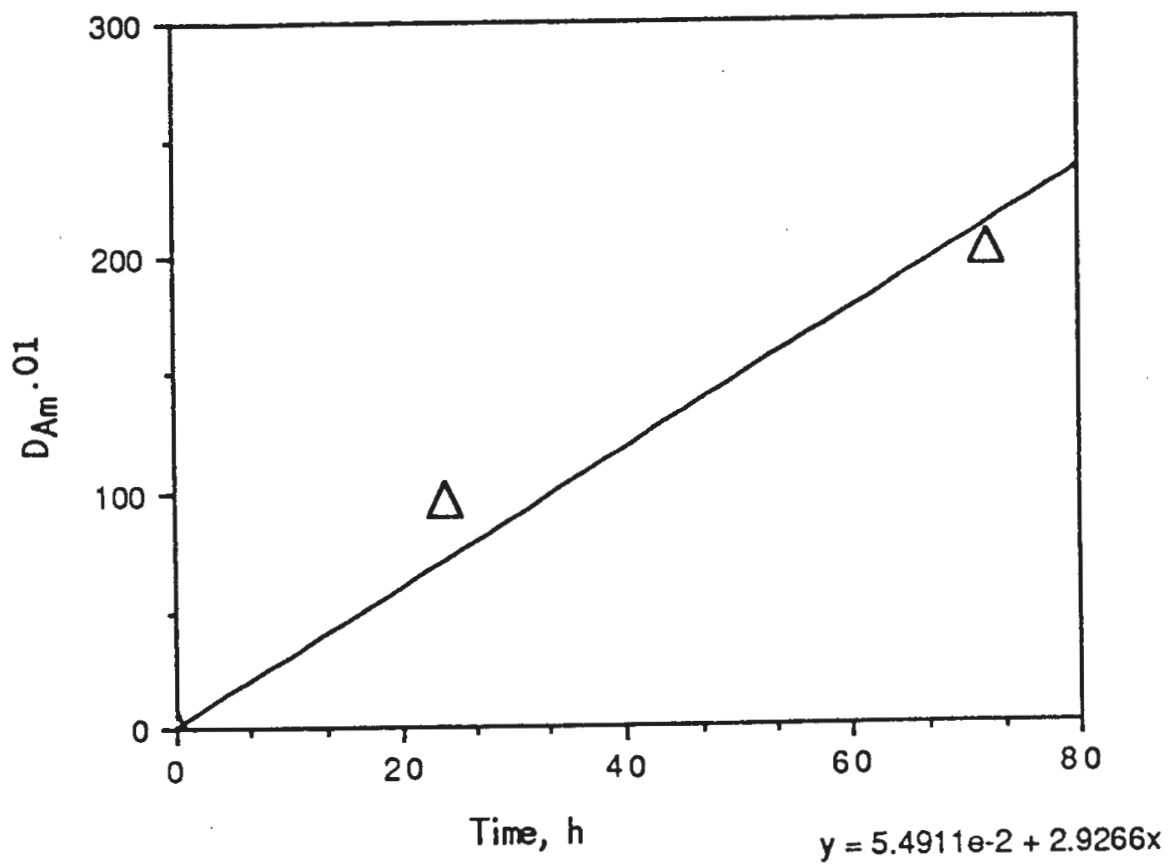

Fig. IV-28. Graph of $\mathrm{D}_{\mathrm{Am}}{ }^{.01}$ versus Hydrolysis Time Using 6.0M $\mathrm{HNO}_{3}$ at $95^{\circ} \mathrm{C}$. Slope of line represents value of $\mathrm{k}_{\mathrm{h}} .01$ used for Eq. IV -2 .

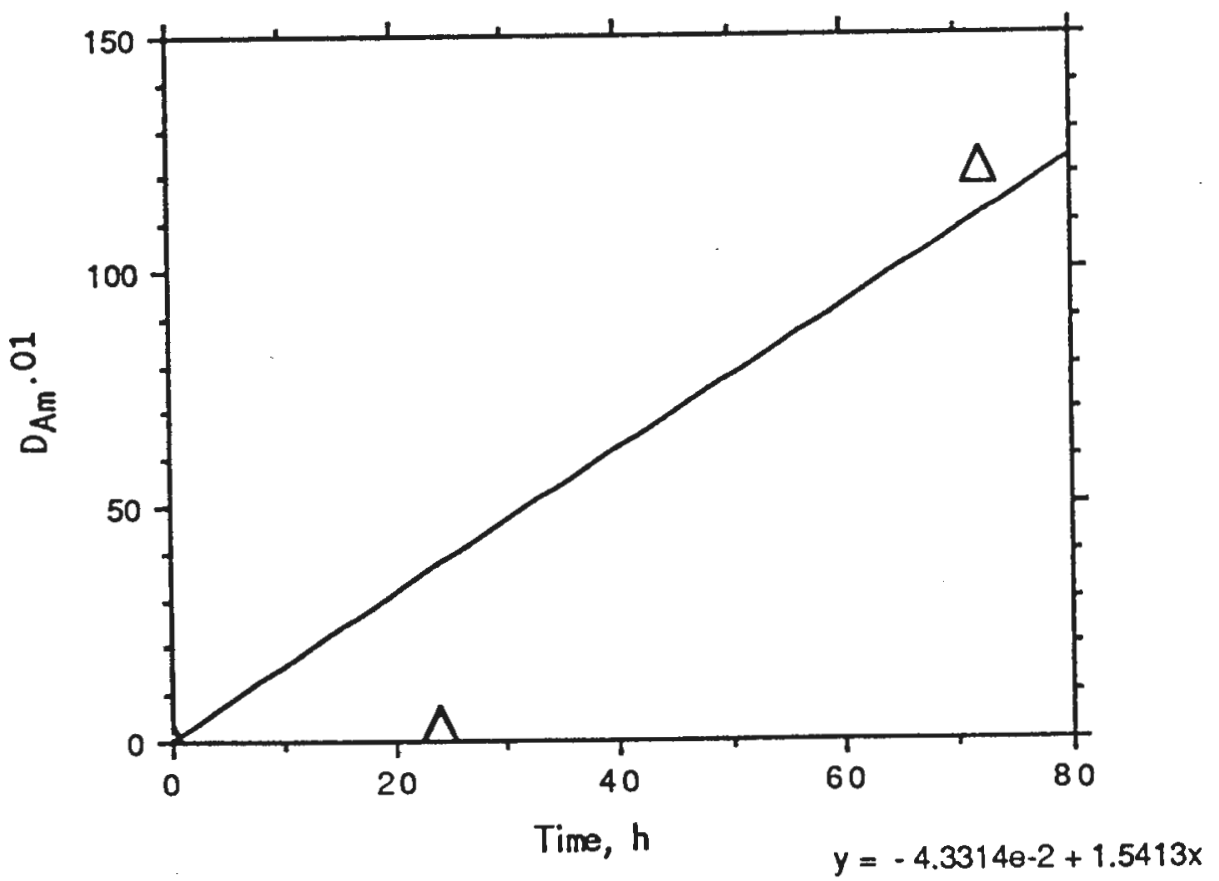

Fig. IV-29. Graph of $\mathrm{D}_{\mathrm{Am}}{ }^{.01}$ versus Hydrolysis Time Using Simulated CAW Containing 1.6 $\mathrm{MNO}_{3}$ at $95^{\circ} \mathrm{C}$. Slope of line represents value of $\mathrm{k}_{\mathrm{h}} .01$ used for Eq. IV-2. 


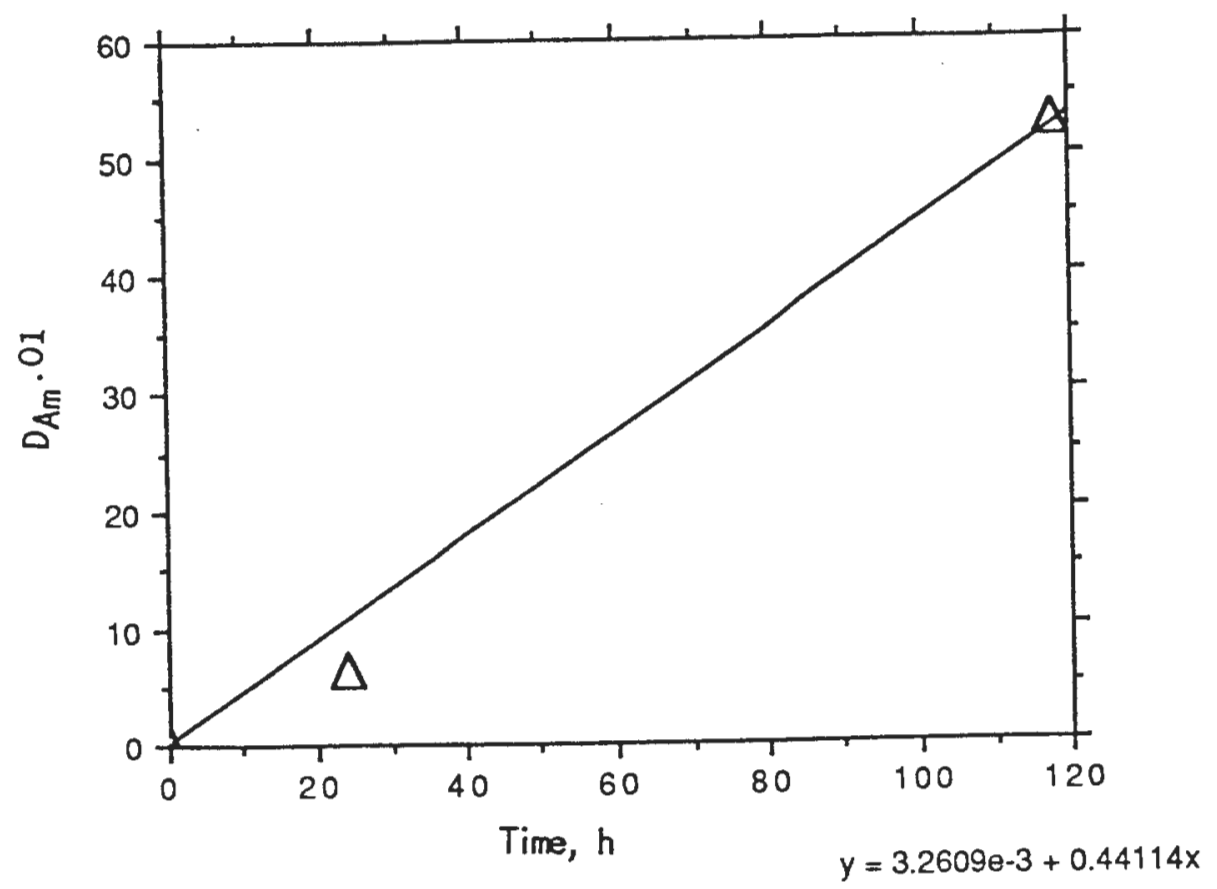

Fig. IV-30. Graph of $\mathrm{D}_{\mathrm{Am}} .01$ versus Hydrolysis Time Using Simulated CAW Containing $2.6 \mathrm{M} \mathrm{HNO}_{3}$ at $95^{\circ} \mathrm{C}$. Slope of line represents value of $\mathrm{k}_{\mathrm{h}} .01$ used for Eq. IV-2.

Figures IV-31 through IV-33 show the graphs used in determining values of $\mathrm{k}_{\mathrm{h}_{\mathrm{o}}} .01$ (y-intercept) and $k_{h}^{\prime .01}$ (slope of line) for 50,70 , and $95^{\circ} \mathrm{C}$. Their values were then used to obtain $\mathrm{k}_{\mathrm{h}}{ }^{.01}$.

Combining Eqs. IV-2 and IV-3 gives

$$
\mathrm{D}_{\mathrm{Am}}^{01}=\mathrm{D}_{\mathrm{Am}_{\mathrm{O}}}^{.01}+\left[\mathrm{k}_{\mathrm{h}_{0}^{\prime}}^{0.01}+\mathrm{k}_{\mathrm{h}}^{\prime} \cdot 01 \quad\{\mathrm{H}\}\right] \mathrm{t}
$$

Both $\mathrm{k}_{\mathrm{h}_{\mathrm{o}}}^{\prime} .01$ and $\mathrm{k}_{\mathrm{h}}^{\prime} .01$ were correlated with temperature using the Arrhenius equation:

$$
\begin{aligned}
& \mathrm{k}_{\mathrm{h}}^{\prime} \cdot 01=\mathrm{A}_{0}^{01} \mathrm{e}^{-\mathrm{E}_{\mathrm{o}}^{\cdot 01} / \mathrm{RT}} \\
& \mathrm{k}_{\mathrm{h}}^{\prime} \cdot 01=\mathrm{A}^{.01} \mathrm{e}^{-\mathrm{E} \cdot 01 / \mathrm{RT}}
\end{aligned}
$$

Values of $A_{0} .01$ and $E_{o}^{.01}$ were determined from the graph of $-\ln k_{b}^{.} .01$ as a function of $1 / T$, shown in Fig. IV-34. Values of $A^{.01}$ and $E^{.01}$ were determined from a graph of -ln $k_{h}^{\prime} .01$ as a function of $1 / T$, shown in Fig. IV-35. 


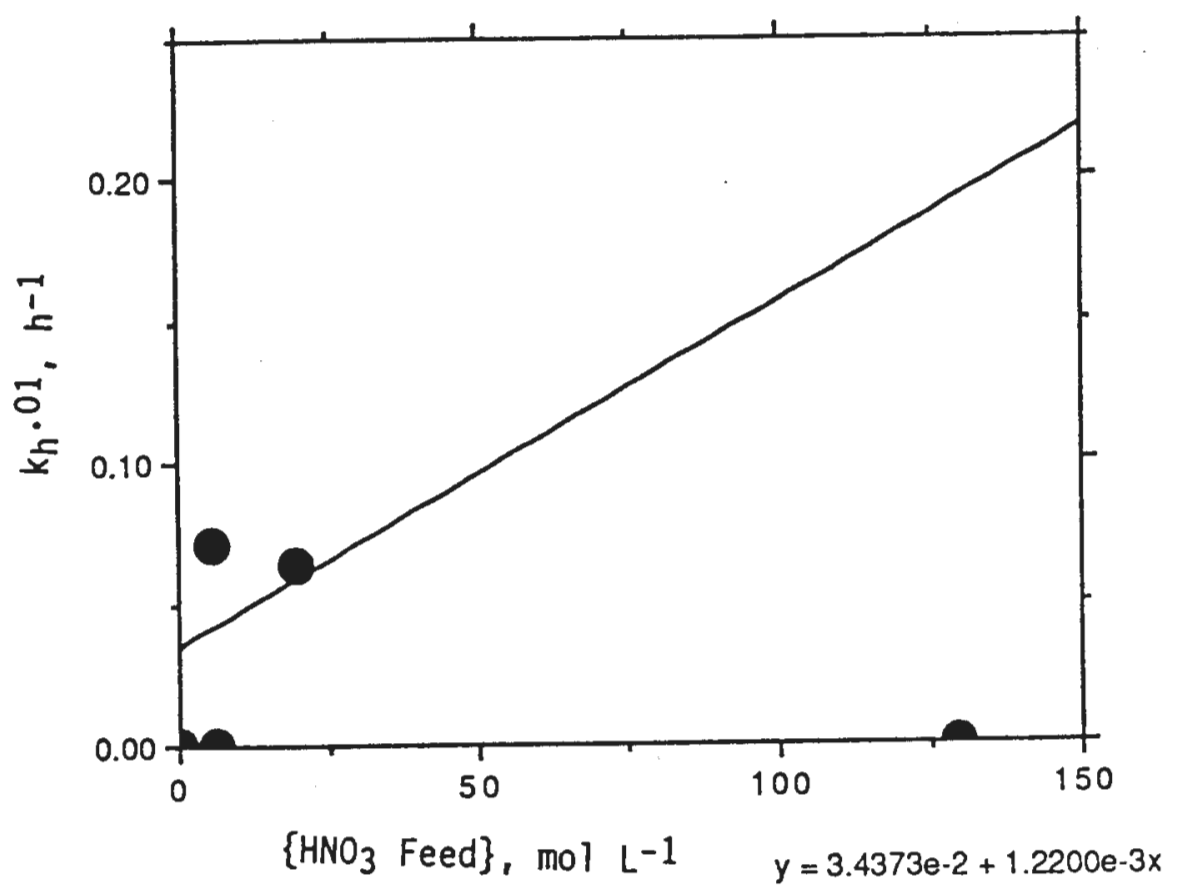

Fig. IV-31. Graph of $\mathrm{k}_{\mathrm{h}}{ }^{.01}$ versus Activity of $\mathrm{HNO}_{3}$ in Aqueous Solution Used as Hydrolytic Agent at $50^{\circ} \mathrm{C}$. For Eq. IV -3, intercept at y axis determines $\mathrm{k}_{\mathrm{h}_{\mathrm{o}}} .01$ and slope determines $\mathrm{k}_{\mathrm{h}} .01$.

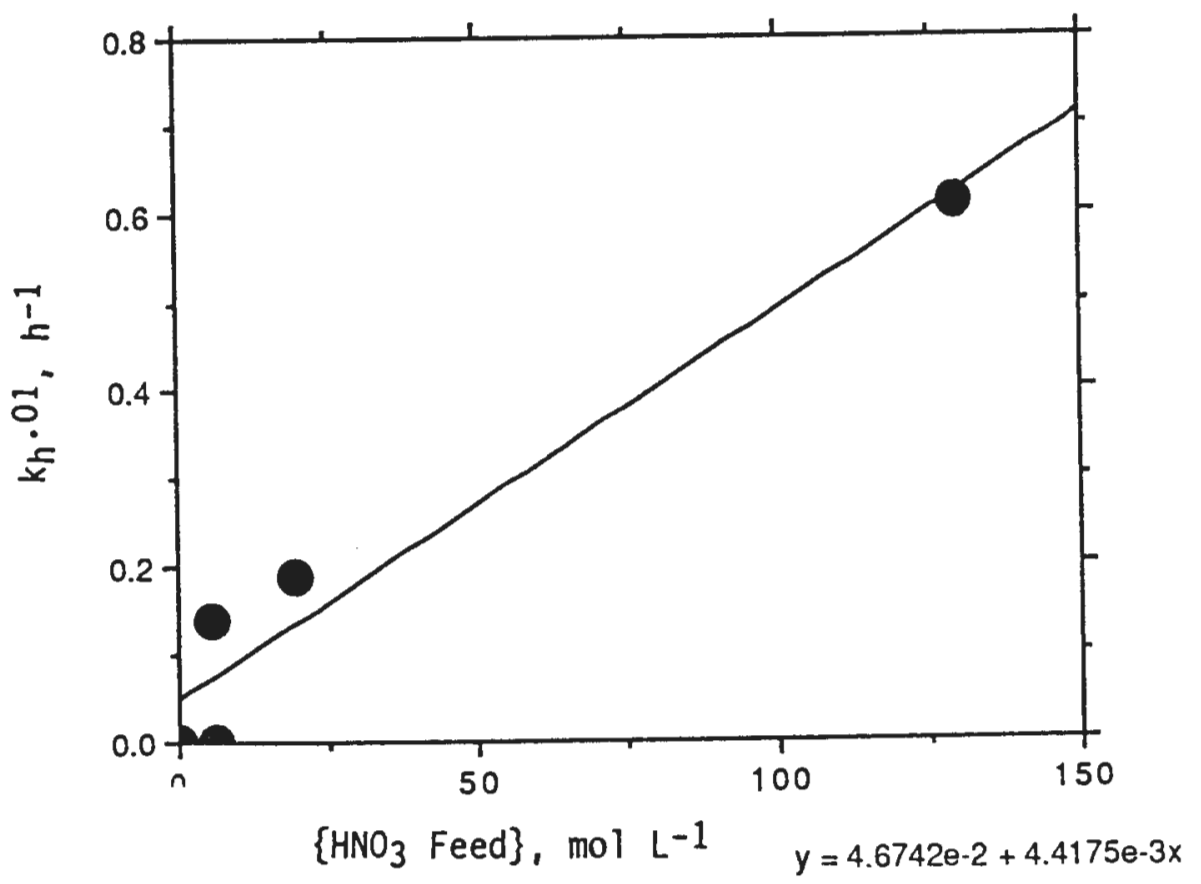

Fig. IV-32. Graph of $\mathrm{k}_{\mathrm{h}}{ }^{.01}$ versus Activity of $\mathrm{HNO}_{3}$ in Aqueous Solution Used as Hydrolytic Agent at $70^{\circ} \mathrm{C}$. For Eq. IV-3, intercept at y axis determines $\mathrm{k}_{\mathrm{h}_{\mathrm{o}}} .01$ and slope determines $\mathrm{k}_{\mathrm{h}} \cdot 01$. 


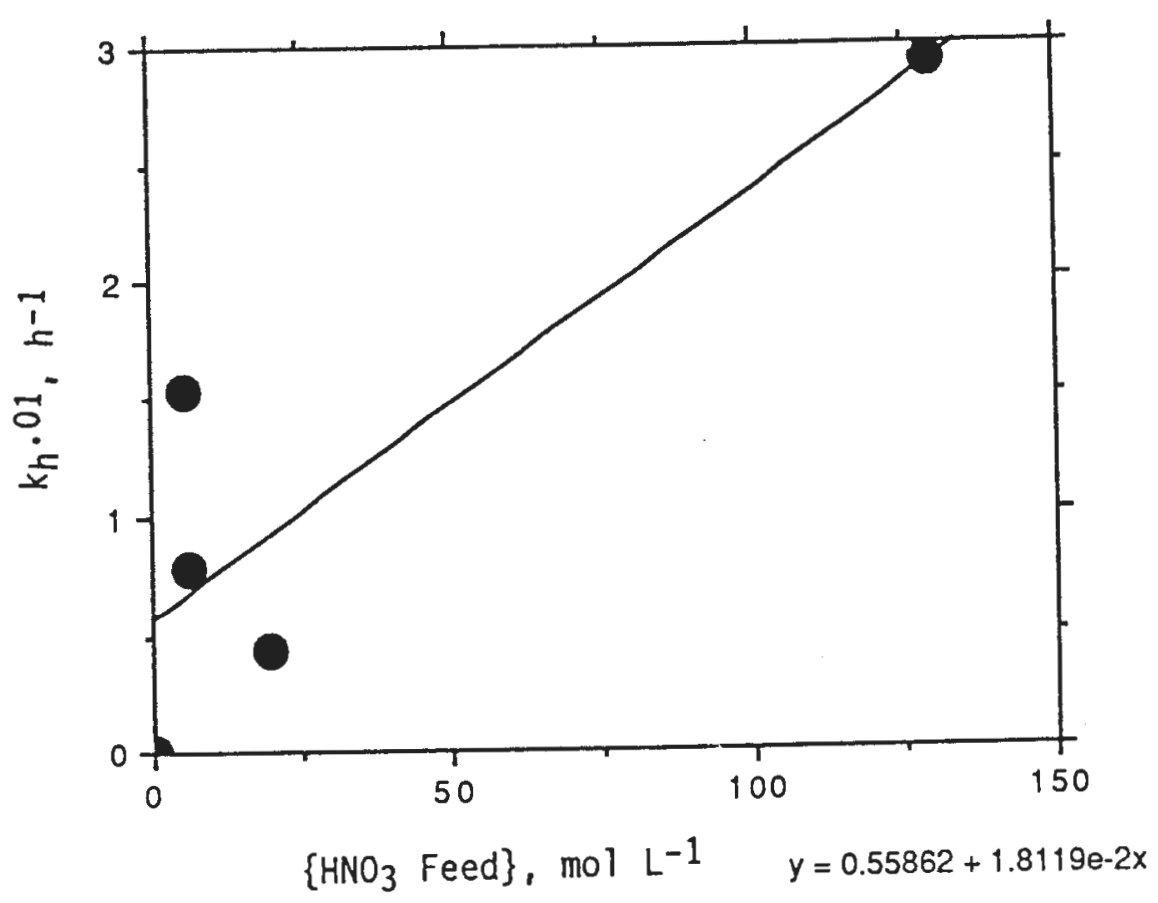

Fig. IV-33. Graph of $\mathrm{k}_{h}{ }^{.01}$ versus Activity of $\mathrm{HNO}_{3}$ in Aqueous Solution Used as Hydrolytic Agent at $95^{\circ} \mathrm{C}$. For Eq. IV -3, intercept at y axis determines $\mathrm{k}_{\mathrm{h}_{\mathrm{o}}}^{\prime .01}$ and slope determines $\mathrm{k}_{\mathrm{h}}^{\prime} \cdot 01$.

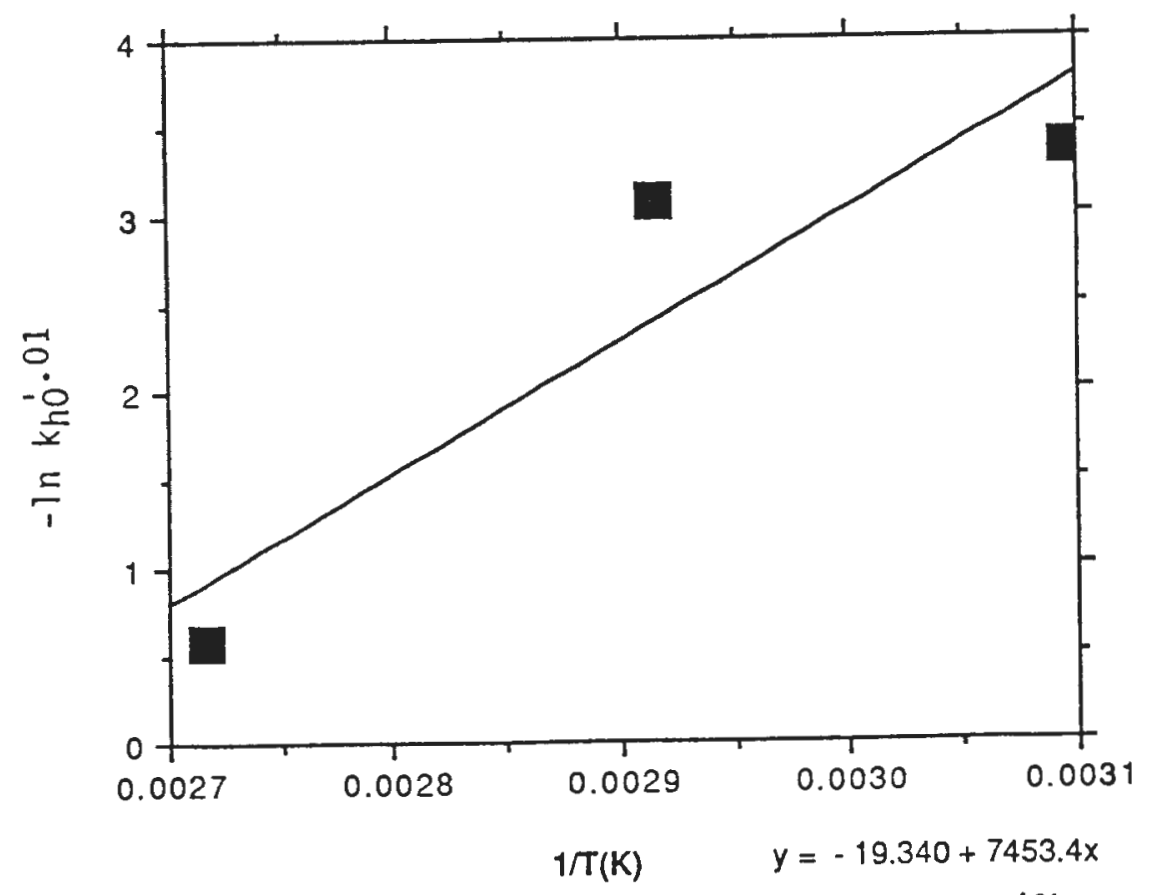

Fig. IV-34. Correlation between Temperature and Rate Constant $k_{h_{0}} \cdot 01$. For Eq. IV-5, intercept at $y$ axis determines $A_{0}{ }^{.01}$ and slope determines $E_{o}{ }^{.01}$. 


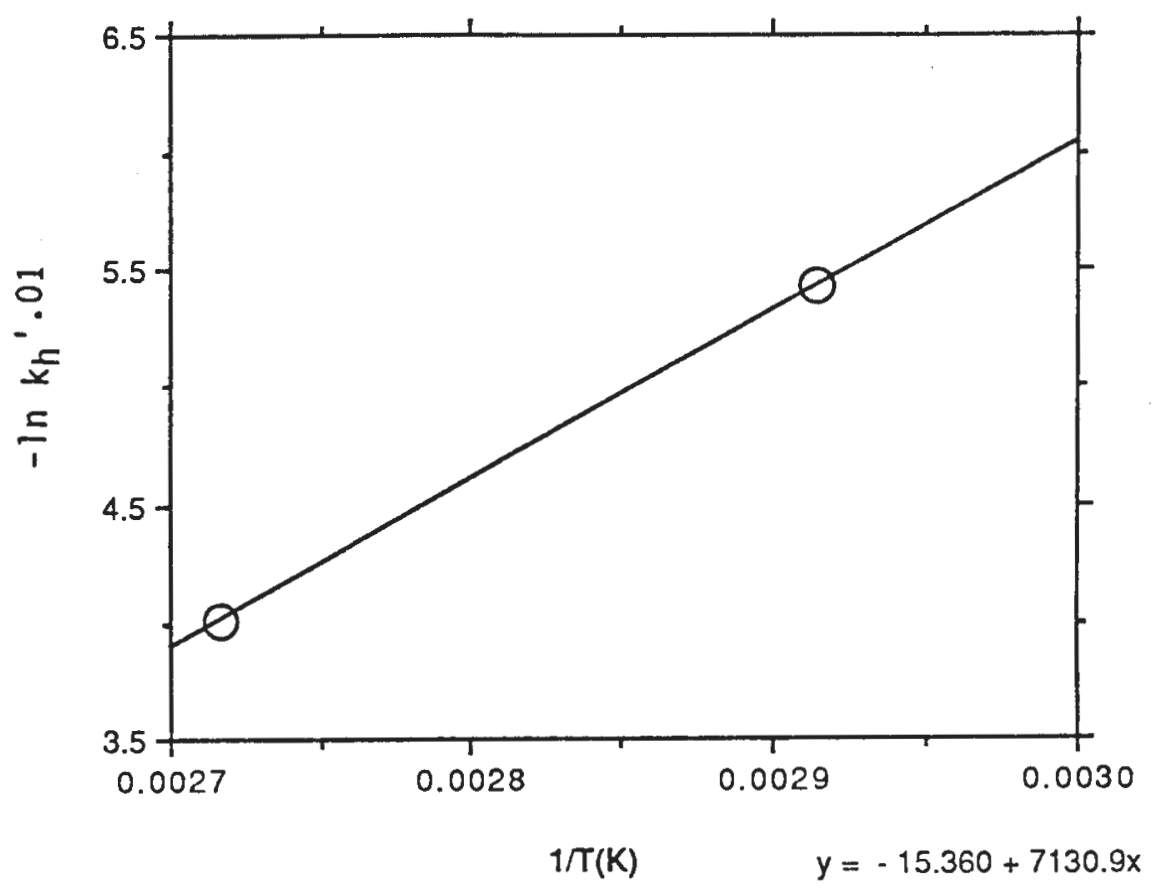

Fig. IV-35. Correlation between Temperature and Rate Constant $\mathrm{k}_{\mathrm{h}}^{\prime} .01$. For Eq. IV-6, intercept at y axis determines $\mathrm{A}^{.01}$ and slope determines $\mathrm{E}^{.01}$.

Combining Eqs. IV-5 and IV-6 with Eq. IV-4 yields

$$
D_{\dot{A m}}^{.01}=D_{\dot{A m}_{0}}^{.01}+\left[A_{0}^{.01} e^{-E_{0}^{.01} / R T}+A^{.01} e^{-E^{.01} / R T}\{\mathrm{H}\}\right] t
$$

where

$$
\begin{aligned}
\mathrm{D}_{\mathrm{Am}}^{.01} & =0.0115 \\
\mathrm{~A}_{\mathrm{o}}^{.01} & =6.97 \times 10^{4} \mathrm{~s}^{-1}\left(2.508 \times 10^{8} \mathrm{~h}^{-1}\right) \\
\mathrm{A}^{.01} & =1.30 \times 10^{3} \mathrm{~L} \mathrm{~s}^{-1} \mathrm{~mol}^{-1}\left(4.686 \times 10^{6} \mathrm{~L} \mathrm{~mol}^{-1} \mathrm{~h}^{-1}\right) \\
\mathrm{E}_{\mathrm{o}}^{.01} & =6.20 \times 10^{4} \mathrm{~J} \mathrm{~mol}^{-1}\left(1.481 \times 10^{4} \mathrm{cal} \mathrm{mol}^{-1}\right) \\
\mathrm{E}^{.01} & =5.94 \times 10^{4} \mathrm{~J} \mathrm{~mol}^{-1}\left(1.417 \times 10^{4} \mathrm{cal} \mathrm{mol}^{-1}\right) \\
\{\mathrm{H}\} & =\text { activity of hydrogen ion in aqueous solution in equilibrium with solvent, } \\
& \text { mol L-1 } \\
\mathrm{R} & =8.323 \mathrm{~J} \mathrm{~mol}^{-1} \mathrm{deg}^{-1}\left(1.987 \mathrm{cal} \mathrm{mol} \mathrm{meg}^{-1}\right) \\
\mathrm{T} & =\text { temperature, degrees Kelvin } \\
\mathrm{t} & =
\end{aligned}
$$

Experimental values of $D_{A m}{ }^{.01}$ and values calculated by Eq. IV-7 are plotted in Fig. IV-36. It was found that differences between calculated and observed values of $\mathrm{D}_{\mathrm{Am}} .01$ could be minimized by using the activity of $\mathrm{HNO}_{3}$ in the feed for $\{\mathrm{H}\}$ in determining the constants for Eq. IV-3, but using the activity of the hydrogen ion for $\{H\}$ when calculating $D_{A m}^{.01}$ from Eq. IV-7. 


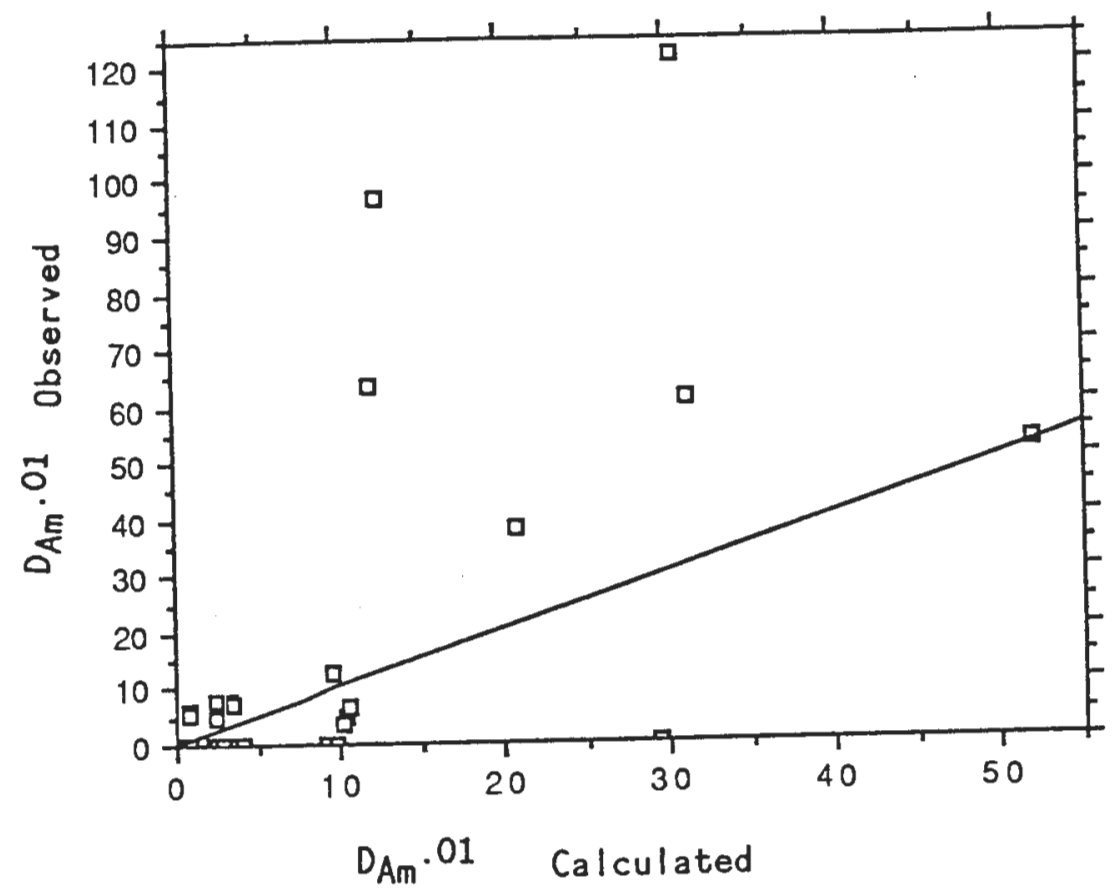

Fig. IV-36. Comparison of Calculated Values for $D_{A m}{ }^{.01}$ with Observed Values Obtained with Solvent Degraded by Hydrolysis at $50-90^{\circ} \mathrm{C}$. The points are determined by the number pairs $\left(D_{A m} .01\right.$ observed, $D_{A m}{ }^{.01}$ calculated). The line is determined by the condition $\mathrm{D}_{\mathrm{Am}}^{\mathrm{Am}}$.

2. Mathematical Expression of $\mathrm{D}_{\mathrm{Am}}^{.05}$

A method similar to that used to derive an expression for $\mathrm{D}_{\mathrm{Am}}{ }^{.01}$ was used to derive one for $\mathrm{D}_{\mathrm{Am}}{ }^{.05}$. By analogy to Eq. IV-1,

$$
\frac{\mathrm{d} \mathrm{D}_{\mathrm{Am}}^{.05}}{\mathrm{dt}}=\mathrm{k}_{\mathrm{h}}^{.05}
$$

which has the integrated form

$$
\mathrm{D}_{\mathrm{Am}}^{.05}=\mathrm{D}_{\mathrm{Am}_{\mathrm{o}}}^{.05}+\mathrm{k}_{\mathrm{h}}^{.05} \mathrm{t}
$$

Therefore, values of $\mathrm{k}_{\mathrm{h}}{ }^{.05}$ were determined from correlations of $\mathrm{D}_{\mathrm{Am}}^{.05}$ with $\mathrm{t}$. Figures IV-37 through IV-51 show the experimental $\mathrm{D}_{\mathrm{Am}}{ }^{.05}$ values for a given combination of temperature and hydrolytic agent as a function of hydrolysis time. Each figure also shows the line used to represent those values, whose slope was taken to equal $\mathrm{k}_{\mathrm{h}} .05$. The correlation of $\mathrm{k}_{\mathrm{h}}{ }^{.05}$ with acidity in the aqueous solution in contact with the solvent during hydrolysis is expressed similarly to Eq. IV-3 as follows:

$$
k_{h} \cdot 05=k_{h_{0}}^{\prime} .05+k_{h}^{\prime} \cdot 05\{\mathrm{H}\}
$$




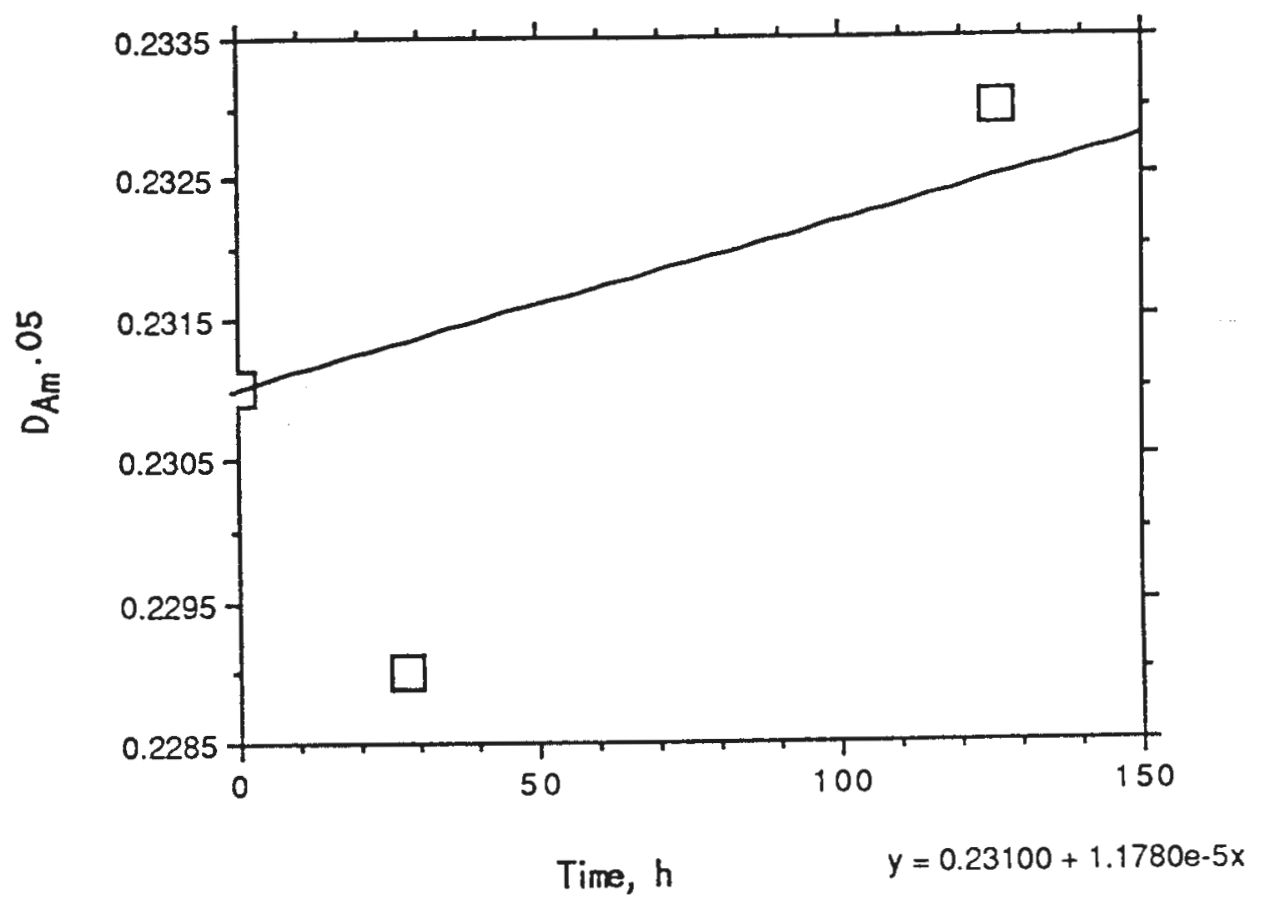

Fig. IV-37. Graph of $\mathrm{D}_{\mathrm{Am}}^{.05}$ versus Hydrolysis Time at $50^{\circ} \mathrm{C}$ with $0.25 \mathrm{M} \mathrm{HNO}_{3}$. The slope of the line was used to determine $k_{h}{ }^{.05}$ for Eq. IV-9.

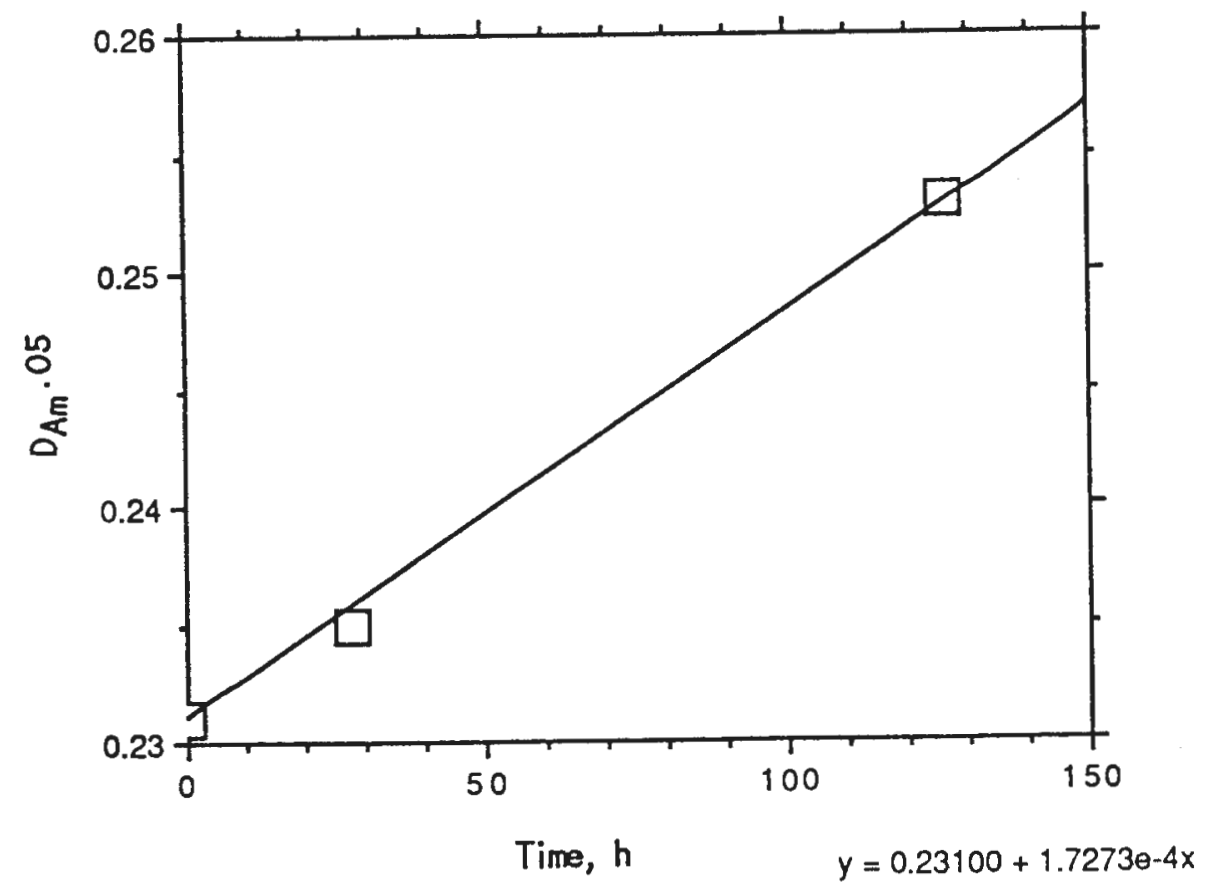

Fig. IV-38. Graph of $\mathrm{D}_{\mathrm{Am}}{ }^{.05}$ versus Hydrolysis Time at $50^{\circ} \mathrm{C}$ with $2.5 \mathrm{M} \mathrm{HNO}_{3}$. The slope of the line was used to determine $\mathrm{k}_{\mathrm{h}}{ }^{.05}$ for Eq. IV-9. 


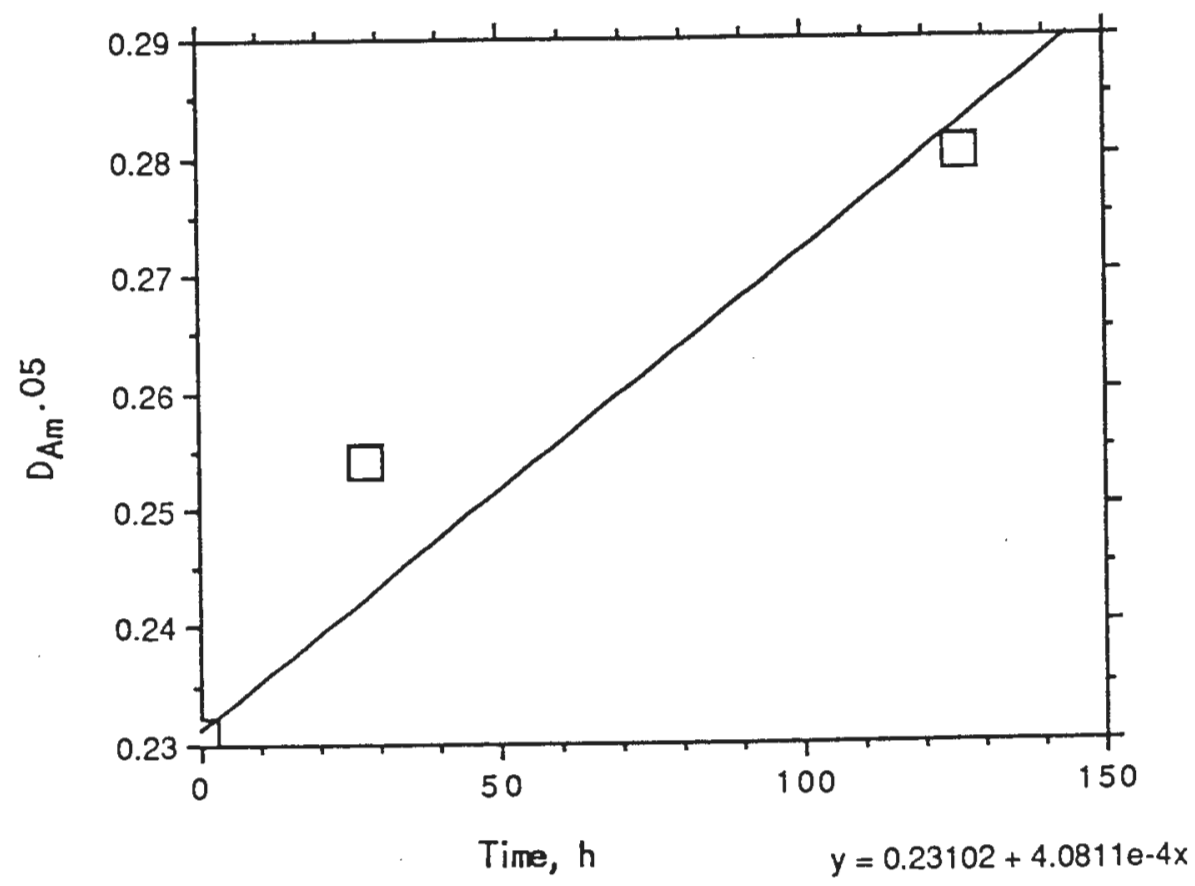

Fig. IV-39. Graph of $\mathrm{D}_{\mathrm{Am}}{ }^{.05}$ versus Hydrolysis Time at $50^{\circ} \mathrm{C}$ with $6.0 \mathrm{M} \mathrm{HNO}_{3}$. The slope of the line was used to determine $\mathrm{k}_{\mathrm{h}}{ }^{05}$ for Eq. IV-9.

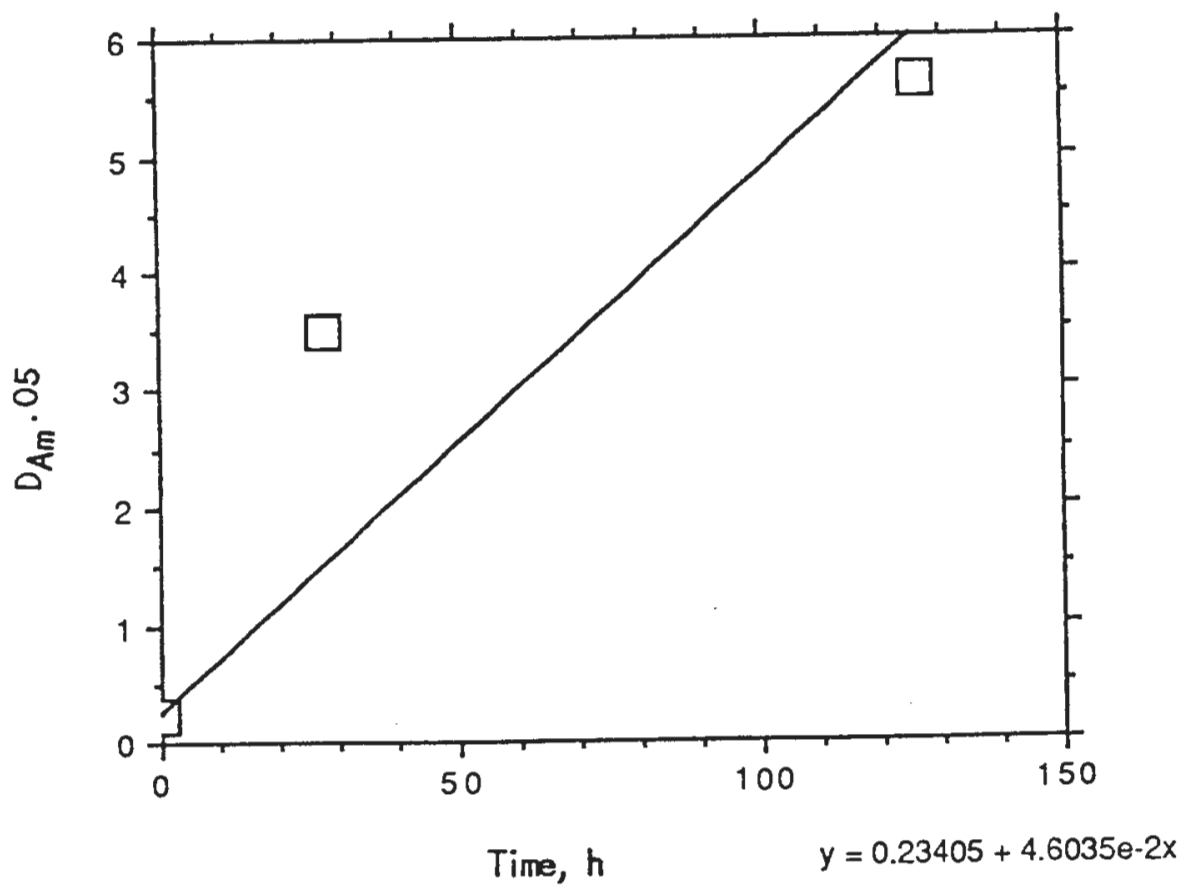

Fig. IV-40. Graph of $\mathrm{D}_{\mathrm{Am}}^{.05}$ versus Hydrolysis Time at $50^{\circ} \mathrm{C}$ with Simulated $\mathrm{CAW}$ Containing $1.6 \mathrm{M} \mathrm{HNO}_{3}$. The slope of the line was used to determine $\mathrm{k}_{\mathrm{h}}{ }^{.05}$ for Eq. IV-9. 


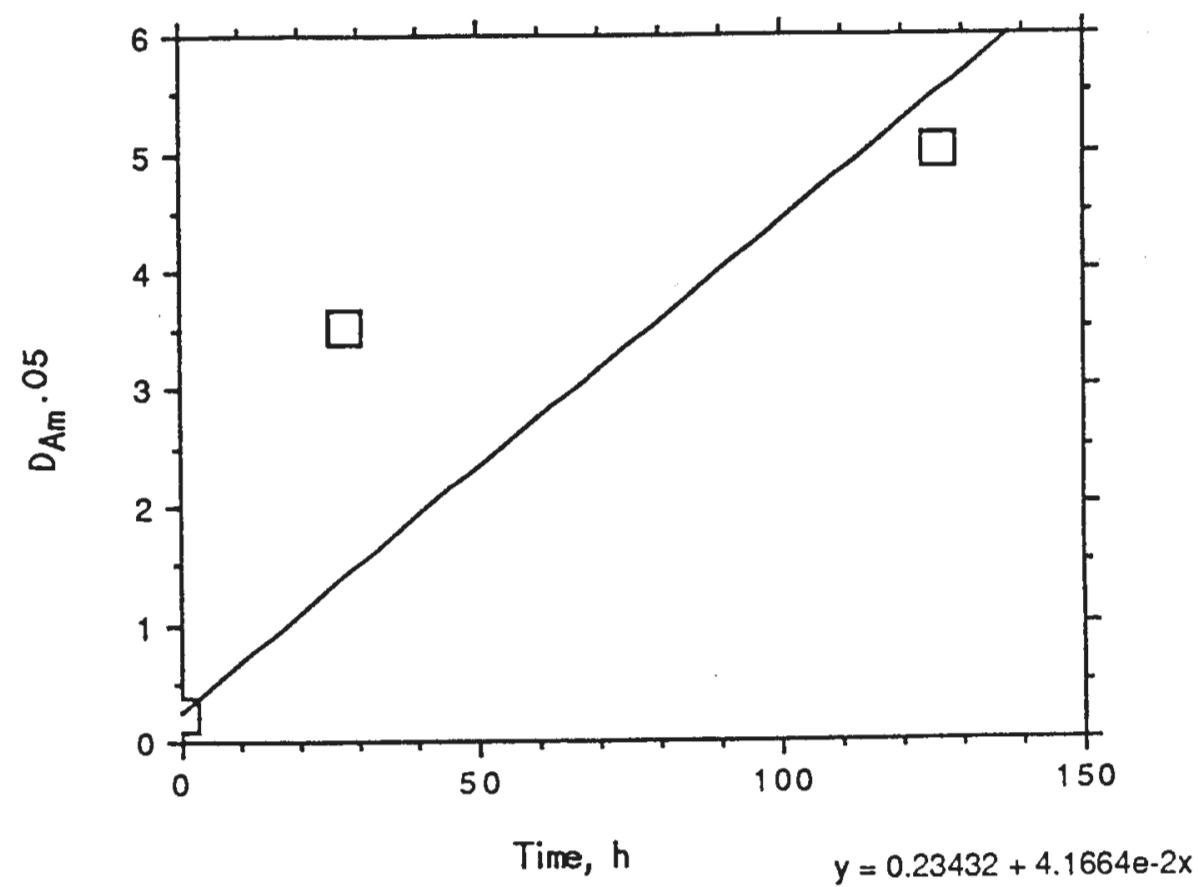

Fig. IV-41. Graph of $\mathrm{D}_{\mathrm{Am}}{ }^{.05}$ versus Hydrolysis Time at $50^{\circ} \mathrm{C}$ with Simulated $\mathrm{CAW}$ Containing $2.6 \mathrm{M} \mathrm{HNO}_{3}$. The slope of the line was used to determine $\mathrm{k}_{\mathrm{h}}{ }^{.05}$ for Eq. IV-9.

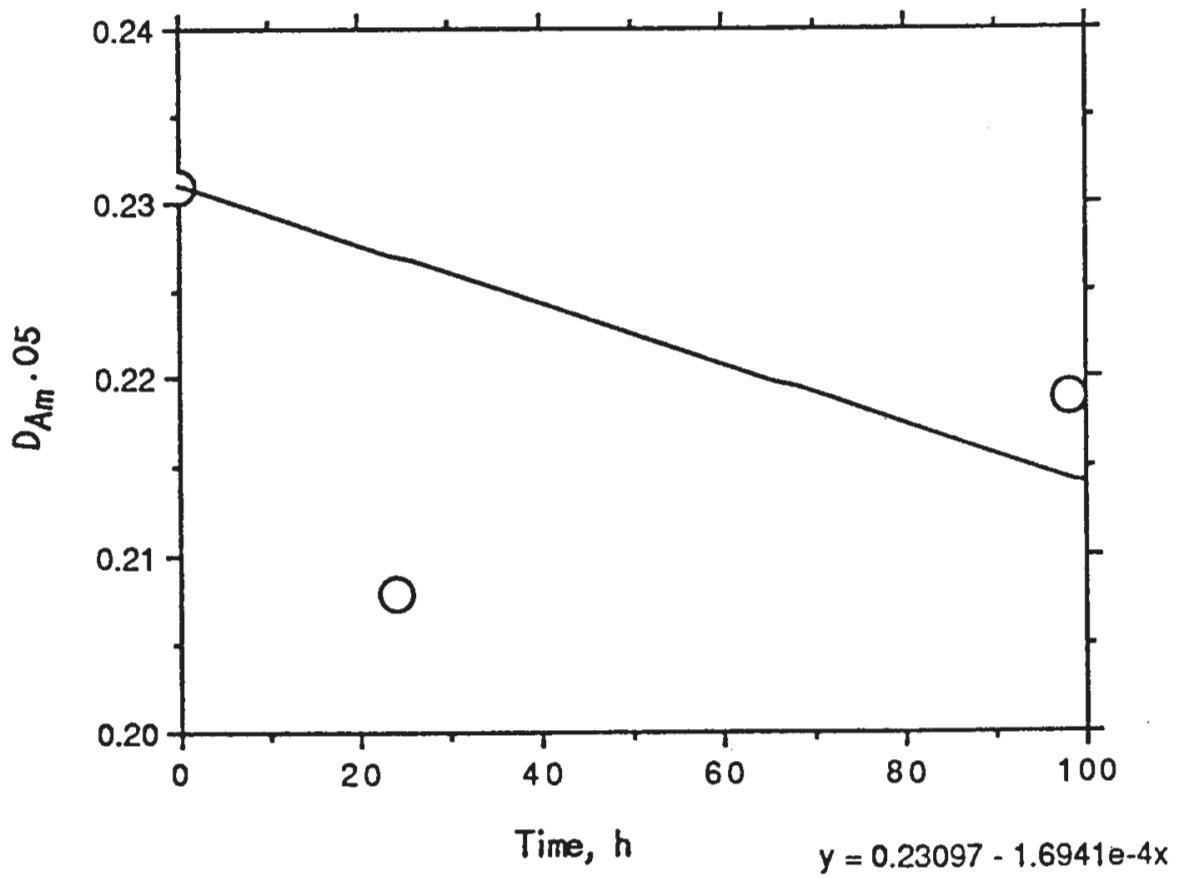

Fig. IV-42. Graph of $\mathrm{D}_{\mathrm{Am}}{ }^{.05}$ versus Hydrolysis Time at $70^{\circ} \mathrm{C}$ with $0.25 \mathrm{M} \mathrm{HNO}_{3}$. The slope of the line was used to determine $k_{h}{ }^{.05}$ for Eq. IV -9 . 


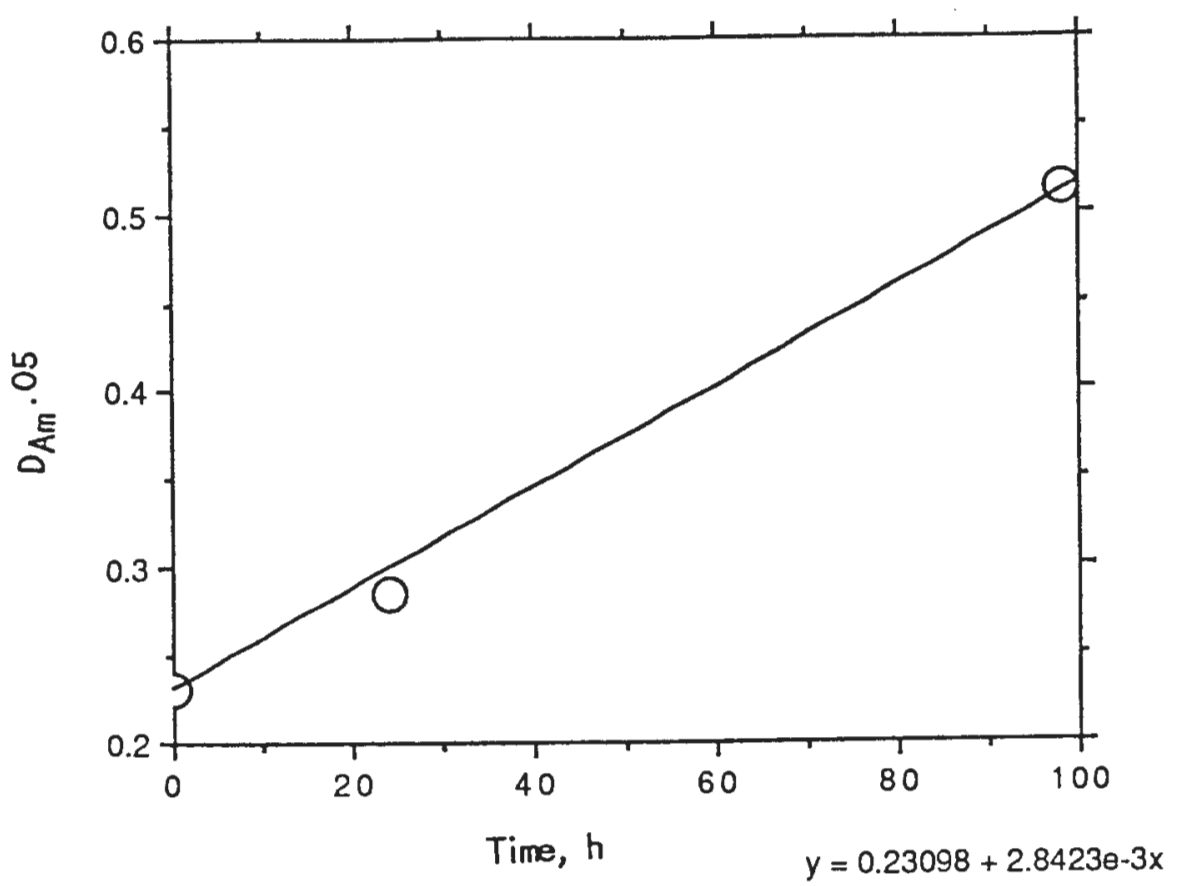

Fig. IV-43. Graph of $\mathrm{D}_{\mathrm{Am}}{ }^{.05}$ versus Hydrolysis Time at $70^{\circ} \mathrm{C}$ with $2.5 \mathrm{M} \mathrm{HNO}_{3}$. The slope of the line was used to determine $\mathrm{k}_{\mathrm{h}}{ }^{.05}$ for Eq. IV-9.

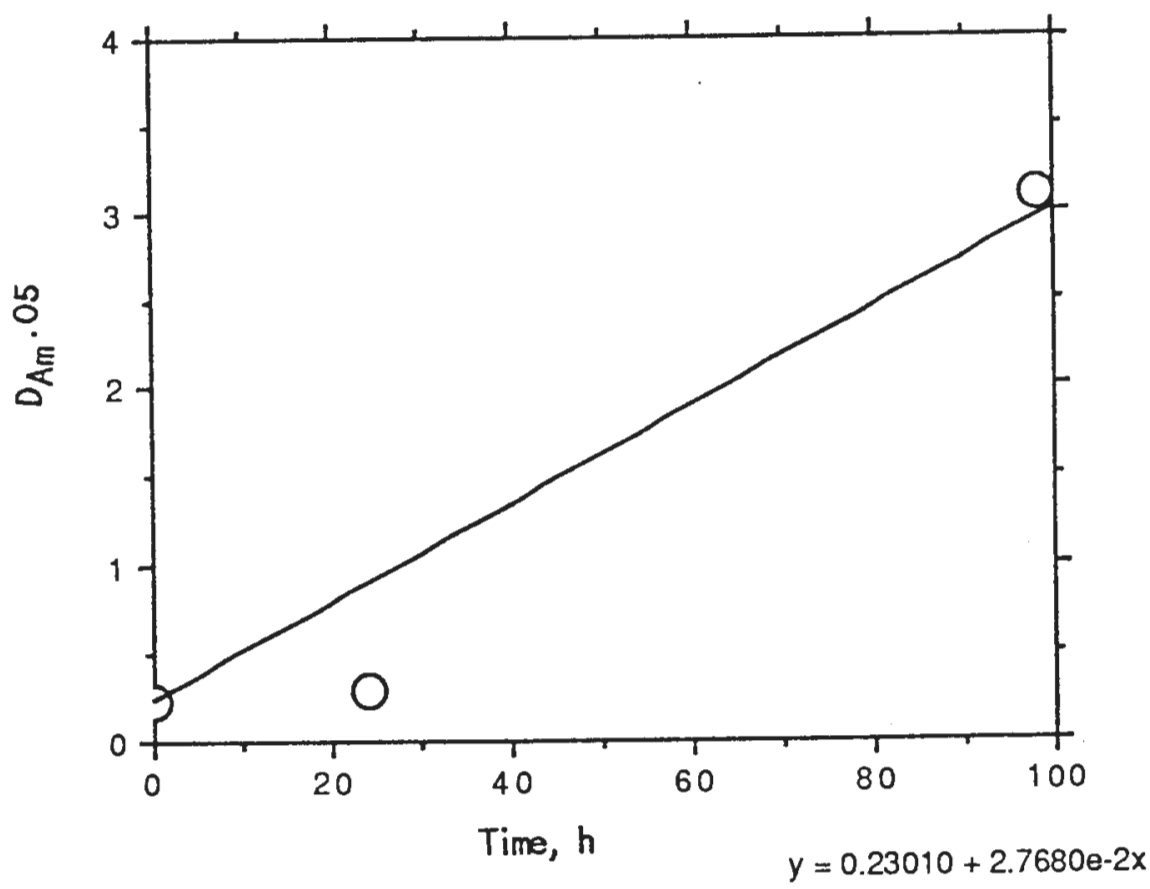

Fig. IV-44. Graph of $\mathrm{D}_{\mathrm{Am}}{ }^{.05}$ versus Hydrolysis Time at $70^{\circ} \mathrm{C}$ with $6.0 \mathrm{M} \mathrm{HNO}_{3}$. The slope of the line was used to determine $\mathrm{k}_{\mathrm{h}}{ }^{.05}$ for Eq. IV -9 . 


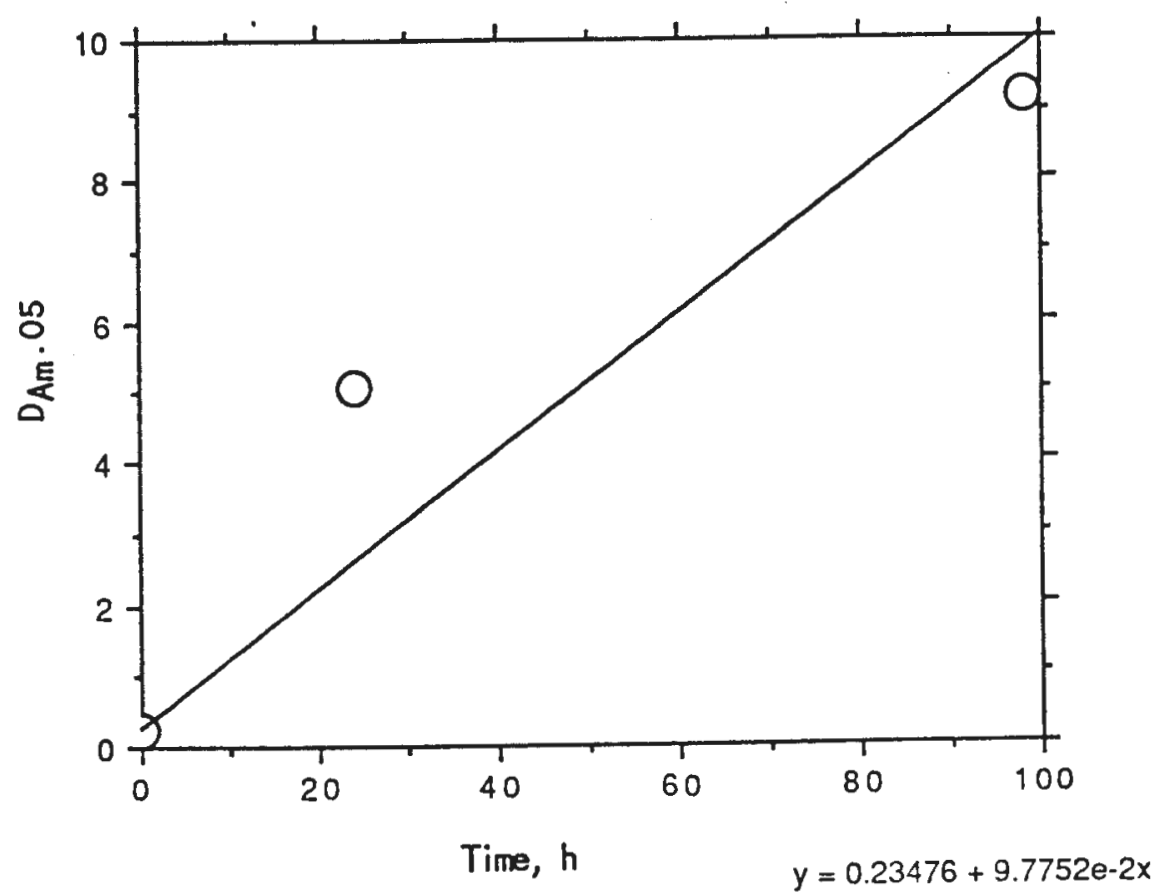

Fig. IV-45. Graph of $\mathrm{D}_{\mathrm{Am}}{ }^{.05}$ versus Hydrolysis Time at $70^{\circ} \mathrm{C}$ with Simulated $\mathrm{CAW}$ Containing $1.6 \mathrm{M} \mathrm{HNO}_{3}$. The slope of the line was used to determine $\mathrm{k}_{\mathrm{h}}{ }^{.05}$ for Eq. IV-9.

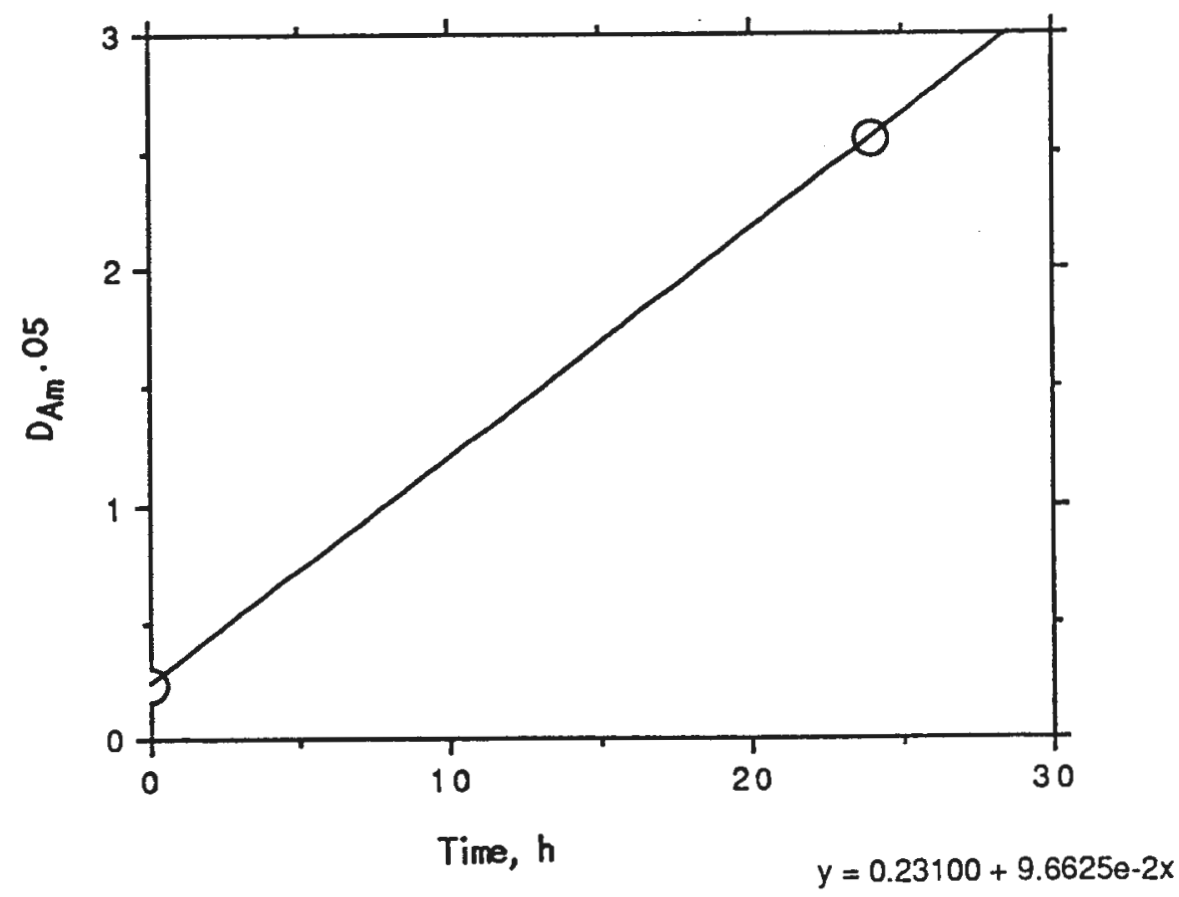

Fig. IV-46. Graph of $\mathrm{D}_{\mathrm{Am}}{ }^{.05}$ versus Hydrolysis Time at $70^{\circ} \mathrm{C}$ with Simulated CAW Containing $2.6 \mathrm{M} \mathrm{HNO}$. The slope of the line was used to determine $\mathrm{k}_{\mathrm{h}}{ }^{.05}$ for Eq. IV-9. 


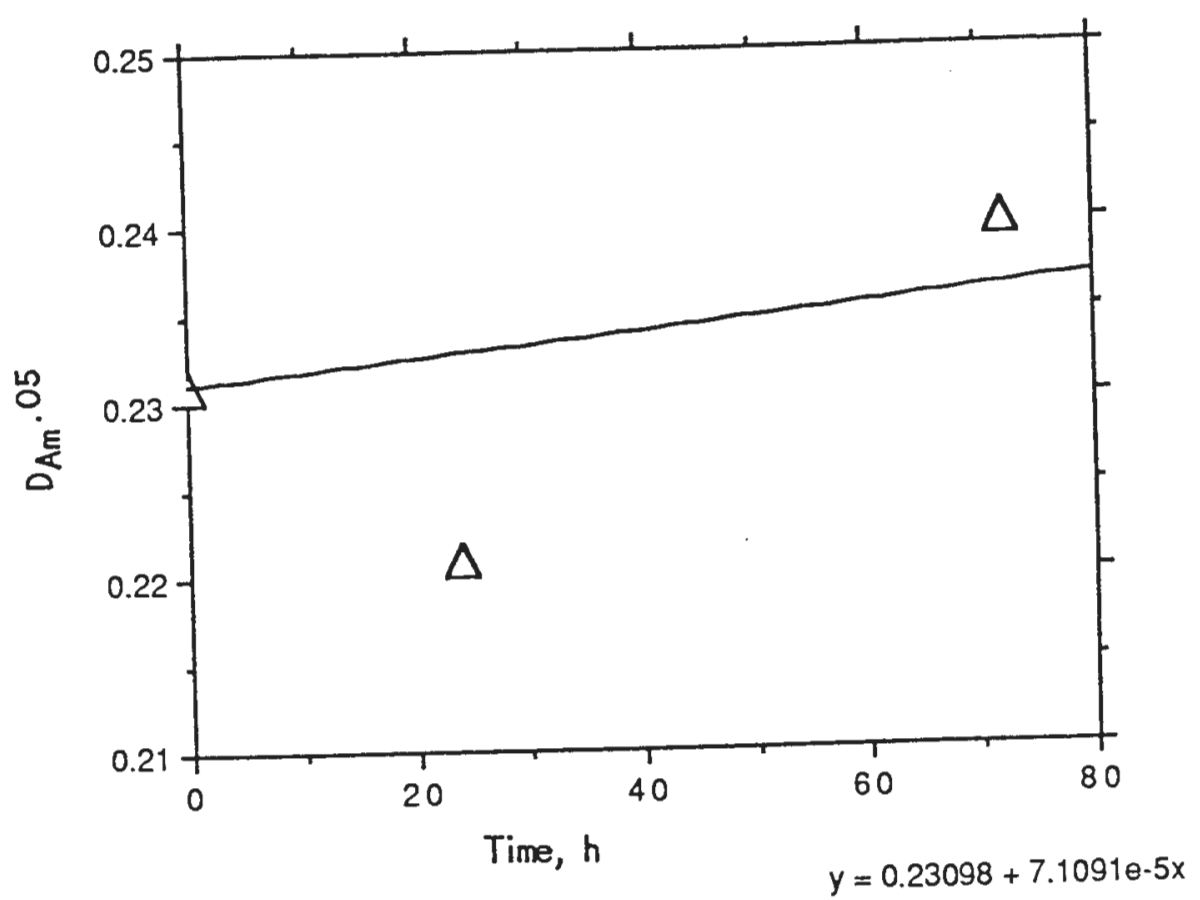

Fig. IV-47. Graph of $\mathrm{D}_{\mathrm{Am}}{ }^{.05}$ versus Hydrolysis Time at $95^{\circ} \mathrm{C}$ with $0.25 \mathrm{M}^{2} \mathrm{HNO}_{3}$. The slope of the line was used to determine $\mathrm{k}_{\mathrm{h}}{ }^{.05}$ for Eq. IV-9.

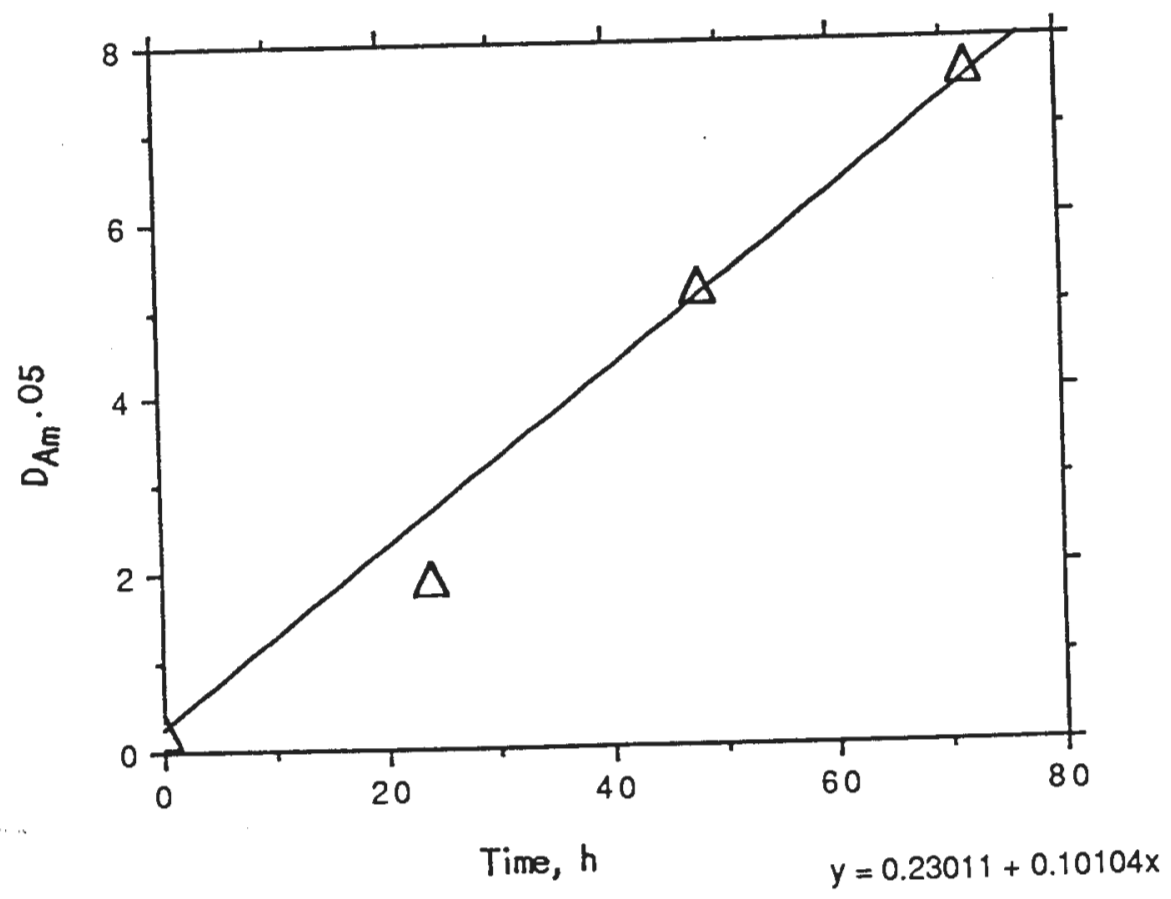

Fig. IV-48. Graph of $\mathrm{D}_{\mathrm{Am}}^{.05}$ versus Hydrolysis Time at $95^{\circ} \mathrm{C}$ with $2.5 \mathrm{M} \mathrm{HNO}_{3}$. The slope of the line was used to determine $k_{h} .05$ for Eq. IV-9. 


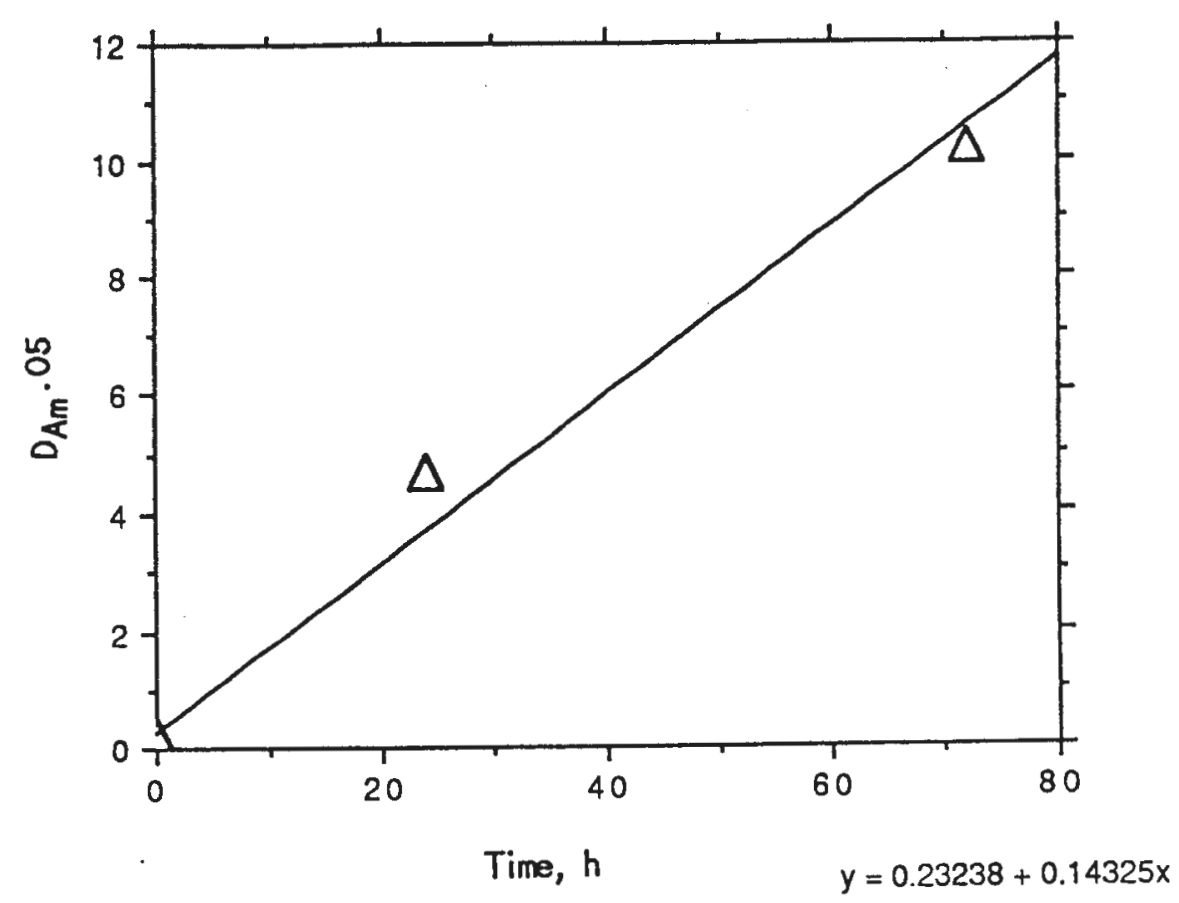

Fig. IV-49. Graph of $\mathrm{D}_{\text {Am }}{ }^{.05}$ versus Hydrolysis Time at $95^{\circ} \mathrm{C}$ with $6.0 \mathrm{M} \mathrm{HNO}_{3}$. The slope of the line was used to determine $\mathrm{k}_{\mathrm{h}}{ }^{.05}$ for Eq. IV-9.

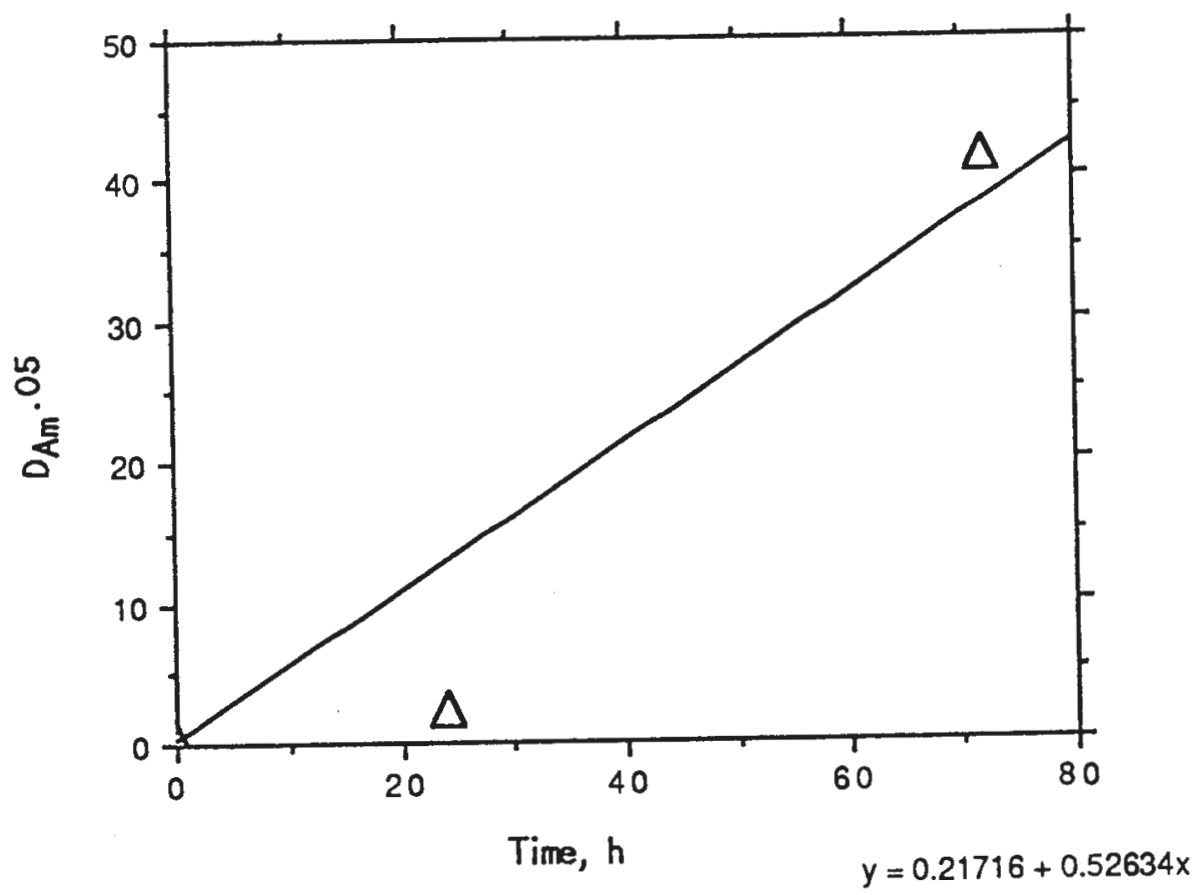

Fig. IV-50. Graph of $\mathrm{D}_{\mathrm{Am}}{ }^{.05}$ versus Hydrolysis Time at $95^{\circ} \mathrm{C}$ with Simulated $\mathrm{CAW}$ Containing $1.6 \mathrm{M} \mathrm{HNO}_{3}$. The slope of the line was used to determine $\mathrm{k}_{\mathrm{h}}{ }^{.05}$ for Eq. IV-9. 


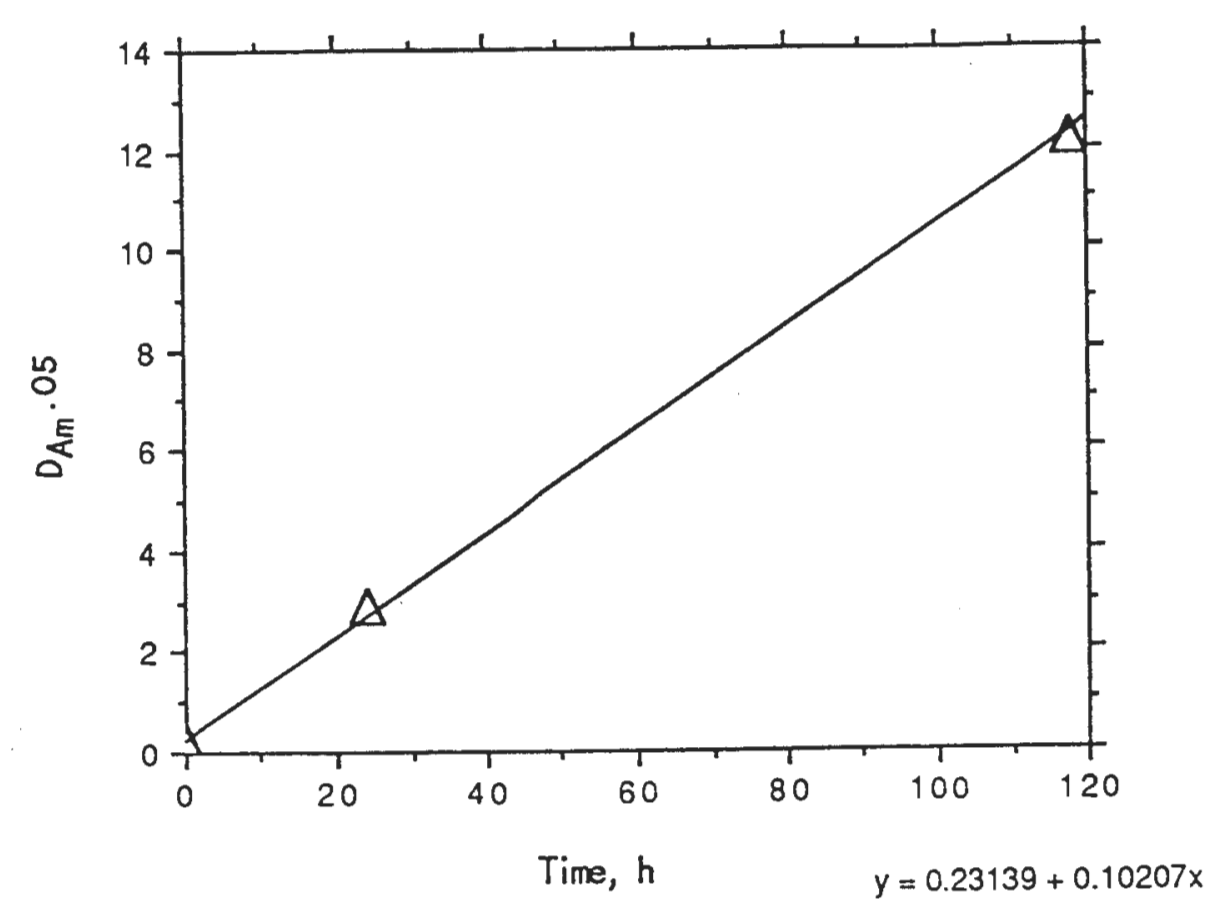

Fig. IV-51. Graph of $\mathrm{D}_{\mathrm{Am}}^{.05}$ versus Hydrolysis Time at $95^{\circ} \mathrm{C}$ with Simulated $\mathrm{CAW}$ Containing $2.6 \mathrm{M} \mathrm{HNO}_{3}$. The slope of the line was used to determine $\mathrm{k}_{\mathrm{h}}{ }^{.05}$ for Eq. IV-9.

Figures IV-52 through IV-54 show the linear correlations of $\mathrm{k}_{\mathrm{h}}{ }^{.05}$ with $\{\mathrm{H}\}$ used to determine values of $\mathrm{k}_{\mathrm{h}_{\mathrm{o}}}^{\prime} .05$ (y-intercept) and $\mathrm{k}_{\mathrm{h}} \cdot .05$ (slope) for 50,70 , and $95^{\circ} \mathrm{C}$. These values could be substituted into Eq. IV-10 for subsequent calculations of values of $k_{h}{ }^{.05}$. For all three temperatures, the correlation coefficient $k_{h}^{\prime} .05$ is a very small number, therefore, for each of the three temperatures, $k_{h}^{\prime} .05$ was assigned a value of zero, and the intercept, $\mathrm{k}_{\mathrm{h}_{\mathrm{o}}} \cdot 05$, was taken to be the average of the values of $\mathrm{k}_{\mathrm{h}} .{ }^{.05}$ obtained for the five aqueous solutions. Combining Eqs. IV-9 and IV-10 yields

$$
\mathrm{D}_{\mathrm{Am}}^{.05}=\mathrm{D}_{\dot{A}_{0}}^{.05}+\left[\mathrm{k}_{\mathrm{h}_{0}}^{\prime} .05+\mathrm{k}_{\mathrm{h}}^{\prime} \cdot 05 \quad\{\mathrm{H}\}\right] \mathrm{t}
$$

but since $\mathrm{k}_{\mathrm{h}}^{\prime} .05 \cong 0$, the expression becomes

$$
\mathrm{D}_{\mathrm{Am}}^{.05}=\mathrm{D}_{\mathrm{Am}_{0}}^{.05}+\left[\mathrm{k}_{\mathrm{b}_{\mathrm{O}}} \cdot 05\right] \mathrm{t}
$$

The values of $\mathrm{k}_{\mathrm{h}_{\mathrm{o}}} \cdot 05$ for 50,70 , and $95^{\circ} \mathrm{C}$ were correlated with temperature by an Arrhenius relation:

$$
\mathrm{k}_{\mathrm{h}}^{0} .05=\mathrm{A}_{0}^{.05} \mathrm{e}^{-\mathrm{E}_{0}^{.05} / \mathrm{RT}}
$$




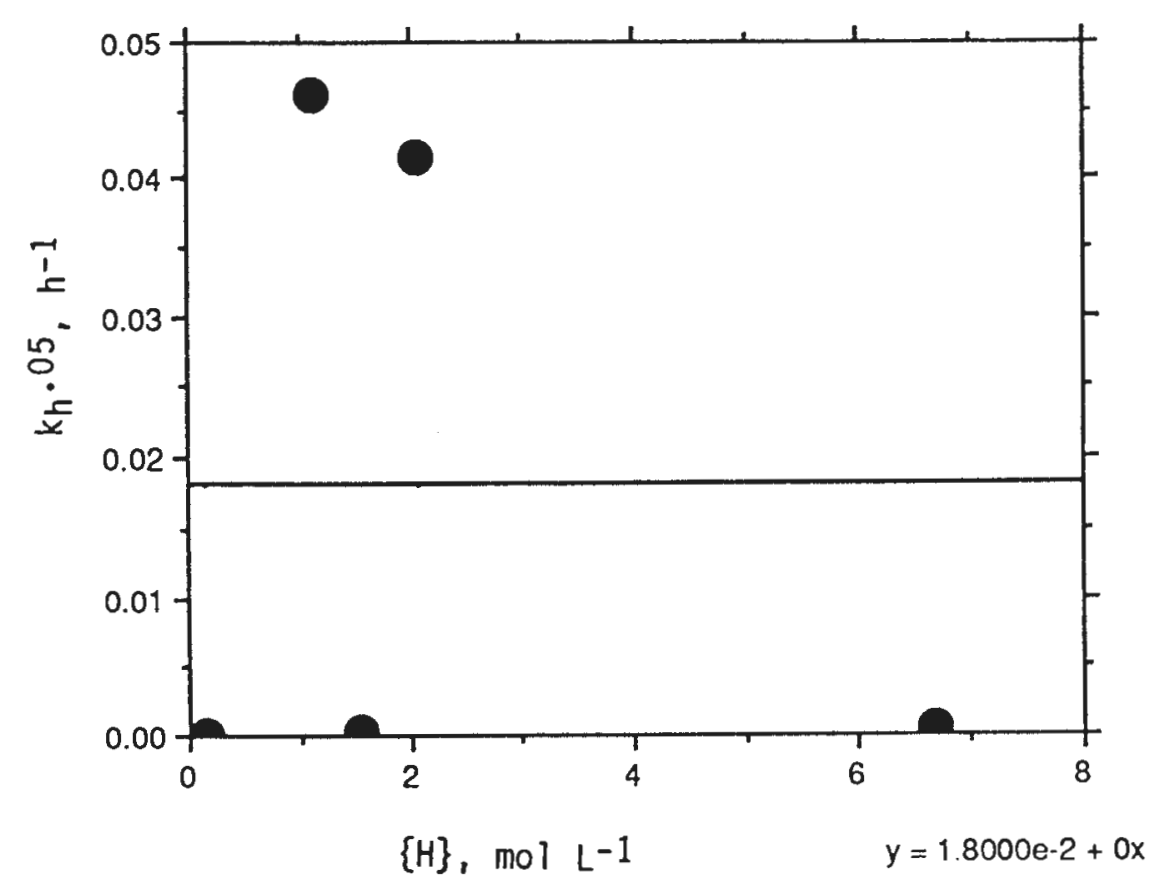

Fig. IV-52. Graph of $k_{h}{ }^{.05}$ versus Activity of Hydrogen Ion in Aqueous Solution Used as Hydrolytic Agent at $50^{\circ} \mathrm{C}$. For Eq. IV-10, intercept at $\mathrm{y}$ axis determines $\mathrm{k}_{\mathrm{h}_{\mathrm{o}}}^{\prime} .05$ and slope determines $\mathrm{k}_{\mathrm{h}}^{\prime} .05$.

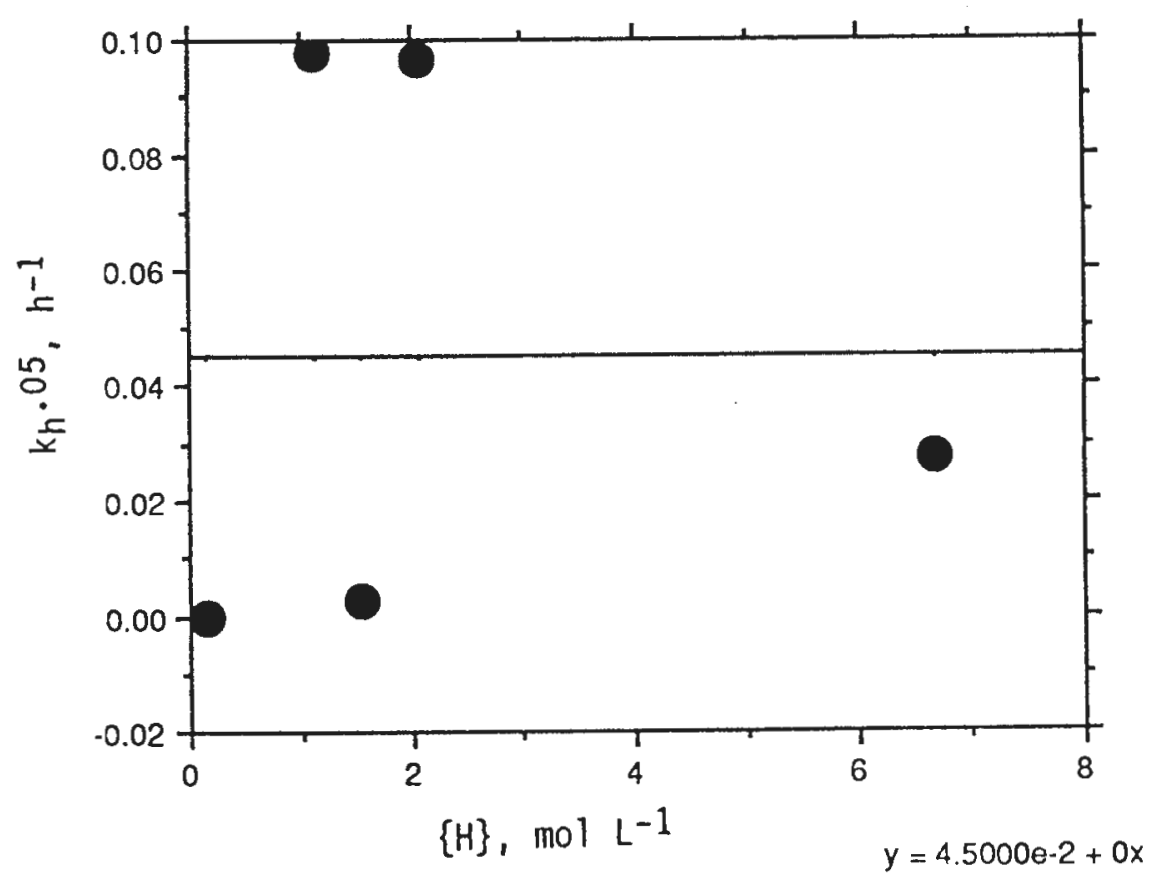

Fig. IV-53. Graph of $k_{h}{ }^{.05}$ versus Activity of Hydrogen Ion in Aqueous Solution Used as Hydrolytic Agent at $70^{\circ} \mathrm{C}$. For Eq. IV-10, intercept at $\mathrm{y}$ axis determines $\mathrm{k}_{\mathrm{h}_{\mathrm{o}}}{ }^{\prime} 05$ and slope determines $\mathrm{k}_{\mathrm{h}}{ }^{\prime} .05$. 


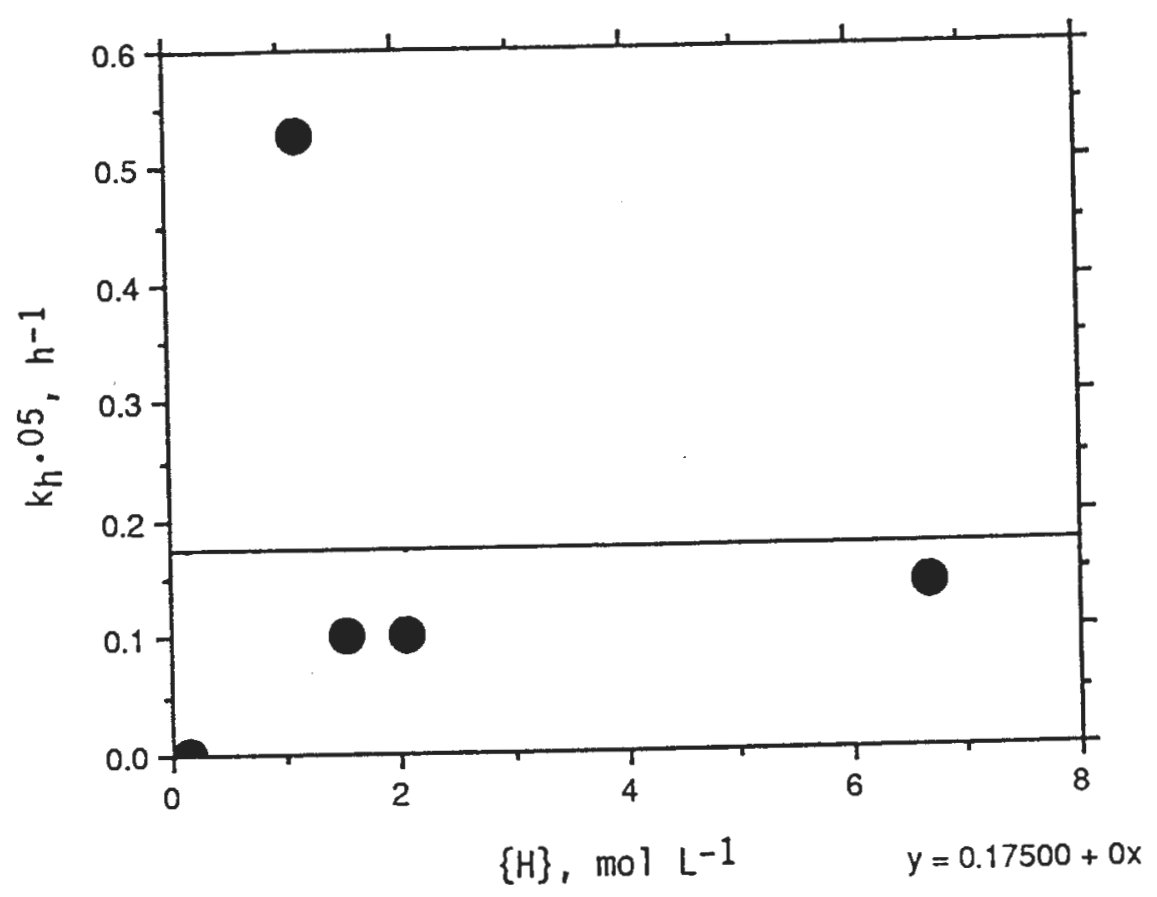

Fig. IV-54. Graph of $\mathrm{k}_{\mathrm{h}}{ }^{.05}$ versus Activity of Hydrogen Ion in Aqueous Solution Used as Hydrolytic Agent at $95^{\circ} \mathrm{C}$. For Eq. IV-10, intercept at $\mathrm{y}$ axis determines $\mathrm{k}_{\mathrm{h}_{\mathrm{o}}^{\prime}}^{\prime .05}$ and slope determines $\mathrm{k}_{\mathrm{h}}^{\prime} .05$.

Values of $A_{0}^{.05}$ and $E_{o}^{.05}$ were determined from the correlation of $-\ln k_{h_{0}} \cdot 05$ with $1 / T$, shown graphically in Fig. IV-55. Combining Eq. IV-12 and IV-13 gives

$$
\mathrm{D}_{\mathrm{Am}}^{.05}=\mathrm{D}_{\mathrm{Am}_{\mathrm{o}}}^{.05}+\left[\mathrm{A}_{\mathrm{o}}^{.05} \mathrm{e}^{-\mathrm{E}_{\mathrm{o}}^{.05} / \mathrm{RT}}\right]_{\mathrm{t}}
$$

where $\mathrm{D}_{\mathrm{Am}_{\mathrm{O}}}^{.05}=0.231$

$$
\begin{array}{ll}
\mathrm{A}_{\mathrm{o}} .05 & =5.92 \times 10^{2} \mathrm{~s}^{-1}\left(2.131 \times 10^{6} \mathrm{~h}^{-1}\right) \\
\mathrm{E}_{\mathrm{o}}^{.05} & =5.01 \times 10^{4} \mathrm{~J} \mathrm{~mol}^{-1}\left(1.197 \times 10^{4} \mathrm{cal} \mathrm{mol}^{-1}\right)
\end{array}
$$

Experimental values of $\mathrm{D}_{\mathrm{Am}}{ }^{.05}$ are compared with values calculated by Eq. IV-14 in Fig. IV-56. 


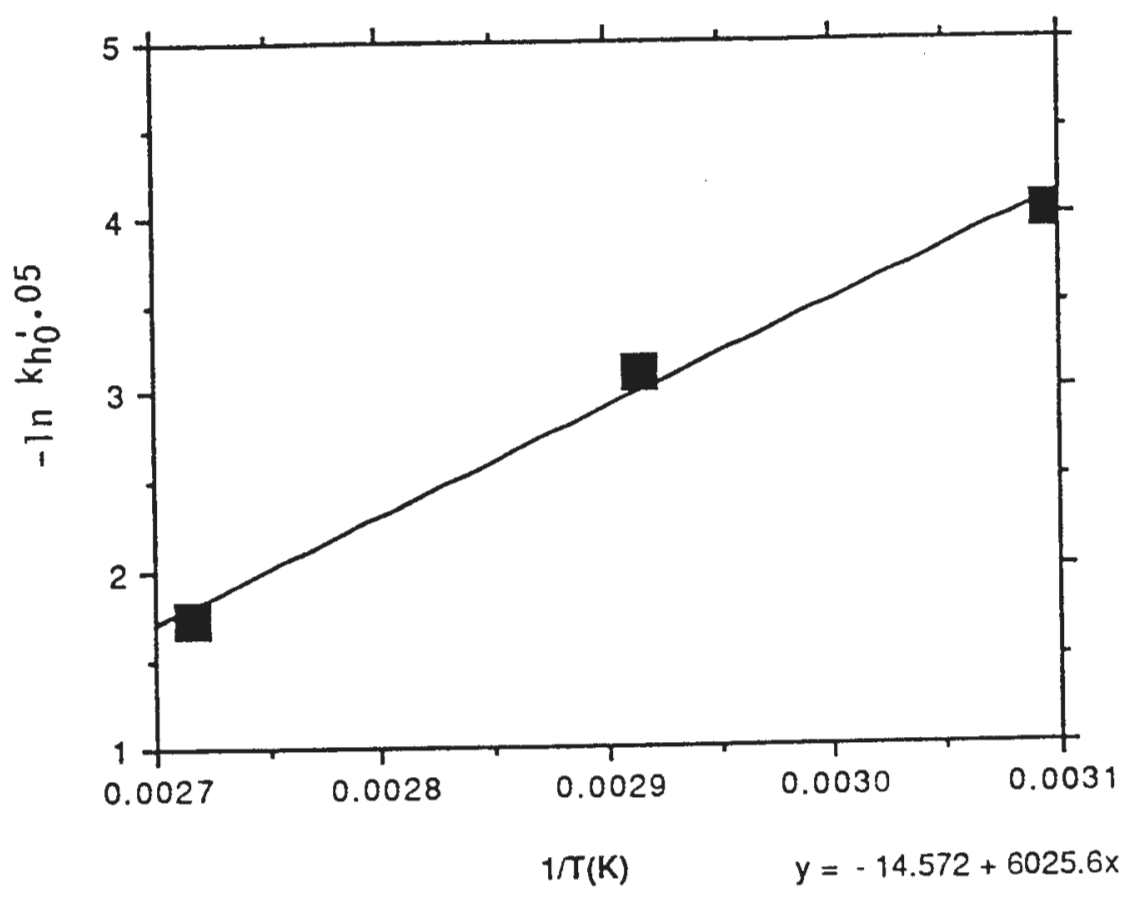

Fig. IV-55. Correlation between Temperature and the Rate Constant $k_{h_{0}}^{\prime} .05$. For Eq. IV-13, intercept at $\mathrm{y}$ axis determines $\mathrm{A}_{\mathrm{o}}^{.05}$ and slope determines $\mathrm{E}_{\mathrm{o}}{ }^{.05}$.

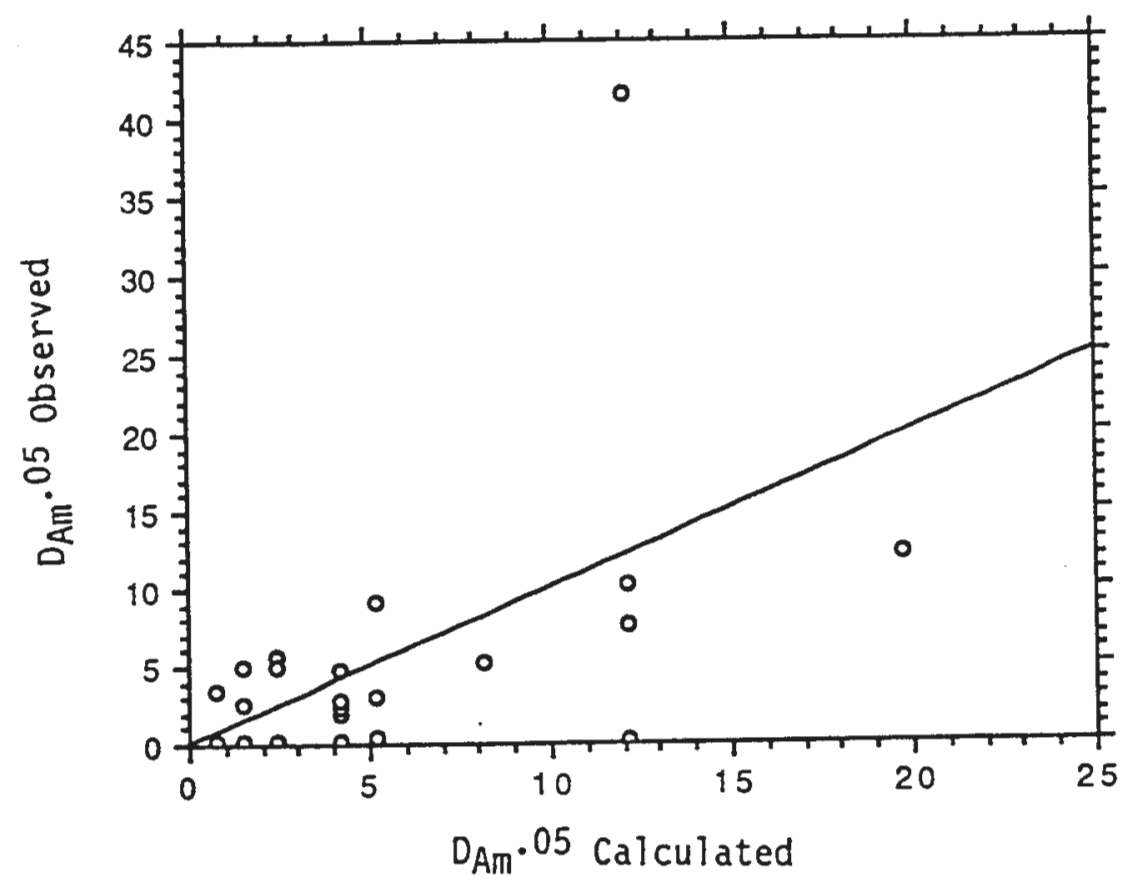

Fig. IV-56. Comparison of Calculated Values for $\mathrm{D}_{\mathrm{Am}}^{.05}$ with Observed Values Obtained with Solvent Degraded by Hydrolysis at $50-95^{\circ} \mathrm{C}$. The points are determined by the number pairs $\left(D_{A m}{ }^{.05}\right.$ observed, $D_{A m}{ }^{.05}$ calculated). The line is determined by the condition ( $\mathrm{D}_{\mathrm{Am}}^{\mathrm{Am}} .05$ observed $=\mathrm{D}_{\mathrm{Am}} .05$ calculated). 


\section{Rate Law for Hydrolysis of CMPO}

The $\mathrm{D}_{\mathrm{Am}}$ values for distribution at $2.0 \mathrm{M}$ decrease with time of hydrolysis. From this behavior, it is inferred that the distribution at $2.0 \mathrm{M} \overline{\mathrm{HNO}} \mathrm{N}_{3}$ is controlled by an extractant, initially present, whose concentration decreases as hydrolysis proceeds, namely, CMPO. Therefore, the $\mathrm{D}_{\mathrm{Am}}$ values for distribution of $\mathrm{Am}$ between degraded solvent and $2 \mathrm{M} \mathrm{HNO}_{3}$ were assumed to be a function of CMPO concentration and were used to derive expressions for its hydrolysis rate.

One of the general characteristics of the graph of $\mathrm{D}_{\mathrm{Am}}$ with time at $2.0 \mathrm{M} \mathrm{HNO}_{3}$ is that the slope decreases with time, suggesting that the destruction rate decreases as CMPO is depleted. This characteristic suggests that hydrolysis can be represented by a rate law in which the rate is proportional to CMPO concentration, of which the simplest type would be first order with respect to CMPO:

$$
-\mathrm{dC} / \mathrm{dt}=\mathrm{k}_{\mathrm{hp}} \mathrm{C}
$$

which, in integrated form, is

$$
C=C_{0} e^{-k_{h p} t}
$$

or

$$
-\ln C=k_{h p} t-\ln C_{0}
$$

where $\mathrm{C}$ is the concentration of CMPO and $\mathrm{C}_{\mathrm{o}}$ is the initial concentration of CMPO.

The americium distribution ratio is proportional to the CMPO concentration, raised to the $\mathrm{n}^{\text {th }}$ power, where $n$ is about 3 :

$$
D_{\mathrm{Am}}^{2.0} / \mathrm{D}_{\mathrm{Am}}^{2.0}=\mathrm{C}^{\mathrm{n}} / \mathrm{C}_{0}^{\mathrm{n}}
$$

or

$$
\mathrm{C}^{\mathrm{n}}=\mathrm{D}_{\mathrm{Am}}^{2.0} / \mathrm{D}_{\mathrm{Am}_{\mathrm{O}}}^{2.0} \cdot \mathrm{C}_{\mathrm{O}}^{\mathrm{n}}
$$

whence

$$
\ln C=1 / n \ln D_{A m}^{2.0}+\ln C_{0}-1 / n \ln D_{A m_{0}}^{2.0}
$$




$$
\ln D_{A m}^{2.0}=-n k_{h p} t+\ln D_{A m}^{2.0}
$$

Thus, $\mathrm{nk}_{\mathrm{hp}}$ could be obtained as the slope of a graph of $\ln \mathrm{D}_{\mathrm{Am}}^{2.0}$ versus $\mathrm{t}$. It is convenient, however, to present the data in the form of a semilog graph, with $\mathrm{D}_{\mathrm{Am}} 2.0$ as the ordinate on a log scale and $t$ as the abscissa on a linear scale. Figures IV-57 through IV-71 show that the experimental data and the lines, chosen by inspection, represent the equation

$$
D_{A r}^{2.0}=\left[D_{A \sigma_{0}}^{2.0}\right] 10^{-(1 / 2.303)\left[n k_{h p}\right](t)}
$$

which is a transformation of Eq. IV-21. Values of $\mathrm{nk}_{\mathrm{hp}}$ were, therefore, obtained from the correlation coefficient $\left[(1 / 2.303)\left(\mathrm{nk}_{\mathrm{hp}}\right)\right]$ of Eq. IV-22.

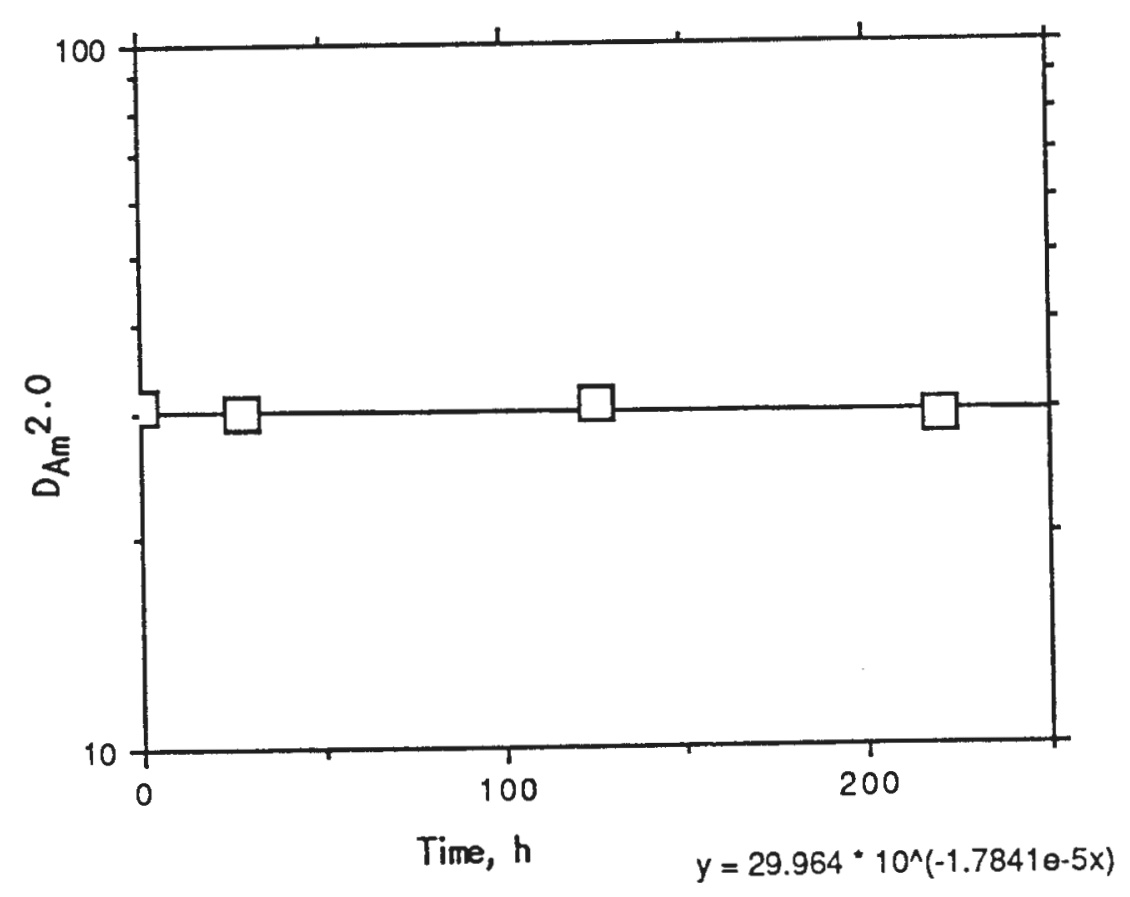

Fig. IV-57. Graph of $\mathrm{D}_{\mathrm{Am}}^{2.0}$ versus Hydrolysis Time at $50^{\circ} \mathrm{C}$ with $0.25 \mathrm{M} \mathrm{HNO}_{3}$. The slope of the line was used to determine $\mathrm{k}_{\mathrm{hp}}{ }^{2.0}$ for Eq. IV-22 from the correlation coefficient. 


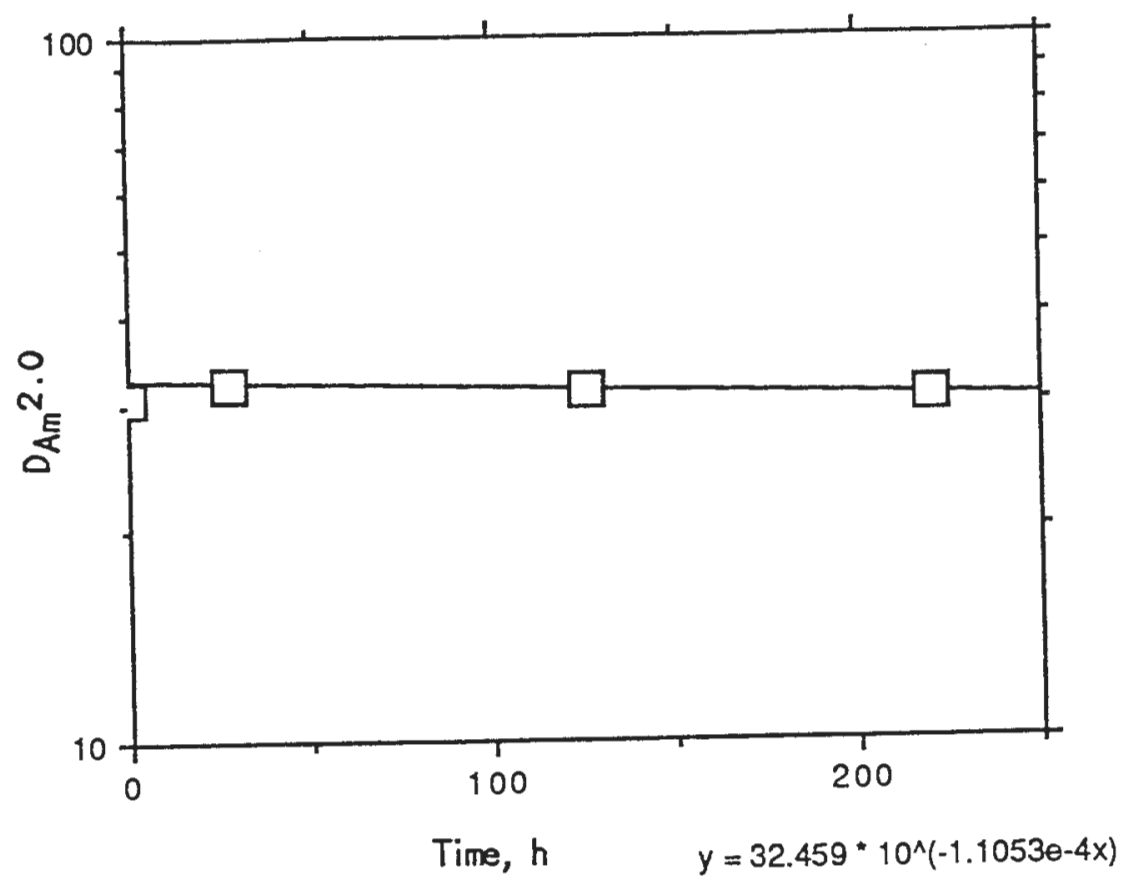

Fig. IV-58. Graph of $\mathrm{D}_{\mathrm{Am}}{ }^{2.0}$ versus Hydrolysis Time at $50^{\circ} \mathrm{C}$ with $2.5 \mathrm{M} \mathrm{HNO}_{3}$. The slope of the line was used to determine $k_{h p}{ }^{2.0}$ for Eq. IV -22 from the correlation coefficient.

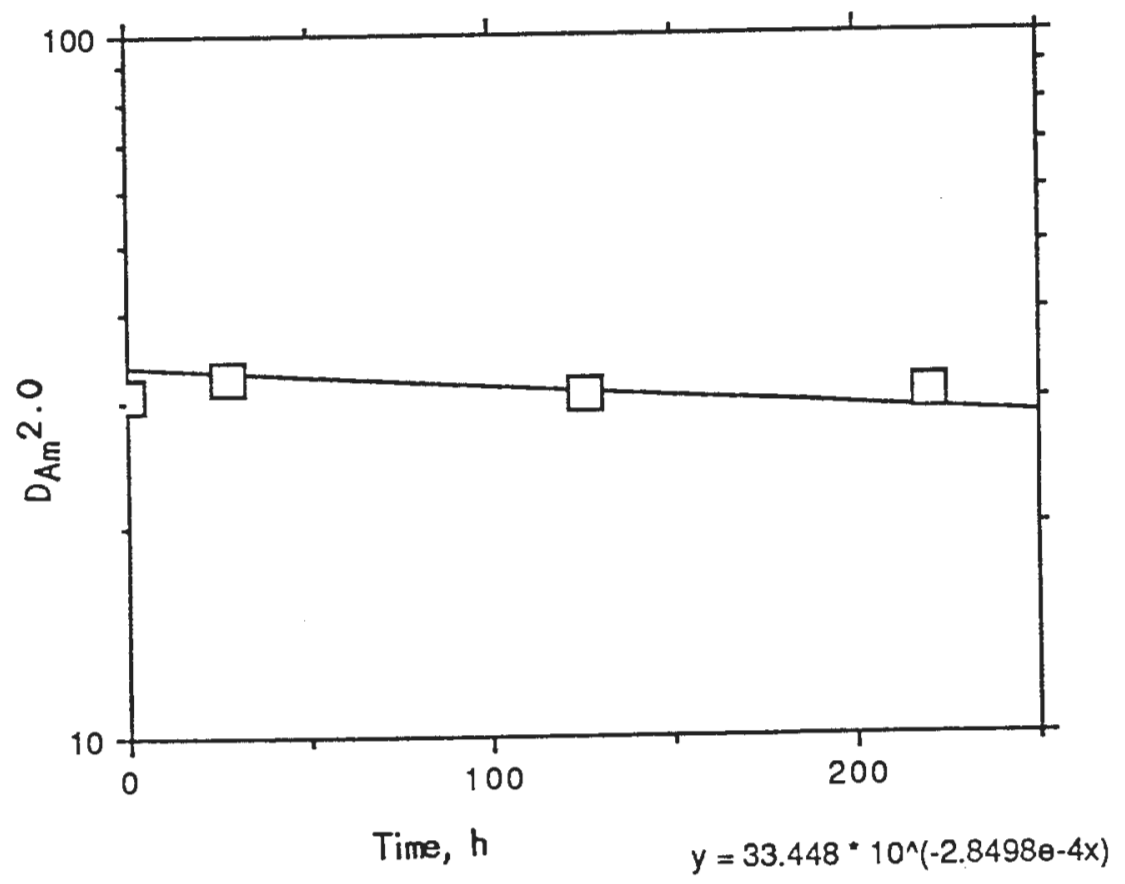

Fig. IV-59. Graph of $\mathrm{D}_{\mathrm{Am}}{ }^{2.0}$ versus Hydrolysis Time at $50^{\circ} \mathrm{C}$ with $6.0 \mathrm{M} \mathrm{HNO}_{3}$. The slope of the line was used to determine $\mathrm{k}_{\mathrm{hp}}{ }^{2.0}$ for Eq. IV-22 from the correlation coefficient. 


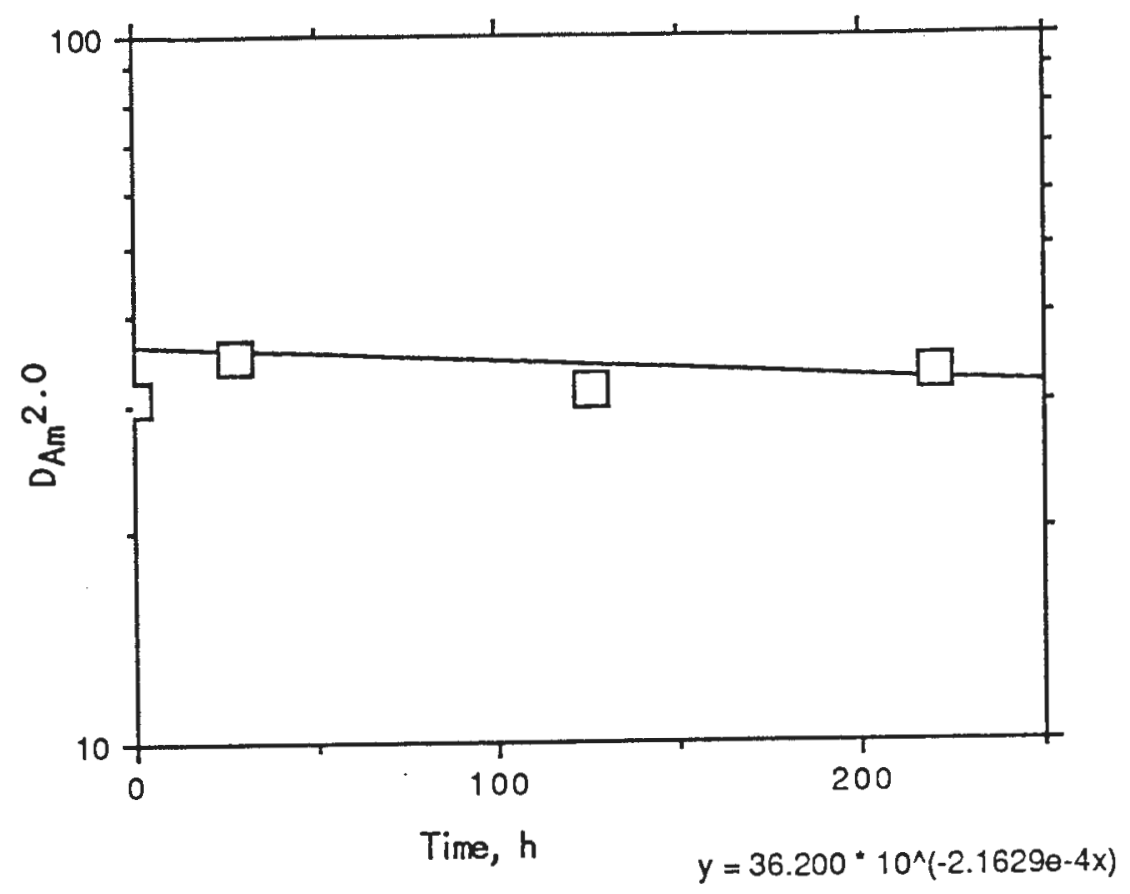

Fig. IV-60. Graph of $\mathrm{D}_{\mathrm{Am}}{ }^{2.0}$ versus Hydrolysis Time at $50^{\circ} \mathrm{C}$ with Simulated $\mathrm{CAW}$ Containing 1.6M $\mathrm{HNO}_{3}$. The slope of the line was used to determine $\mathrm{k}_{\mathrm{hp}}{ }^{2.0}$ for Eq. IV-22 from the correlation coefficient.

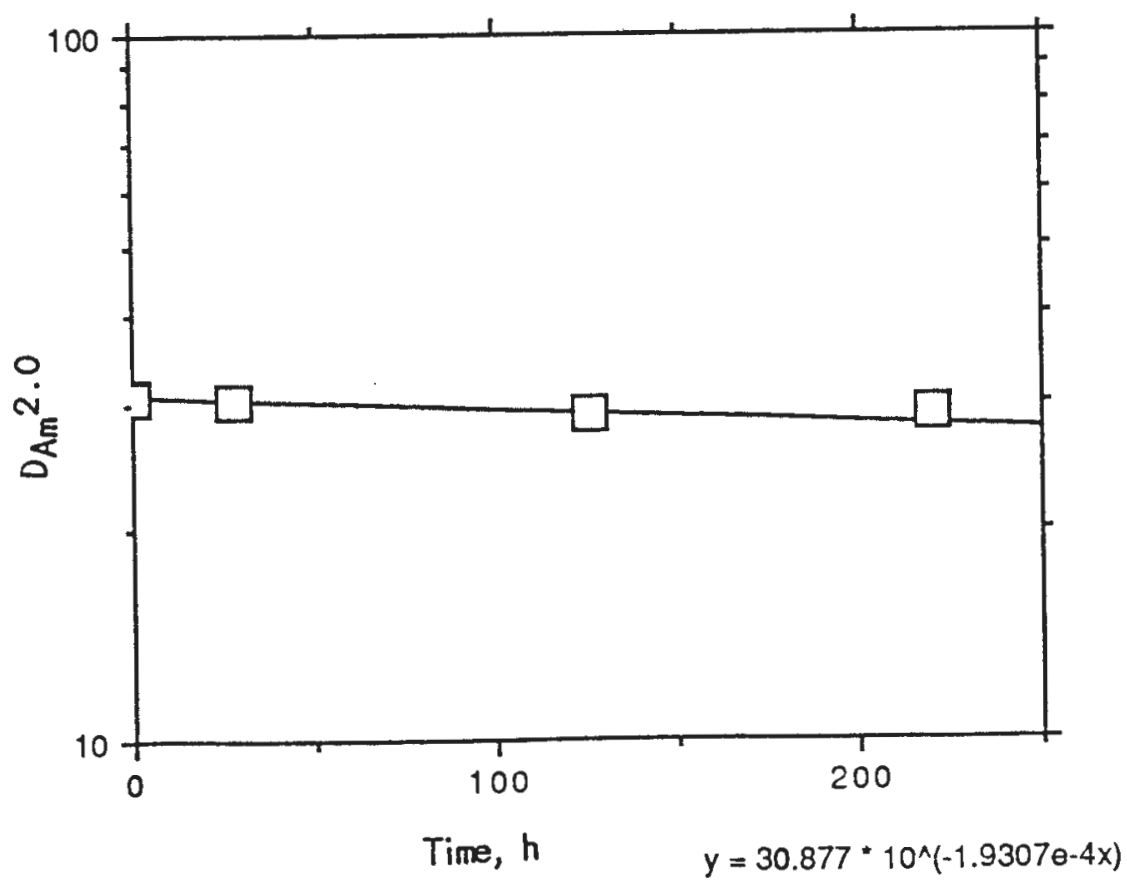

Fig. IV-61. Graph of $\mathrm{D}_{\mathrm{Am}}{ }^{2.0}$ versus Hydrolysis Time at $50^{\circ} \mathrm{C}$ with Simulated $\mathrm{CAW}$ Containing $2.6 \mathrm{M} \mathrm{HNO}_{3}$. The slope of the line was used to determine $\mathrm{k}_{\mathrm{hp}}{ }^{2.0}$ for Eq. IV-22 from the correlation coefficient. 


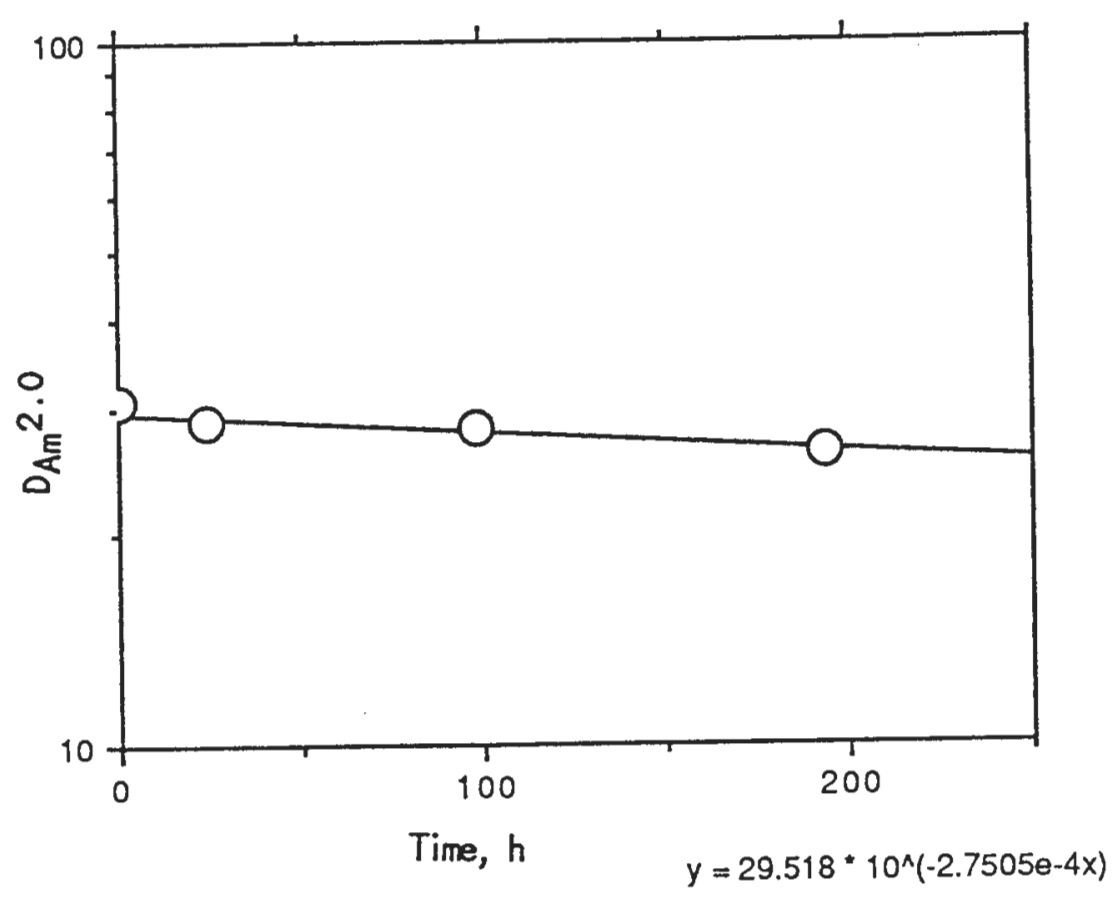

Fig. IV-62. Graph of $\mathrm{D}_{\mathrm{Am}}{ }^{2.0}$ versus Hydrolysis Time at $70^{\circ} \mathrm{C}$ with $0.25 \mathrm{M} \mathrm{HNO}_{3}$. The slope of the line was used to determine $\mathrm{k}_{\mathrm{hp}}{ }^{2.0}$ for Eq. IV-22 from the correlation coefficient.

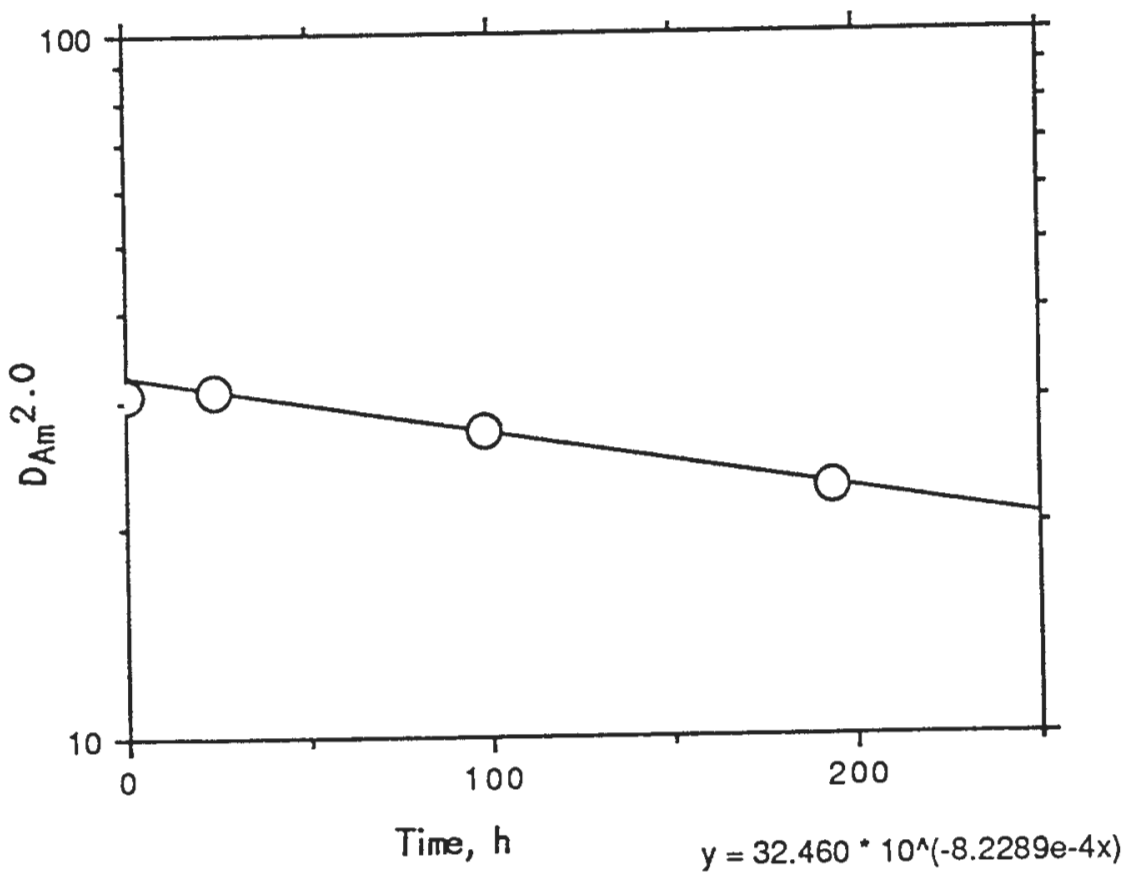

Fig. IV-63. Graph of $\mathrm{D}_{\mathrm{Am}}{ }^{2.0}$ versus Hydrolysis Time at $70^{\circ} \mathrm{C}$ with $2.5 \mathrm{M} \mathrm{HNO}_{3}$. The slope of the line was used to determine $\mathrm{k}_{\mathrm{hp}}{ }^{2.0}$ for Eq. IV -22 from the correlation coefficient. 


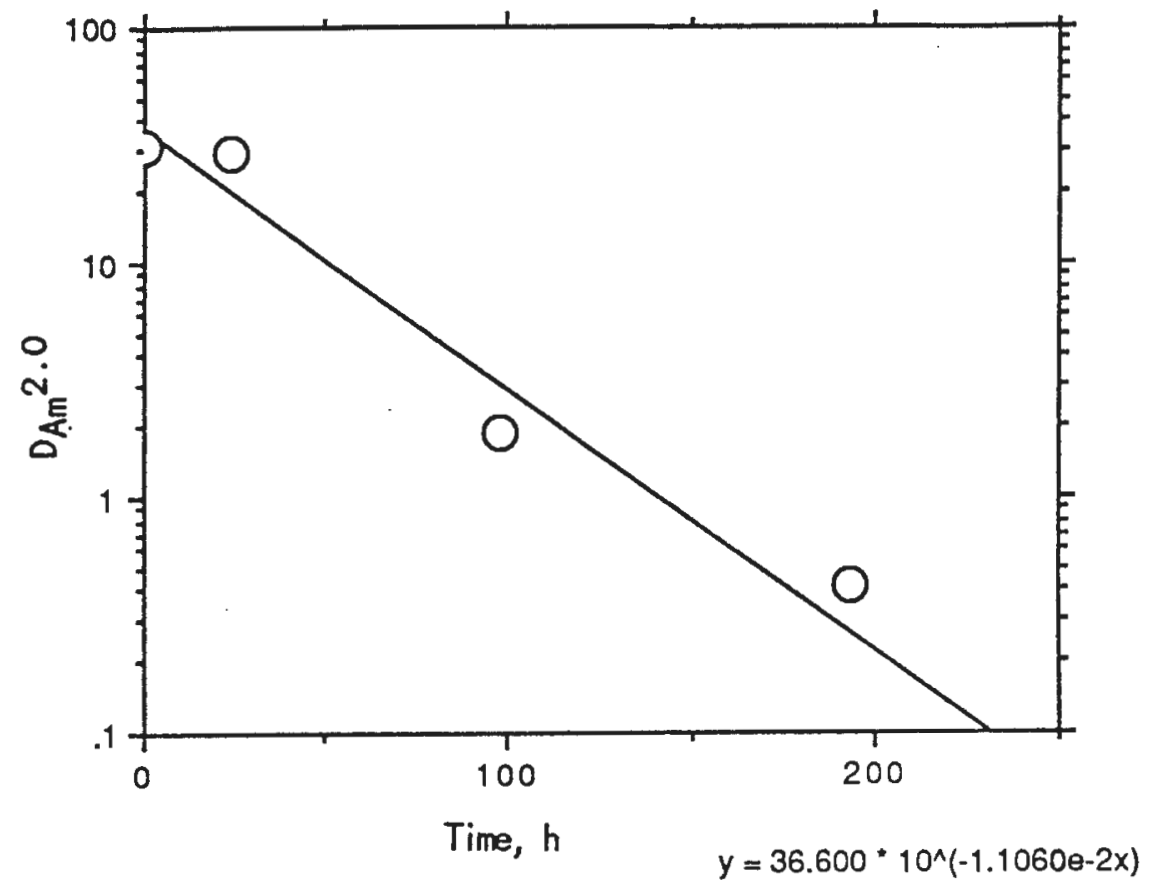

Fig. IV-64. Graph of $\mathrm{D}_{\mathrm{Am}}{ }^{2.0}$ versus Hydrolysis Time at $70^{\circ} \mathrm{C}$ with $6.0 \mathrm{M} \mathrm{HNO}_{3}$. The slope of the line was used to determine $\mathrm{k}_{\mathrm{hp}}{ }^{2.0}$ for Eq. IV -22 from the correlation coefficient.

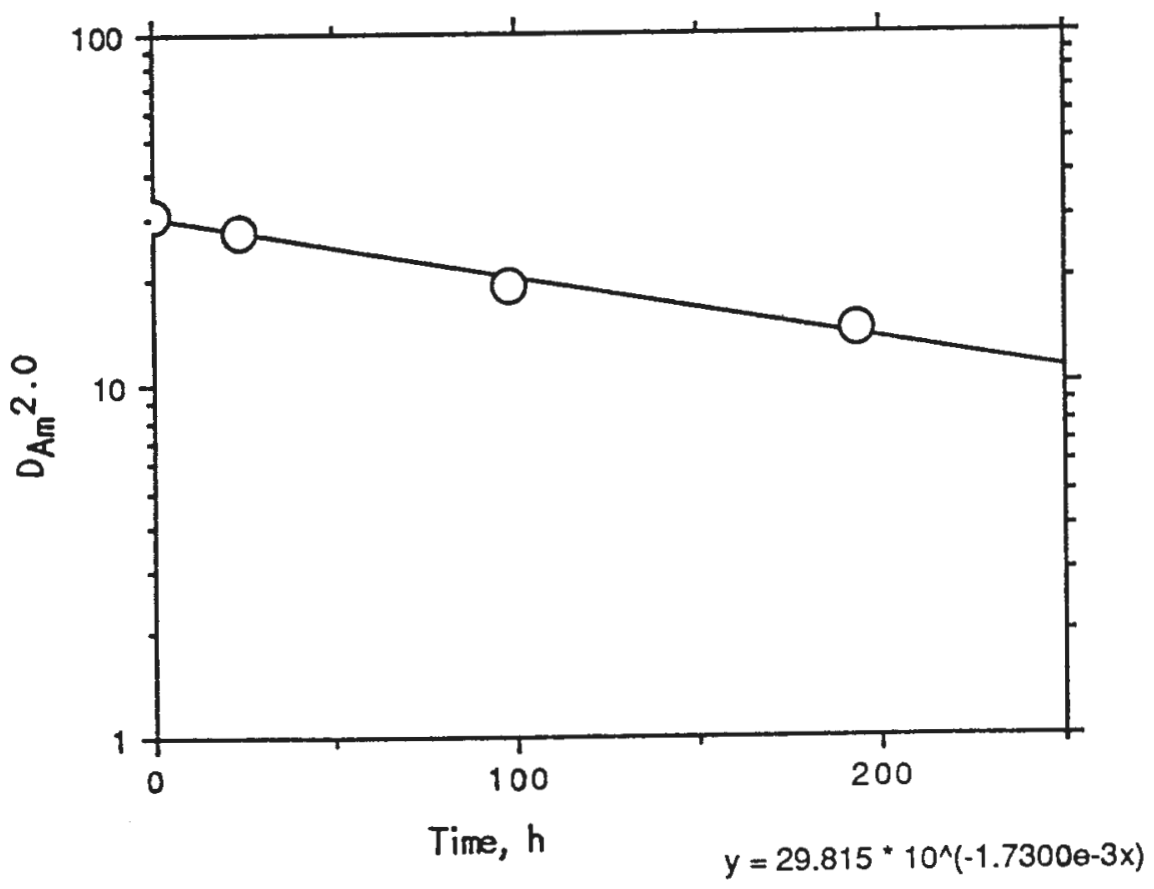

Fig. IV-65. Graph of $\mathrm{D}_{\mathrm{Am}}{ }^{2.0}$ versus Hydrolysis Time at $70^{\circ} \mathrm{C}$ with Simulated $\mathrm{CAW}$ Containing $1.6 \mathrm{M} \mathrm{HNO}_{3}$. The slope of the line was used to determine $\mathrm{k}_{\mathrm{hp}}{ }^{20}$ for Eq. IV-22 from the correlation coefficient. 


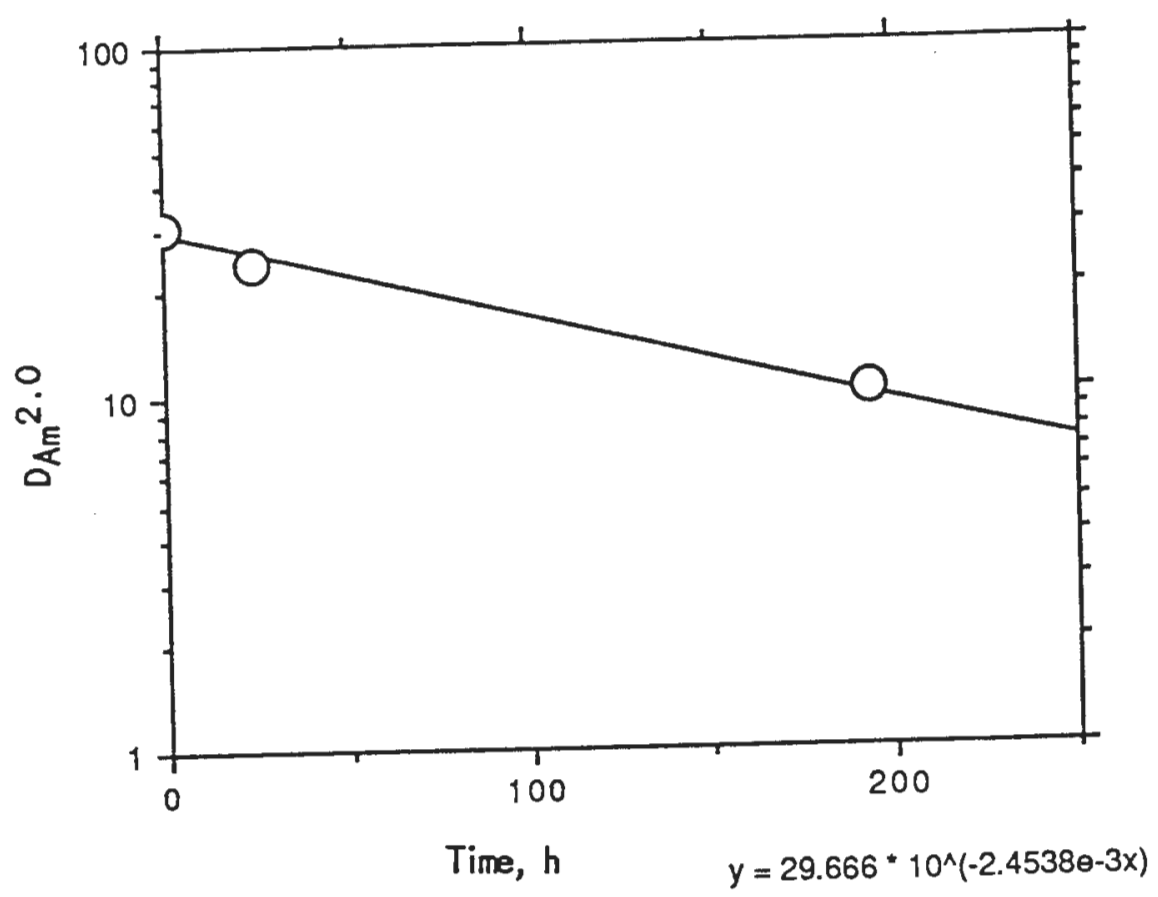

Fig. IV-66. Graph of $\mathrm{D}_{\mathrm{Am}}^{2.0}$ versus Hydrolysis Time at $70^{\circ} \mathrm{C}$ with Simulated $\mathrm{CAW}$ Containing 2.6M $\mathrm{HNO}_{3}$. The slope of the line was used to determine $\mathrm{k}_{\mathrm{hp}}{ }^{2.0}$ for Eq. IV-22 from the correlation coefficient.

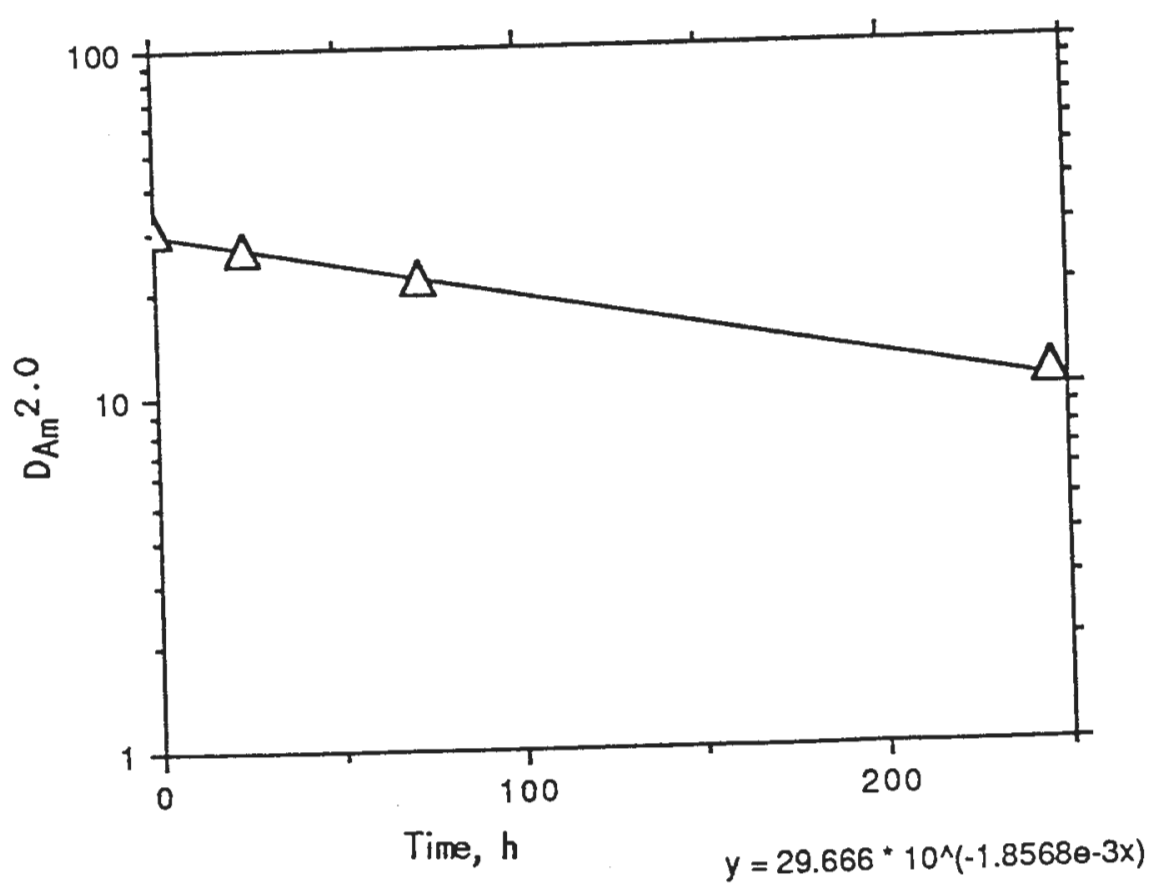

Fig. IV-67. Graph of $\mathrm{D}_{\mathrm{Am}}{ }^{2.0}$ versus Hydrolysis Time at $95^{\circ} \mathrm{C}$ with $0.25 \mathrm{M} \mathrm{HNO}_{3}$. The slope of the line was used to determine $\mathrm{k}_{\mathrm{hp}}{ }^{2.0}$ for Eq. IV-22 from the correlation coefficient. 


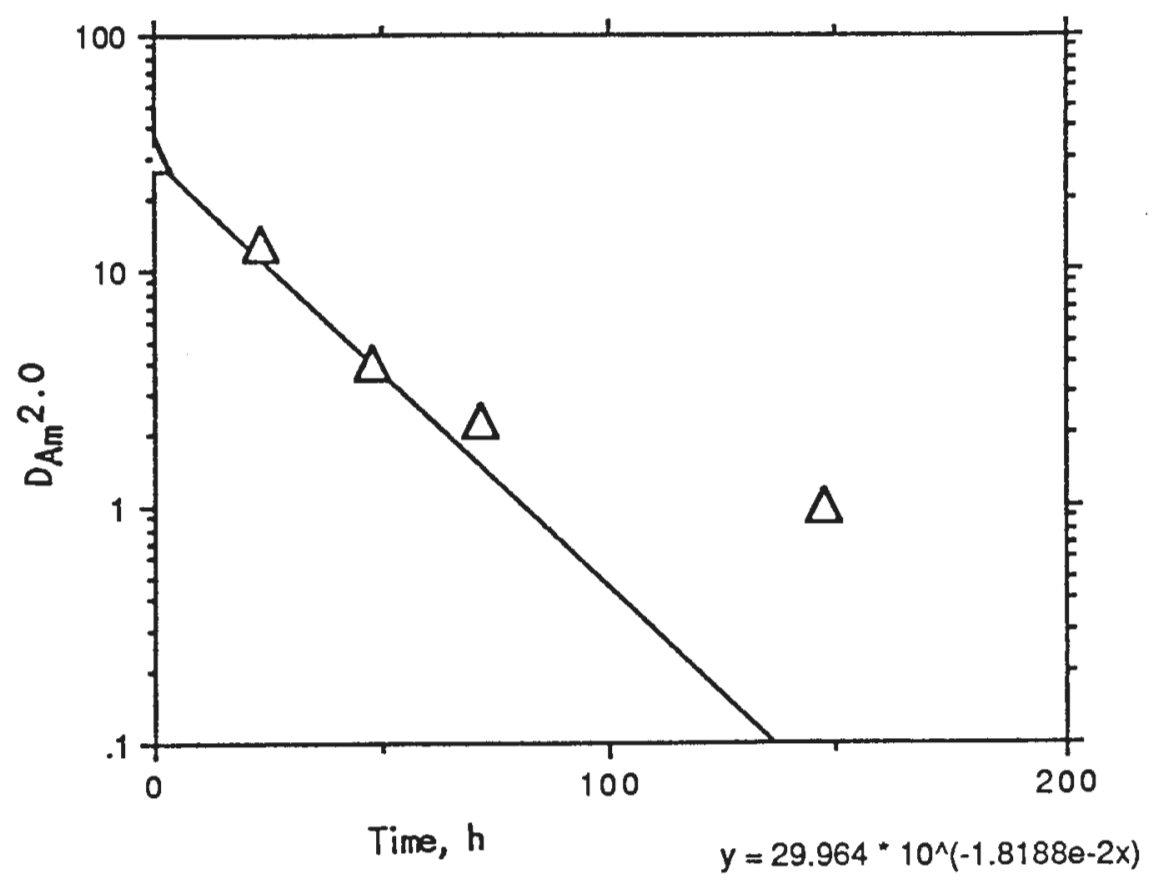

Fig. IV-68. Graph of $\mathrm{D}_{\mathrm{Am}}{ }^{2.0}$ versus Hydrolysis Time at $95^{\circ} \mathrm{C}$ with $2.5 \mathrm{M} \mathrm{HNO}_{3}$. The slope of the line was used to determine $\mathrm{k}_{\mathrm{hp}}{ }^{2.0}$ for Eq. IV -22 from the correlation coefficient.

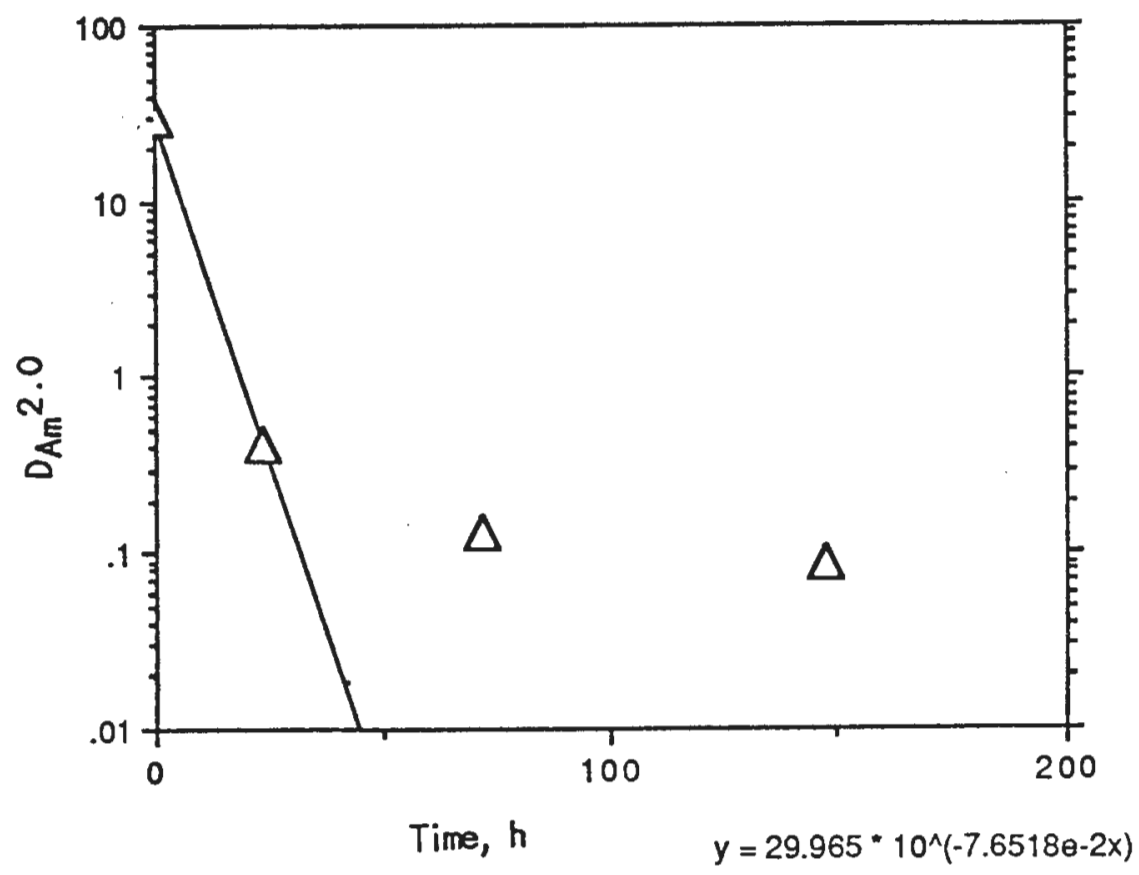

Fig. IV-69. Graph of $\mathrm{D}_{\mathrm{Am}}{ }^{2.0}$ versus Hydrolysis Time at $95^{\circ} \mathrm{C}$ with $6.0 \mathrm{M} \mathrm{HNO}_{3}$. The slope of the line was used to determine $\mathrm{k}_{\mathrm{hp}}{ }^{2.0}$ for Eq. IV -22 from the correlation coefficient. 


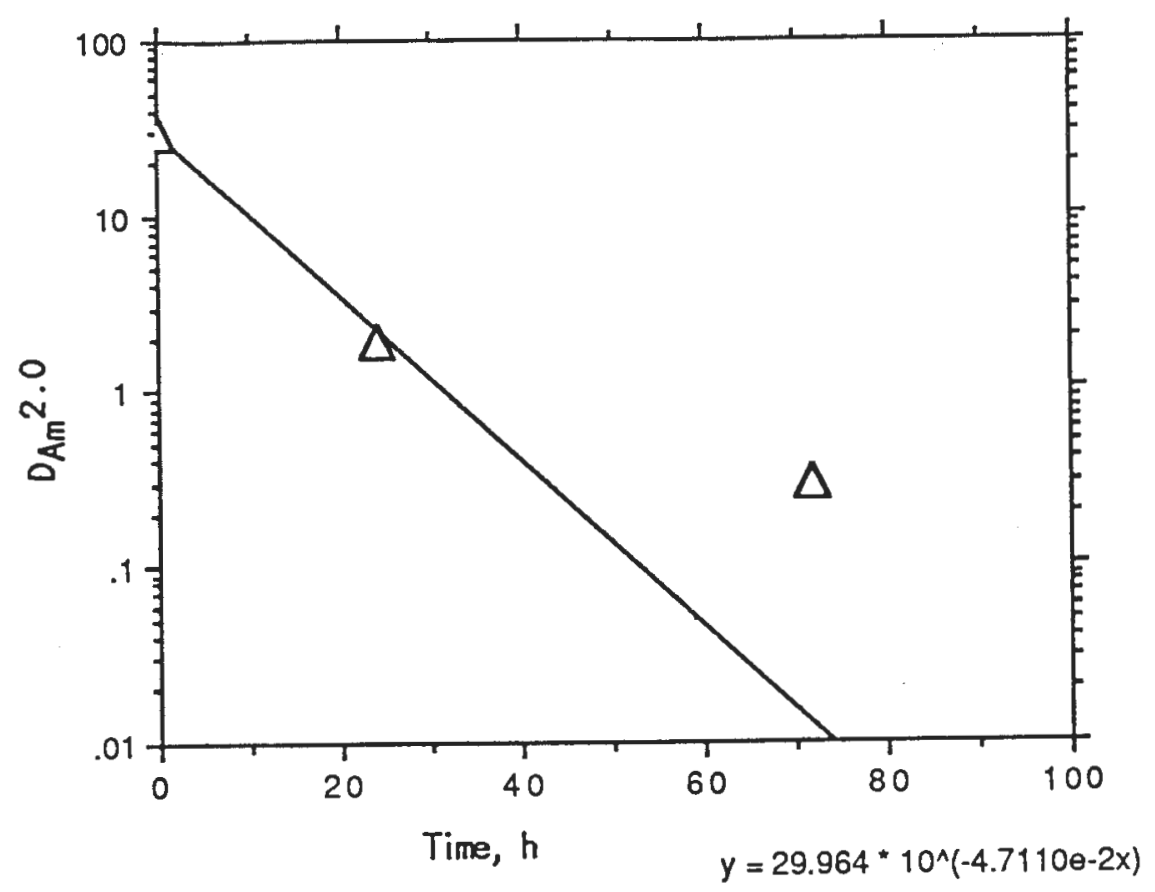

Fig. IV-70. Graph of $\mathrm{D}_{\mathrm{Am}}{ }^{2.0}$ versus Hydrolysis Time at $95^{\circ} \mathrm{C}$ with Simulated $\mathrm{CAW}$ Containing 1.6 $\mathrm{M} \mathrm{HNO}_{3}$. The slope of the line was used to determine $\mathrm{k}_{\mathrm{hp}}{ }^{20}$ for Eq. IV-22 from the correlation coefficient.

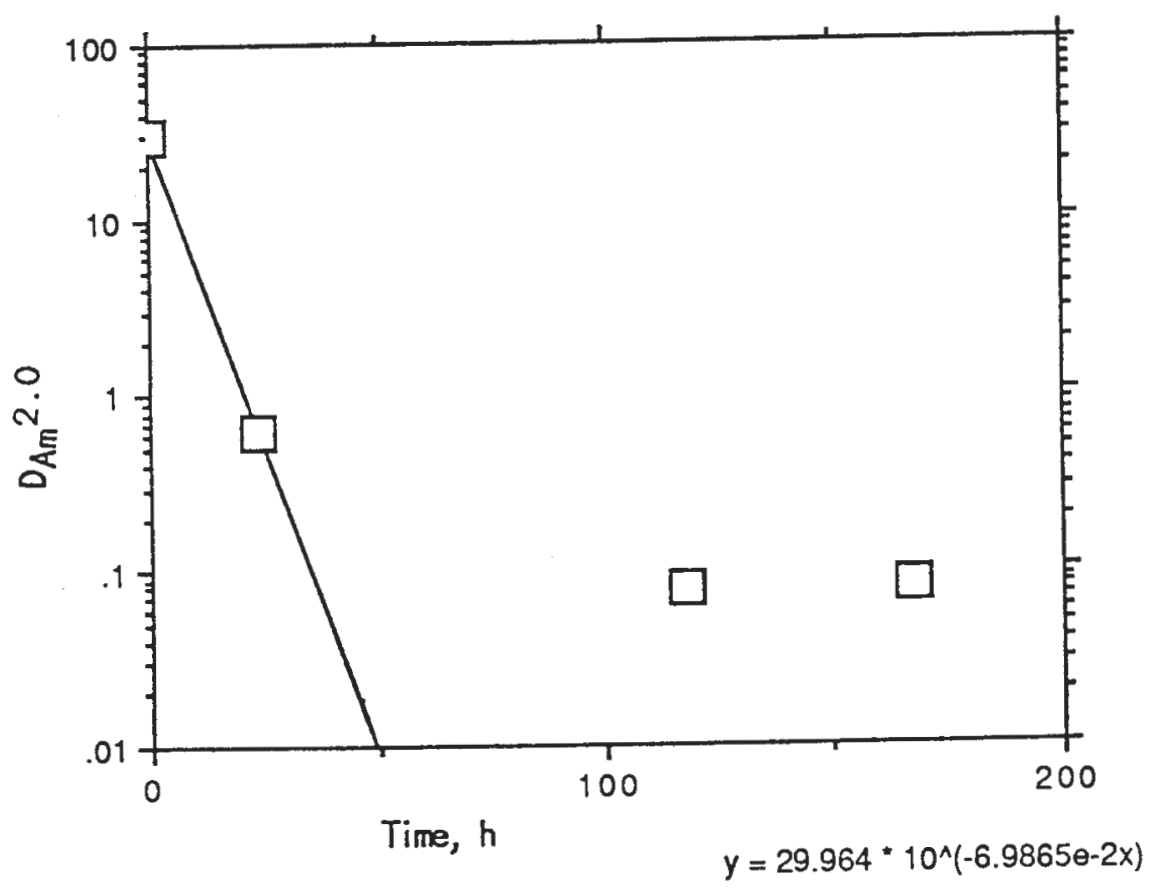

Fig. IV-71. Graph of $\mathrm{D}_{\mathrm{Am}}{ }^{2.0}$ versus Hydrolysis Time at $95^{\circ} \mathrm{C}$ with Simulated CAW Containing 2.6 $\mathrm{M} \mathrm{HNO}_{3}$. The slope of the line was used to determine $\mathrm{k}_{\mathrm{hp}}{ }^{2.0}$ for Eq. IV-22 from the correlation coefficient. 
For the data obtained, the dependence of $\ln \mathrm{D}_{\mathrm{Am}}{ }^{2.0}$ on $\mathrm{t}(\mathrm{Eq} . \mathrm{IV}-21)$ is not linear over the entire time span of up to $800 \mathrm{~h}$. Therefore, since solvent in centrifugal contactors will be in contact with aqueous acid only a few hours in an entire operating year, the values of $\mathrm{nk}_{\mathrm{hp}}$ were derived from data obtained for hydrolytic periods of $200 \mathrm{~h}$ or less.

Another general characteristic of the variation of $\mathrm{D}_{\mathrm{Am}}$ with time is a dependence on acid concentration. This characteristic suggests that a representative rate law must express dependence on acidity. Thus, Eq. IV-15 is treated as a pseudo-first-order rate law, and $\mathrm{k}_{\mathrm{hp}}$ is expressed as a function of acidity. Tests of the data showed that $\mathrm{k}_{\mathrm{hp}}$ was best correlated with the activity of hydrogen ion in the aqueous phase in equilibrium with solvent, $\{\mathrm{H}\}$, as follows:

$$
k_{h p}=k_{h}\{H\}
$$

or

$$
\mathrm{nk}_{\mathrm{hp}}=\mathrm{nk}_{\mathrm{h}}\{\mathrm{H}\}
$$

Values of $\mathrm{nk}_{\mathrm{h}}$ were obtained through determining the slopes of graphs of $\mathrm{nk}_{\mathrm{hp}}$ versus $\{\mathrm{H}\}$, shown in Figs. IV-72, IV-73, and IV-74 for 50,70 , and $95^{\circ} \mathrm{C}$, respectively. The lines in these figures were drawn based on inspection of the data.

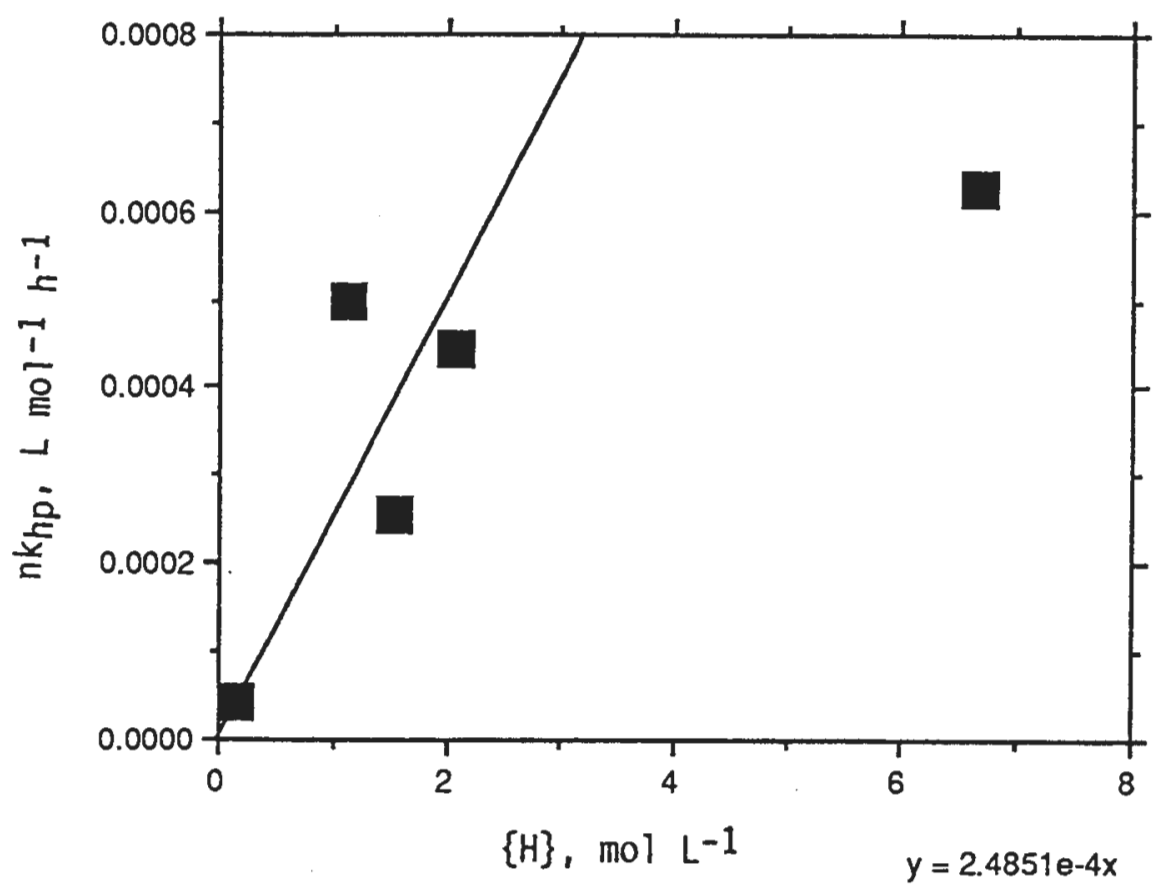

Fig. IV-72. Rate Constant, $\mathrm{nk}_{\mathrm{h}}$, for Hydrolysis of CMPO at $50^{\circ} \mathrm{C}$. Correlation between $\mathrm{nk}_{\mathrm{hp}}$ and $\{\mathrm{H}\}$ expressed by Eq. IV-24. 


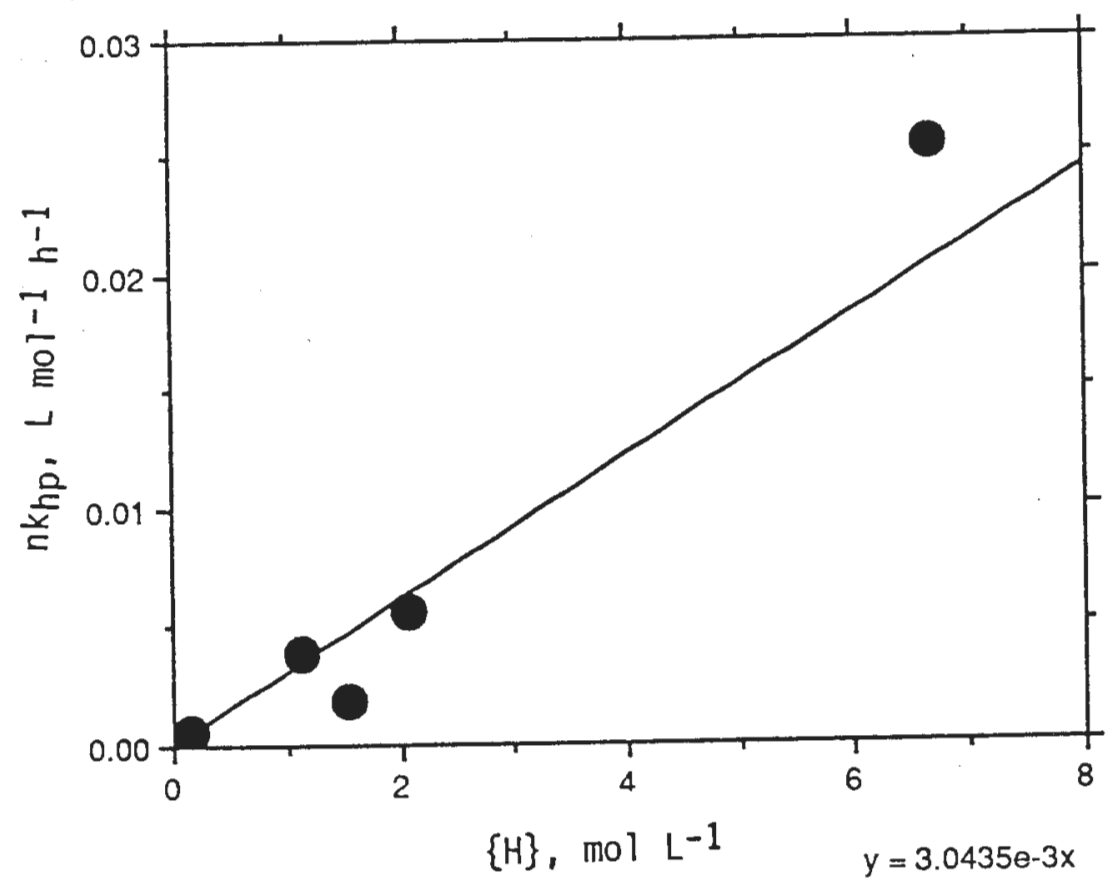

Fig. IV-73. Rate Constant, $\mathrm{nk}_{\mathrm{h}}$, for Hydrolysis of CMPO at $70^{\circ} \mathrm{C}$. Correlation between $n k_{h p}$ and $\{\mathrm{H}\}$ expressed by Eq. IV-24.

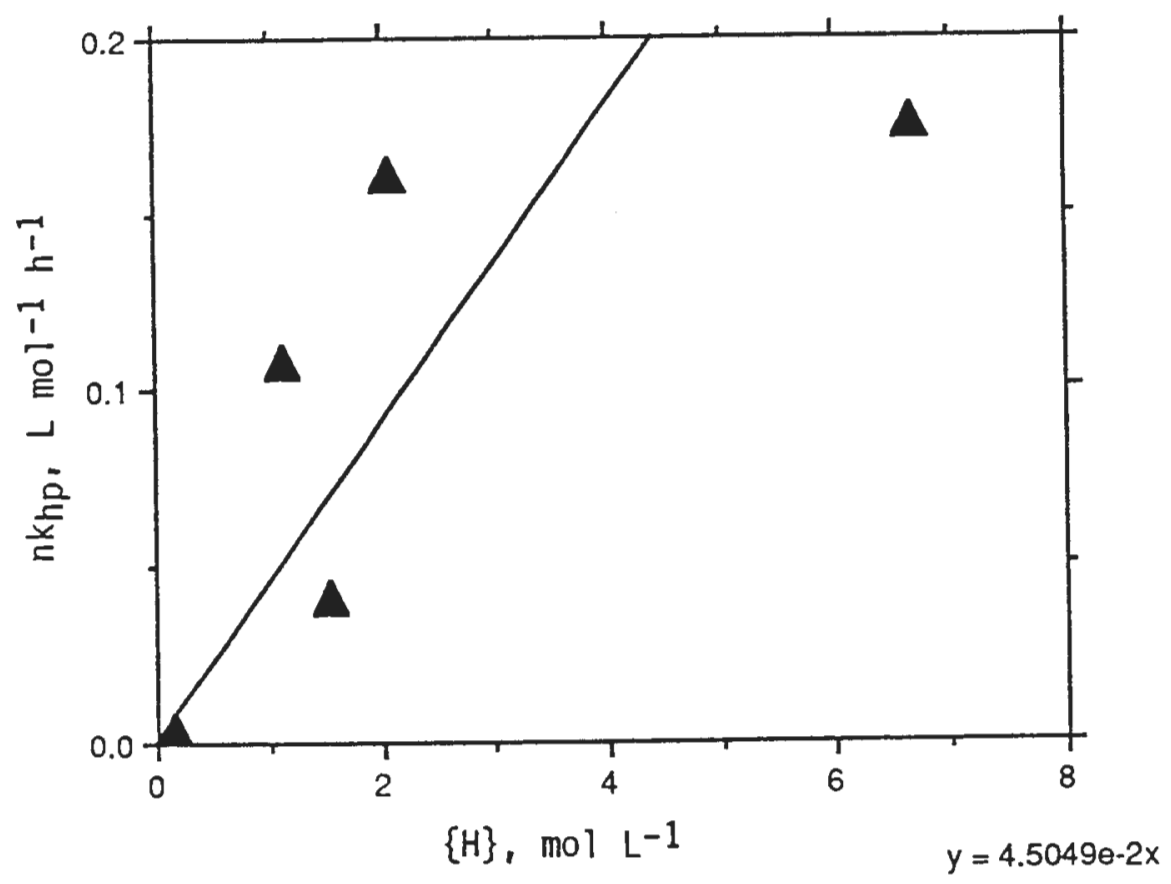

Fig. IV-74. Rate Constant, $\mathrm{nk}_{\mathrm{h}}$, for Hydrolysis of CMPO at $95^{\circ} \mathrm{C}$. Correlation between $\mathrm{nk}_{\mathrm{hp}}$ and $\{\mathrm{H}\}$ expressed by Eq. IV-24.

The dependence of $\mathrm{k}_{\mathrm{h}}$ on temperature was correlated by an Arrhenius equation:

$$
k_{h}=A e^{-E / R T}
$$


or

$$
n k_{h}=n A e^{-E / R T}
$$

and

$$
-\ln n k_{h}=E / R T \quad-\ln n A
$$

Values for $\mathrm{nA}$ and $\mathrm{E}$ were obtained from the graph of $-\ln n \mathrm{k}_{\mathrm{h}}$ as a linear function of $1 / \mathrm{T}$, shown in Fig. IV-75.

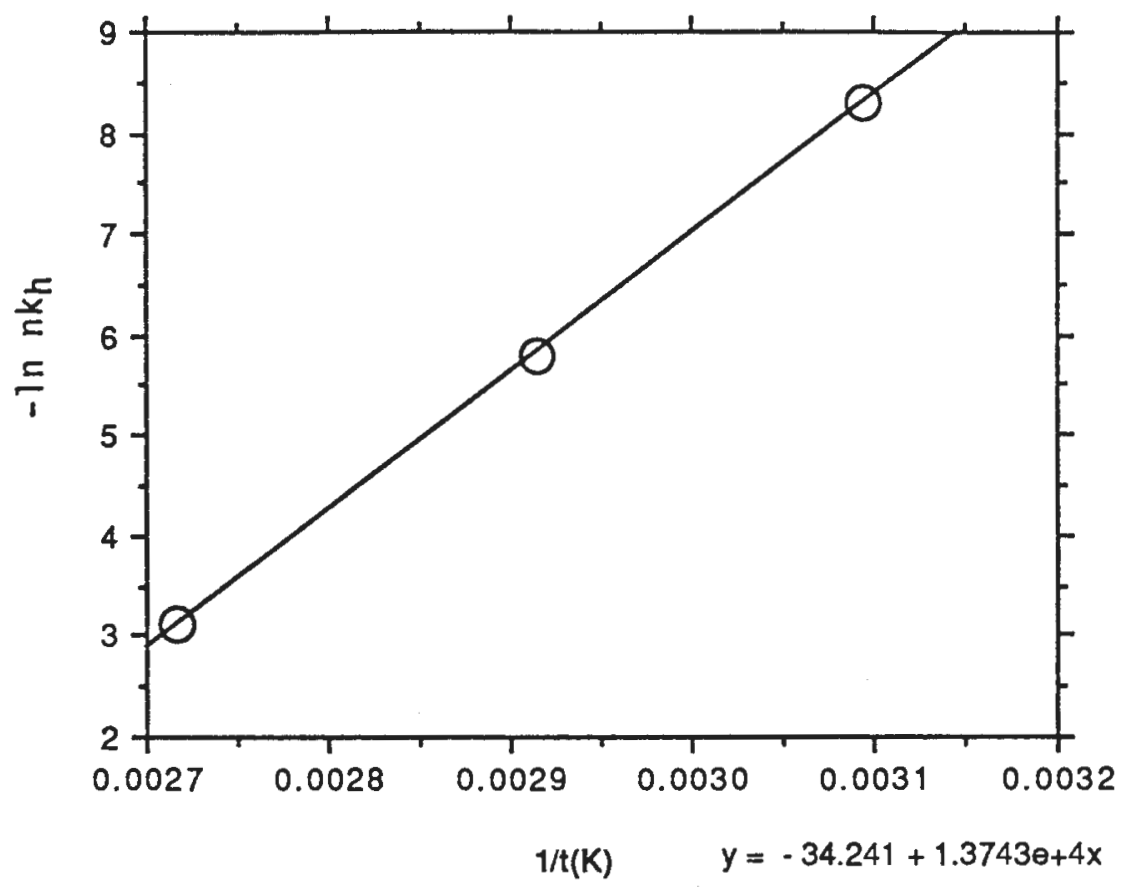

Fig. IV-75. Correlation between Temperature and $\ln n k_{\mathrm{h}}$ Used to Determine $A$ and $E$ for Eq. IV-27. A and $E$ are subsequently used for calculating concentration of CMPO as function of hydrolysis time. Values of $\ln n_{k}$ used here were based on values of $k_{h}$ in units of $\mathrm{L} \mathrm{mol}^{-1} \mathrm{~h}^{-1}$.

Combining equations IV-16, IV-23, and IV-25, the expression for the concentration of CMPO remaining in NPH solvent after hydrolysis during a time period $t$ is

$$
C=C_{0} e^{-A e^{-E / R T}}\{H\} t
$$

where $\mathrm{R}=8.323 \mathrm{~J} \mathrm{~mol}^{-1} \mathrm{deg}^{-1}\left(1.987 \mathrm{cal} \mathrm{mol}^{-1} \operatorname{degree}^{-1}\right)$

$\mathrm{T}=$ temperature, degrees Kelvin = degrees centigrade +273.12

$\mathrm{t}=$ hydrolysis time, $\mathrm{s}(\mathrm{h})$

$\{\mathrm{H}\}=$ activity of hydrogen ion in the aqueous phase in equilibrium with solvent, $\mathrm{mol} \mathrm{L}^{-1}$ 
And for the case in which $\mathrm{D}_{\mathrm{Am}}{ }^{2.0}$ varies with the third power of $\mathrm{C}(\mathrm{i} . \mathrm{e} ., \mathrm{n}=3$ ), fitting Eq. IV-27 yields the following:

$$
\begin{aligned}
& \mathrm{A}=6.86 \times 10^{10} \mathrm{~L} \mathrm{~mol}^{-1} \mathrm{~s}^{-1}\left(2.47 \times 10^{14} \mathrm{~L} \mathrm{~mol}^{-1} \mathrm{~h}^{-1}\right) \\
& \mathrm{E}=1.14 \times 10^{5} \mathrm{~J} \mathrm{~mol}^{-1}\left(27.3 \times 10^{3} \mathrm{cal} \mathrm{mol}^{-1}\right)
\end{aligned}
$$

4. Calculated $\mathrm{D}_{\mathrm{Am}}^{2.0}$ Values

The validity of the correlation constants in representing the performance of degraded solvent can be judged by comparing observed values of $D_{A m}$ with values of $D_{A m}$ in which $C$ is derived from Eq. IV-28. Considering the relationship between $\mathrm{D}_{\mathrm{Am}}$ and $\mathrm{CMPO}$ concentration given in Eq. IV-18, Eq. IV-28 yields

$$
\frac{\mathrm{C}}{\mathrm{C}_{\mathrm{o}}}=\mathrm{e}^{-\mathrm{Ae^{-E } / \mathrm { RT }}}\{\mathrm{H}\} \mathrm{t}=\frac{\left[\mathrm{D}_{\mathrm{Am}}^{2.0}\right]^{1 / \mathrm{n}}}{\left[\mathrm{D}_{\mathrm{Am}}^{2.0}\right]^{1 / n}}
$$

Then,

$$
\left[D_{A m}^{2.0}\right]^{1 / n}=\left[D_{A_{0}}^{2.0}\right]^{1 / n} e^{-A e^{-E / R T}} \quad\{H\} t
$$

The experimental values of $\mathrm{D}_{\mathrm{Am}}{ }^{2.0}$ are compared with values calculated by Eq. IV-30 in Fig. IV-76.

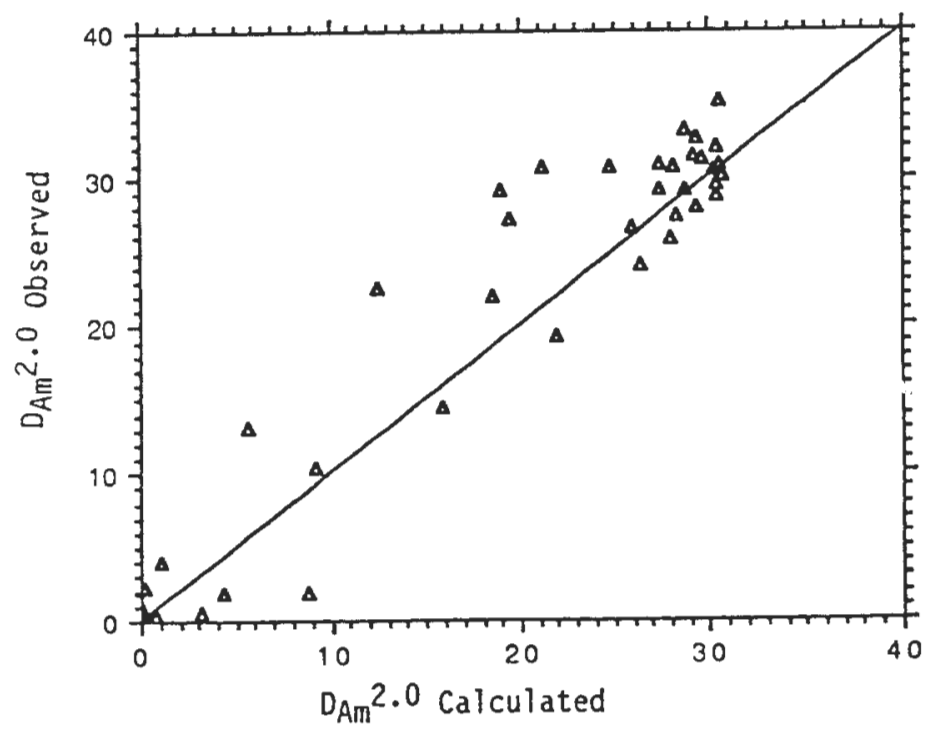

Fig. IV-76. Comparison of Calculated Values for $\mathrm{D}_{\mathrm{Am}}{ }^{2.0}$ with Observed Values Obtained for Solvent Degraded by Hydrolysis at $50-95^{\circ} \mathrm{C}$. The points are determined by the number pairs ( $\mathrm{D}_{\mathrm{Am}}{ }^{2.0}$ observed, $\mathrm{D}_{\mathrm{Am}}{ }^{2.0}$ calculated). The line is determined by the condition ( $\mathrm{D}_{\mathrm{Am}}^{\mathrm{Am}} 2.0$ observed $=\mathrm{D}_{\mathrm{Am}} 2.0$ calculated). 


\section{APPLICATION OF EXPRESSIONS FOR RADIOLYSIS AND HYDROLYSIS TO PROCESSING SYSTEMS}

Operators of the TRUEX process will wish to estimate the changes that occur in TRUEX-NPH solvent during processing. Simultaneous actions of hydrolysis and radiolysis during processing will decrease CMPO concentration and increase the concentration of CMPO decomposition products. Equations for calculating CMPO concentrations are derived in Appendix C. These changes will significantly affect the extraction properties of TRUEX-NPH solvent, depending on the conditions used in extraction. In the present study, the extraction properties of the solvent are evaluated by the distribution ratios of americium between degraded solvent and nitric acid solutions of $0.01,0.05$, and $2.0 \mathrm{M} \mathrm{HNO}_{3}$, namely, values of $\mathrm{D}_{\mathrm{Am}}{ }^{.01}, \mathrm{D}_{\mathrm{Am}}{ }^{.05}$, and $\mathrm{D}_{\mathrm{Am}}{ }^{2.0}$. Furthermore, the values of $\mathrm{D}_{\mathrm{Am}}{ }^{2.0}$, under the assumptions described in Sec. IV.C.3, are also used to express the change in CMPO concentration during a process cycle.

From experimental observation of radiolysis and hydrolysis, algorithms were derived for calculating the $D_{A m}$ values listed above. Algorithms expressing these $D_{A m}$ values as a function of dose alone are described in Section III. Also, algorithms expressing these $D_{A m}$ values as a function of hydrolytic effects alone are described in Section IV. These two types of equations are combined to express the value of $D_{A m}$ after completion of a cycle because solvent changes result from both radiolysis and hydrolysis in the extraction, scrub, strip, and rinse sections of a cycle.

The algebraic expression of $D_{A m}{ }^{.01}$ as a function of dose alone is described in Sec. III.C. and as a function of hydrolysis alone in Sec. IV.C. Derivation of the combination of these two types of equations is described in Appendix D. Thus, the value of $D_{A m}{ }^{.01}$ that should be exhibited by solvent after passing through one process cycle is represented by

$$
\begin{aligned}
D_{A_{r}}^{.01}=D_{A_{0}}^{.01}+k_{r}^{.01}(P) & \left(N_{n}\right]\left[t_{s}\right]+A_{0}^{.01} e^{-E / R T}\left[N_{n}+N_{b}+N_{P}+N_{r}\right\} t_{s} \\
& +A .01 e^{-E / R T}\left[\left\{H_{n}\right\} N_{n}+\left\{H_{b}\right\} N_{b}+\left\{H_{p}\right\} N_{p}+\left\{H_{r}\right\} N_{r}\right\}_{s}
\end{aligned}
$$

$$
\text { where } \begin{aligned}
\mathrm{D}_{\mathrm{Am}_{\mathrm{o}}}^{.01} & =0.0115 \\
\mathrm{R} & =8.323 \mathrm{~J} \mathrm{~mol}^{-1} \mathrm{deg}^{-1}\left(1.987 \mathrm{cal} \mathrm{mol}^{-1} \mathrm{deg}^{-1}\right) \\
\mathrm{T} & =\text { temperature, } \mathrm{K} \\
\mathrm{t}_{\mathrm{s}} & =\text { residence time of solvent in any stage, } \mathrm{s}(\mathrm{h}) \\
\{\mathrm{H}\} & =\text { hydrogen ion activity, mol L-1 } \\
\mathrm{N} & =\text { number of stages in a section } \\
\mathrm{P} & =\text { absorbed dose rate to solvent in extraction section, } \mathrm{W} \mathrm{L}^{-1} \\
\mathrm{k}_{\mathrm{r}}^{\prime} .01 & =5.64 \times 10^{-5} \mathrm{~L} \mathrm{~W}^{-1} \mathrm{~s}^{-1}\left(0.203 \mathrm{~L} \mathrm{~W}^{-1} \mathrm{~h}^{-1}\right) \\
\mathrm{A}_{\mathrm{o}}^{.01} & =6.97 \times 10^{4} \mathrm{~s}^{-1}\left(2.508 \times 10^{8} \mathrm{~h}^{-1}\right) \\
\mathrm{A}^{.01} & =1.30 \times 10^{3} \mathrm{~L} \mathrm{~mol}^{-1} \mathrm{~s}^{-1}\left(4.686 \times 10^{6} \mathrm{~L} \mathrm{~mol}^{-1} \mathrm{~h}^{-1}\right) \\
\mathrm{E}_{\mathrm{o}}^{.01} & =6.20 \times 10^{4} \mathrm{~J} \mathrm{~mol}^{-1}\left(1.481 \times 10^{4} \mathrm{cal} \mathrm{mol}^{-1}\right)
\end{aligned}
$$




$$
\mathrm{E}^{.01}=5.94 \times 10^{4} \mathrm{~J} \mathrm{~mol}^{-1}\left(1.417 \times 10^{4} \mathrm{cal} \mathrm{mol}^{-1}\right)
$$

Subscripts $n, b, p$, and $r$ indicate extraction, scrub, strip, and rinse sections, respectively.

A sample calculation using typical parameters with Eq. V-1 is given in Appendix D.1. During one cycle, the value of $\mathrm{D}_{\mathrm{Am}} .01$ increases by almost $30 \%$. This relatively large change is associated with a very small change in the CMPO concentration (as inferred from $D_{A m}$ measurements) and, therefore, a relatively small increase in concentration of CMPO decomposition products. This relationship agrees with other observations [NASH] that the acidic products of CMPO decomposition, which would be least repressed in low acid media, must be very powerful extractants.

An expression characterizing the $D_{A m} .05$ expected for solvent that had passed through a process cycle was also developed by combining an algorithm representing the $\mathrm{D}_{\mathrm{Am}}{ }^{.05}$ for solvent that had been degraded by radiolysis alone (Sec. III.C) and an algorithm representing the $\mathrm{D}_{\mathrm{Am}}{ }^{.05}$ for solvent that had been degraded by hydrolysis alone (Sec. IV.C). The derivation is described in Appendix D. The value of the $\mathrm{D}_{\mathrm{Am}}{ }^{.05}$ for solvent degraded by passing through one process cycle consisting of extraction, scrubbing, stripping, and rinsing stages has a different dependence on $\{H\}$ than $D_{A m}{ }^{.01}$ and is represented by

$$
\mathrm{D}_{\mathrm{Am}}^{.05}=\mathrm{D}_{\mathrm{Am}}^{.05}+\mathrm{k}_{\mathrm{r}} .05(\mathrm{P})\left(\mathrm{N}_{\mathrm{n}}\right)\left[\mathrm{t}_{s}\right)+\mathrm{A}_{\mathrm{O}}^{.05} \mathrm{e}^{-\mathrm{E}_{0}^{.05} / \mathrm{RT}}\left(\mathrm{N}_{\mathrm{D}}+\mathrm{N}_{\mathrm{b}}+\mathrm{N}_{\mathrm{P}}+\mathrm{N}_{r}\right\} \mathrm{t}_{s}
$$

$$
\text { where } \begin{aligned}
\mathrm{D}_{\mathrm{Am}_{\mathrm{O}}}{ }^{.05} & =0.231 \\
\mathrm{~A}_{\mathrm{o}}^{.05} & =5.92 \times 10^{2} \mathrm{~s}^{-1}\left(2.131 \times 10^{6} \mathrm{~h}^{-1}\right) \\
\mathrm{E}_{\mathrm{o}} .05 & =5.01 \times 10^{4} \mathrm{~J} \mathrm{~mol}^{-1}\left(1.197 \times 10^{4} \mathrm{cal} \mathrm{mol}^{-1}\right) \\
\mathrm{k}_{\mathrm{r}} .05 & =8.78 \times 10^{6} \mathrm{~L} \mathrm{~W}^{-1} \mathrm{~s}^{-1}\left(0.0316 \mathrm{~L} \mathrm{~W}^{-1} \mathrm{~h}^{-1}\right)
\end{aligned}
$$

In addition, $P, R, T, N_{n}, N_{b}, N_{p}, N_{r}$, and $t_{s}$ have the same values as listed for Eq. IV-1.

A sample calculation with Eq. V-2 using typical parameters is described in Appendix D. In the course of one cycle, $D_{A m}{ }^{.05}$ increases by about $1 \%$. The much larger change for $D_{A m}{ }^{.01}$ compared with $\mathrm{D}_{\mathrm{Am}}{ }^{.05}$ is consistent with theories that the nonacidic products of CMPO degradation, which would be more important for extractions in $0.05 \underline{\mathrm{M}}$ than in $0.01 \underline{\mathrm{M}} \mathrm{HNO}_{3}$, are less powerful extractants than the acidic products.

An expression characterizing the CMPO concentration expected for solvent that had passed through a process cycle was also developed (see Appendix C) by combining an algorithm representing the CMPO concentration in solvent that had been degraded by radiolysis alone (Sec. III.C) and an algorithm representing the CMPO concentration for solvent that had been degraded by hydrolysis alone (Sec. IV.C). The value of the CMPO concentration for solvent degraded by passing through one process cycle consisting of extraction, scrubbing, stripping, and rinsing stages is represented by 


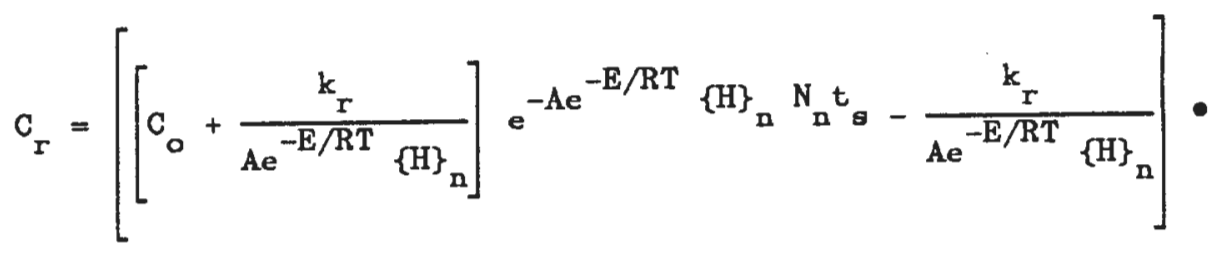

$$
\begin{aligned}
& \left.\left.e^{-\left[( A e ^ { - E / R T } ] [ t _ { s } ] \left[\left\{H_{b} N_{b}+\{{ }\}_{p} N_{p}+\{H\}\right.\right.\right.}{ }_{r} N_{r}\right]\right]
\end{aligned}
$$

where $C_{0}=0.20 \mathrm{~mol} \mathrm{~L}^{-1}$

$$
\begin{aligned}
A= & 6.86 \times 10^{10} \mathrm{~L} \mathrm{~mol}^{-1} \mathrm{~s}^{-1}\left(2.47 \times 10^{14} \mathrm{~L} \mathrm{~mol}^{-1} \mathrm{~h}^{-1}\right) \\
k_{\mathrm{r}}= & (\mathrm{G})(\mathrm{M})(\mathrm{P})^{*}=7.8 \times 10^{-8} \mathrm{P} \mathrm{mol} \mathrm{W} \mathrm{W}^{-1} \mathrm{~s}^{-1}\left(2.8 \times 10^{-4} \mathrm{P} \mathrm{mol} \mathrm{W}^{-1} \mathrm{~h}^{-1}\right) \\
& \text { where } \mathrm{P}=\text { absorbed dose rate to solvent, } \mathrm{W} \mathrm{L}^{-1} \\
\mathrm{E}= & 1.14 \times 10^{5} \mathrm{~J} \mathrm{~mol}^{-1}\left(27.3 \times 10^{3} \mathrm{cal} \mathrm{mol}^{-1}\right)
\end{aligned}
$$

Values for the other parameters are the same as given earlier.

The results of sample calculations for typical process conditions using Eq. V-3 are given in Appendix C. These calculations yielded numerical values for CMPO concentration and also for the fraction of CMPO remaining after 1 to 100 cycles. For these calculations, the CMPO concentration for solvent exiting the first cycle was used as the CMPO concentration for solvent entering the second cycle, etc. The results show that the fraction of CMPO decomposed at the end of cycle 100 , corresponding to about one year of processing according to the assumptions described in Appendix $\mathrm{C}$, is $8.6 \times 10^{-4}$. 


\section{EFFECTS OF WASHING DEGRADED SOL VENTS}

The effectiveness of removing the products of CMPO degradation by washing was tested on some of the distribution systems that were exposed to radiolysis or hydrolysis. Since some of the products are known to be acidic, the effect of a basic wash (i.e., aqueous sodium carbonate solution) is of interest. There is a precedent for the use of aqueous sodium carbonate washes for restoring solvent performance: they have been employed routinely on a plant scale to remove the acidic products of TBP radiolysis that occur in the solvent extraction processes applied to reprocessing of irradiated fuels [STEVENSON]. Furthermore, recent tests on a laboratory scale [NASH] with solvent mixtures similar to the one of interest here have demonstrated partial removal of the degradation products of CMPO by carbonate washing.

In the work described here, the effect of carbonate washing was observed for a limited set of conditions, including solvent that had been hydrolyzed in contact with 2.5 and $6.0 \mathrm{M} \mathrm{HNO}_{3}$ at temperatures of 50 and $70^{\circ} \mathrm{C}$ and solvent that had been irradiated in contact with $0.25,2.5$, and $6.0 \mathrm{M}$ $\mathrm{HNO}_{3}$. Appendix $\mathrm{E}$ includes graphical comparisons of $\mathrm{D}_{\mathrm{Am}}$ values obtained with degraded solvent washed with carbonate and degraded solvent not washed with carbonate. Figure VI-1 presents the $\mathrm{D}_{\mathrm{Am}}{ }^{.01}$ values for carbonate-washed solvents that had been degraded by radiolysis. Similarly, Fig. VI-2 presents the $\mathrm{D}_{\mathrm{Am}}{ }^{.05}$ values for carbonate-washed solvents that had been degraded by radiolysis.

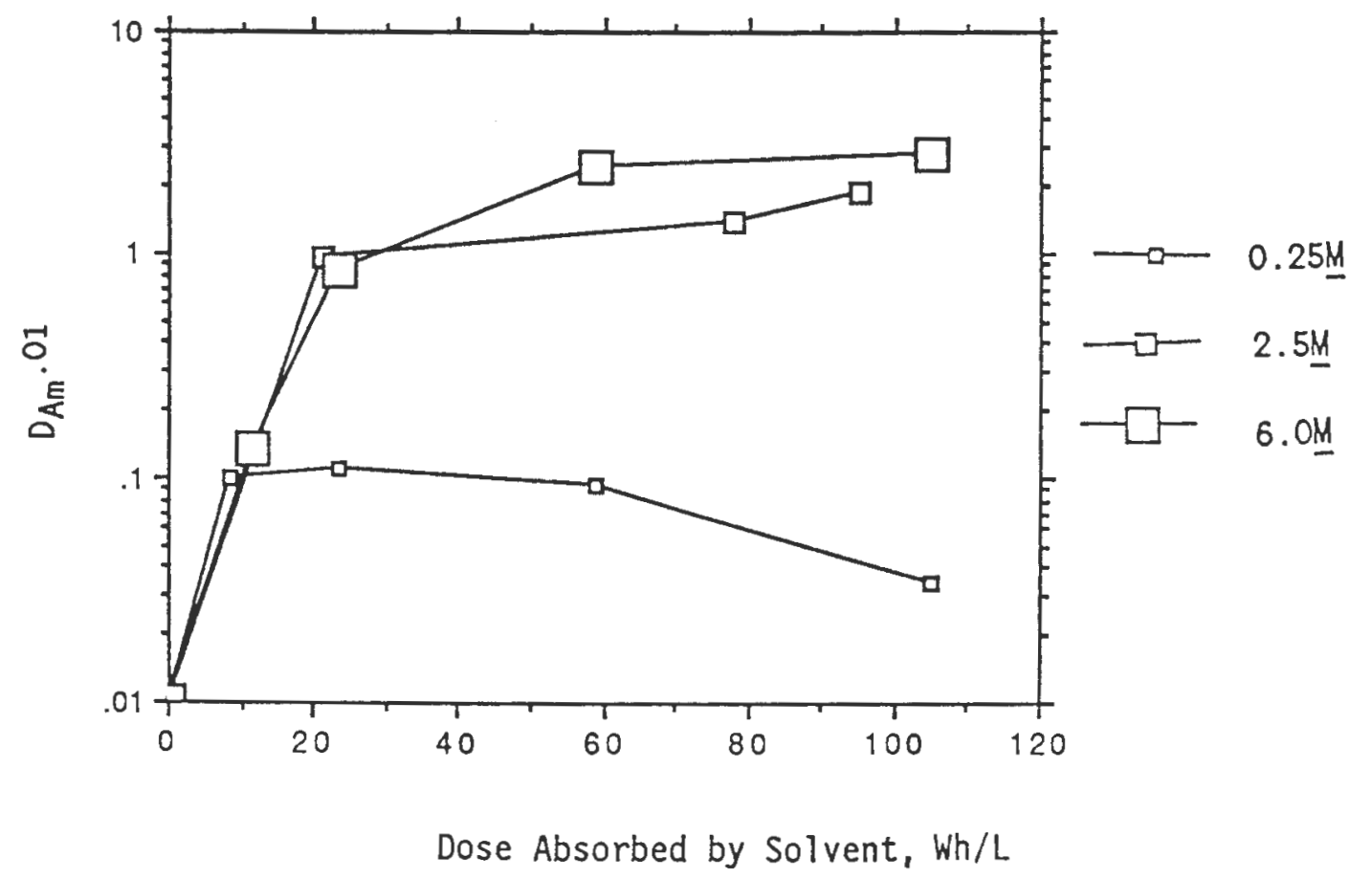

Fig. VI-1. Graph of $\mathrm{D}_{\mathrm{Am}}^{.01}$ as Function of Dose and Concentration of Acid in Contact with Solvent during Irradiation. Solvent washed with aqueous carbonate following irradiation. 


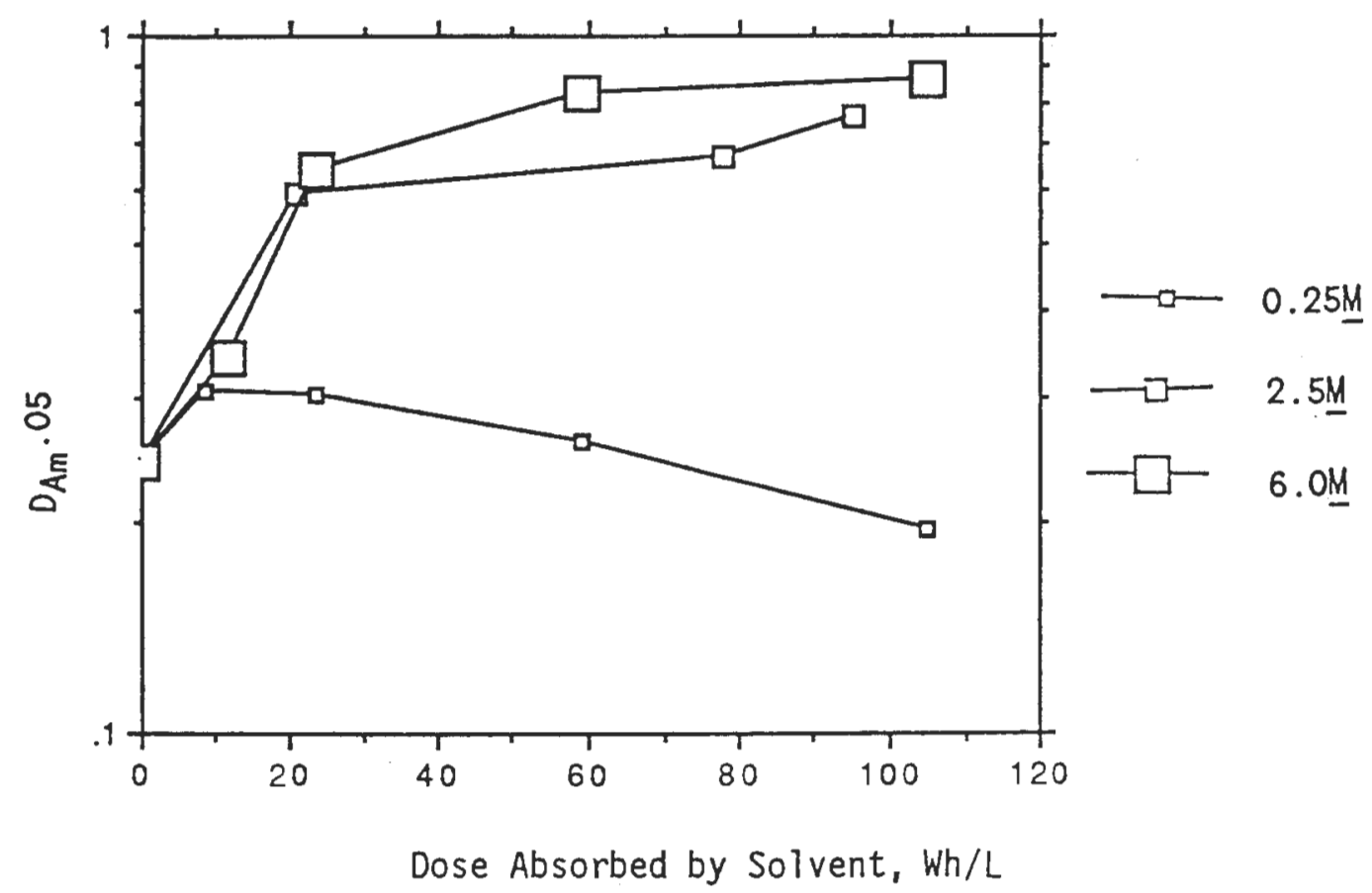

Fig. VI-2. Graph of $\mathrm{D}_{\mathrm{Am}}{ }^{.05}$ as Function of Dose and Concentration of Acid in Contact with Solvent during Irradiation. Solvent washed with aqueous carbonate following irradiation.

From Figs. VI-1, VI-2, and those presented in Appendix E, some generalizations are made concerning the effects of carbonate washing of degraded solvents. These distribution measurements involve solvent samples that have the same degradation history; thus, the same mixture of extractants is present in both, but the behavior of that mixture of extractants depends on the acid concentration used in measuring the $\mathrm{D}_{\mathrm{Am}}$. The following generalizations are made:

(1) $\mathrm{D}_{\mathrm{Am}}{ }^{.01}$ and $\mathrm{D}_{\mathrm{Am}}{ }^{.05}$ generally increase with the extent of degradation. This behavior is consistent with information from another source [NASH], which reported that acidic products can act as extractants at these low acidities and that the concentrations of acidic products increase with the extent of solvent degradation.

(2) Washing with aqueous carbonate generally decreases the $\mathrm{D}_{\mathrm{Am}}$ values obtained with solvent that has been subjected to hydrolysis or radiolysis. The effects of degradation and washing can be judged by comparing any $D_{A m}$ value with the $D_{A m_{0}}$ value obtained at the same acid concentration. The $\mathrm{D}_{\mathrm{Am}_{\mathrm{O}}}$ values determined for fresh solvent are listed in Appendix B.

(3) For systems hydrolyzed at $50^{\circ} \mathrm{C}$, the $\mathrm{D}_{\mathrm{Am}}$ shows little dependence on hydrolysis time, regardless of whether the degraded solvent was washed with carbonate or not. This behavior can be expected, since the rate of hydrolysis is low at $50^{\circ} \mathrm{C}$.

(4) All $\mathrm{D}_{\text {Am }}$ values for degraded solvents fall into two groups corresponding to the two acid concentrations, 0.01 and $0.05 \mathrm{M}$, used in determining the $\mathrm{D}_{\mathrm{Am}}$ distribution. This behavior is assumed to be consistent with the response of acidic extractants to the aqueous acid concentration used in the distribution measurement. 
(5) $\mathrm{D}_{\mathrm{Am}} .01$ increases at a higher rate with degradation than $\mathrm{D}_{\mathrm{Am}} .05$, as might be expected, because at $0.01 \underline{\mathrm{M}} \mathrm{HNO}_{3}$ the highly effective acidic extractants have a better chance to operate.

(6) The values of $\mathrm{D}_{\mathrm{Am}}{ }^{.05}$ in many cases are not much greater than the $\mathrm{D}_{\mathrm{Am}_{\mathrm{o}}}^{.05}$ value. On the other hand, the values of $\mathrm{D}_{\mathrm{Am}}{ }^{.01}$ are more sensitive indicators of the presence of acidic extractants and become much greater than those of $\mathrm{D}_{\mathrm{Am}} .01$ as solvent degradation increases. These relatively high values of $\mathrm{D}_{\mathrm{Am}}{ }^{.01}$ are significantly lowered by carbonate washing, but they are still greater than the corresponding $\mathrm{D}_{\mathrm{Am}_{\mathrm{O}}}^{.01}$ values, indicating that carbonate washing is not $100 \%$ effective. 


\section{CHANGE OF ACIDITY ACCOMPANYING RADIOLYSIS AND HYDROLYSIS}

As degradation of TRUEX-NPH solvent in contact with aqueous solution proceeds, the acidities of both phases also change. The cause of this acidity change has been mainly attributed to the transformation of organic molecules followed by redistribution of acidic species between organic and aqueous phases [NASH]. For several organic-aqueous pairs subjected to radiolysis or hydrolysis, acidity changes in the organic phase were measured. After hydrolysis, samples of the organic phase were removed and washed, and the washings were analyzed for acidity. In two cases, the aqueous phase in contact with solvent that had undergone radiolysis was analyzed for acidity. For these cases, the observed increase of acidity in the aqueous phase was expressed as a $G$ value for radiolysis.

\section{A. Changes in Acidity of Aqueous Phase in Contact with TRUEX-NPH Solvent During Radiolysis}

The acidity of aqueous solution in contact with TRUEX-NPH solvent was measured by titration with a standard aqueous base as described in Appendix F. The behavior of two aqueous samples having different initial concentrations of $\mathrm{HNO}_{3}(0.25 \mathrm{M}$ and $6.0 \mathrm{M})$ was observed in this work. Information on the extraction of nitric acid by TRUEX-NPH solvent indicates that distribution of $\mathrm{HNO}_{3}$ between phases would convert these aqueous concentrations to $0.208 \mathrm{M}$ and $4.59 \underline{\mathrm{M}}$. For both solutions, irradiation increased the concentration of $\mathrm{H}^{+}$above these values.

The information on acidity as a function of dose was used to calculate a $G$ value for the increase of $\mathrm{H}^{+}$in the aqueous phase as described in Appendix F. For the solution with an initial concentration of $0.25 \mathrm{M}$, a $\mathrm{G}$ value of $1.2 \times 10^{-7} \mathrm{~mol} \mathrm{~J}^{-1}\left(1.2 \mathrm{H}^{+}\right.$ions per $\left.100 \mathrm{eV}\right)$ was obtained. Using this $\mathrm{G}$ value and the equation

$$
C-C_{0}=(G)(M)(P)(t)
$$

which is analogous to Eq. III-9, and, in the present application, $\mathrm{C}=\left[\mathrm{H}^{+}\right]$and $\mathrm{C}_{\mathrm{o}}=$ initial $\left[\mathrm{H}^{+}\right]$, it is estimated that in a solution with an initial concentration of $0.25 \mathrm{M} \mathrm{HNO}_{3}$, which exposes the solvent to an absorbed dose rate ${ }^{*}$ of $0.1 \mathrm{~W} \mathrm{~L}^{-1}$, the $\left[\mathrm{H}^{+}\right]$would increase at a rate of $1 \times 10^{-8} \mathrm{~mol} \mathrm{~L}^{-1} \mathrm{~s}^{-1}\left(4 \times 10^{-5} \mathrm{~mol}\right.$ $\left.\mathrm{L}^{-1} \mathrm{~h}^{-1}\right)$.

\section{B. Changes in Acidity of Organic Phase During Hydrolysis}

The change in acidity of the organic phase accompanying hydrolysis was determined, as described in Appendix F, for TRUEX-NPH solvent hydrolyzed while in contact with nitric acid solutions having

\footnotetext{
"In the absence of information on absorbed dose rate for solvent from high-level wastes that are candidates for application of TRUEX, the value of $0.1 \mathrm{~W} \mathrm{~L}^{-1}$, derived from other studies of the effect of processing on solvents [VAN GEEL], is adopted for sample calculations. This value is considered to be a conservative estimate; it represents experience in the processing of thermal reactor fuels. Furthermore, this value falls in the range of values of absorbed dose rates given in an earlier review of solvent stability in processing of thermal reactor fuels [BLAKE]. A lower value would probably be encountered in the processing of high-level wastes that have been stored for many years.
} 
concentrations of $0.25,2.5$, and $6.0 \mathrm{M}$ at temperatures of 50,70 , and $95^{\circ} \mathrm{C}$. The concentrations of $\mathrm{H}^{+}$in the aqueous washings, measured by titration with an aqueous solution of standard base, are considered to indicate the concentration of $\mathrm{HNO}_{3}$ in the organic phase. Furthermore, the decrease in concentration is assumed to result from the complexing agent or agents, present initially, that become less available for complexing $\mathrm{HNO}_{3}$ as hydrolysis proceeds. The decrease may also result from disappearance of $\mathrm{HNO}_{3}$ from the system (e.g., by decomposition).

The variations of acidity in the organic phase with hydrolysis time are shown graphically in Appendix F. No attempt is made to derive an algebraic expression for rate of acidity change with hydrolysis time, but some general trends in the data are evident. At $0.25 \underline{\mathrm{M}} \mathrm{HNO}_{3}$, there is little change in acidity accompanying hydrolysis at $50^{\circ}$ and $70^{\circ} \mathrm{C}$; furthermore, the rate of acidity change accompanying hydrolysis at $95^{\circ} \mathrm{C}$ seems inconsistent with results at the two lower temperatures.

At $2.5 \mathrm{M} \mathrm{HNO}_{3}$, the acidity for hydrolysis at $70^{\circ} \mathrm{C}$ and $95^{\circ} \mathrm{C}$ definitely decreases to a level that does not change after about $200 \mathrm{~h}$. The initial rates of acidity change increase in the order $50<70<95^{\circ} \mathrm{C}$, whereas the final rates depend on temperature in the order $50>70>95^{\circ} \mathrm{C}$. For example, at $70^{\circ} \mathrm{C}$ the final acidity is about $87 \%$ of the initial, and at $95^{\circ} \mathrm{C}$ the final acidity is about $37 \%$ of the initial.

At $6.0 \mathrm{M} \mathrm{HNO}_{3}$, the general trends are similar to those described for hydrolysis with solvent in contact with $2.5 \mathrm{M} \mathrm{HNO}_{3}$. At $70^{\circ} \mathrm{C}$ the final acidity is about $73 \%$ of the initial, and at $95^{\circ} \mathrm{C}$ the final acidity is about $25 \%$ of the initial. 


\section{EFFECTS OF SOLVENT DEGRADATION ON DISTRIBUTION BEHAVIOR OF NONTRANSURANIC ELEMENTS}

For some of the TRUEX-NPH samples that had been degraded in the presence of simulated CAW, the organic phase was analyzed to provide observations concerning the effect of solvent degradation on extraction behavior of the nonTRU elements in wastes. The simulated CAW was an aqueous solution containing a mixture of salts with the composition expected for the CAW waste stream stored on the Hanford site. Samples of the simulated CAW had two acid concentrations, 1.6 and 2.6푸 the salt concentrations were the same in both cases.

The procedures used to make these observations consisted of stirring TRUEX-NPH in contact with a CAW solution for a measured time at a constant temperature of 50,70 , or $95^{\circ} \mathrm{C}$, then separating a sample of the organic phase and washing it with several portions of water. The collected washings were diluted to a standard volume, and an aliquot of this volume was removed and analyzed by the ICP method for a number of elements.

The ICP analyses of concentrations in the washings were used to calculate concentrations of each element in the solvent. The volumes of solvent sample, collected washings of the sample, and aliquots of the washings were used for these analyses.

The behavior of nonTRU elements obtained from this work was examined for the concentration variation with hydrolysis time (i.e., with the extent of solvent degradation). It was found that the elements present in the CAW solutions fall into two general types: those whose concentrations are measurable and can be represented as a function of hydrolysis time and those whose concentrations are so low that ICP analysis permits their expression only as maximum values that do not vary with hydrolysis time and do not depend regularly on temperature.

Graphs illustrating these two types of behavior are presented in Appendix G. Elements with measurable concentrations include several rare earths: Y, La, Ce, Pr, Sm, and Eu. As expected, the rare earths behave similarly, and some generalities can be expressed. (1) The concentration is inversely dependent on hydrolysis temperature. (2) At a constant hydrolysis temperature, the concentration is inversely dependent on acid concentration, the solutions hydrolyzed by $1.6 \mathrm{M}$ acid showing greater values than those hydrolyzed by $2.6 \mathrm{M}$ acid. (3) The concentrations are little affected by solvent degradation, declining slightly as hydrolysis time, and thus extent of solvent degradation, increases. The elements $\mathrm{Al}$, $\mathrm{Fe}$, and $\mathrm{Zr}$ also have measurable concentrations, but the shapes of the graphs of concentration versus time differ from those of the rare earths; generalities are not obvious.

The elements that exhibit the second type of behavior include $\mathrm{Ag}, \mathrm{Ca}, \mathrm{Mg}, \mathrm{Rh}, \mathrm{Ru}, \mathrm{Cr}, \mathrm{Ni}, \mathrm{Sr}, \mathrm{Mn}$, $\mathrm{Be}, \mathrm{Cd}, \mathrm{Pd}, \mathrm{Cu}, \mathrm{Mo}, \mathrm{Ba}$, and $\mathrm{Ti}$. The concentrations are generally about the same for $1.6 \mathrm{M}$ acid as for 2.6M acid. Given the limitations of the analysis for these elements, small differences should not be

considered significant. These maximum concentrations range from about $1 \times 10^{-5}$ to about $2 \times 10^{-3} \underline{\mathrm{M}}$. 


\section{REFERENCES}

BLAKE

C. A. Blake, Jr., Solvent Stability in Nuclear Fuel Processing: Evaluation of the Literature, Calculation of Radiation Dose, and Effects of Iodine and Plutonium, Oak Ridge National Laboratory Report ORNL-4212 (1968).

\section{CHIARIZIA}

R. Chiarizia and E. P. Horwitz, "Hydrolytic and Radiolytic Degradation of Octyl(Phenyl)-N,NDiisobutylcarbamoylmethylphosphine Oxide and Related Compounds", Solvent Extr. Ion Exch. $\underline{4}(4), 677-723$ (1986).

\section{GRANVILLE}

W. A. Granville, P. F. Smith, and W. R. Longley, Elements of Calculus, Ginn and Co., Athenaeum Press, Boston, pp. 379-380 (1946).

\section{NASH}

K.L. Nash, R. C. Gatrone, G.A. Clark, P. G. Rickert, and E. P. Horwitz, "Hydrolytic and Radiolytic Degradation of O $\phi D(i B) C M P O:$ Continuing Studies", Sep. Sci. Tech. 23 (12 \& 13), 1355(1988).

\section{STEVENSON}

R. L. Stevenson and P. E. Smith, Chapter 4, "Aqueous Separation", in Reactor Handbook, Second Ed., Vol. II, Fuel Reprocessing, S. M. Stoller and R. B. Richards, eds., Interscience Publishers, New York (1961).

\section{TREVORROW}

L. E. Trevorrow and G. F. Vandegrift, Alternatives for Disposal of Raffinate from the TRUEX Process, Argonne National Laboratory Report ANL-89/27 (1989).

\section{VANDEGRIFT}

G. F. Vandegrift, R. A. Leonard, M. J. Steindler, E. P. Horwitz, L. J. Basile, H. Diamond, D. G. Kalina, and L. Kaplan, Transuranic Decontamination of Nitric Acid Solutions by the TRUEX Solvent Extraction Process - Preliminary Development Studies, Argonne National Laboratory Report ANL-84-45 (1984).

\section{VAN GEEL}

J. van Geel, C. Joseph, E. Detilleux, W. Heinz, J. Centeno, and B. Gustafsson, Chemical Aspects of Solvent Extraction on Plant Scale at Eurochemic, in Proceedings of the International Solvent Extraction Conference ISEC 71, Vol. I, The Hague, April 19-23, 1971, Society of Chemical Industry, London (1971). 


\section{APPENDIX A. REAGENTS}

\section{Preparation of Simulated CAW Waste}

A solution that simulates the CAW waste stream stored on the Hanford site was prepared as a doubly concentrated stock solution. All nitrates, sulfates, and other water-soluble salts were dissolved in water. Special treatment was required to bring some elements into the solution; $\mathrm{Cs}_{2} \mathrm{CO}_{3}, \mathrm{TiO}_{2}$, and the metals $\mathrm{Sn}$ and $\mathrm{Sb}$ were dissolved in $20 \mathrm{~mL}$ of concentrated $\mathrm{H}_{2} \mathrm{SO}_{4} ; \mathrm{MoO}_{3}$ and $\mathrm{TeO}_{2}$ were each dissolved in $5 \mathrm{~mL}$ of $10 \mathrm{~N} \mathrm{NaOH}$; and $\mathrm{Na}_{2} \mathrm{SiO}_{3} \cdot 9 \mathrm{H}_{2} \mathrm{O}$ was dissolved in about $500 \mathrm{~mL}$ of water with about $50 \mathrm{~mL}$ of concentrated sulfuric acid. These solutions were combined with the solutions of soluble salts. Additional quantities of nitric and sulfuric acids were added finally, and the combined solutions were made up to a volume of $20 \mathrm{~L}$ with water.

Samples of simulated CAW solution to be used as the aqueous phase in hydrolysis or radiolysis experiments were prepared from the stock solution. An aliquot of the stock was mixed with a measured volume of $\mathrm{HNO}_{3}$ and the mixture was diluted to a standard volume. Mixtures of two different acid concentrations were prepared: 1.6 and $2.6 \mathrm{M}$; cation concentrations were half those in the original stock solution.

The composition of the doubly concentrated CAW stock solution is summarized in Tables A-1 and A-2.

Table A-1. Preparation of 20-L, Doubly Concentrated Synthetic CAW Feed Solution

\begin{tabular}{|c|c|c|c|}
\hline Ion & $\begin{array}{c}\text { Concentration, } \\
\underline{\mathrm{M}}\end{array}$ & Form of Addition & Amount Added \\
\hline \multicolumn{4}{|l|}{ Inert Cation } \\
\hline $\mathrm{H}(\mathrm{I})$ & 2.47 & $\mathrm{HNO}_{3}, \mathrm{H}_{2} \mathrm{SO}_{4}, \mathrm{HF}, \mathrm{H}_{2} \mathrm{C}_{2} \mathrm{O}_{4}$ & See Table II-3 \\
\hline $\mathrm{Fe}$ (III) & 0.26 & $\mathrm{Fe}\left(\mathrm{NO}_{3}\right)_{3} \bullet 9 \mathrm{H}_{2} \mathrm{O}$ & $2100.8 \mathrm{~g}$ \\
\hline $\mathrm{Cr}$ (III) & 0.026 & $\mathrm{Cr}\left(\mathrm{NO}_{3}\right)_{3} \bullet 9 \mathrm{H}_{2} \mathrm{O}$ & $\begin{array}{l}90.90 \text { g solid: } \\
480 \mathrm{~mL}(0.61 \underline{\mathrm{M}})\end{array}$ \\
\hline $\mathrm{Ni}$ (II) & 0.0138 & $\mathrm{Ni}\left(\mathrm{NO}_{3}\right)_{2} \cdot 6 \mathrm{H}_{2} \mathrm{O}$ & $80.26 \mathrm{~g}$ solid \\
\hline $\mathrm{Al}$ (II) & 0.71 & $\mathrm{Al}\left(\mathrm{NO}_{3}\right)_{3} \bullet 9 \mathrm{H}_{2} \mathrm{O}$ & $5327.2 \mathrm{~g}$ solid \\
\hline $\mathrm{Be}$ (II) & $2.6 \times 10^{-3}$ & $\mathrm{Be}\left(\mathrm{SO}_{4}\right) \bullet 4 \mathrm{H}_{2} \mathrm{O}$ & $9.21 \mathrm{~g}$ solid \\
\hline $\mathrm{Na}(\mathrm{I})$ & 0.380 & $\begin{array}{l}\mathrm{NaH}_{2} \mathrm{PO}_{4} \bullet 2 \mathrm{H}_{2} \mathrm{O} \\
\mathrm{NaHSO}_{4} \bullet \mathrm{H}_{2} \mathrm{O} \\
\mathrm{Na}_{2} \mathrm{SiO}_{3} \bullet 9 \mathrm{H}_{2} \mathrm{O} \\
\mathrm{NaOH}\end{array}$ & $\begin{array}{l}8.12 \mathrm{~g} \\
755.71 \mathrm{~g} \\
104.6 \mathrm{~g} \\
5.0 \mathrm{~mL}(10.0 \mathrm{M})\end{array}$ \\
\hline $\mathrm{Ca}$ (II) & $2.01 \times 10^{-3}$ & $\mathrm{Ca}\left(\mathrm{NO}_{3}\right)_{2} \bullet 4 \mathrm{H}_{2} \mathrm{O}$ & $9.47 \mathrm{~g}$ solid \\
\hline $\mathrm{Cu}(\mathrm{II})$ & $2.80 \times 10^{-3}$ & $\mathrm{CuSO}_{4} \cdot 5 \mathrm{H}_{2} \mathrm{O}$ & $13.98 \mathrm{~g}$ \\
\hline $\mathrm{Mg}$ (II) & $2.60 \times 10^{-3}$ & $\mathrm{MgSO}_{4}$ & $148.6 \mathrm{~mL}(0.35 \underline{\mathrm{M}})$ \\
\hline Mn (II) & $2.80 \times 10^{-3}$ & $\mathrm{MnSO}_{4} \cdot \mathrm{H}_{2} \mathrm{O}$ & $43.1 \mathrm{~mL}(1.30 \mathrm{M})$ \\
\hline Si (IV) & $1.84 \times 10^{-2}$ & $\mathrm{Na}_{2} \mathrm{SiO}_{3} \bullet 9 \mathrm{H}_{2} \mathrm{O}$ & 104.6 \\
\hline $\mathrm{Ti}$ & $4.00 \times 10^{-5}$ & $\begin{array}{r}\mathrm{TiO}_{2}\left(\mathrm{in} \mathrm{H}_{2} \mathrm{SO}_{4}\right) \\
\text { (contd) }\end{array}$ & $0.060 \mathrm{~g}$ \\
\hline
\end{tabular}


Table A-1. (contd)

\begin{tabular}{|c|c|c|c|}
\hline Ion & $\begin{array}{c}\text { Concentration, } \\
\underline{M}\end{array}$ & Form of Addition & Amount Added \\
\hline \multicolumn{4}{|l|}{ Fission Products } \\
\hline $\mathrm{Zr}(\mathrm{IV})$ & 0.0113 & $\mathrm{ZrO}\left(\mathrm{NO}_{3}\right)_{2} \bullet \mathrm{H}_{2} \mathrm{O}$ & $\begin{array}{l}19.943 \mathrm{~g} \text { plus } \\
1000 \mathrm{~mL} \text { soln } \\
(32.37 \mathrm{~g} / \mathrm{L})\end{array}$ \\
\hline $\mathrm{Cd}(\mathrm{II})$ & $1.00 \times 10^{-4}$ & $\mathrm{Cd}\left(\mathrm{NO}_{3}\right)_{2} \bullet 4 \mathrm{H}_{2} \mathrm{O}$ & $38.5 \mathrm{~mL}(0.052 \mathrm{M})$ \\
\hline $\mathrm{Nb}(\mathrm{V})$ & $1.88 \times 10^{-3}$ & $\mathrm{NbH}$ & $0.35 \mathrm{~g}$ in $\mathrm{H}_{2} \mathrm{SO}_{4}$ \\
\hline Mo (VI) & $3.60 \times 10^{-4}$ & $\mathrm{MoO}_{3}$ & $1.04 \mathrm{~g}$ in $\mathrm{NaOH}$ \\
\hline $\mathrm{Se}(\mathrm{IV})$ & $1.90 \times 10^{-4}$ & $\mathrm{H}_{2} \mathrm{SeO}_{3}$ & $0.49 \mathrm{~g}$ \\
\hline $\mathrm{Rb}(\mathrm{I})$ & $1.040 \times 10^{-3}$ & $\mathrm{RbNO}_{3}$ & $3.70 \mathrm{~g}$ \\
\hline Sr (II) & $2.80 \times 10^{-3}$ & $\mathrm{Sr}\left(\mathrm{NO}_{3}\right)_{2}$ & $11.86 \mathrm{~g}$ \\
\hline Y (III) & $1.48 \times 10^{-3}$ & $\mathrm{Y}\left(\mathrm{NO}_{3}\right)_{3} \bullet 6 \mathrm{H}_{2} \mathrm{O}$ & $11.33 \mathrm{~g}$ \\
\hline $\mathrm{Rh}$ (III) & $1.14 \times 10^{-3}$ & $\mathrm{Rh}\left(\mathrm{NO}_{3}\right)_{3} \bullet 2 \mathrm{H}_{2} \mathrm{O}(39.9 \% \mathrm{Rh})$ & $5.88 \mathrm{~g}$ \\
\hline $\mathrm{Pd}(\mathrm{II})$ & $1.14 \times 10^{-3}$ & $\mathrm{Pd}\left(\mathrm{NO}_{3}\right)_{2} \bullet \mathrm{H}_{2} \mathrm{O}(40.5 \% \mathrm{Pd})$ & $5.67 \mathrm{~g}$ \\
\hline $\mathrm{Ag}(\mathrm{I})$ & $7.2 \times 10^{-5}$ & $\mathrm{AgNO}_{3}$ & $0.2455 \mathrm{~g}$ \\
\hline Sn (IV) & $4.8 \times 10^{-5}$ & Sn (metal) & $0.11 \mathrm{~g}$ in $\mathrm{H}_{2} \mathrm{SO}_{4}$ \\
\hline $\mathrm{Sb}(\mathrm{V})$ & $2.4 \times 10^{-5}$ & Sb (metal) & $0.060 \mathrm{~g}$ in $\mathrm{H}_{2} \mathrm{SO}_{4}$ \\
\hline $\mathrm{Te}(\mathrm{IV})$ & $6.60 \times 10^{-4}$ & $\mathrm{TeO}_{2}$ & $2.11 \mathrm{~g}$ in $\mathrm{NaOH}$ \\
\hline Cs $(I)$ & $4.60 \times 10^{-3}$ & $\mathrm{CsNO}_{3}$ & $16.52 \mathrm{~g}$ \\
\hline & & $\mathrm{Cs}_{2} \mathrm{CO}_{3}$ & $1.18 \mathrm{~g}$ in $\mathrm{H}_{2} \mathrm{SO}_{4}$ \\
\hline $\mathrm{Ba}(\mathrm{II})$ & $2.20 \times 10^{-3}$ & $\mathrm{Ba}\left(\mathrm{NO}_{3}\right)_{2}$ & $11.31 \mathrm{~g}$ \\
\hline \multicolumn{4}{|c|}{ Fission Product Rare Earth } \\
\hline $\mathrm{La}(\mathrm{III})$ & $2.00 \times 10^{-3}$ & $\mathrm{La}\left(\mathrm{NO}_{3}\right)_{3} \bullet 6 \mathrm{H}_{2} \mathrm{O}$ & $17.32 \mathrm{~g}$ \\
\hline $\mathrm{Ce}$ (III) & $4.80 \times 10^{-3}$ & $\mathrm{Ce}\left(\mathrm{NO}_{3}\right)_{3} \bullet 6 \mathrm{H}_{2} \mathrm{O}$ & $41.70 \mathrm{~g}$ \\
\hline $\operatorname{Pr}(\mathrm{III})$ & $7.24 \times 10^{-3}$ & $\operatorname{Pr}\left(\mathrm{NO}_{3}\right)_{3} \bullet 6 \mathrm{H}_{2} \mathrm{O}$ & $60.39 \mathrm{~g}$ \\
\hline $\operatorname{Sm}(\mathrm{III})$ & $1.36 \times 10^{-3}$ & $\mathrm{Sm}\left(\mathrm{NO}_{3}\right)_{3} \cdot 5 \mathrm{H}_{2} \mathrm{O}$ & $11.60 \mathrm{~g}$ \\
\hline $\mathrm{Eu}(\mathrm{III})$ & $9.7 \times 10^{-5}$ & $\mathrm{Eu}\left(\mathrm{NO}_{3}\right)_{3} \cdot 5 \mathrm{H}_{2} \mathrm{O}$ & $0.82 \mathrm{~g}$ \\
\hline Gd (III) & $2.4 \times 10^{-5}$ & $\mathrm{Gd}\left(\mathrm{NO}_{3}\right)_{3} \cdot 5 \mathrm{H}_{2} \mathrm{O}$ & $0.21 \mathrm{~g}$ \\
\hline \multicolumn{4}{|l|}{ Anions } \\
\hline $\mathrm{NO}_{3}^{-}$ & 3.96 & & \\
\hline F- & 0.300 & & \\
\hline $\mathrm{SO}_{4}^{2-}$ & 0.55 & & \\
\hline $\mathrm{PO}_{4}^{3-}$ & 0.00260 & & \\
\hline $\mathrm{C}_{2} \mathrm{O}_{4}=$ & 0.36 & $\mathrm{H}_{2} \mathrm{C}_{2} \mathrm{O}_{4} \cdot 2 \mathrm{H}_{2} \mathrm{O}$ & $907.9 \mathrm{~g}$ \\
\hline
\end{tabular}


Table A-2. Mineral Acids Added to Doubly Concentrated Synthetic CAW

\begin{tabular}{llc}
\hline Acids Added & Form & Amount, mL \\
\hline $\mathrm{HNO}_{3}$ & Concentrated & 1224 \\
$\mathrm{H}_{2} \mathrm{SO}_{4}$ & Concentrated & 291 \\
$\mathrm{HF}$ & Concentrated & 153 \\
\hline
\end{tabular}

\section{Nitric Acid}

Aliquots of reagent grade nitric acid were diluted to standard volumes to provide the acid solutions of $0.25,2.5$, and $6.0 \mathrm{M}$ that were in contact with TRUEX-NPH during radiolysis and hydrolysis. The same techniques were used to prepare the solutions of $0.01,0.05$, and $2.0 \mathrm{M}$ that were used in determination of $\mathrm{D}_{\mathrm{Am}}$ values for distribution of americium between aqueous $\mathrm{HNO}_{3}$ and degraded solvent.

\section{TRUEX-NPH Solvent}

Batches of TRUEX-NPH solvent were prepared by mixing weighed quantities of TBP, CMPO, and the alkane diluent. The CMPO was obtained from M \& T Chemicals, Rahway, NJ. The diluent was a Conoco product. Analyses of the diluent by gas chromotography showed that it contained 98.87 to $99.37 \%$ of n-alkanes $\left(C_{10}-C_{16}\right)$ by weight and $0.58-1.11 \%$ branched alkanes $\left(C_{12}-C_{16}\right.$ isomers $)$. The measured density of the TRUEX-NPH mixture at $25^{\circ} \mathrm{C}$ was $0.854 \mathrm{~g} / \mathrm{mL}$.

\section{Standard Sodium Hydroxide}

The standard base used in titrations to determine the change of acidity in aqueous and organic phases (Sec. VI) was a $0.1 \underline{\mathrm{M}}$ solution of $\mathrm{NaOH}$.

\section{Americium Spike}

The americium spike used to determine values of $\mathrm{D}_{\mathrm{Am}}$ was a solution with a concentration of $1.64 \times 10^{5} \mathrm{cpm} / \mu \mathrm{L}$ of americium in $2 \underline{\mathrm{M}} \mathrm{HNO}_{3}$.

\section{Carbonate Wash Solution}

The carbonate wash used to measure the effects of washing samples of degraded solvents before determining $\mathrm{D}_{\mathrm{Am}}(\mathrm{Sec}$. VI) was a solution of sodium carbonate in water with a concentration of $0.25 \underline{\mathrm{M}}$. 


\section{APPENDIX B. BASELINE DAm $_{\text {AETERMINATIONS }}$}

In this work, $\mathrm{D}_{\mathrm{Am}}$ between aqueous $\mathrm{HNO}_{3}$ of $0.01,0.05$, or $2.0 \mathrm{M}$ concentration and many different samples of degraded TRUEX-NPH solvent is correlated with hydrolysis times or dose. For each of these correlations, $\mathrm{D}_{\mathrm{Am}}$ at zero hydrolysis time or zero dose rate is relevant. Therefore, for each acid concentration, $0.01,0.05$, and $2.0 \mathrm{M}$, a number of measurements of $\mathrm{D}_{\mathrm{Am}}$ were made involving fresh TRUEX-NPH solvent, representing $\mathrm{D}_{\mathrm{Am}}$ at zero hydrolysis time or zero dose.

The procedure used in determining these $\mathrm{D}_{\mathrm{Am}}$ values was similar to that described in Sec. III, except that the samples of TRUEX-NPH solvent had not been subjected to degradation.

These $D_{A m}$ values were obtained on a number of different dates and employed TRUEX-NPH solvent prepared by two different experimenters. They also involved two different batches of CMPO and two different batches of diluent. Since variations in $D_{\text {Am }}$ could not be correlated with any of these experimental differences, an average of the $D_{A m}$ values for forward extraction (extraction of Am from aqueous to organic) was used to represent each acid concentration.

The results of these $D_{\text {Am }}$ determinations are listed in Table B-1.

Table B-1. Distribution of Am between Fresh TRUEX-NPH Solvent and Aqueous Nitric Acid

\begin{tabular}{|c|c|c|c|c|}
\hline $\mathrm{HNO}_{3}, \underline{\mathrm{M}}$ & $\mathrm{D}_{\mathrm{f}}^{\mathrm{a}}$ & $\mathrm{D}_{\mathrm{b}}^{\mathrm{b}}$ & $\mathrm{D}_{\mathrm{f}}^{\mathrm{c}}\left(\mathrm{CO}_{3}{ }^{2}\right)$ & $\mathrm{D}_{\mathrm{b}}^{\mathrm{d}}\left(\mathrm{CO}_{3}=\right.$ \\
\hline \multicolumn{5}{|c|}{ Diluent Batch - 375} \\
\hline 0.01 & 0.0100 & 0.042 & -- & -- \\
\hline 0.01 & 0.0127 & 0.0508 & 0.0098 & 0.057 \\
\hline 0.01 & 0.011 & 0.0416 & 一 & - \\
\hline 0.01 & 0.0121 & 0.0422 & -- & -- \\
\hline 0.01 & 0.0111 & 0.0413 & -- & -- \\
\hline 0.05 & 0.234 & 0.211 & 0.244 & 0.0252 \\
\hline 0.05 & 0.234 & 0.258 & -- & -- \\
\hline 0.05 & 0.227 & 0.230 & -- & -- \\
\hline 2.0 & 28.4 & 42.3 & 29.9 & 42.9 \\
\hline 2.0 & 36.5 & 33.8 & 32.0 & 35.8 \\
\hline 2.0 & 33.7 & 30.7 & -- & -- \\
\hline 2.0 & 22.4 & -- & - & -- \\
\hline 2.0 & 31.0 & 35.9 & -- & -- \\
\hline 2.0 & 31.9 & 38.7 & -- & -- \\
\hline 2.0 & 32.5 & 37.8 & -- & -- \\
\hline 2.0 & 31.1 & 38.0 & - & -- \\
\hline 2.0 & 28.4 & 22.8 & -- & -- \\
\hline 2.0 & 29.2 & 28.1 & -- & -- \\
\hline 2.0 & 28.7 & 29.8 & - & - \\
\hline 2.0 & 29.7 & 28.3 & - & -- \\
\hline
\end{tabular}


Table B-1. (contd)

\begin{tabular}{cllll}
\hline $\mathrm{HNO}_{3}, \underline{\mathrm{M}}$ & $\mathrm{D}_{\mathrm{f}}^{\mathrm{a}}$ & $\mathrm{D}_{\mathrm{b}}^{\mathrm{b}}$ & $\mathrm{D}_{\mathrm{f}}^{\mathrm{c}}\left(\mathrm{CO}_{3}^{-}\right)$ & $\mathrm{D}_{\mathrm{b}}{ }^{d}\left(\mathrm{CO}_{3}^{=}\right)$ \\
\hline 0.01 & 0.0118 & 0.0451 & - & -- \\
0.01 & 0.0118 & 0.0494 & - & -- \\
0.05 & 0.214 & 0.217 & - & -- \\
0.05 & 0.216 & 0.234 & -- & -- \\
2.0 & 28.5 & 30.3 & - & -- \\
2.0 & 28.9 & 29.1 & -- & --
\end{tabular}

Diluent Batch - 414

\begin{tabular}{lllll}
0.01 & 0.0115 & 0.063 & 0.0096 & 0.051 \\
0.01 & 0.0115 & 0.060 & -- & -- \\
0.01 & 0.0116 & 0.055 & - & -- \\
0.05 & 0.242 & 0.243 & 0.246 & 0.239 \\
0.05 & 0.244 & 0.266 & - & -- \\
0.05 & 0.236 & 0.239 & -- & -- \\
2.0 & 30.2 & 45.3 & 28.5 & 44.8 \\
2.0 & 32.05 & 36.7 & -- & -- \\
2.0 & 34.1 & 40.0 & -- & -- \\
2.0 & 33.5 & 40.5 & - & -- \\
2.0 & 34.3 & 40.3 & -- & -- \\
2.0 & 29.2 & 39.7 & - & -- \\
\hline
\end{tabular}

aDistribution coefficient of $\mathrm{Am}^{3+}$; forward extraction. bDistribution coefficient of $\mathrm{Am}^{3+}$; back extraction. 'Same as footnote a after a carbonate wash.

${ }^{\mathrm{d}}$ Same as footnote $\mathrm{b}$ after $\mathrm{a}$ carbonate wash. 


\section{APPENDIX C. CALCULATION OF CMPO CONCENTRATIONS IN PROCESSING SYSTEMS}

The concentration of CMPO in the TRUEX-NPH solvent will decrease during processing because of radiolysis and hydrolysis. The decreased concentration of CMPO will affect the extraction behavior of TRUEX-NPH solvent during processing. Equations for calculating the concentration of CMPO remaining or the fraction of CMPO remaining after exposure to radiolysis and hydrolysis during one or more typical process cycles were derived and are presented below. These calculations are carried out with the aid of parameters determined in experimental studies of the radiolysis and hydrolysis of the solvent. Concentrations of CMPO were derived from measurements of $\mathrm{D}_{\mathrm{Am}}{ }^{2.0}$ and the assumptions described in Secs. III.C.3 and IV.C.3.

The TRUEX-NPH solvent flows in series through the extraction, scrub, strip, and rinse sections. Therefore, in going through a cycle, the concentrations of CMPO would be decreased by the changes that occurred in all four sections. It is assumed that both radiolysis and hydrolysis destroy CMPO in the extraction section, but only hydrolysis destroys it in the scrub, strip, and rinse sections. Furthermore, hydrolysis will proceed to different extents in each section because the acid concentrations and residence times are typically different. In the scrub and strip sections, the acid concentrations are usually much lower than that in the extraction section; consequently, the effect on CMPO concentration in the scrub and strip sections will be smaller.

\section{Radiolysis of TRUEX-NPH Solvent}

The rate of change of CMPO concentration from radiolysis is related to the radiation chemical yield ( $\mathrm{G}$ value) and the absorbed dose rate for the solvent.

$$
(-d C / d t)_{r}=(G)(P)(M)
$$

where $\mathrm{G}=$ radiation chemical yield ( $\mathrm{G}$ value), $\mathrm{mol} \mathrm{J}^{-1}$ (molecules CMPO destroyed/100 eV),

$\mathrm{P}=$ absorbed dose rate to the solvent, $\mathrm{WL}^{-1}$

$\mathrm{M}=$ a product of dimensional equivalents, $3.73 \times 10^{-4}(100 \mathrm{eV} / \mathrm{Wh})(\mathrm{mol} / \mathrm{molecule})$

Since $\mathrm{G}$ and $\mathrm{P}$ would normally be constants characteristic of the solvent and the radiation level of the solution, the rate of change of CMPO concentration by radiolysis can be treated as a constant for a given processing campaign:

$$
(-d C / d t)_{r}=k_{r}=(G)(P)(M)
$$

\section{Hydrolysis of TRUEX-NPH Solvent}

Experimental data obtained on the hydrolysis of CMPO can be represented by a pseudofirst-order rate law with respect to the concentration of CMPO as follows:

$$
(-d C / d t)_{h}=k_{h p} C
$$


where $\mathrm{k}_{\mathrm{hp}}$ is the pseudo-first-order rate constant and $\mathrm{C}$ is the concentration of CMPO. However, $\mathrm{k}_{\mathrm{hp}}$ is dependent on acidity and can be expressed by

$$
k_{h_{p}}=k_{h}\{H\}
$$

where $\{\mathrm{H}\}$ is the activity of hydrogen ion in the aqueous phase after equilibration with the organic phase, and $\mathrm{k}_{\mathrm{h}}$ is a rate constant that is dependent on temperature and is expressed by an Arnenius relationship. This relationship is

$$
k_{h}=A e^{-E / R T}
$$

and, when combined with Eq. C-4, yields

$$
k_{h p}=A e^{-E / R T}\{H\}
$$

\section{Rate of Destruction of CMPO in Extraction Section}

The overall rate of change in CMPO concentration in the extraction section is the sum of the rate of radiolysis and the rate of hydrolysis as follows:

$$
-d C / d t=(-d C / d t)_{r}+(-d C / d t)_{h}
$$

Substituting from Eqs. C-2 and C-3 gives

$$
-d C / d t=k_{r}+k_{h p} C
$$

or

$$
d C / d t+k_{h p} C=-k_{r}
$$

Equation C-9 is a linear, first-order differential equation of the general form

$$
d y / d x+R y=Q
$$

where $\mathrm{R}$ and $\mathrm{Q}$ are either functions of $\mathrm{x}$ alone or constants [GRANVILLE]. Solving it results in

$$
y=e^{-\int R d x}\left(\int Q e^{\int R d x} d x+I\right)
$$


where I is an integration constant. By analogy, the solution of Eq. C-9 is

$$
\left.C=e^{-\int k_{h p} d t} \mid \int\left(-k_{r}\right) e^{\int k_{h p} d t} d t+I\right]
$$

Upon integration, it becomes

$$
\left.c_{n}=e^{-k_{h p} t} \mid-k_{r}\right\}\left\{\left[\frac{e^{k_{p} t}}{k_{h p}}\right]+I\right\}
$$

where $\mathrm{C}_{\mathrm{n}}$ is the concentration of CMPO in TRUEX-NPH solvent at the exit of the extraction section, and $t$ is the residence time in the extraction section. Multiplying and cancelling exponential terms gives

$$
C_{n}=-\frac{k_{r}}{k_{h p}}+I e^{-k_{h p} t}\left(-k_{r}\right)
$$

When $t=0, C_{n}=C_{o}$, the concentration of CMPO in the feed. Then,

$$
I=-\frac{\mathrm{C}_{0}}{\mathrm{k}_{\mathrm{r}}}-\frac{1}{\mathrm{k}_{\mathrm{h}_{\mathrm{p}}}}
$$

Substituting this expression for I into Eq. C-14,

$$
\begin{aligned}
& \left.c_{n}=\frac{k_{r}}{k_{h p}}+\left(-\frac{c_{0}}{k_{r}}-\frac{1}{k_{h p}}\right)\left(e^{-k_{h p} t}\right) \mid-k_{r}\right) \\
& C_{n}=-\frac{k_{r}}{k_{h p}}+C_{o} e^{-k_{h p} t}+\frac{k_{r} e^{-k_{h p} t}}{k_{h p}} \\
& c_{n}=c_{o} e^{-k_{h p} t}+\frac{k_{r}}{k_{h_{p}}}\left|e^{-k_{h p} t^{t}}-1\right|
\end{aligned}
$$

or

$$
C_{n}=C_{0} e^{-k_{h p} t}-\frac{k_{r}}{k_{h p}}\left[1-e^{-k_{h p} t}\right]
$$


Substituting for $\mathrm{k}_{\mathrm{hp}}$ from Eq. C-6,

$$
C_{n}=C_{0} e^{-A e^{-E / R T}\left\{H_{n} t\right.}-\frac{k_{r}}{A e^{-E / R T}\{H\}}\left(1-e^{-A e^{-E / R T}\{H\}_{n} t}\right)
$$

where $\{\mathrm{H}\}_{\mathrm{n}}=$ activity of hydrogen ion in aqueous feed after equilibration with the organic phase

$N_{n}=$ number of stages in the extraction section

$\mathrm{t}_{\mathrm{s}} \quad=$ residence time in any stage

$\mathrm{t}=\mathrm{N}_{\mathrm{n}} \mathrm{t}_{\mathrm{s}}$

Therefore, the concentration of CMPO in solvent at the end of the extraction section is

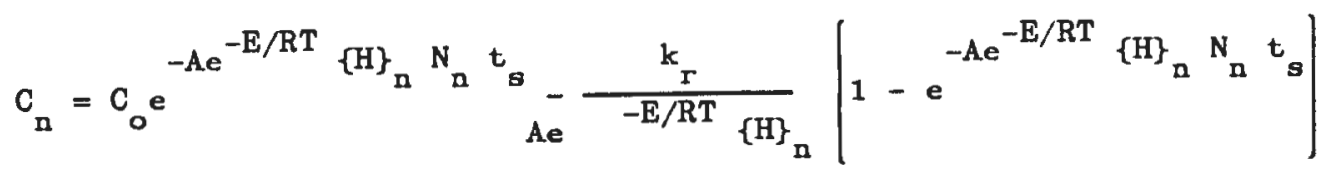

or

$$
C_{n}=\left[C_{0}+\frac{k_{r}}{A e^{-E / R T}\left\{H_{n}\right.}\right] e^{-A e^{-E / R T}\left\{H_{n} N_{n} t_{s}\right.}-\frac{k_{r}}{A e^{-E / R T}\{H\}_{n}}
$$

\section{Destruction of CMPO in Scrub Section}

The concentration of CMPO at the beginning of the scrub section is $C_{n}$, the concentration at the exit of the extraction section, which is obtained from Eq. C-21. Thus, the concentration at the exit of the scrub section, $\mathrm{C}_{\mathrm{b}}$, which decreased by hydrolysis, can be calculated by the integrated form of Eq. C-3 as follows:

$$
c_{b}=c_{n} e^{-k_{h p} t}
$$

Substituting from Eq. C-4 for k $\mathrm{hp}$

$$
C_{b}=C_{n} e^{-\left\{k_{b}\right\}\left\{\{H\}_{b}\right\}(t)}
$$

and substituting from Eq. C-5 for $\mathrm{k}_{\mathrm{h}}$,

$$
C_{b}=C_{n} e^{-\left[A e^{-E / R T}\right]\left[\{H\}_{b}\right](t)}
$$


Furthermore, $t$ is a function of two components, $N_{b}$ and $t_{s}$; therefore, the concentration of CMPO in solvent at the end of the scrub section is

$$
\left.C_{b}=C_{n} e^{-\left[A e^{-E / R T}\right]\left[\{H\}_{b}\right.}\right]\left[\begin{array}{ll}
N_{b} & t_{s}
\end{array}\right]
$$

where $\{\mathrm{H}\}_{b}$ is the activity of $\mathrm{H}^{+}$in the scrub section after equilibration with the organic phase, $\mathrm{N}_{\mathrm{b}}$ is the number of stages in the scrub section, and $t_{s}$ is the residence time.

\section{Destruction of CMPO in Strip Section}

The concentration of CMPO in TRUEX-NPH solvent at the beginning of the strip section is $\mathrm{C}_{\mathrm{b}}$, the concentration at the exit of the scrub section obtained from Eq. C-26. Since the destruction of CMPO in the strip section is assumed to occur by the same mechanism as in the scrub section, the concentration at the end of the strip section, $\mathrm{C}_{\mathrm{p}}$, can be expressed in a form analogous to that of Eq. C-26. Therefore, the concentration of CMPO in solvent at the end of the strip section is

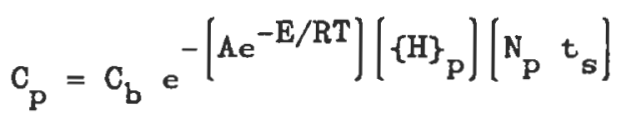

where $\{\mathrm{H}\}_{\mathrm{p}}$ is the activity of $\mathrm{H}^{+}$in the aqueous strip after equilibration with the organic phase, and $\mathrm{N}_{\mathrm{p}}$ is the number of stages in the strip section.

\section{Destruction of CMPO in Rinse Section}

The concentration of CMPO in TRUEX-NPH solvent at the beginning of the rinse section is $\mathrm{C}_{\mathrm{p}}$, the concentration at the exit of the strip section obtained from Eq. C-27. Since the destruction of CMPO in the rinse section is assumed to occur by the same mechanism as in the strip section, the concentration at the end of the rinse section, $\mathrm{C}_{\mathrm{r}}$, can be expressed in a form analogous to that of Eq. C-26. Therefore, the concentration of CMPO in solvent at the end of the rinse section, which is also the CMPO concentration at the end of a cycle, can be expressed as

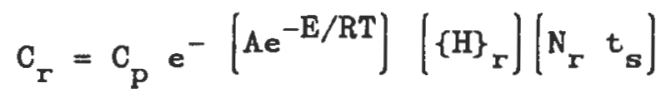

where $\{\mathrm{H}\}_{\mathrm{r}}$ is the activity of $\mathrm{H}^{+}$in the aqueous rinse after equilibration with the organic phase, and $\mathrm{N}_{\mathrm{r}}$ is the number of stages in the rinse section.

If $C_{r}$ in Eq. $C-28$ is evaluated by substituting the values for $C_{p}$ from Eq. C-27, $C_{b}$ from Eq. C-26, and $C_{n}$ from Eq. C-22, then 


$$
\begin{aligned}
C_{r}= & {\left[C_{0}+\frac{k_{r}}{A e^{-E / R T}\{H\}_{n}}\right] e^{-A e^{-E / R T}\left\{H_{n} N_{n} t\right.}-\left[\frac{k_{r}}{A e^{-E / R T}\{H\}}\right] } \\
& e^{-}\left[\left\{A e^{-E / R T}\right]\left[t_{s}\right]\left\{\{H\}_{b} N_{b}+\{H\}_{p} N_{p}+\{H\}_{r} N_{r}\right]\right]
\end{aligned}
$$

\section{Calculating the Extent of Solvent Degradation over Given Processing Period}

Equation C-29 can be used to predict the effect of one or more cycles on the CMPO concentration. On the other hand, a user may wish to calculate the effect of a given processing period, such as a processing year, on the CMPO concentration. If so, the number of cycles run in the period must be calculated, and that number used as $\mathrm{n}$ in Eq. C-29 to calculate the CMPO concentration remaining or fraction reacted. The bases for calculating the number of cycles per period are the following:

(1) One cycle corresponds to one exposure; thus, 1 cycle/exposure.

(2) The number of times that the quantity of solvent required for one cycle is exposed to radiolysis and hydrolysis each time the total solvent inventory is run through the process is assumed to be 1 exposure/inventory.

(3) The time required to run the solvent inventory through the process; for example, processing days required to run the total inventory through the process once, i.e., processing days per inventory $i_{p}$.

(4) The definition of the period of interest; e.g., processing days (proc. d) per processing period, $d_{p}$.

Thus, the cycles per period $=$

$$
\frac{1 \text { cycle }}{\text { exposure }} \times \frac{1 \text { exposure }}{\text { inventory }} \times \frac{\text { inventory }}{i p, \text { proc.d }} \times \frac{d \text { p,proc. } d}{\text { proc. period }}
$$

For example, if $i_{p}=2$ proc. $d$ /inventory

$$
d_{p}=200 \text { proc. } d / \text { proc. } y
$$

then, $(1 \times 1 \times 200) / 2=100$ cycles/proc. $y$, and this value would be used as $n$ in Eq. C-29.

\section{Example of Calculating Concentration of CMPO as Function of Number of Process Cycles}

The concentration of CMPO in TRUEX-NPH solvent at the end of each cycle was calculated for 1 through 100 cycles, using the output of cycle 1 as the input to cycle 2 , etc. The parameters used in this example were as follows: 


\section{a. Constants}
$\mathrm{A}=6.8 \times 10^{10} \mathrm{~L} \mathrm{~mol}^{-1} \mathrm{~s}^{-1}\left(2.47 \times 10^{14} \mathrm{~L} \mathrm{~mol}^{-1} \mathrm{~h}^{-1}\right)$.
$\mathrm{E}=1.14 \times 10^{5} \mathrm{~J} \mathrm{~mol}^{-1}\left(27.3 \times 10^{3} \mathrm{cal} \mathrm{mol}^{-1}\right)$.

The values of $A$ and $E$ were determined from studies described in Sec. IV on hydrolysis of TRUEX-NPH solvent in the range $50-95^{\circ} \mathrm{C}$, assuming that the $\mathrm{D}_{\mathrm{Am}}^{2.0}$ is proportional to [CMPO $]^{3}$.

$\mathrm{G}=7.9 \times 10^{-8} \mathrm{~mol} \mathrm{~J}^{-1}(0.76$ molecule CMPO destroyed per $100 \mathrm{eV}$ absorbed by TRUEXNPH solvent).

This value results from the radiolysis studies described in Sec. III, assuming that the $\mathrm{D}_{\mathrm{Am}}^{2.0}$ is proportional to [CMPO] ${ }^{3}$.

$\mathrm{M}=1 \mathrm{~J} \mathrm{~W}^{-1} \mathrm{~s}^{-1}\left(3.73 \times 10^{-4} 100 \mathrm{eV} \mathrm{mol} \mathrm{W}^{-1} \mathrm{~h}^{-1}\right.$ molecule $\left.^{-1}\right)$.

This constant is a product of dimensional equivalents.

$\mathrm{R}=8.323 \mathrm{~J} \mathrm{~mol}^{-1} \mathrm{deg}^{-1}\left(1.987 \mathrm{cal} \mathrm{mol}^{-1} \mathrm{deg}^{-1}\right)$, the gas constant.

$\mathrm{k}_{\mathrm{r}}=(\mathrm{G})(\mathrm{P})(\mathrm{M})$, from Eq. C-2.

b. Variables

$\mathrm{C}_{\mathrm{o}}=$ Concentration of CMPO in fresh TRUEX-NPH solvent; $0.2 \mathrm{~mol} \mathrm{~L}^{-1}$

$\mathrm{T}=323.12 \mathrm{~K}\left(50^{\circ} \mathrm{C}\right)$.

$\mathrm{t}_{\mathrm{s}} \quad=$ Residence time of solvent in any stage, $20 \mathrm{~s}(0.00556 \mathrm{~h})$.

$\{\mathrm{H}\}_{\mathfrak{n}}=$ Activity of $\mathrm{H}^{+}$in aqueous phase of extraction section after equilibration with organic phase; $1.26 \mathrm{M}$.

$\{\mathrm{H}\}_{b}=$ Activity of $\mathrm{H}^{+}$in aqueous scrub solution after equilibration with organic phase; $0.04 \underline{\text { M. }}$.

$\{\mathrm{H}\}_{\mathrm{p}}=$ Activity of $\mathrm{H}^{+}$in aqueous stripping solution after equilibration with organic phase; 0.04 M.

$\{\mathrm{H}\}_{\mathrm{r}}=$ Activity of $\mathrm{H}^{+}$in aqueous rinse solution after equilibration with organic phase; $0.1 \mathrm{M}$.

$\mathbf{N}_{\mathbf{n}} \quad$ = Number of extraction stages per cycle; 2 .

$\mathrm{N}_{\mathrm{b}}$ = Number of scrub stages per cycle; 3 .

$\mathrm{N}_{\mathrm{p}}=$ Number of stripping stages per cycle; 8 . 
$N_{r}=$ Number of rinse stages per cycle; 1 .

$\mathrm{P}=$ Absorbed dose rate to solvent; $0.1 \mathrm{~W} \mathrm{~L}^{-1^{*}}$

\section{c. Graphic Representation of Fraction of CMPO Remaining as Function of Cycle Numbers}

The fraction of CMPO decomposed, as a function of cycle number, for the set of variables listed above, is shown in Fig. C-1. The fraction of CMPO decomposed at the end of cycle 100, corresponding to about one year of processing, according to the assumptions described in Section C.7, is $8.6 \times 10^{-4}$.

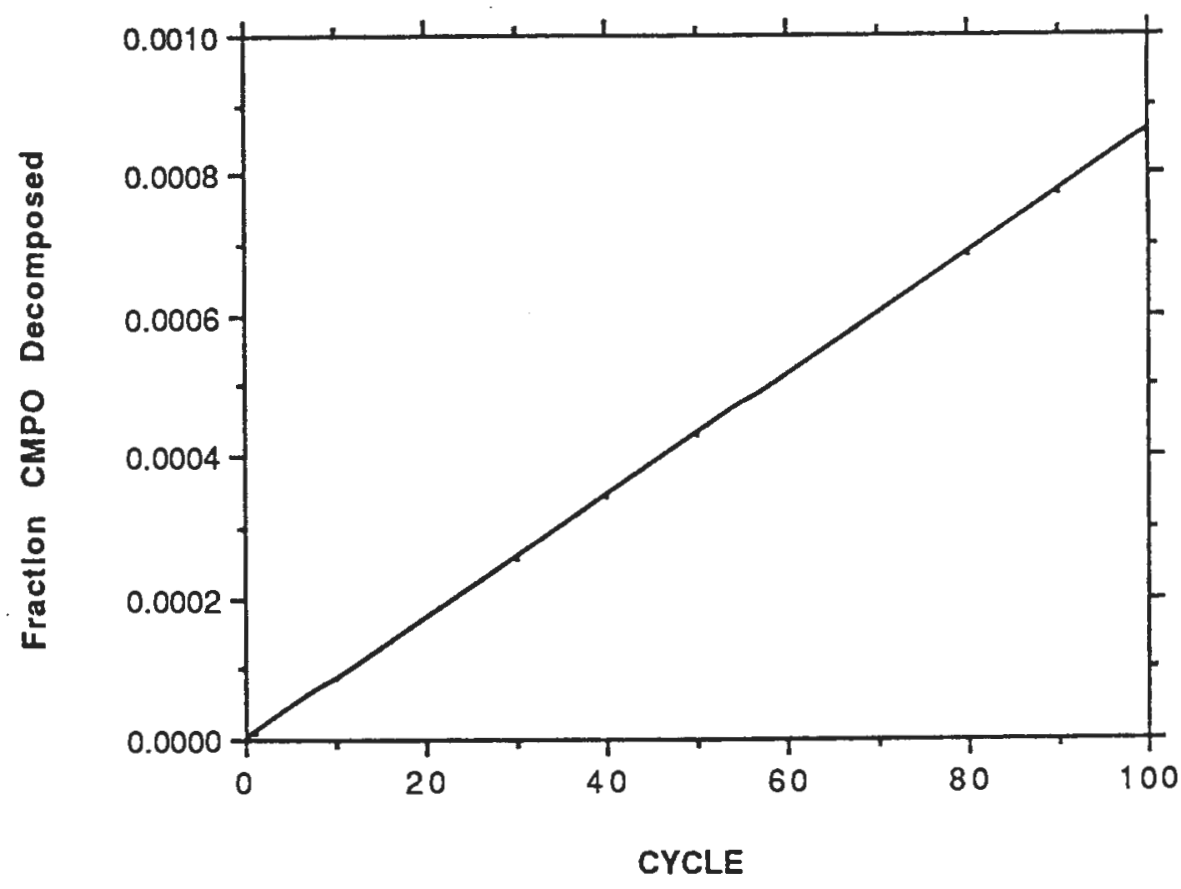

Fig. C-1. Fraction of CMPO Decomposed as Function of Number of Process Cycles

"In the absence of information on absorbed dose rate to solvent from high-level wastes that are candidates for application of TRUEX, the value of $0.1 \mathrm{~W} \mathrm{~L}^{-1}$, derived from other studies of the effect of processing on solvents [VAN GEEL], is adopted for sample calculations. This value is considered to be a conservative estimate; it represents experience in the processing of thermal reactor fuels.

Furthermore, this value falls in the range of values of absorbed dose rates given in an earlier review of solvent stability in processing of thermal reactor fuels [BLAKE]. A lower value would probably be encountered in the processing of high-level wastes that have been stored for many years. 


\section{APPENDIX D. EXPRESSIONS FOR VARIATION OF D ${ }_{\mathrm{Am}}^{.01} \mathrm{AND}_{\mathrm{Am}}^{.05} \mathrm{WITH}$ RADIOLYSIS AND HYDROLYSIS APPLIED TO PROCESS SYSTEMS}

Expressions for $\mathrm{D}_{\mathrm{Am}}{ }^{.01}$ and $\mathrm{D}_{\mathrm{Am}}{ }^{.05}$ versus dose were presented in Sec. III. Also, expressions for $\mathrm{D}_{\mathrm{Am}}{ }^{.01}$ and $\mathrm{D}_{\mathrm{Am}}{ }^{.05}$ versus hydrolysis time and temperature were presented in Sec. IV. These expressions are combined here in calculations made to illustrate the changes in $\mathrm{D}_{\mathrm{Am}}{ }^{.01}$ and $\mathrm{D}_{\mathrm{Am}}{ }^{.05}$ as a function of the number of process cycles.

1. Variation of $\mathrm{D}_{\mathrm{Am}}{ }^{0.1}$ with Cycle Number

In the extraction section of a TRUEX process, the total rate of change of $\mathrm{D}_{\mathrm{Am}}{ }^{.01}$ would be the sum of the effects of hydrolysis and radiolysis,

$$
\frac{d D_{A m}^{.01}}{d t}=\left(\frac{d D_{A m}^{.01}}{d t}\right)_{h}+\left(\frac{d D_{A m}^{.01}}{d t}\right)_{T}
$$

The rate of change of $\mathrm{D}_{\mathrm{Am}}{ }^{.01}$ with dose was treated as a constant in Eq. III-3, and the rate of change of $\mathrm{D}_{\mathrm{Am}}{ }^{.01}$ with hydrolysis time was treated as a constant in Eq. IV-1. Thus, Eq. D-1 can be expressed as

$$
\frac{d D_{A m}^{.01}}{d t}=k_{h}^{.01}+K_{r}^{.01}
$$

Then,

$$
\int d D_{A m}^{.01}=\int k_{h}^{.01} d t+\int k_{r}^{.01} d t
$$

and

$$
\mathrm{D}_{\mathrm{Am}_{\mathrm{n}}}^{.01}=\mathrm{k}_{\mathrm{h}}^{.01} \mathrm{t}+\mathrm{k}_{\mathrm{r}}^{.01} \mathrm{t}+\text { integration constant }
$$

or

$$
\mathrm{D}_{\mathrm{Am}}^{.01}=\mathrm{D}_{\mathrm{Am}}^{.01}+\mathrm{k}_{\mathrm{h}}^{.01} \mathrm{t}+\mathrm{k}_{\mathrm{r}}^{.01} \mathrm{t}
$$

where $\mathrm{D}_{\mathrm{Am}} .01$ is the integration constant and the value characteristic of feed to the extraction section. From Sec. III.C. $1, \mathrm{k}_{\mathrm{r}} .01=\mathrm{k}_{\mathrm{r}} \cdot .01$ (P), and from Eqs. IV-3, IV-5, and IV-6,

$$
k_{h}^{.01}=A_{o}^{.01} e^{-E_{\circ}^{\cdot 01} / R T}+A^{.01} e^{-E^{.01} / R T}\left\{H_{n}\right.
$$


Furthermore, $t=N_{n} t$, where $N_{n}$ is the number of extraction stages, and $t_{s}$ is the residence time per stage. When these expressions are substituted into Eq. D-5, the value of $\mathrm{D}_{\mathrm{Am}}$ at the end of the extraction section becomes

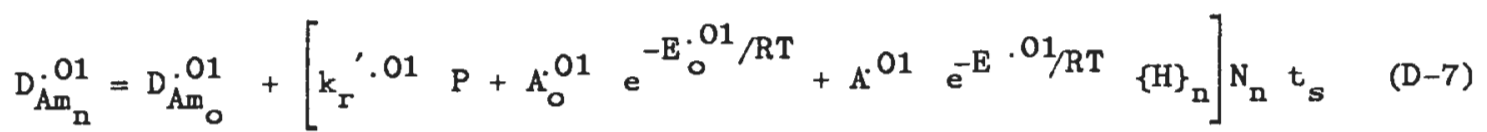

Analogous expressions can be derived for the value of $\mathrm{D}_{\mathrm{Am}}^{.01}$ at the end of succeeding sections. However, since no radiolysis is assumed to occur in these sections, terms involving $\mathrm{k}_{\mathrm{r}}$ will not be included.

Scrub section becomes

$$
D_{\dot{A m}_{b}}^{.01}=D_{\dot{A m}_{n}}^{.01}+\left[A_{0}^{.01} e^{-E_{0}^{.01} / R T}+A^{.01} e^{-E \cdot 01} / R T\left\{H_{b}\right] N_{b} t_{s}\right.
$$

Strip section is

$$
D_{\mathrm{Am}_{\mathrm{p}}}^{.01}=\mathrm{D}_{\mathrm{Am}_{\mathrm{b}}}^{.01}+\left[\mathrm{A}_{\mathrm{o}}^{.01} \mathrm{e}^{-\mathrm{E}_{\mathrm{o}}^{.01} / \mathrm{RT}}+\mathrm{A}^{.01} \mathrm{e}^{-\mathrm{E}^{\cdot 01} / \mathrm{RT}}\{\mathrm{H}\}_{\mathrm{p}}\right] \mathrm{N}_{\mathrm{p}} \mathrm{t}_{\mathrm{s}}
$$

Rinse section is

$$
D_{A_{r}}^{.01}=D_{A_{P}}^{.01}+\left[A_{0}^{.01} e^{-E_{0}^{.01} / R T}+A^{.01} e^{-E^{.01} / R T}\{H\}_{r}\right] N_{r} t_{S}
$$

Eliminating values of $D_{A m}{ }^{.01}$ at intermediate sections by adding Eqs. D-7 through D-10, the value of $\mathrm{D}_{\mathrm{Am}_{\mathrm{r}}}^{.01}$ at the end of a cycle is:

$$
\begin{aligned}
& D_{A_{r}}^{01}=D_{A_{0}}^{01}+k_{r}^{\prime} .01 P N_{n} t_{s}+A_{0}^{01} e^{-E_{0}^{.01 / R T}}\left[N_{n}+N_{b}+N_{P}+N_{r}\right] t_{s} \\
& +A^{.01} e^{-E^{.01} / R T}\left\{\{H\}_{n} N_{n}+\{H\}_{b} N_{b}+\{H\}_{p} N_{p}+\{H\}_{r} N_{r}\right\} t_{s}
\end{aligned}
$$

From Eq. D-11, numerical values of $\mathrm{D}_{\mathrm{Am}_{\mathrm{r}}}^{.01}$ at the end of a cycle were obtained for 100 cycles. The value of $D_{A m_{r}} .01$ for the end of the first cycle was used as the value of $D_{A m_{o}} .01$ for the second cycle, etc. The parameters used in this example are 


$$
\begin{aligned}
\mathrm{D}_{\mathrm{Am}_{\mathrm{o}}}^{.01} & =0.0115 \\
\mathrm{k}_{\mathrm{r}}^{\prime .01} & =5.64 \times 10^{-5} \mathrm{~L} \mathrm{~W}^{-1} \mathrm{~s}^{-1}\left(0.203 \mathrm{~L} \mathrm{~W}^{-1} \mathrm{~h}^{-1}\right) \\
\mathrm{P} & =0.1 \mathrm{~W} \mathrm{~L}^{-1 *} \\
\mathrm{~A}_{\mathrm{o}}^{.01} & =6.97 \times 10^{4} \mathrm{~s}^{-1}\left(2.508 \times 10^{8} \mathrm{~h}^{-1}\right) \\
\mathrm{A}^{.01} & =1.30 \times 10^{3} \mathrm{~L} \mathrm{~mol}^{-1} \mathrm{~s}^{-1}\left(4.686 \times 10^{6} \mathrm{~L} \mathrm{~mol}^{-1} \mathrm{~h}^{-1}\right) \\
\mathrm{E}_{\mathrm{o}}^{.01} & =6.20 \times 10^{4} \mathrm{~J} \mathrm{~mol}^{-1}\left(1.481 \times 10^{4} \mathrm{cal} \mathrm{mol}^{-1}\right) \\
\mathrm{E}^{.01} & =5.94 \times 10^{4} \mathrm{~J} \mathrm{~mol}^{-1}\left(1.417 \times 10^{4} \mathrm{cal} \mathrm{mol}^{-1}\right) \\
\mathrm{R} & =8.323 \mathrm{~J} \mathrm{~mol}^{-1} \mathrm{deg}^{-1}\left(1.987 \mathrm{cal} \mathrm{mol}^{-1} \mathrm{deg}^{-1}\right) \\
{[\mathrm{H}]_{\mathrm{n}} } & =1.26 \mathrm{~mol} \mathrm{~L}^{-1} \\
{[\mathrm{H}\}_{\mathrm{b}} } & =0.04 \mathrm{~mol} \mathrm{~L}^{-1} \\
{[\mathrm{H}\}_{\mathrm{p}} } & =0.04 \mathrm{~mol} \mathrm{~L}^{-1} \\
{[\mathrm{H}]_{\mathrm{r}} } & =0.1 \mathrm{~mol} \mathrm{~L}^{-1}
\end{aligned}
$$

and $T, N_{n}, N_{b}, N_{p}, N_{r}$, and $t_{s}$ have the same values as those listed in C.8.a and C.8.b.

The results are represented graphically in Fig. D-1. In the course of one cycle, the value of $\mathrm{D}_{\mathrm{Am}} .01$ increases by almost $30 \%$. Since the decrease of CMPO concentration in one cycle is quite small (Sec. C.8), only small quantities of products are generated per cycle. Therefore, the relatively large change of $\mathrm{D}_{\mathrm{Am}}{ }^{.01}$ indicates that the acidic products of CMPO are relatively powerful extractants.

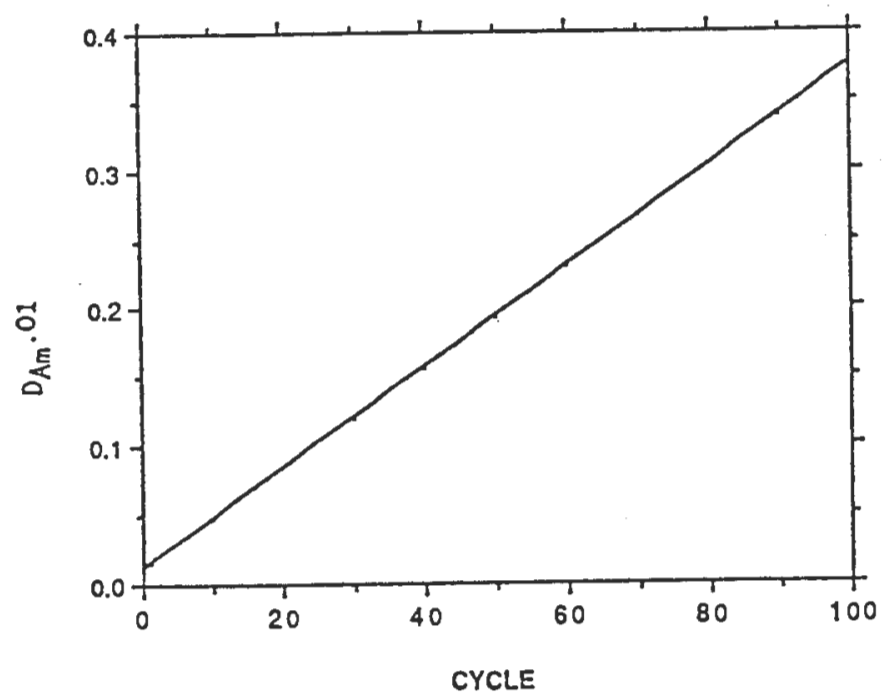

Fig. D-1. Calculated Values of $\mathrm{D}_{\mathrm{Am}}^{.01}$ versus Number of Process Cycles

*In the absence of information on absorbed dose rate to solvent from high-level wastes that are candidates for application of TRUEX, the value of $0.1 \mathrm{~W} \mathrm{~L}^{-1}$, derived from other studies of the effect of processing on solvents [VAN GEEL], is adopted for sample calculations. This value is considered to be a conservative estimate; it represents experience in the processing of thermal reactor fuels. Furthermore, this value falls in the range of values of absorbed dose rates given in an earlier review of solvent stability in processing of thermal reactor fuels [BLAKE]. A lower value would probably be encountered in the processing of high-level wastes that have been stored for many years. 


\section{Variation of $D_{A m}^{.05}$ with Cycle Number}

The value of $D_{A m_{n}}^{.05}$ at the end of the extraction section can be expressed by an analogue of Eq. D-5 as follows:

$$
\mathrm{D}_{\dot{A m}_{\mathrm{n}}}^{.05}=\mathrm{D}_{\dot{A m}_{0}}^{.05}+\mathrm{k}_{\mathrm{h}}^{.05} \mathrm{t}+\mathrm{k}_{\mathrm{I}}^{.05} \mathrm{t}
$$

By analogy to the discussion given in Sec. III.C. $1, \mathrm{k}_{\mathrm{r}}^{.05}=\mathrm{k}_{\mathrm{r}}^{0.05}(\mathrm{P})$. If we use an analogue of Eq. IV-3 to evaluate $\mathrm{k}_{\mathrm{h}} .05$,

$$
k_{b^{\circ}}^{.05}=k_{h_{0}^{\prime}}^{\prime} .05+k_{h}^{\prime} .05\left\{H_{n}\right.
$$

But $\mathrm{k}_{\mathrm{h}}^{\prime} .05 \equiv 0$. Therefore,

$$
\mathrm{k}_{\mathrm{h}}^{.05}=\mathrm{k}_{\mathrm{h}_{\mathrm{o}}}^{.05}=\mathrm{A}_{\mathrm{o}}^{.05} \mathrm{e}^{-\mathrm{E} \cdot 05 / \mathrm{RT}}
$$

When these values are substituted into Eq. D-12, the value of $\mathrm{D}_{\mathrm{Am}}^{.05}$ at the end of the extraction section is

$$
\mathrm{D}_{\dot{A m}_{\mathrm{n}}}^{.05}=\mathrm{D}_{\mathrm{Am}_{\mathrm{O}}}^{.05}+\left[\mathrm{k}_{\mathrm{T}}^{.05} \mathrm{P}+\mathrm{A}_{0}^{.05} \mathrm{e}^{-\mathrm{E}_{0}^{.05} / \mathrm{RT}}\right] \mathrm{N}_{\mathrm{n}} \mathrm{t}_{S}
$$

Analogous expressions can be derived for the value of $\mathrm{D}_{\mathrm{Am}}^{.05}$ at the end of the scrub, strip, and rinse sections. However, since no radiolysis occurs in these sections, terms involving $\mathrm{k}_{\mathrm{r}}^{.05}$ will not be included.

Scrub section becomes

$$
\mathrm{D}_{\mathrm{Am}_{\mathrm{b}}}^{.05}=\mathrm{D}_{\mathrm{Am}_{\mathrm{n}}}^{.05}+\left[\mathrm{A}_{0}^{.05} \mathrm{e}^{-\mathrm{E}_{0}^{.05} / \mathrm{RT}}\right] \mathrm{N}_{\mathrm{b}} \mathrm{t}_{\mathrm{b}}
$$

Strip section is

$$
\mathrm{D}_{\mathrm{Am}_{\mathrm{p}}}^{.05}=\mathrm{D}_{\mathrm{Am}_{\mathrm{b}}}^{.05}+\left[\mathrm{A}_{0}^{.05} \mathrm{e}^{-\mathrm{E}_{0}^{.05} / \mathrm{RT}}\right] \mathrm{N}_{\mathrm{p}} \mathrm{t}_{\mathrm{s}}
$$

Rinse section is

$$
D_{A_{r}}^{.05}=D_{A_{P}}^{.05}+\left[A_{0}^{.05} e^{-E_{0}^{.05} / R T}\right] N_{r} t_{S}
$$


Eliminating values of $\mathrm{D}_{\mathrm{Am}}{ }^{.05}$ at intermediate sections by adding Eqs. D-15 through D-18, the value of $\mathrm{D}_{\mathrm{Am}_{\mathrm{r}}}^{.05}$ at the end of a cycle is

$$
\mathrm{D}_{\dot{A m}_{T}}^{.05}=\mathrm{D}_{\mathrm{Am}_{0}}^{.05}+\mathrm{k}_{T}^{\prime .05}(\mathrm{P}) \mathrm{N}_{\mathrm{n}} \mathrm{t}_{s}+\mathrm{A}_{0}^{.05} \mathrm{e}^{-\mathrm{E}_{0}^{.05} / \mathrm{RT}}\left(\mathrm{N}_{\mathrm{n}}+\mathrm{N}_{\mathrm{b}}+\mathrm{N}_{\mathrm{p}}+\mathrm{N}_{T}\right) \mathrm{t}_{s}
$$

From Eq. D-19, numerical values of $\mathrm{D}_{\mathrm{Am}} .05$ at the end of a cycle were obtained over a range of 1-100 cycles. The value of $D_{A m}{ }_{r}^{.05}$ for the end of the first cycle was used as the value of $D_{A m_{0}}{ }^{.05}$ for the second cycle, etc. The parameters used in this example are

$$
\begin{array}{ll}
\mathrm{D}_{\text {Am }_{0}}^{.05} & =0.231 \\
\mathrm{~A}_{\mathrm{o}}^{.05} & =5.92 \times 10^{2} \mathrm{~s}^{-1}\left(2.131 \times 10^{6} \mathrm{~h}^{-1}\right) \\
\mathrm{E}_{\mathrm{o}}^{.05} & =5.01 \times 10^{4} \mathrm{~J} \mathrm{~mol}^{-1}\left(1.197 \times 10^{4} \mathrm{cal} \mathrm{mol}^{-1}\right) \\
\mathrm{k}_{\mathrm{l}}^{.05} & =8.78 \times 10^{-6} \mathrm{~L} \mathrm{~W}^{-1} \mathrm{~s}^{-1}\left(0.0316 \mathrm{~L} \mathrm{~W}^{-1} \mathrm{~h}^{-1}\right)
\end{array}
$$

where $P, R, T, N_{n}, N_{b}, N_{p}, N_{r}$, and $t_{s}$ have the same values as listed in Secs. C.8.a and C.8.b.

In the course of one cycle, the value of $\mathrm{D}_{\mathrm{Am}}{ }^{.05}$ changes by about $1 \%$. Comparison of this change with the larger change for $D_{\text {Amn }}{ }^{01}$ described in Sec. D. 1 is consistent with theories that the nonacidic products of CMPO degradation are less powerful extractants than acidic products. The results are represented graphically in Fig. D-2.

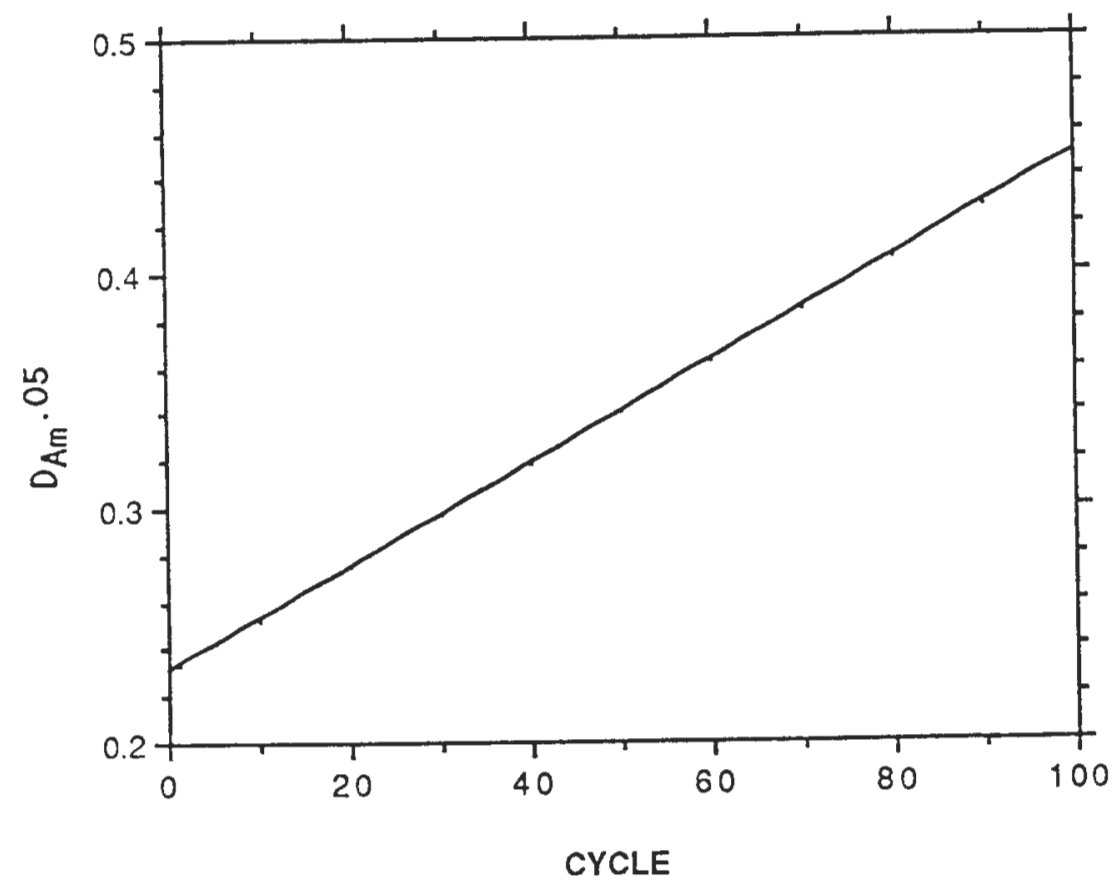

Fig. D-2. Calculated Values of $\mathrm{D}_{\mathrm{Am}}{ }^{.05}$ versus Number of Process Cycles 


\section{APPENDIX E. SOLVENT WASHING DATA}

The effectiveness of removing the products of CMPO degradation by washing was tested on some of the distribution systems that were exposed to radiolysis or hydrolysis. The effect of carbonate washing was observed on solvent that had been irradiated in contact with $0.25,2.5$, and $6.0 \mathrm{M} \mathrm{HNO}_{3}$, solvent that had been hydrolyzed in contact with 2.5 and $6.0 \mathrm{M} \mathrm{HNO}_{3}$ at temperatures of 50 and $70^{\circ} \mathrm{C}$, and solvent that had been hydrolyzed in contact with simulated $\mathrm{CAW}$ containing $1.6 \mathrm{M} \mathrm{HNO}_{3}$ at $70^{\circ} \mathrm{C}$. Graphical comparisons of $\mathrm{D}_{\mathrm{Am}}$ values obtained with degraded solvent washed with carbonate and degraded solvent not washed with carbonate are presented in Figs. E-1 through E-6 for radiolysis and in Figs. E-7 through E-14 for hydrolysis.

In general, carbonate washing results in a lower value of $\mathrm{D}_{\mathrm{Am}}$, presumably because the carbonate counteracts the acidic products of degradation and the high capacity for americium extraction associated with them. From Figs. VI-1, VI-2, and Figs. E-1 through E-14, some generalizations concerning the effects of carbonate washing of degraded solvents are made in Sec. VI.

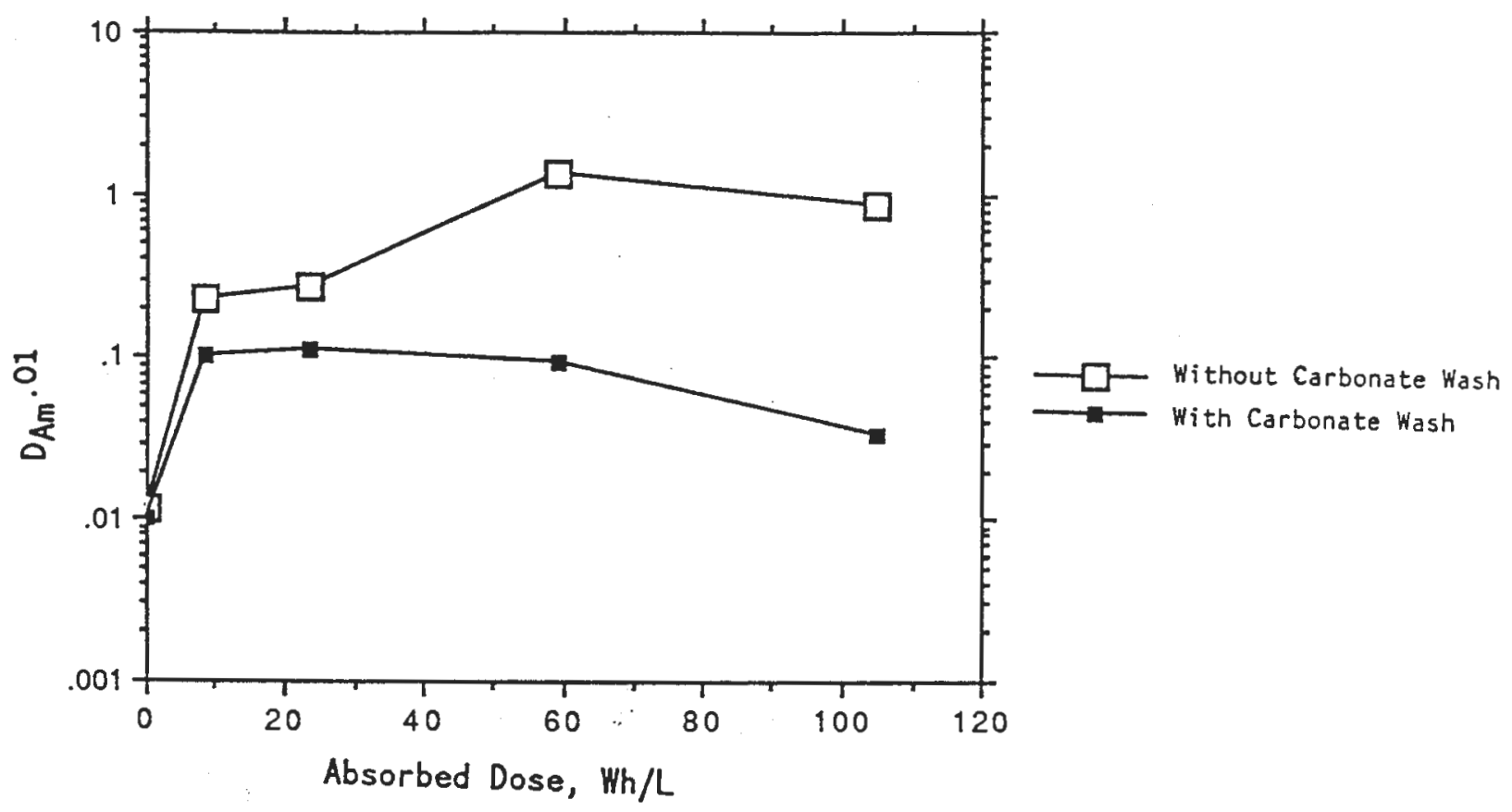

Fig. E-1. $\mathrm{D}_{\mathrm{Am}}{ }^{.01}$ as a Function of Dose Absorbed by Solvent Irradiated in Contact with $0.25 \mathrm{M} \mathrm{HNO}_{3}$. Comparison of solvent samples washed with aqueous sodium carbonate following irradiation with those that were not. 


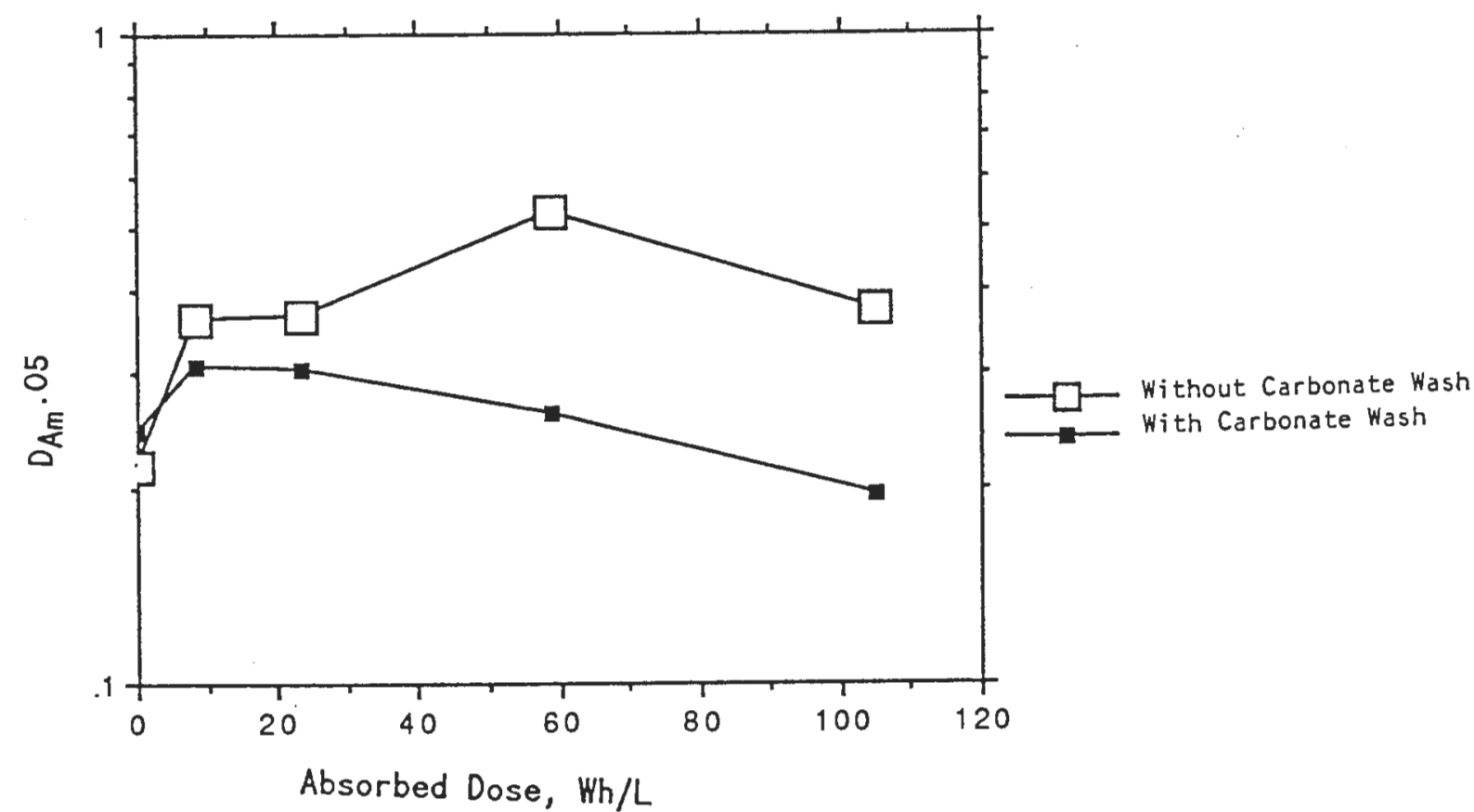

Fig. E-2. $\mathrm{D}_{\mathrm{Am}}^{.05}$ as a Function of Dose Absorbed by Solvent Irradiated in Contact with $0.25 \mathrm{M} \mathrm{HNO}_{3}$. Comparison of solvent samples washed with aqueous sodium carbonate following irradiation with those that were not.

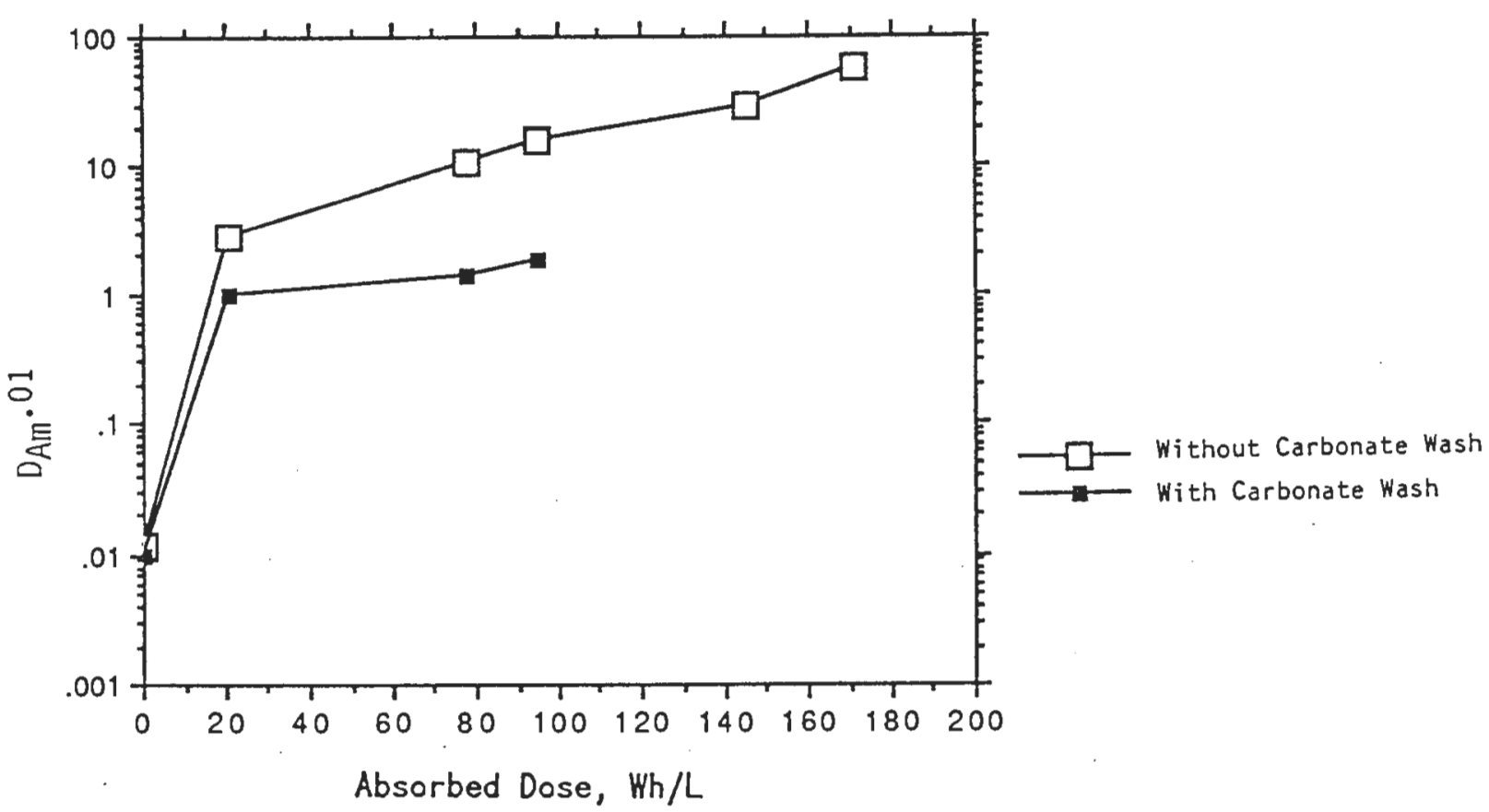

Fig. E-3. $\mathrm{D}_{\mathrm{Am}}^{.01}$ as a Function of Dose Absorbed by Solvent Irradiated in Contact with $2.5 \mathrm{M} \mathrm{HNO}_{3}$. Comparison of solvent samples washed with aqueous sodium carbonate following irradiation with those that were not. 


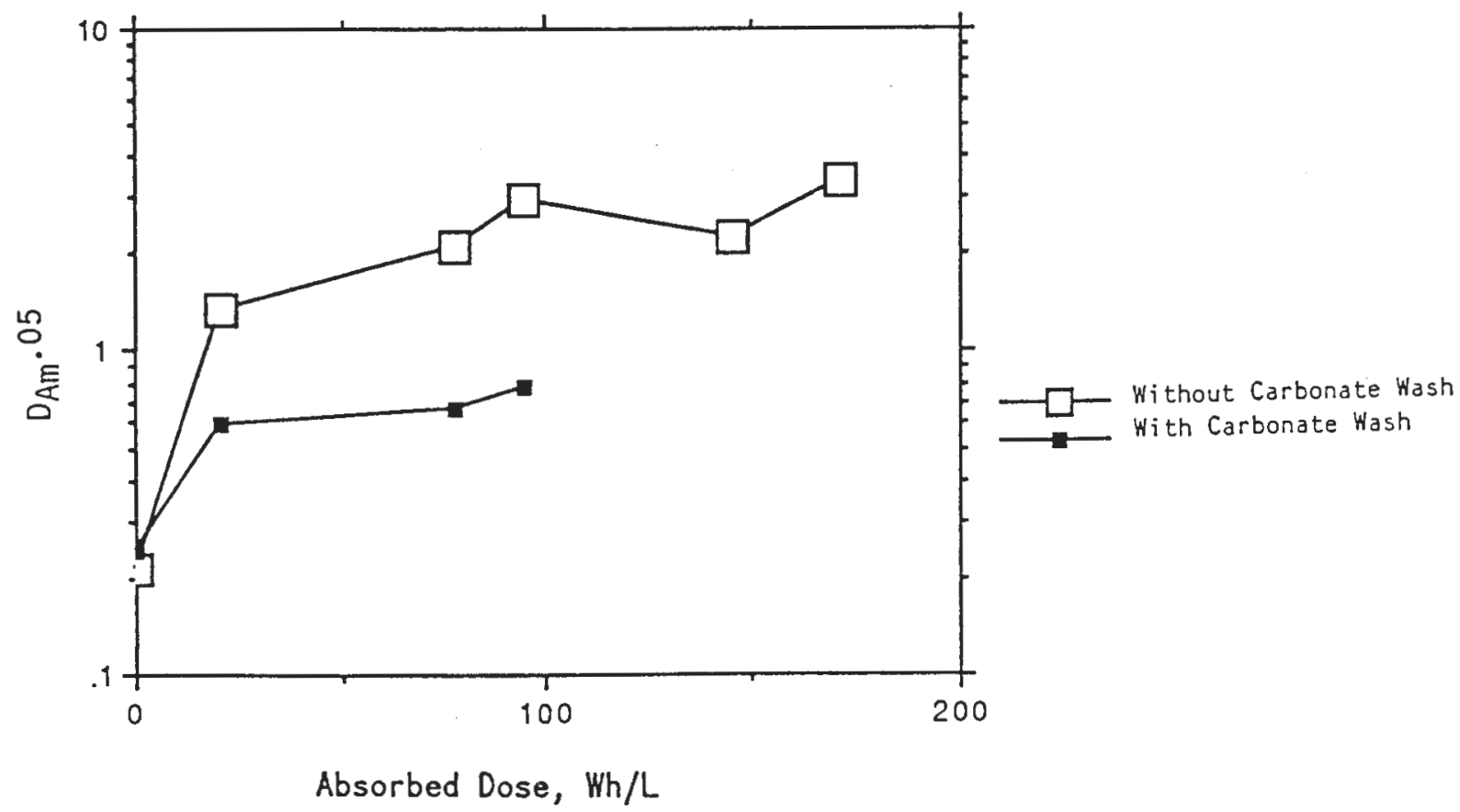

Fig. E-4. $\quad \mathrm{D}_{\mathrm{Am}}^{.05}$ as a Function of Dose Absorbed by Solvent Irradiated in Contact with $2.5 \underline{\mathrm{M}} \mathrm{HNO}_{3}$. Comparison of solvent samples washed with aqueous sodium carbonate following irradiation with those that were not.

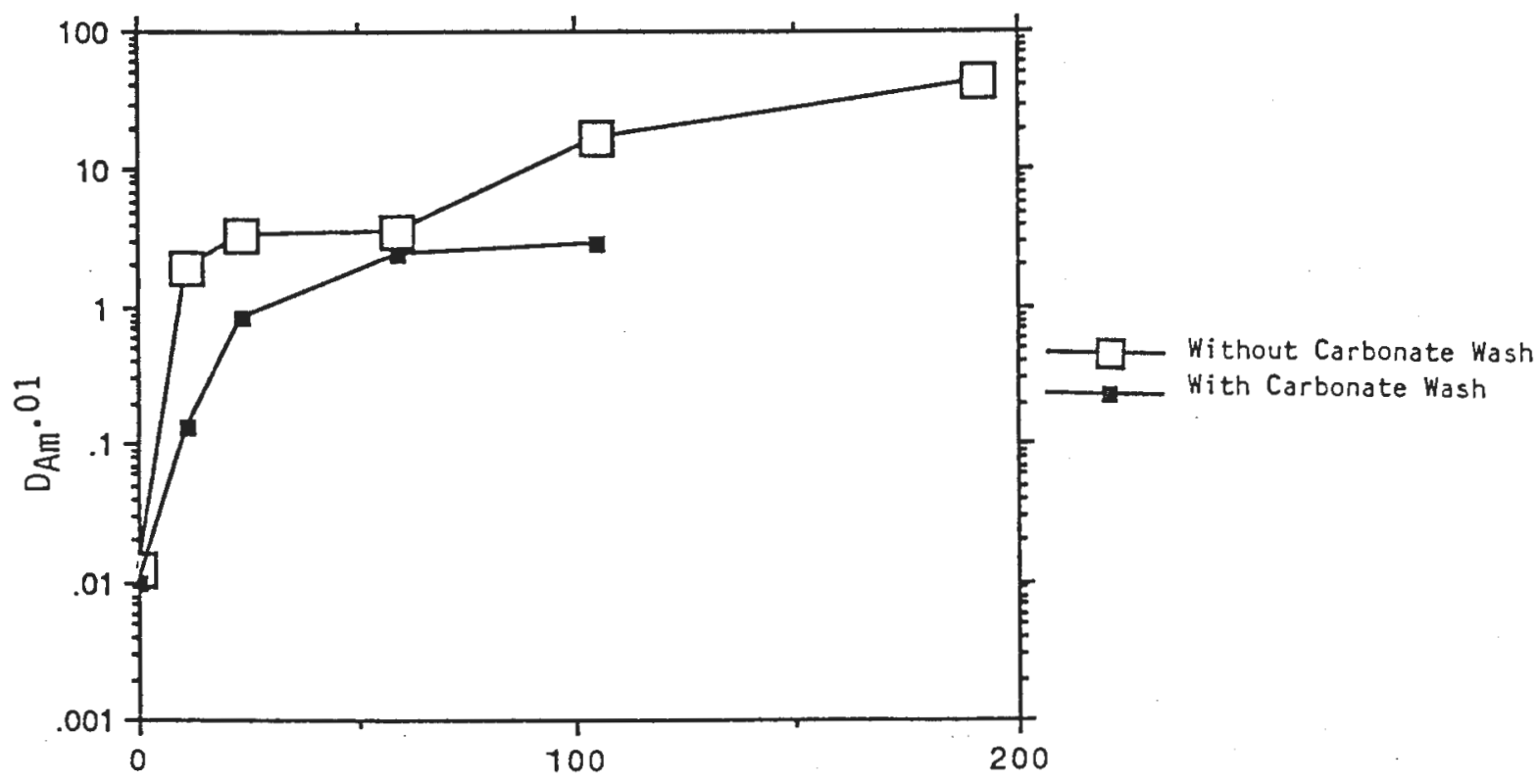

Absorbed Dose, Wh/L

Fig. E-5. $\mathrm{D}_{\mathrm{Am}} .01$ as a Function of Dose Absorbed by Solvent Irradiated in Contact with $6.0 \mathrm{M} \mathrm{HNO}_{3}$. Comparison of solvent samples washed with aqueous sodium carbonate following irradiation with those that were not. 


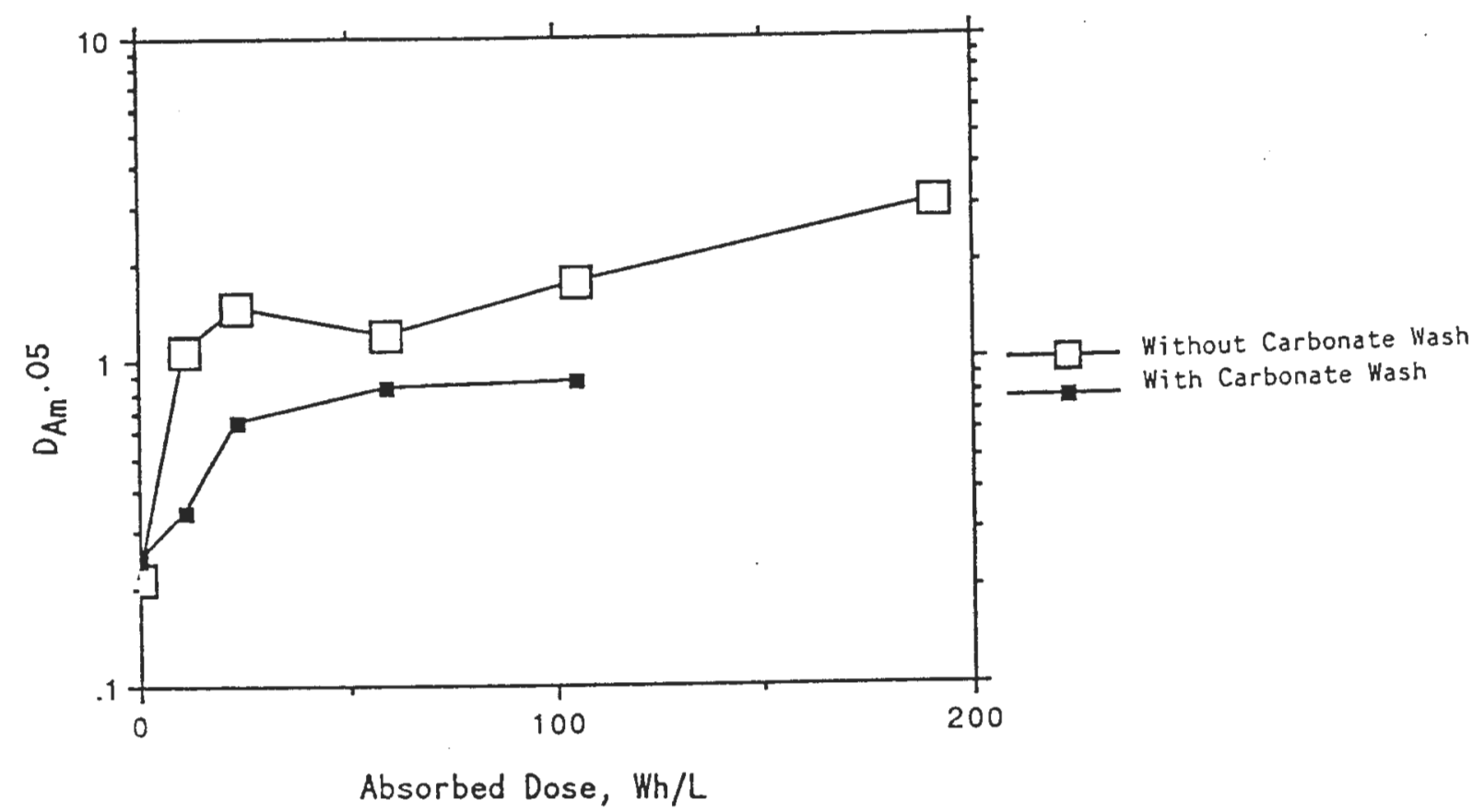

Fig. E-6. $\mathrm{D}_{\mathrm{Am}}^{.05}$ as a Function of Dose Absorbed by Solvent Irradiated in Contact with 6.0M $\mathrm{HNO}_{3}$. Comparison of solvent samples washed with aqueous sodium carbonate following irradiation with those that were not.

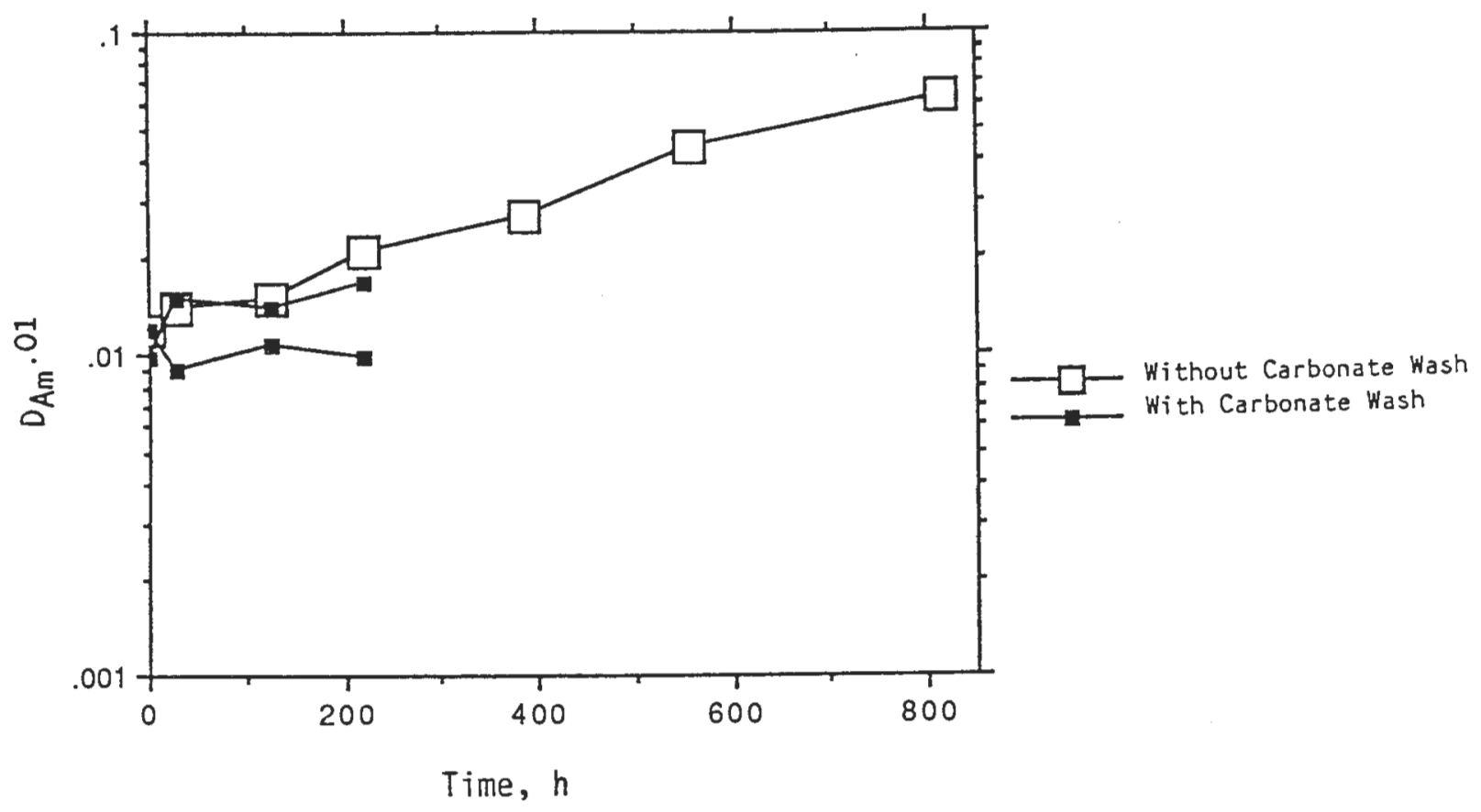

Fig. E-7. $\mathrm{D}_{\mathrm{Am}}{ }^{.01}$ as a Function of Reaction Time for Hydrolysis of Solvent by $2.5 \mathrm{M} \mathrm{HNO}_{3}$ at $50^{\circ} \mathrm{C}$. Comparison of solvent samples washed with aqueous sodium carbonate following hydrolysis with those that were not. 


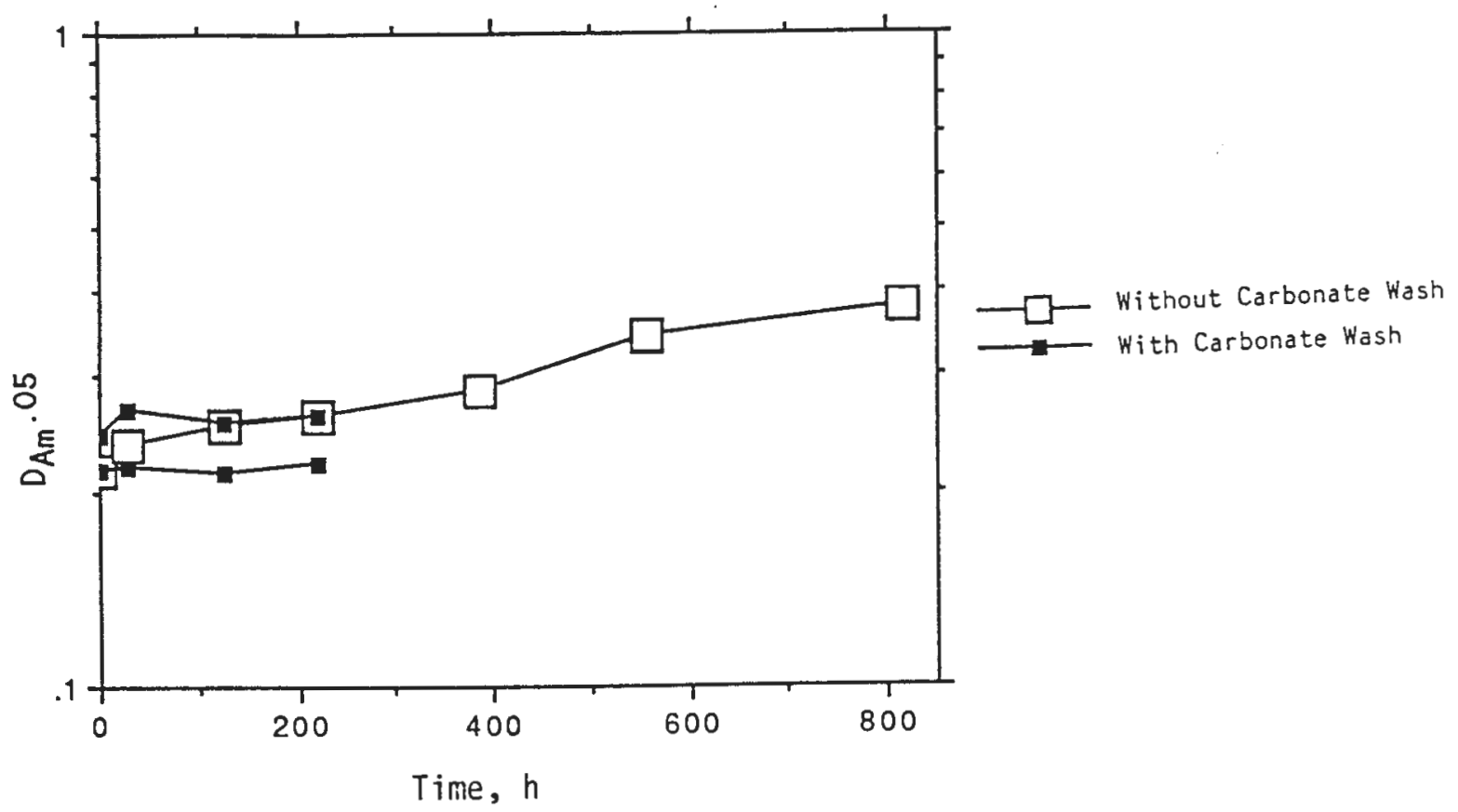

Fig. E-8. $\mathrm{D}_{\mathrm{Am}}^{.05}$ as a Function of Reaction Time for Hydrolysis of Solvent by $2.5 \mathrm{M} \mathrm{HNO}_{3}$ at $50^{\circ} \mathrm{C}$. Comparison of solvent samples washed with aqueous sodium carbonate following hydrolysis with those that were not.

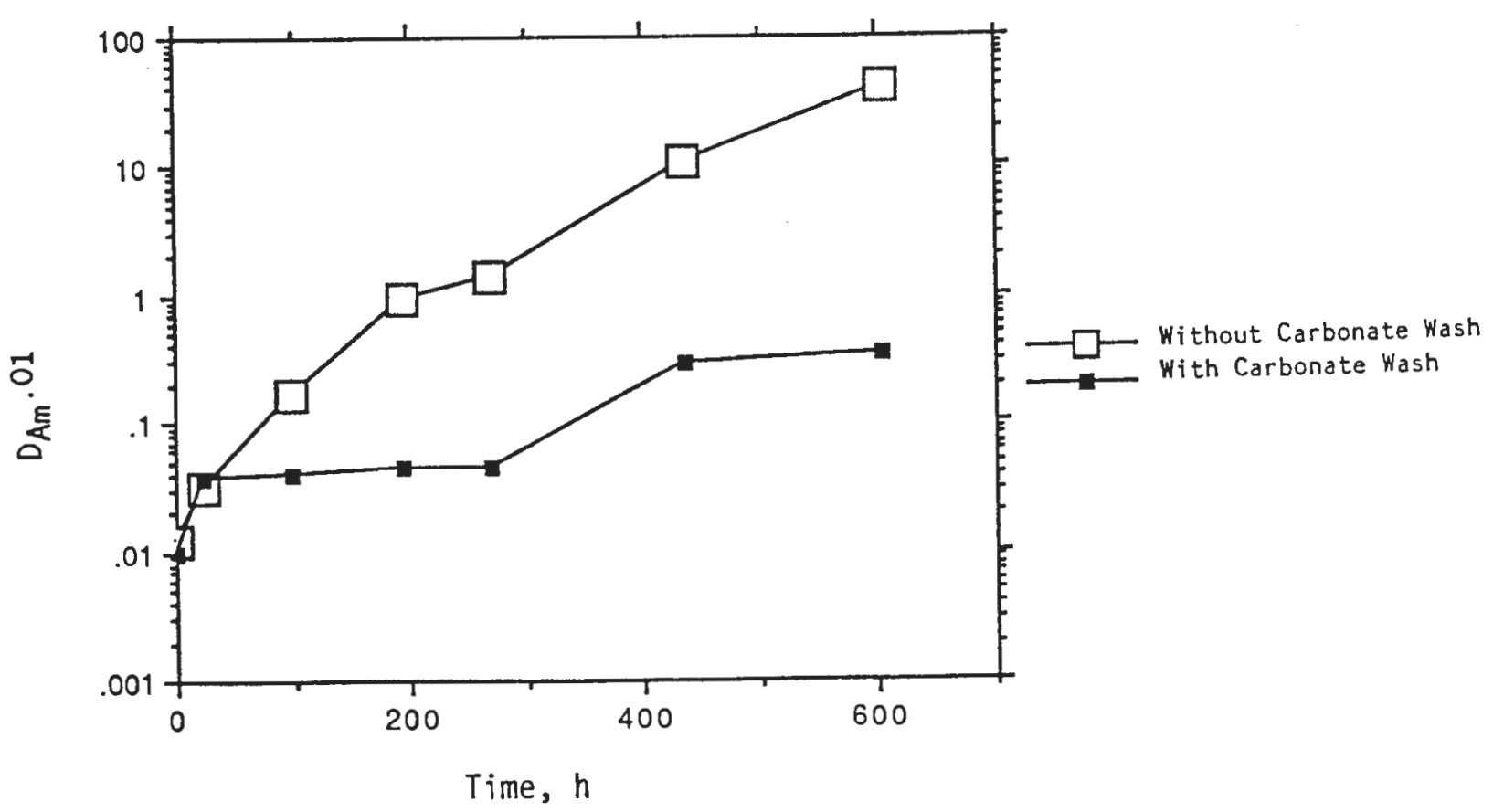

Fig. E-9. $\mathrm{D}_{\mathrm{Am}}^{.01}$ as a Function of Reaction Time for Hydrolysis of Solvent by $2.5 \mathrm{M} \mathrm{HNO}_{3}$ at $70^{\circ} \mathrm{C}$. Comparison of solvent samples washed with aqueous sodium carbonate following hydrolysis with those that were not. 


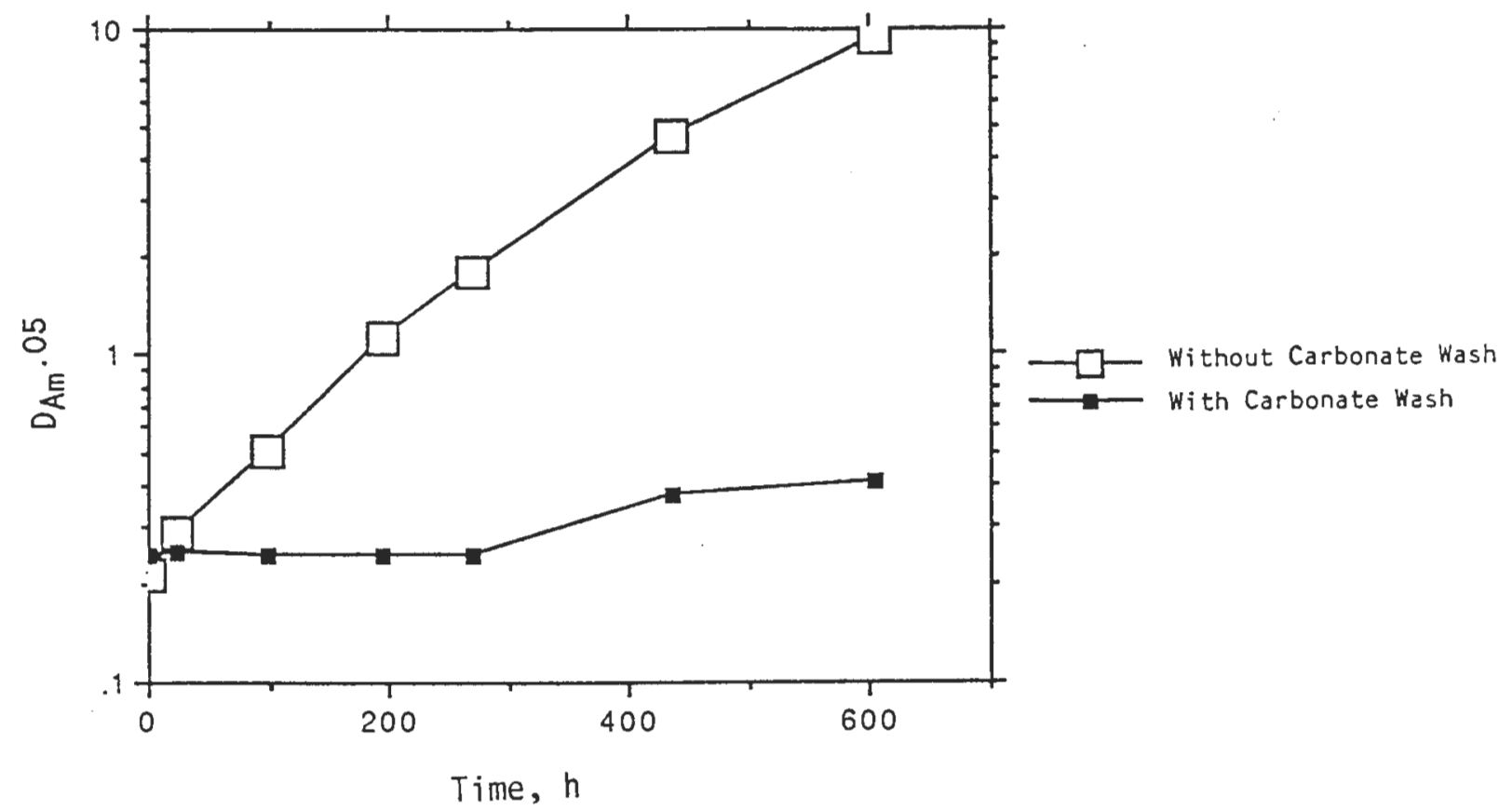

Fig. E-10. $\mathrm{D}_{\mathrm{Am}}^{.05}$ as a Function of Reaction Time for Hydrolysis of Solvent by $2.5 \underline{\mathrm{M}} \mathrm{HNO}_{3}$ at $70^{\circ} \mathrm{C}$. Comparison of solvent samples washed with aqueous sodium carbonate following hydrolysis with those that were not.

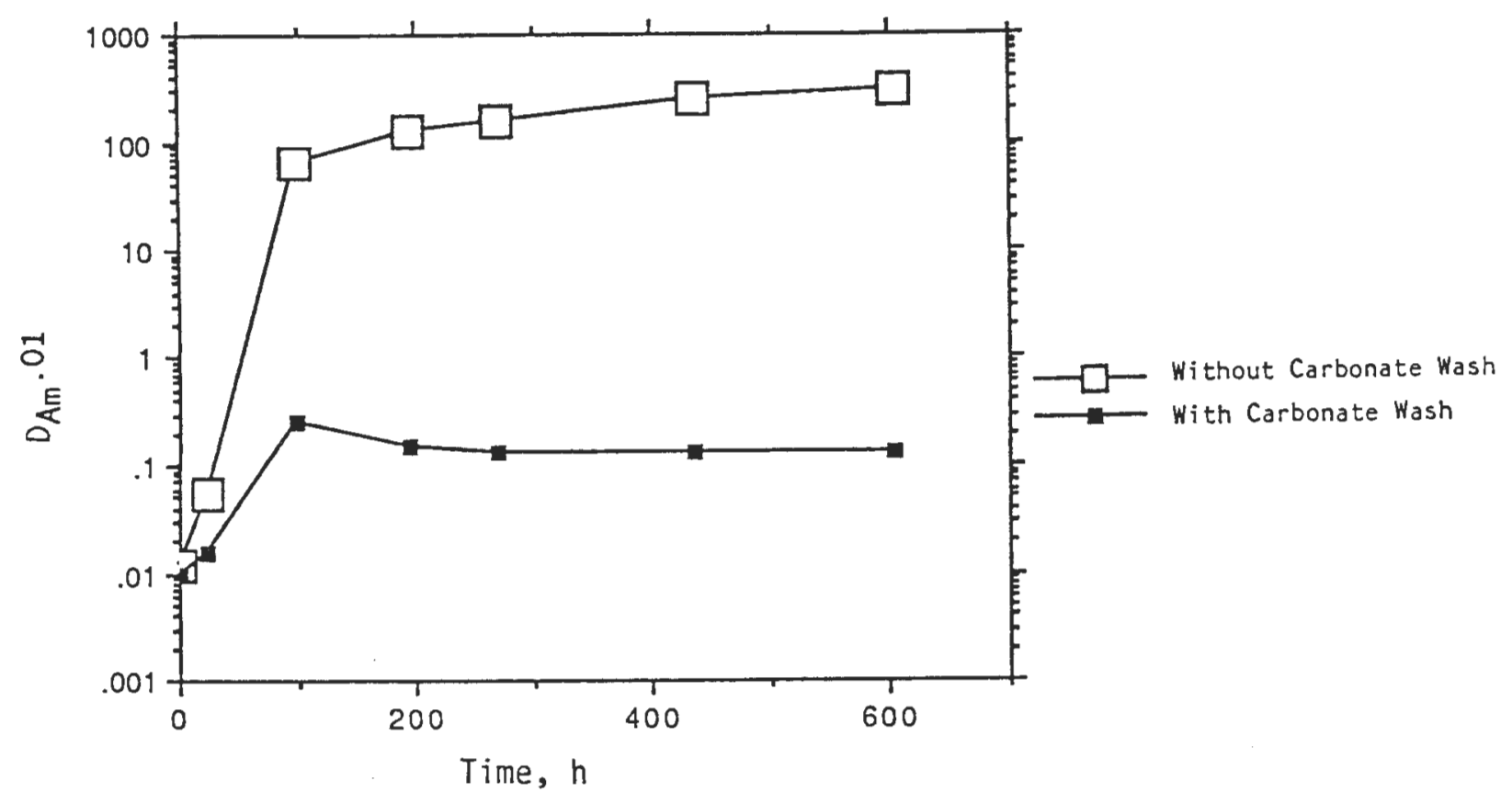

Fig. E-11. $\mathrm{D}_{\mathrm{Am}}^{.01}$ as a Function of Reaction Time for Hydrolysis of Solvent by $6.0 \mathrm{M} \mathrm{HNO}_{3}$ at $70^{\circ} \mathrm{C}$. Comparison of solvent samples washed with aqueous sodium carbonate following hydrolysis with those that were not. 


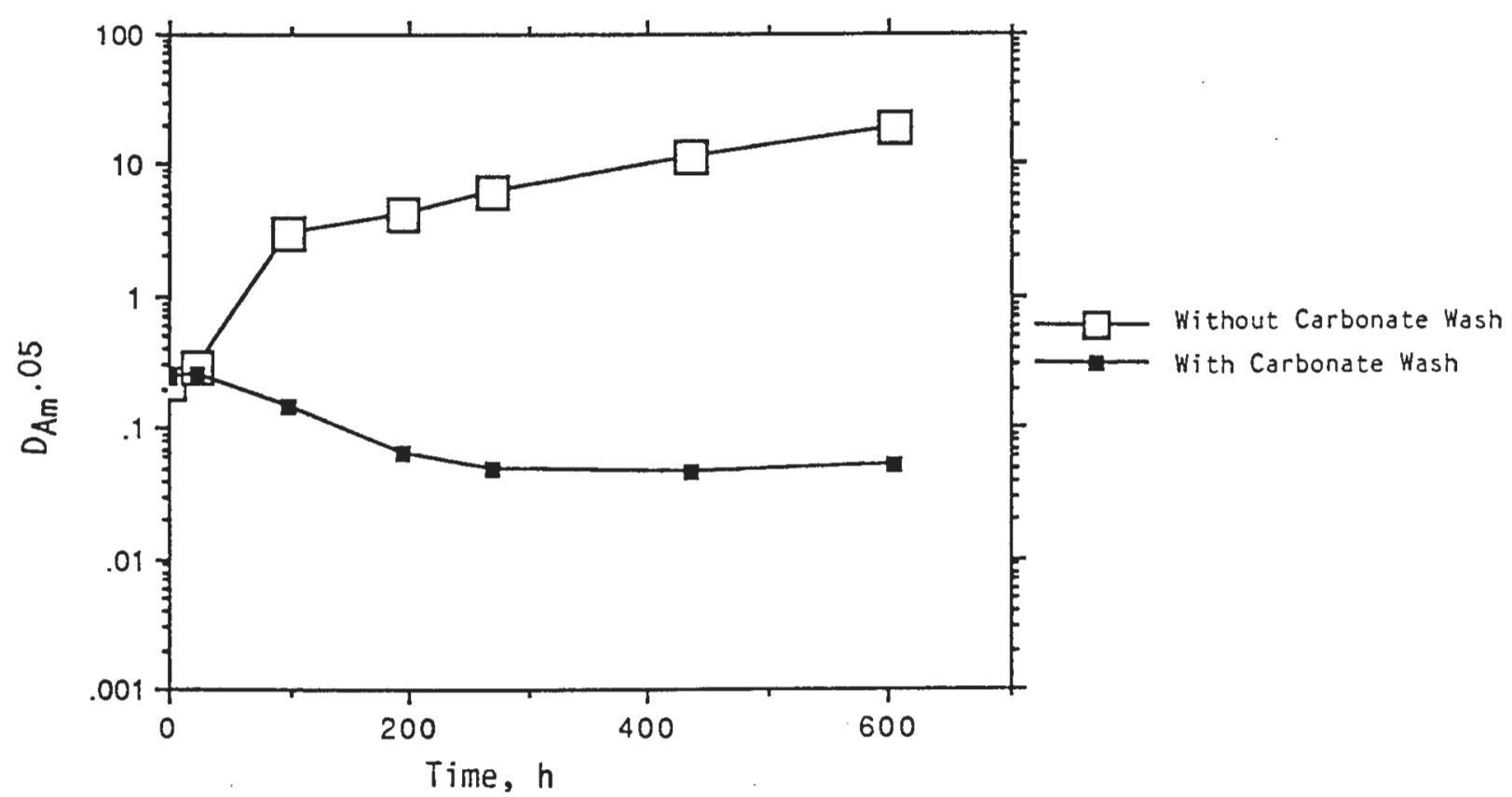

Fig. E-12. $\mathrm{D}_{\mathrm{Am}}{ }^{.05}$ as a Function of Reaction Time for Hydrolysis of Solvent by $6.0 \mathrm{M} \mathrm{HNO}_{3}$ at $70^{\circ} \mathrm{C}$. Comparison of solvent samples washed with aqueous sodium carbonate following hydrolysis with those that were not.

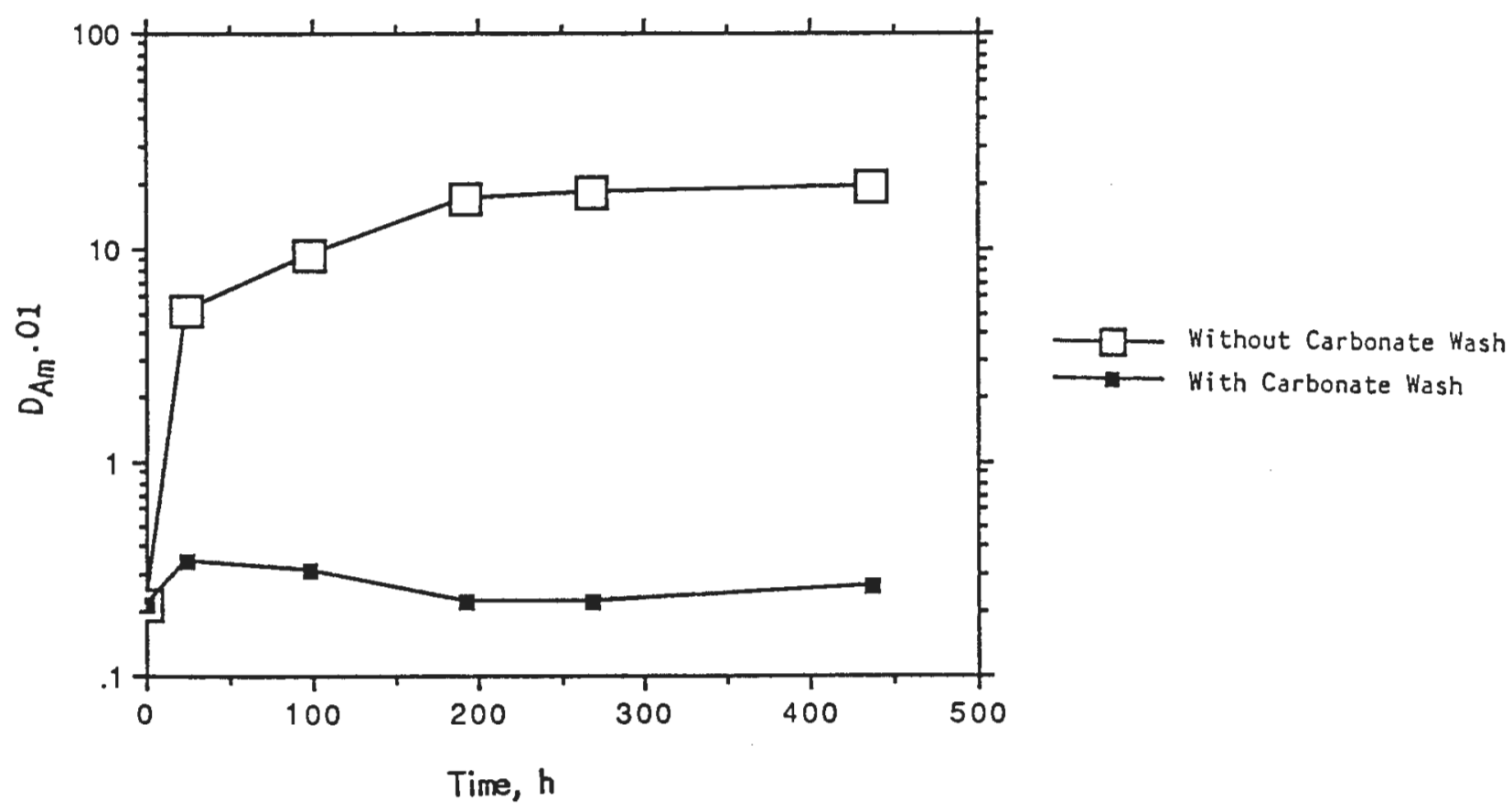

Fig. E-13. $\mathrm{D}_{\mathrm{Am}}^{.01}$ as a Function of Reaction Time for Hydrolysis of Solvent by Simulated CAW Containing $1.6 \mathrm{M} \mathrm{HNO}_{3}$ at $70^{\circ} \mathrm{C}$. Comparison of solvent samples washed with aqueous sodium carbonate following hydrolysis with those that were not. 


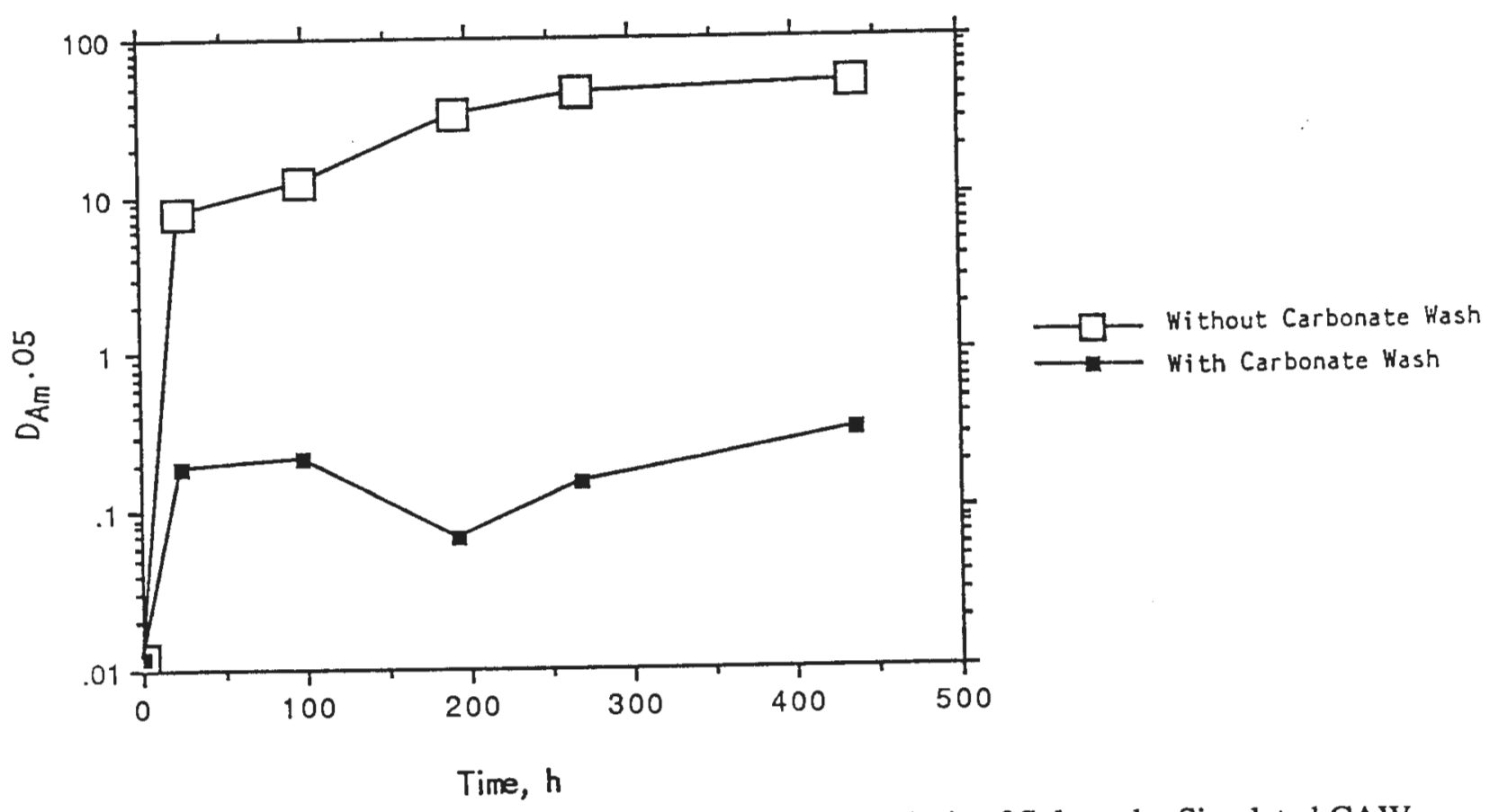

Fig. E-14. $\mathrm{D}_{\mathrm{Am}}{ }^{.05}$ as a Function of Reaction Time for Hydrolysis of Solvent by Simulated CAW Containing $1.6 \mathrm{M} \mathrm{HNO}_{3}$ at $70^{\circ} \mathrm{C}$. Comparison of solvent samples washed with aqueous sodium carbonate following hydrolysis with those that were not. 


\section{APPENDIX F. ACIDITY OF ORGANIC AND AQUEOUS PHASES}

\section{Procedures for Determining Acidity Changes}

The concentration of acidic species in a sample of solvent was determined by washing with water, diluting the washings to a measured volume, and titrating an aliquot of it with standard base. Degraded solvent was centrifuged, and a measured portion of 6-8 mL organic phase was withdrawn for analysis. If the acid was originally $0.25 \underline{\mathrm{M}}$, the wash was one part organic to one part aqueous; otherwise, the ratio was 1 to 3. For TRUEX-NPH samples in contact with just nitric acid, the sample was washed three times with water. The washings from each organic sample were collected and diluted to a standard volume with distilled water. From each flask of collected washings, two aliquots were withdrawn. Each aliquot was titrated against a standard solution of $0.1 \mathrm{M} \mathrm{NaOH}$, using a buret with 1- or 10-mL capacity. End points of the titrations were determined with a Metrohm 670 Titroprocessor. For a few cases, the acidity of aqueous nitric acid that had been in contact with solvent during radiolysis or hydrolysis was determined by similar titrations.

\section{Acidity in Aqueous Phase Resulting from Radiolysis}

Analyses for the change of acidity in aqueous $\mathrm{HNO}_{3}$, initially $0.25 \underline{\mathrm{M}}$, irradiated in contact with TRUEX-NPH solvent are presented in Fig. F-1 as a graph of $\left[\mathrm{H}^{+}\right]$versus dose. In this system, there is a definite increase of $\left[\mathrm{H}^{+}\right]$with dose, which can be expressed by an equation similar to Eq. III-9,

$$
\left[\mathrm{H}^{+}\right]=\left[\mathrm{H}^{+}\right]_{0}+(\mathrm{G})(\mathrm{M}) \quad(\mathrm{P})(\mathrm{t})
$$

where $\left[\mathrm{H}^{+}\right]_{0}=$ initial concentration of hydrogen ion in the aqueous phase

$\mathrm{G}=$ radiation chemical yield, $\mathrm{H}$ ions $\mathrm{J}^{-1}$ (hydrogen ions appearing in aqueous phase per 100 eV absorbed by solvent)

$\mathrm{M}, \mathrm{P}$, and $\mathrm{t}$ are defined in Sec. III.

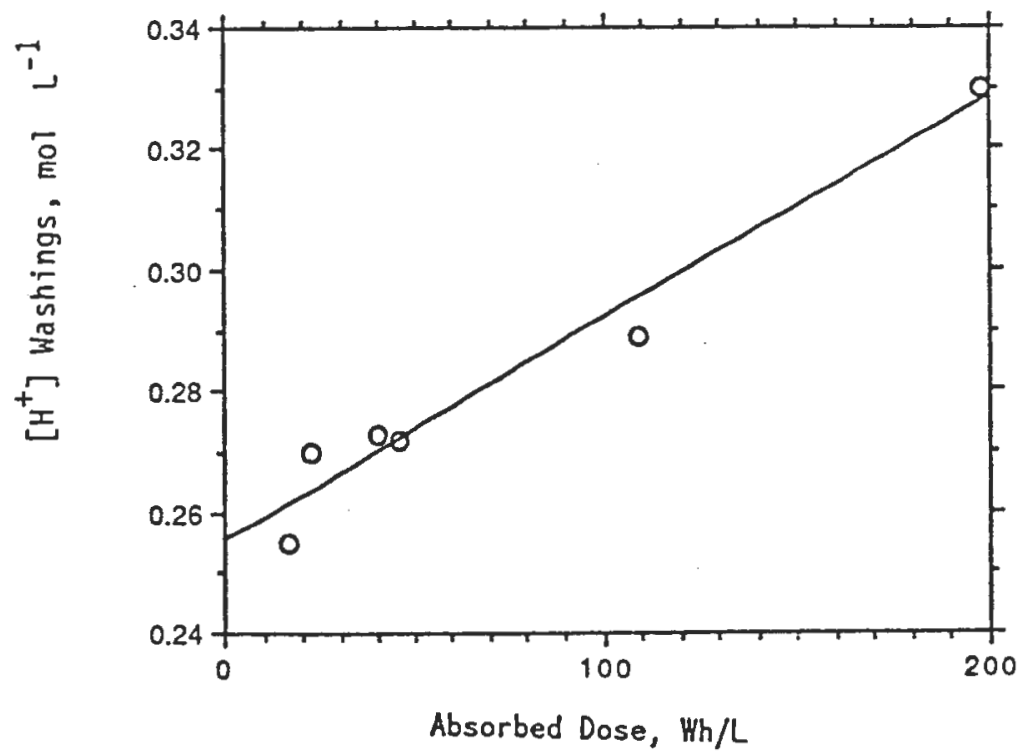

Fig. F-1. Acidity of the Aqueous Phase, Initially $0.25 \underline{\mathrm{M}} \mathrm{HNO}_{3}$, in Contact with TRUEX-NPH Solvent versus Radiation Dose Absorbed by the Solvent 
The slope of the graph in Fig. F-1 is $3.653 \times 10^{-4} \mathrm{~mol} \mathrm{~W}^{-1} \mathrm{~h}^{-1}$. From this slope, a G value can be calculated for the increase of $\left[\mathrm{H}^{+}\right]$in the aqueous phase, as follows:

$$
\begin{aligned}
& G=\left[\left(3.853 \times 10^{-4} \text { mol } W^{-1} h^{-1}\right)\right], \\
& {\left[3.73 \times 10^{-4} \text { molecules }{ }^{-1} \mathrm{~W}^{-1} \mathrm{~h}^{-1}(100 \mathrm{eV}) \mathrm{mol}\right]} \\
& =0.98 \mathrm{H} \text { ions } / 100 \mathrm{eV}\left(6.1 \times 10^{18} \mathrm{H} \text { ions } \mathrm{J}^{-1}\right)
\end{aligned}
$$

The relatively small difference between this value and the value of 0.76 molecule $/ 100 \mathrm{eV}$ for destruction of CMPO (Sec. III) suggests that the destruction of a molecule of CMPO and the appearance of a hydrogen ion in the aqueous phase are related.

Analyses for the acidity change in the aqueous $\mathrm{HNO}_{3}$, initially $6.0 \mathrm{M}$, irradiated in contact with TRUEX-NPH solvent are sparse and do not provide a basis for deriving an expression of $\left[\mathrm{H}^{+}\right]$as a function of dose or for determining a $G$ value for the appearance of $\left[\mathrm{H}^{+}\right]$in the aqueous phase. Figure $\mathrm{F}-2$ shows, however, that the data could be represented by a line having the same slope (i.e., same radiation chemical yield) as the $0.25 \underline{\mathrm{M}}$ system and passing through a point determined by the average value of $\mathrm{H}^{+}$ and the average dose.

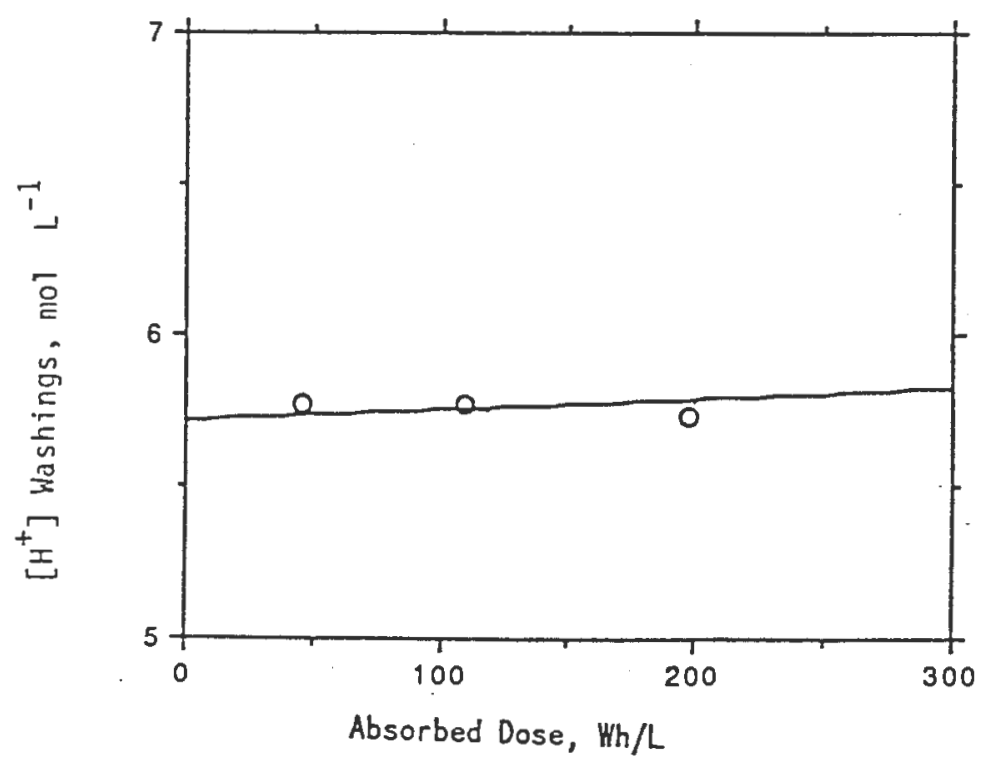

Fig. F-2. Acidity of the Aqueous Phase, Initially 6.0 $\mathrm{MNNO}_{3}$, in Contact with TRUEX-NPH Solvent versus Radiation Dose Absorbed by the Solvent

\section{Acidity in Organic Phase Resulting from Radiolysis}

Acidity changes in the organic phase hydrolyzed in contact with aqueous $\mathrm{HNO}_{3}$ were determined for systems in which the acid concentrations were initially $0.25,2.5$, and $6.0 \mathrm{M}$. Variations of acidity in the organic phase with hydrolysis time are represented in Figs. F-3 to F-5. No attempt is made to derive an algebraic expression for rate of acidity change with hydrolysis time, but some general trends in the data are evident. The trends can be most readily viewed if the data are grouped according to the initial acidity of the aqueous phase in contact with the solvent. 


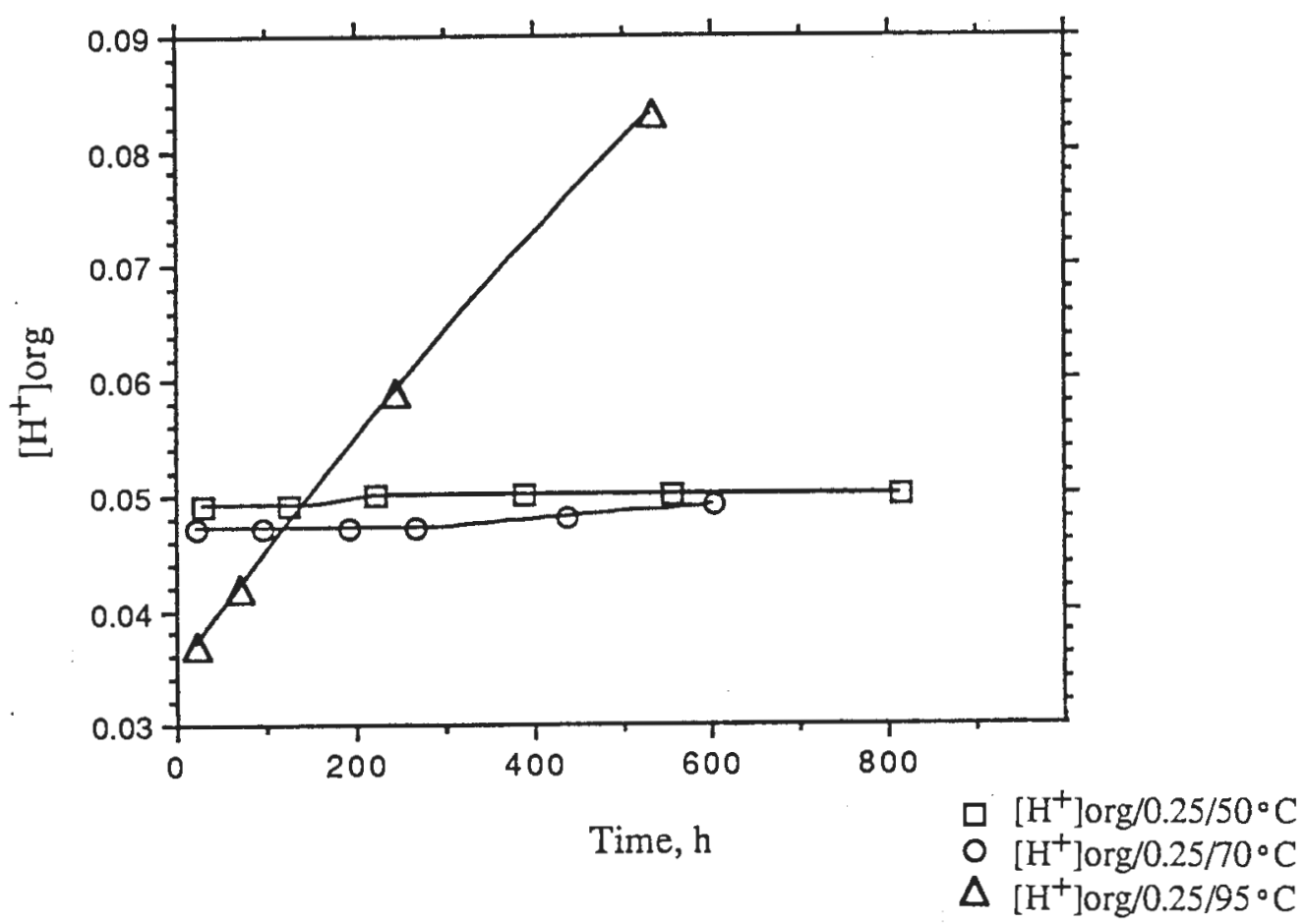

Fig. F-3. Change of Acidity in TRUEX-NPH Solvent versus Reaction Time at 50, 70, and $95^{\circ} \mathrm{C}$ in Contact with an Aqueous Phase That Was Initially $0.25 \underline{\mathrm{M}} \mathrm{HNO}_{3}$

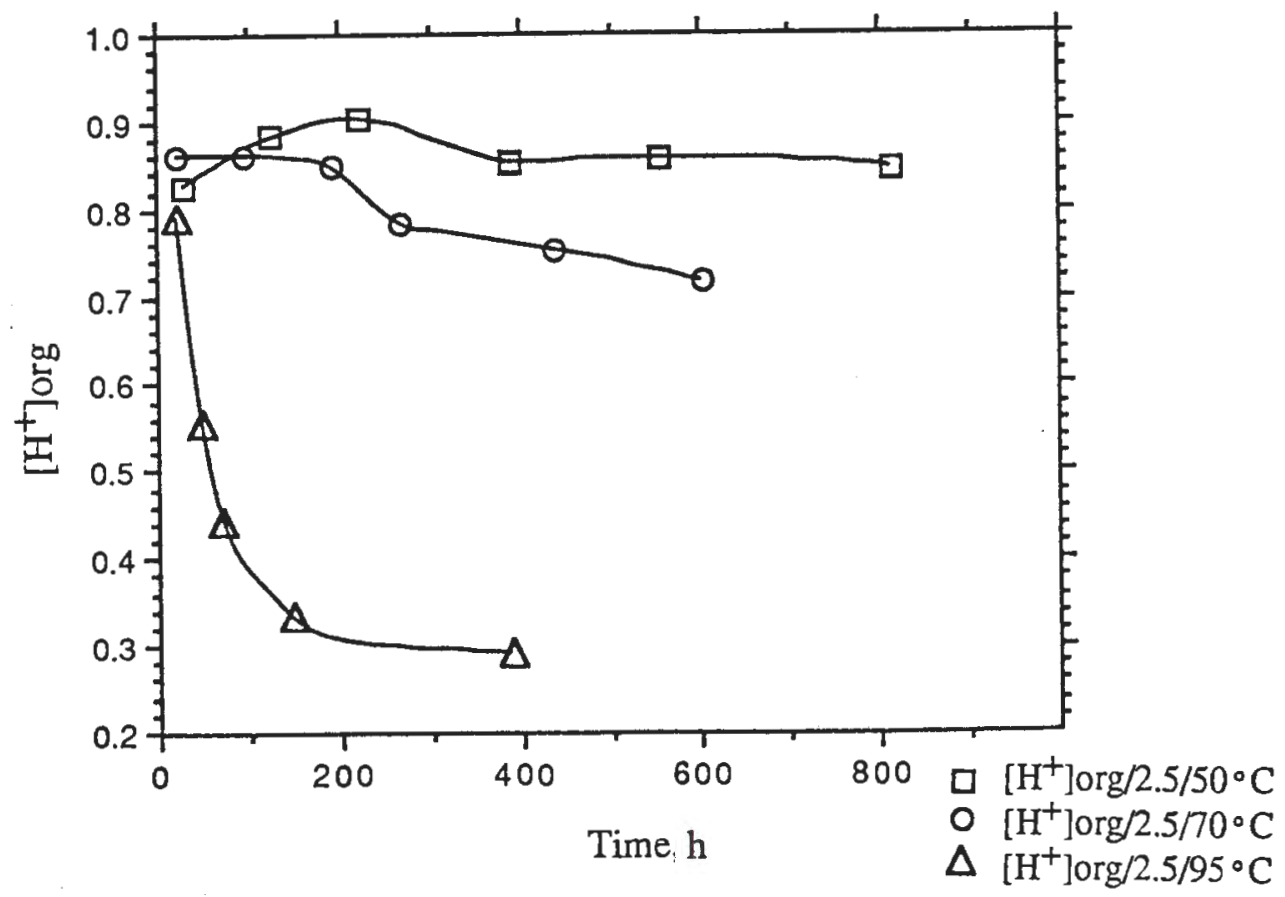

Fig. F-4. Change of Acidity in TRUEX-NPH Solvent versus Reaction Time at 50, 70, and $95^{\circ} \mathrm{C}$ in Contact with an Aqueous Phase That Was Initially $2.5 \underline{\mathrm{M}} \mathrm{HNO}_{3}$ 


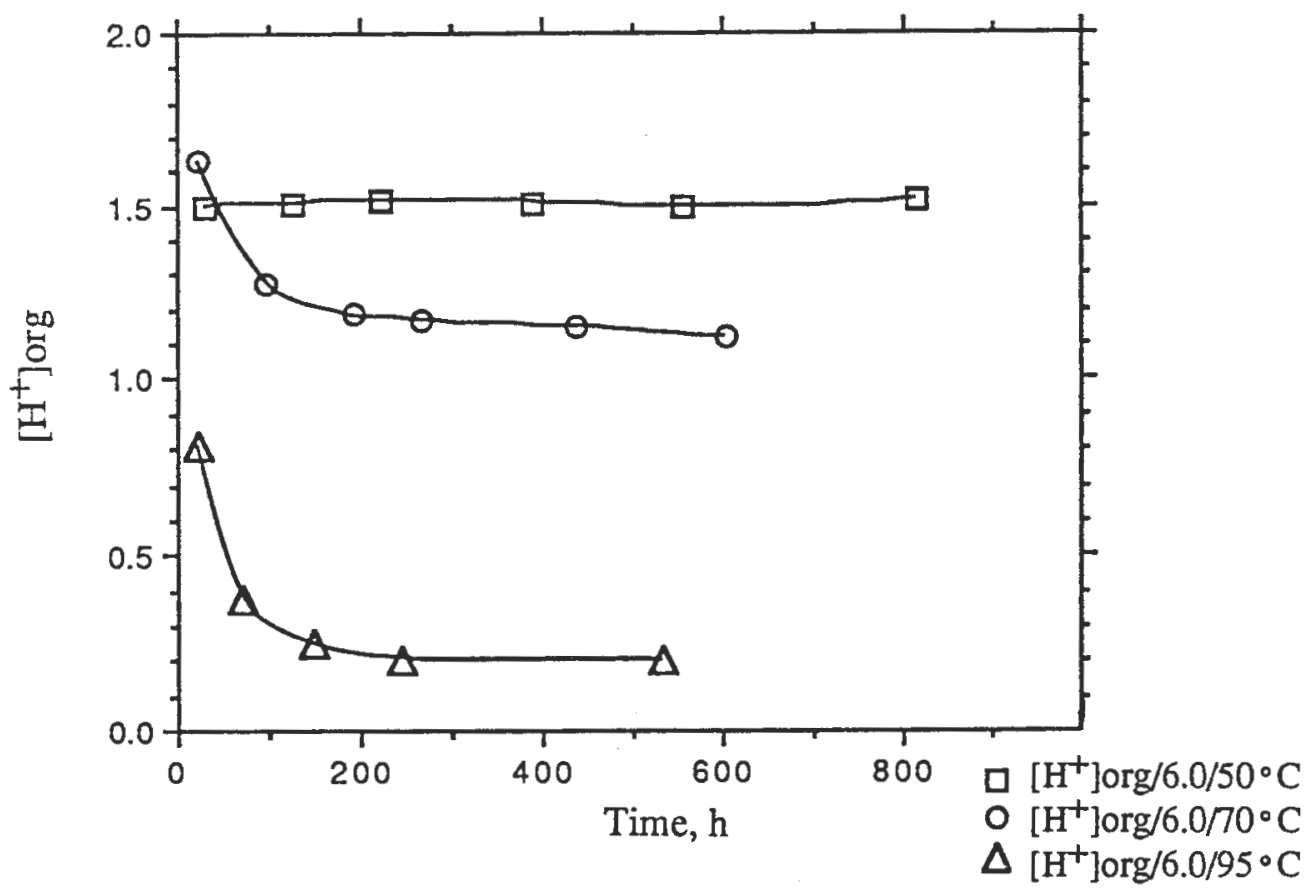

Fig. F-5. Change of Acidity in TRUEX-NPH Solvent versus Reaction Time at 50, 70, and $95^{\circ} \mathrm{C}$ in Contact with an Aqueous Phase That Was Initially 6.0 $\mathrm{M} \mathrm{HNO}_{3}$

Thus, Fig. F-3 shows the results obtained for hydrolysis in contact with $0.25 \underline{\mathrm{M}} \mathrm{HNO}_{3}$. At this acidity, there is little change for hydrolysis at $50^{\circ}$ and $70^{\circ} \mathrm{C}$; the rate of acidity change accompanying hydrolysis at $95^{\circ} \mathrm{C}$ seems inconsistent with results at the two lower temperatures.

Figure F-4 shows the results obtained for hydrolysis of solvent in contact with $2.5 \underline{\mathrm{M}} \mathrm{HNO}_{3}$. In this system, the acidity definitely decreases for hydrolysis at $70^{\circ} \mathrm{C}$ and $95^{\circ} \mathrm{C}$ to a level that does not change after about $200 \mathrm{~h}$. The initial slopes of the curves show that the initial rates of acidity change increase in the same order as temperature, whereas the final acidity concentrations decrease as temperature increases. At $70^{\circ} \mathrm{C}$, the final acidity is about $87 \%$ of the initial acidity, and at $95^{\circ} \mathrm{C}$, the final acidity is about $37 \%$ of the initial acidity.

From Fig. F-5, showing the results obtained for hydrolysis of solvent in contact with $6.0 \mathrm{M}$ $\mathrm{HNO}_{3}$, it can be concluded that the general trends are similar to those described for hydrolysis of solvent in contact with $2.5 \mathrm{M} \mathrm{HNO}_{3}$. At $70^{\circ} \mathrm{C}$, the final acidity is about $73 \%$ of the initial acidity, and at $95^{\circ} \mathrm{C}$, the final acidity is about $25 \%$ of the initial acidity. 


\section{APPENDIX G. ANALYSES OF NONTRANSURANIC ELEMENTS IN DEGRADED SOLVENT EQUILIBRATED WITH SYNTHETIC WASTE SOLUTIONS}

Information on the effects of solvent degradation on nonTRU elements in distribution systems was obtained as follows. The TRUEX-NPH solvent was stirred in contact with simulated CAW solution for a measured time at a constant temperature of 50,70 , or $95^{\circ} \mathrm{C}$; then a sample of the organic phase was separated and washed with several portions of water. The collected washings were diluted to a standard volume, and an aliquot of this volume was removed and analyzed by the ICP method for a number of elements.

The ICP analyses of concentrations in the washings, reported in $\mu \mathrm{g} / \mathrm{mL}$, were used to calculate concentrations of each element in the solvent. Used for this purpose were volumes of solvent sample, collected washings of the sample, and an aliquot of the washings. The concentration was calculated as follows:

$$
\begin{aligned}
& \frac{\mu_{\mathrm{g}} \text { element }}{\mathrm{mL}} \bullet \frac{\mathrm{g}}{10^{8} \mu_{\mathrm{g}}} \bullet \frac{1}{\mathrm{at} . \text { wt. of element }} \frac{\text { mol }}{\mu_{\mathrm{g}}} \bullet \\
& \frac{\text { vol. aq. washings, mL }}{\text { vol. org. phase sample, mL }} \cdot \frac{10^{3} \mathrm{~mL}}{\mathrm{~L}}=\frac{\text { mol element }}{\mathrm{L}}
\end{aligned}
$$

The variation of concentration with hydrolysis time showed two general types of behavior:

(1) Concentrations are measurable and can be represented as a function of hydrolysis time. (See Figs. G-1 through G-18).

(2) Concentrations are so low that ICP analysis permits their expression only as maximum values that do not vary with hydrolysis time and do not depend regularly on temperature. (See Fig. G-19).

More detailed conclusions on these results are presented in Sec. VIII.

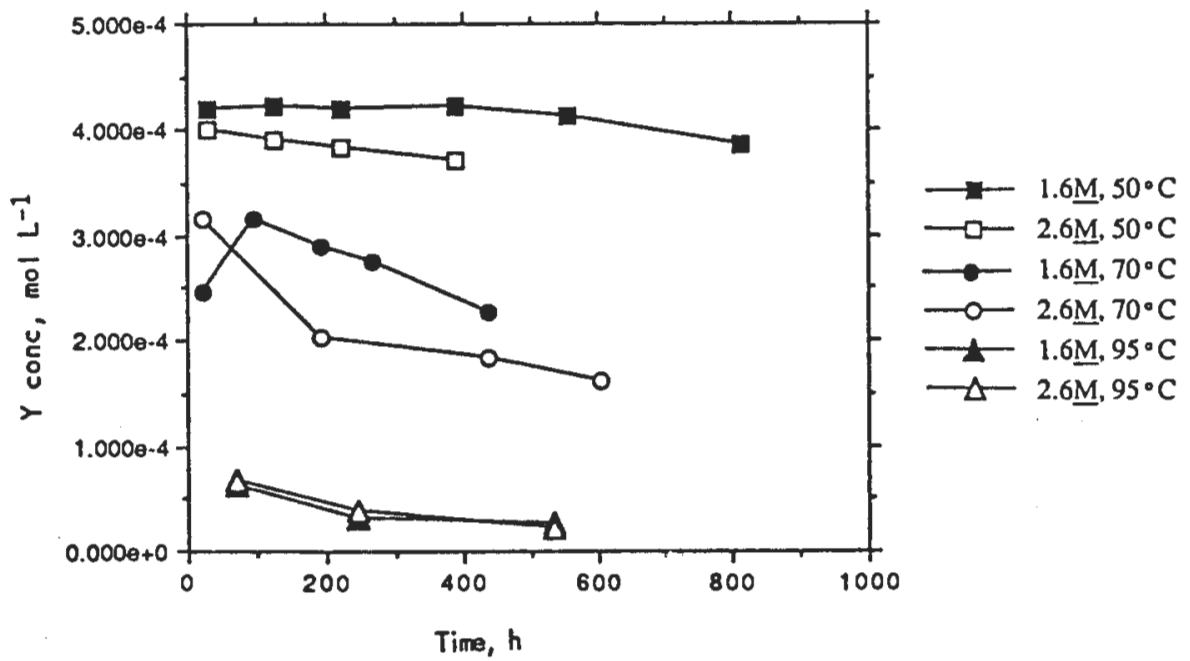

Fig. G-1. Concentration of Yttrium in TRUEX-NPH Solvent Degraded by Hydrolysis at 50,70 , or $95^{\circ} \mathrm{C}$ in Contact with Simulated CAW Containing 1.6 or $2.6 \mathrm{M} \mathrm{H}^{+}$ 


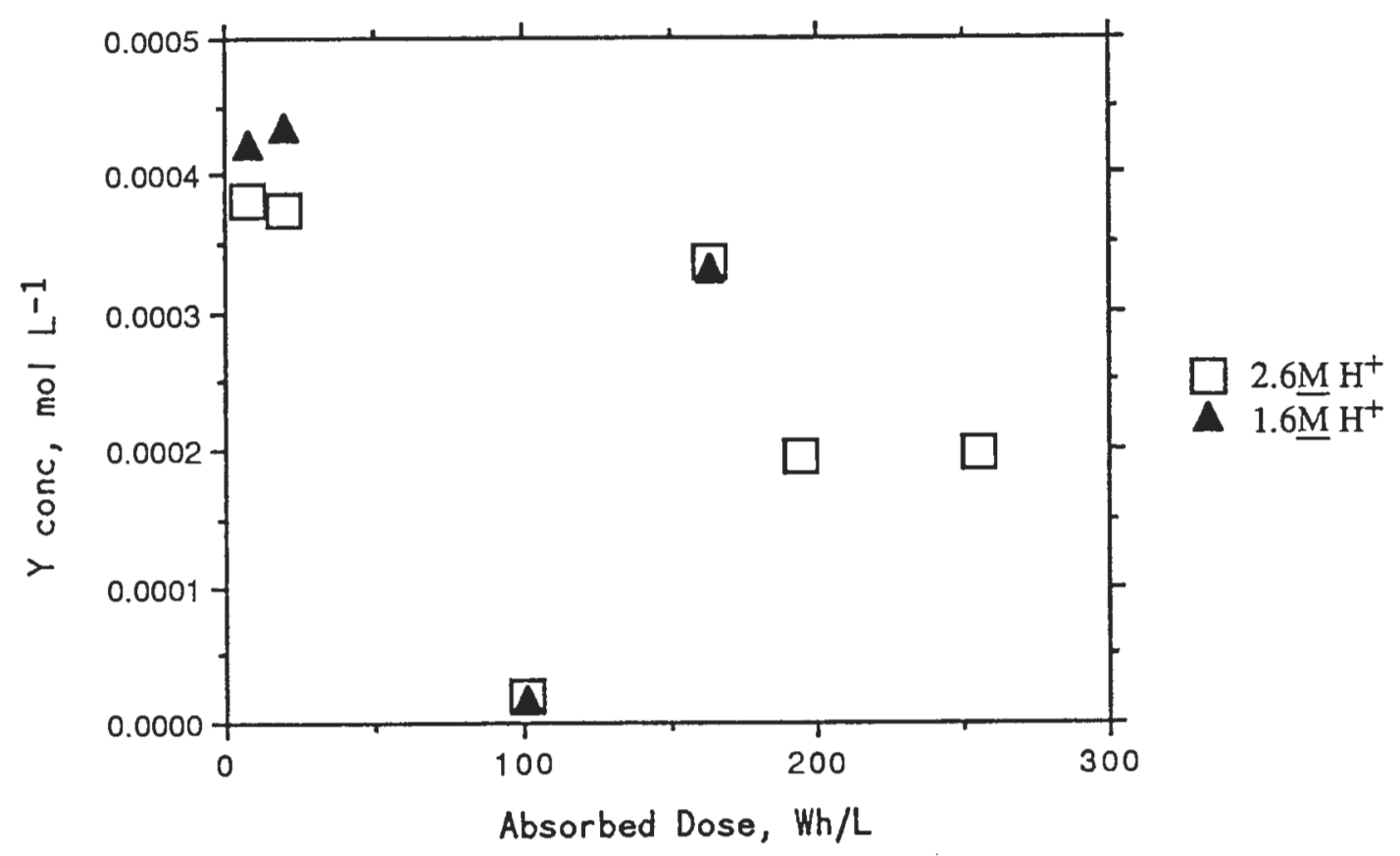

Fig. G-2. Concentration of Yttrium in TRUEX-NPH Solvent Degraded by Radiolysis at $50^{\circ} \mathrm{C}$ in Contact with Simulated CAW Containing 1.6 or $2.6 \mathrm{M} \mathrm{H} \mathrm{H}^{+}$

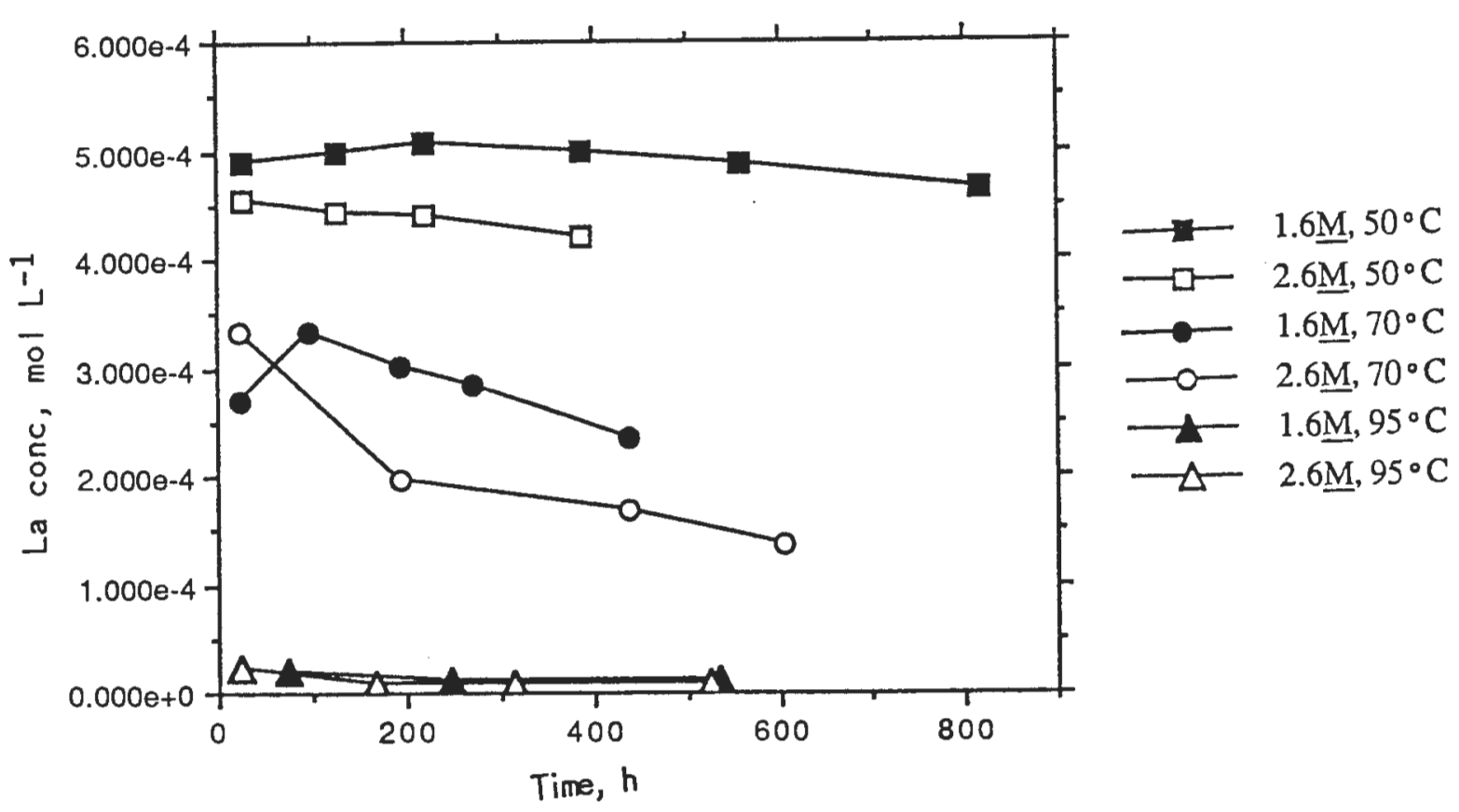

Fig. G-3. Concentration of Lanthanum in TRUEX-NPH Solvent Degraded by Hydrolysis at 50,70 , or $95^{\circ} \mathrm{C}$ in Contact with Simulated CAW Containing 1.6 or $2.6 \mathrm{M} \mathrm{H}{ }^{+}$ 


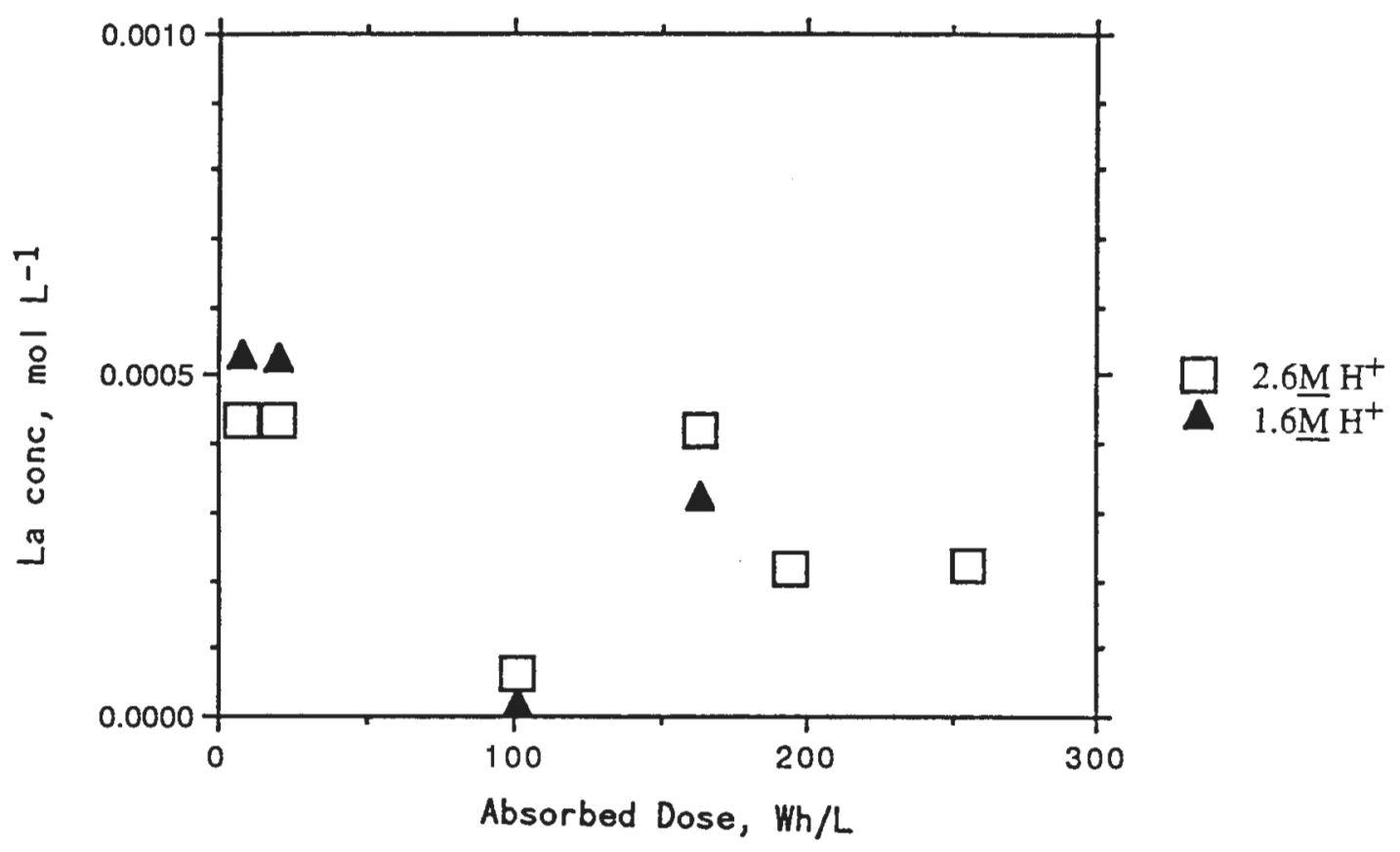

Fig. G-4. Concentration of Lanthanum in TRUEX-NPH Solvent Degraded by Radiolysis at $50^{\circ} \mathrm{C}$ in Contact with Simulated CAW Containing 1.6 or $2.6 \mathrm{M} \mathrm{H} \mathrm{H}^{+}$

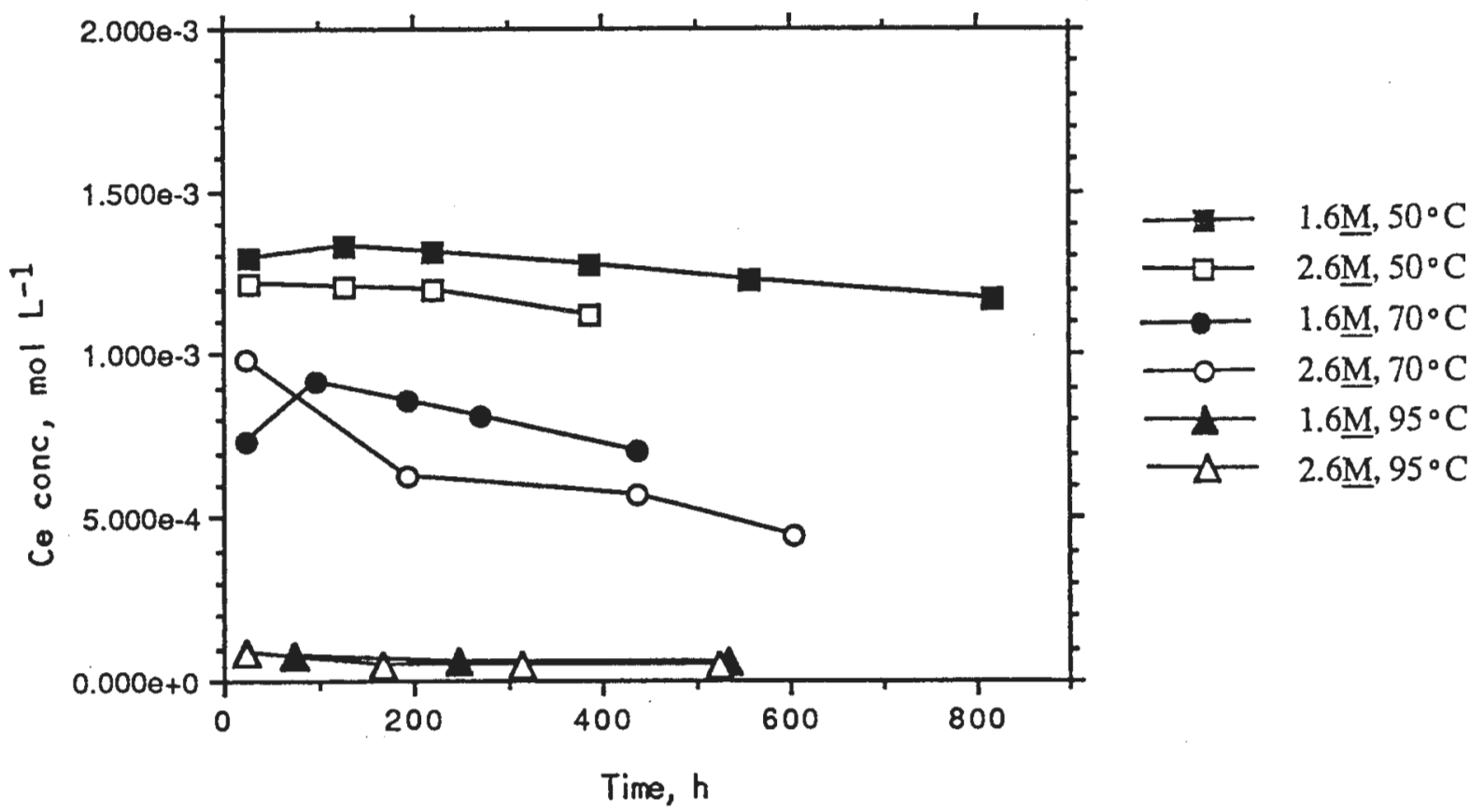

Fig. G-5. Concentration of Cerium in TRUEX-NPH Solvent Degraded by Hydrolysis at 50,70 , or $95^{\circ} \mathrm{C}$ in Contact with Simulated CAW Containing 1.6 or $2.6 \underline{\mathrm{M} \mathrm{H}^{+}}$ 


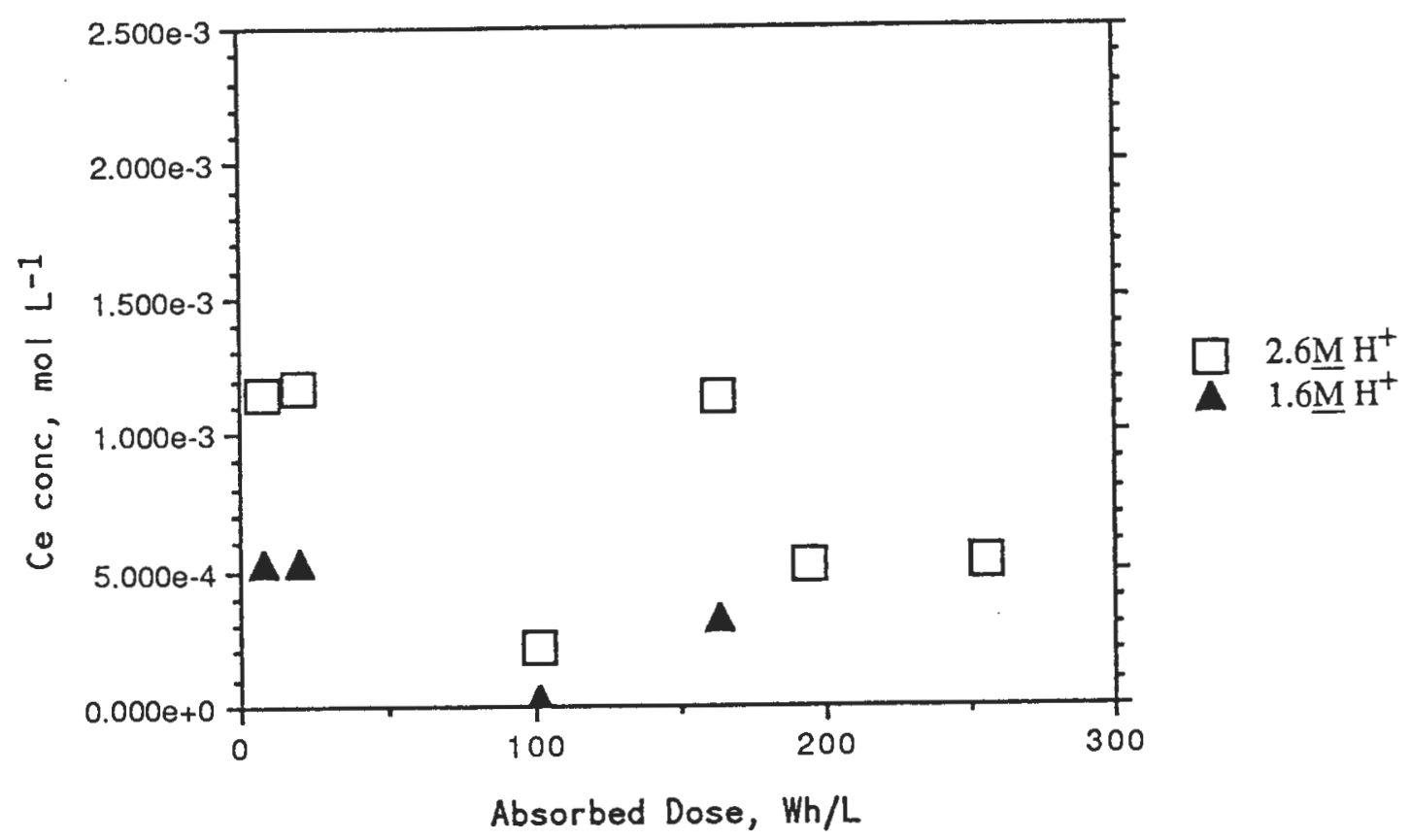

Fig. G-6. Concentration of Cerium in TRUEX-NPH Solvent Degraded by Radiolysis at $50^{\circ} \mathrm{C}$ in Contact with Simulated CAW Containing 1.6 or $2.6 \underline{\mathrm{M} \mathrm{H}^{+}}$

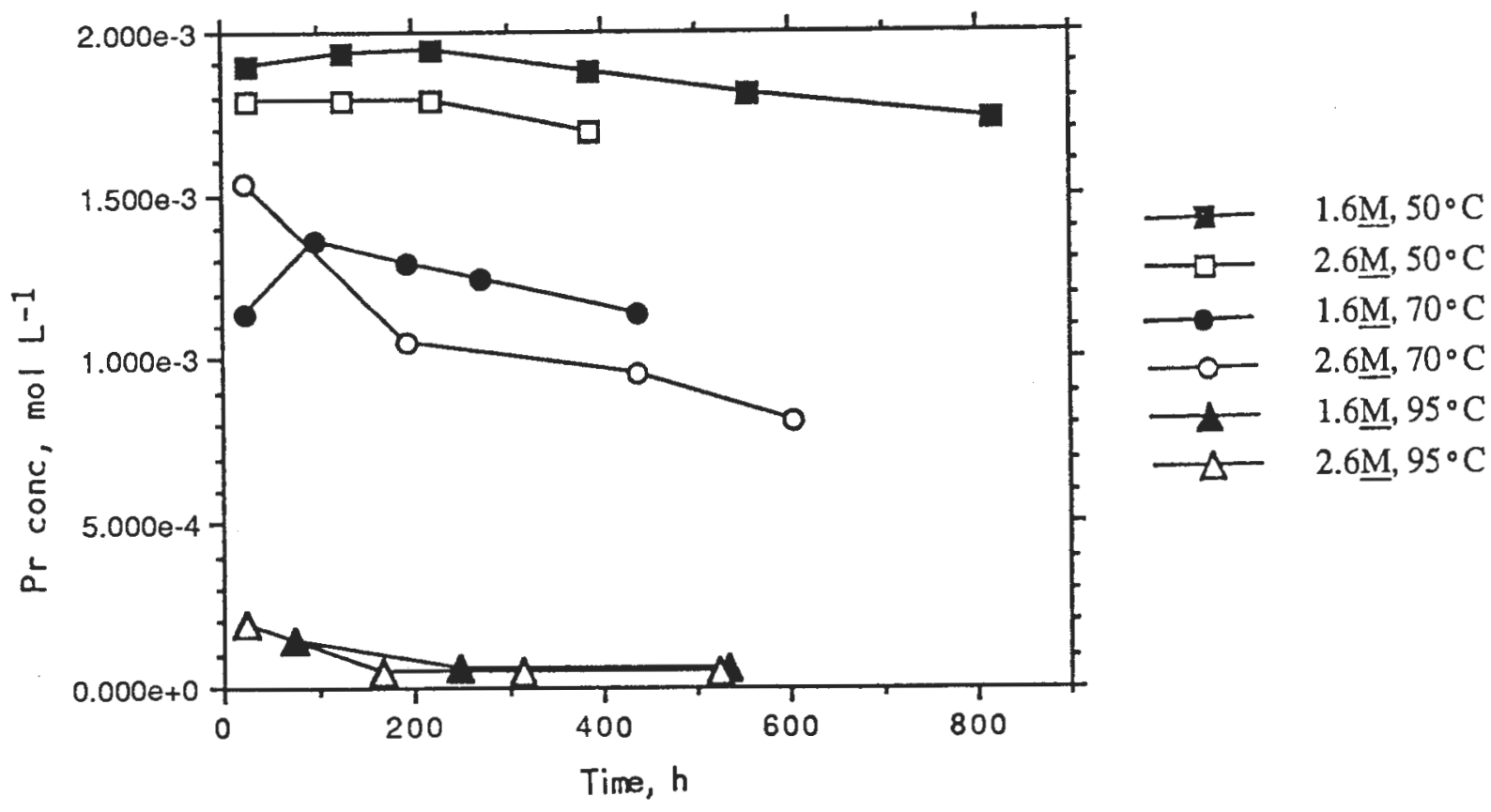

Fig. G-7. Concentration of Praseodymium in TRUEX-NPH Solvent Degraded by Hydrolysis at 50,70 , or $95^{\circ} \mathrm{C}$ in Contact with Simulated CAW Containing 1.6 or $2.6 \underline{\mathrm{M} \mathrm{H}}{ }^{+}$ 


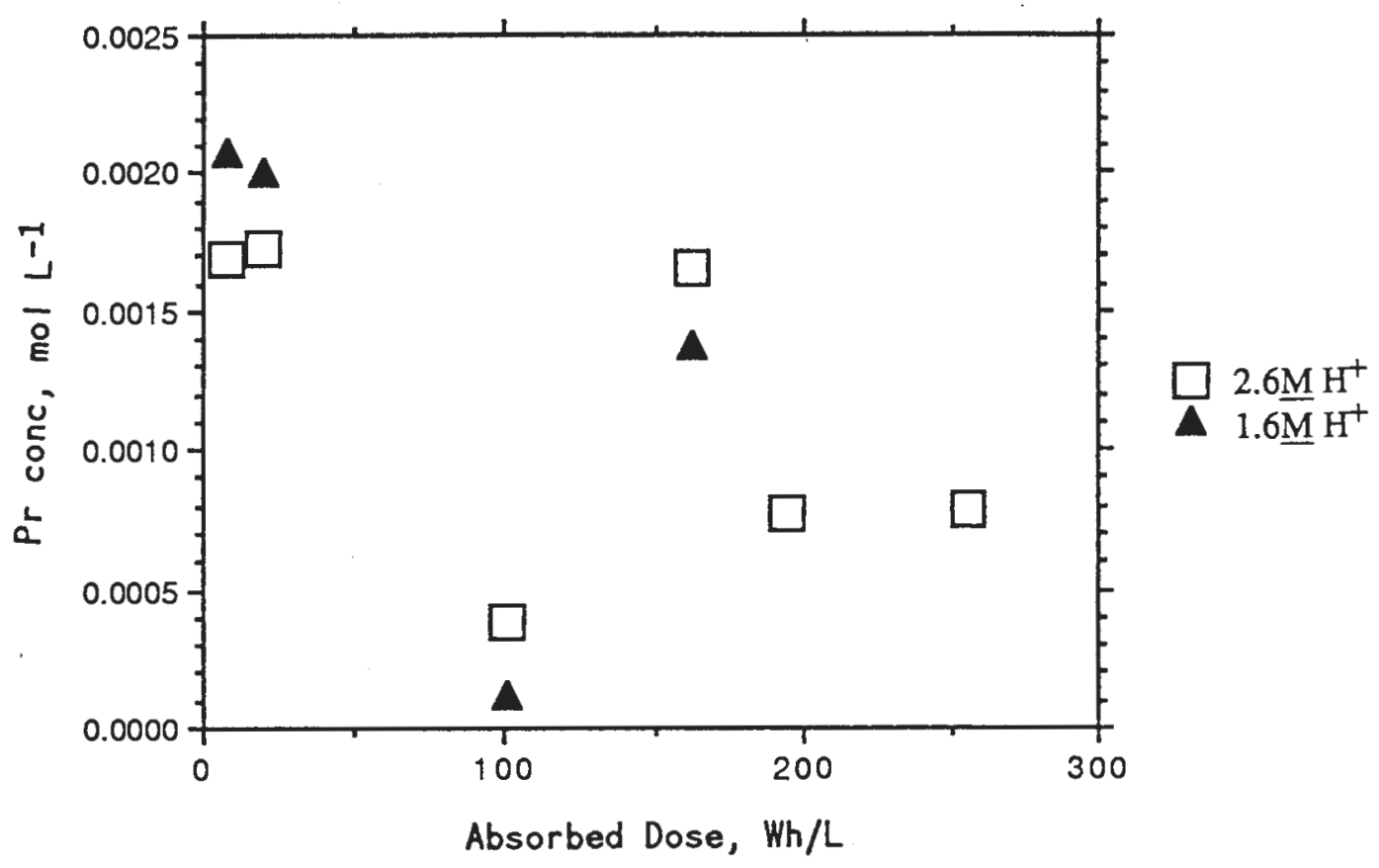

Fig. G-8. Concentration of Praseodymium in TRUEX-NPH Solvent Degraded by Radiolysis at $50^{\circ} \mathrm{C}$ in Contact with Simulated CAW Containing 1.6 or $2.6 \mathrm{M} \mathrm{H} \mathrm{H}^{+}$

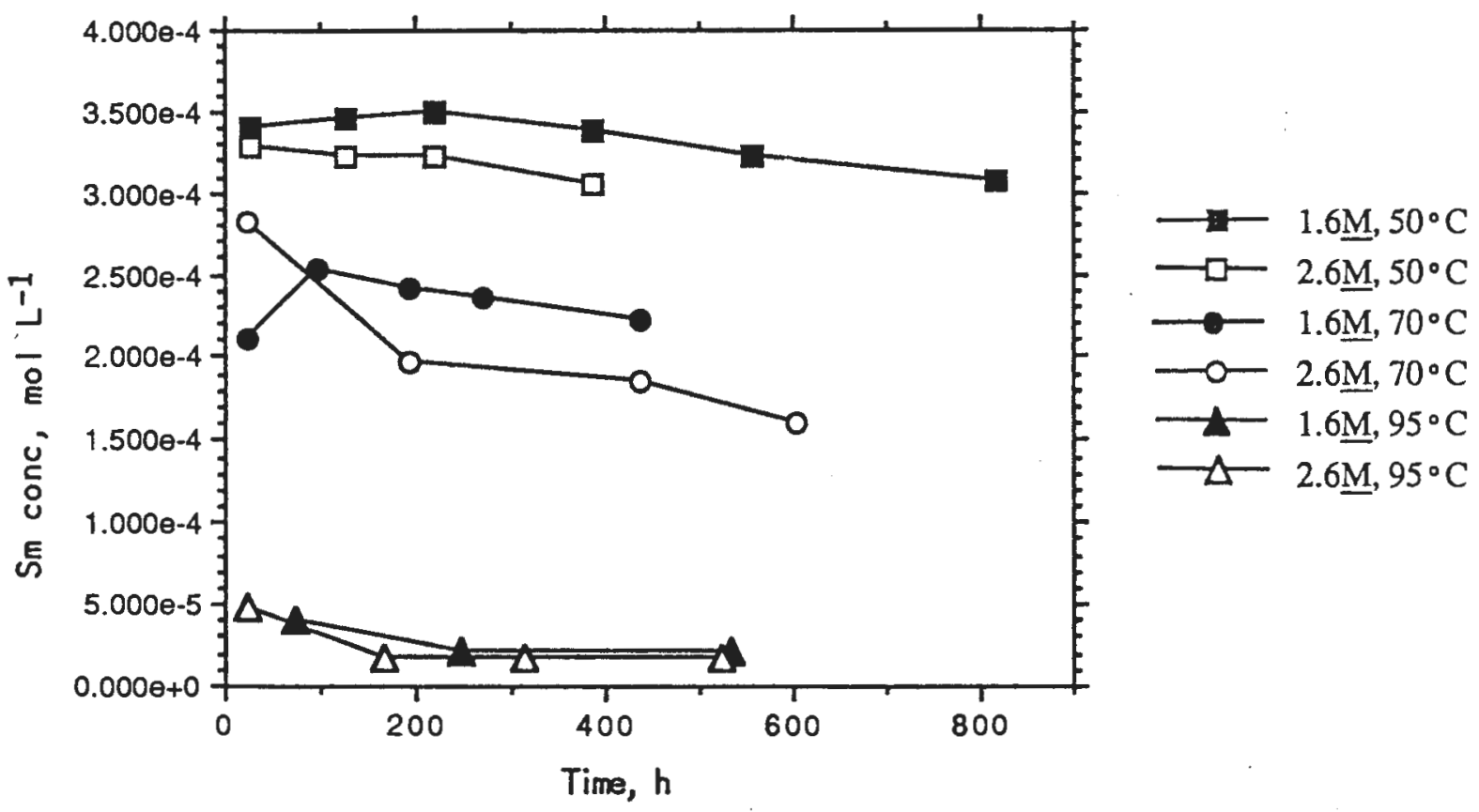

Fig. G-9. Concentration of Samarium in TRUEX-NPH Solvent Degraded by Hydrolysis at 50,70 , or $95^{\circ} \mathrm{C}$ in Contact with Simulated CAW Containing 1.6 or $2.6 \mathrm{M} \mathrm{H} \mathrm{H}^{+}$ 


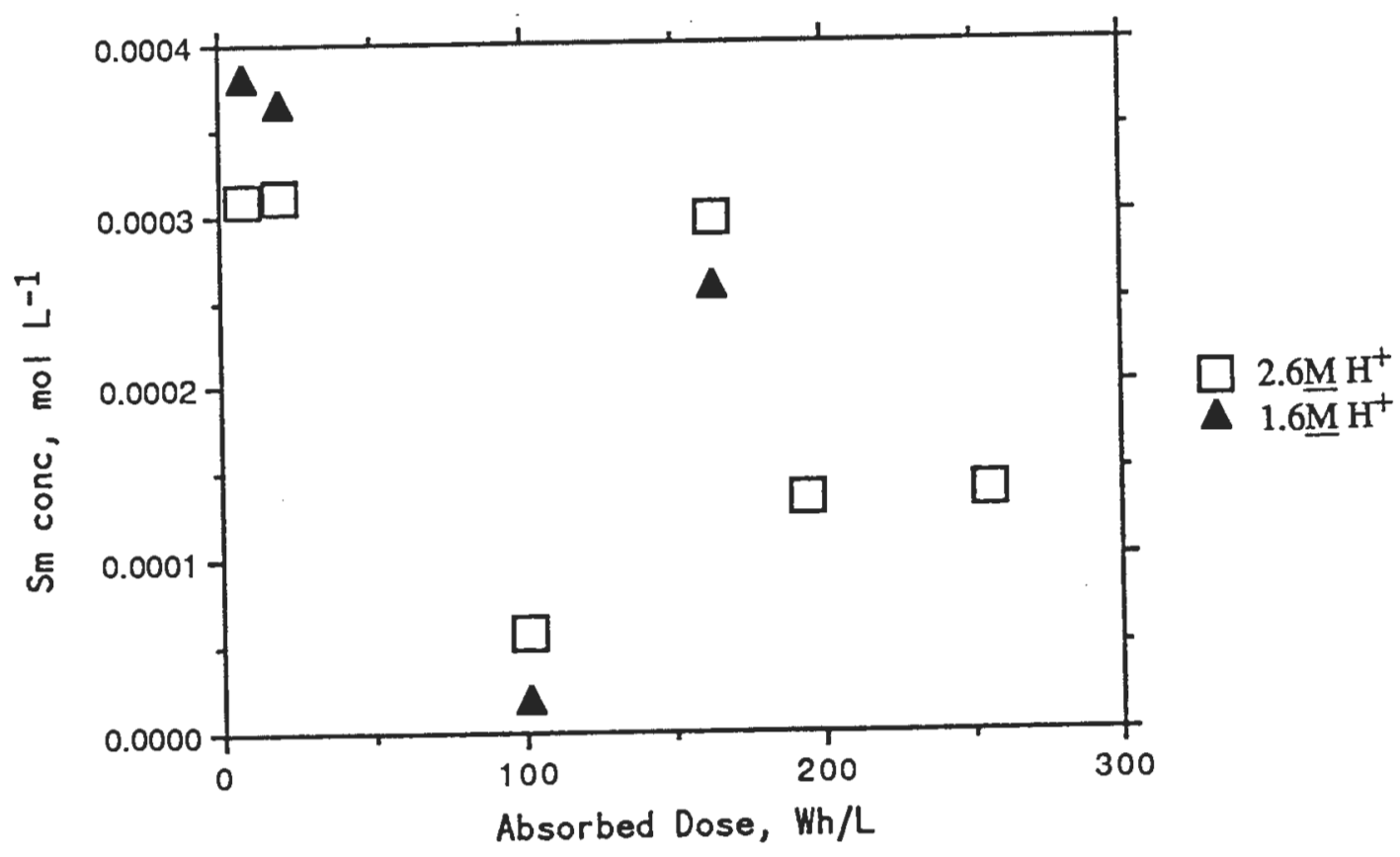

Fig. G-10. Concentration of Samarium in TRUEX-NPH Solvent Degraded by Radiolysis at $50^{\circ} \mathrm{C}$ in Contact with Simulated CAW Containing 1.6 or $2.6 \underline{\mathrm{M}} \mathrm{H}^{+}$

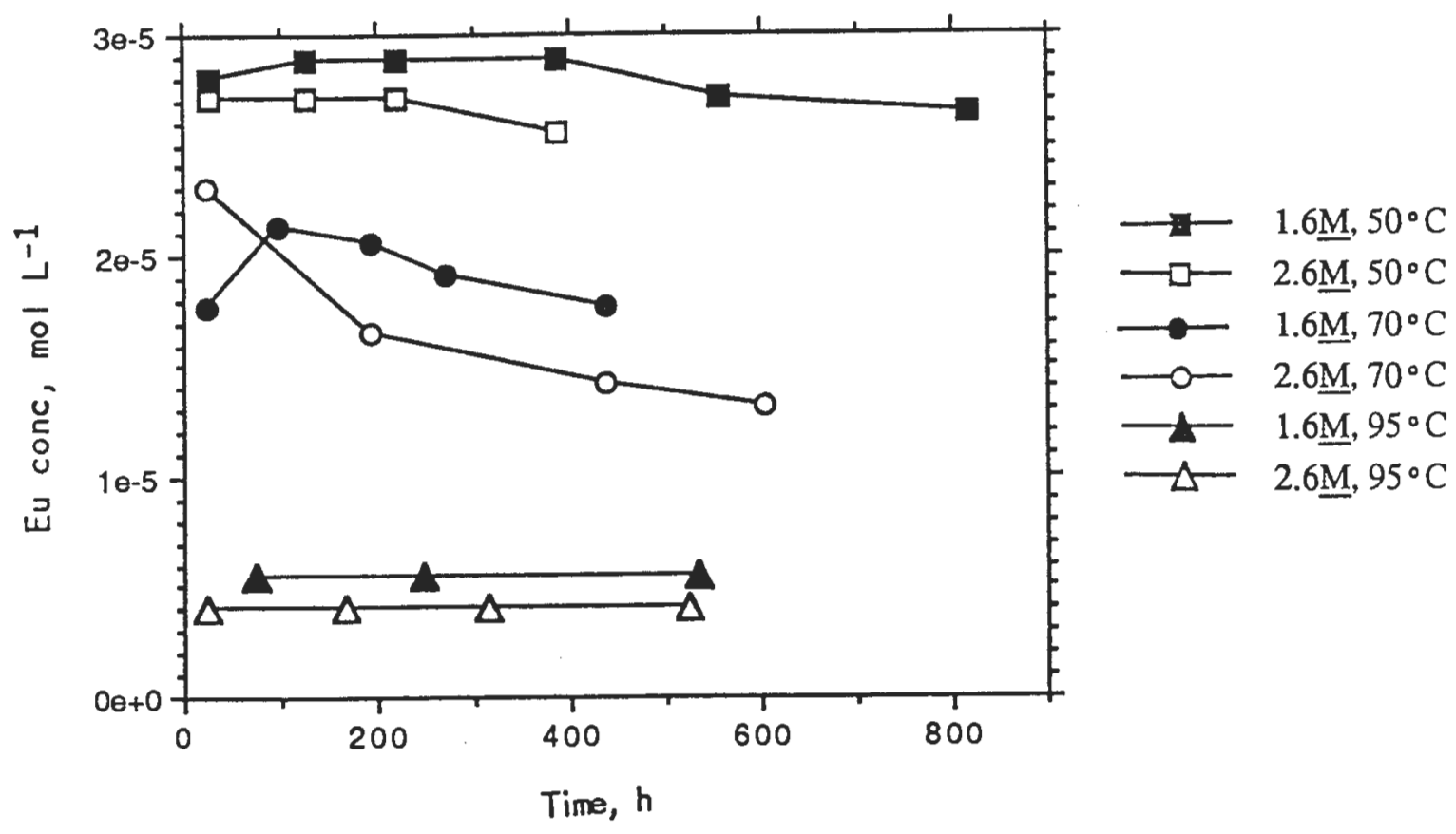

Fig. G-11. Concentration of Europium in TRUEX-NPH Solvent Degraded by Hydrolysis at 50,70 , or $95^{\circ} \mathrm{C}$ in Contact with Simulated CAW Containing 1.6 or $2.6 \underline{\mathrm{M}} \mathrm{H}^{+}$ 


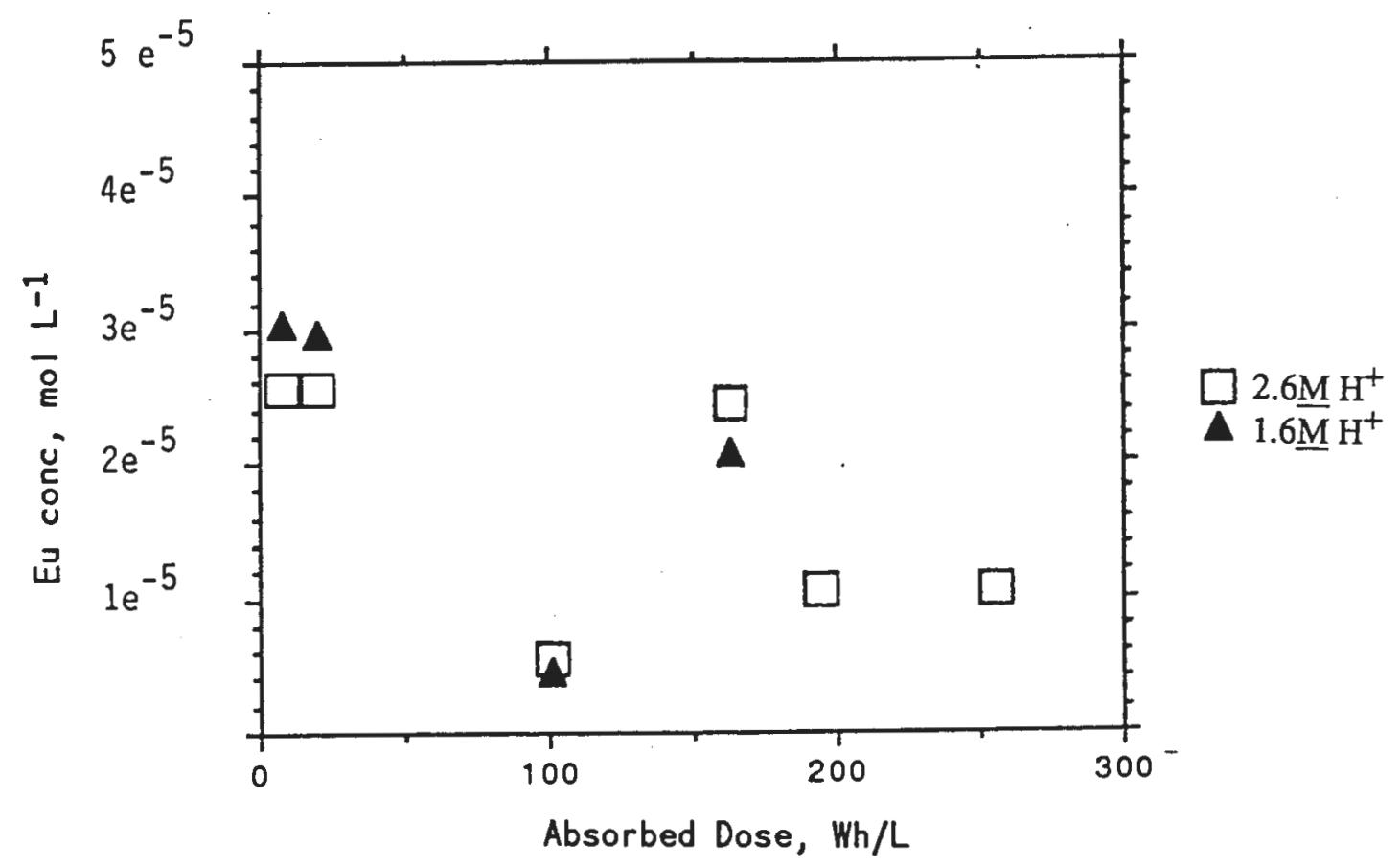

Fig. G-12. Concentration of Europium in TRUEX-NPH Solvent Degraded by Radiolysis at $50^{\circ} \mathrm{C}$ in Contact with Simulated CAW Containing 1.6 or $2.6 \underline{\mathrm{M}} \mathrm{H}^{+}$

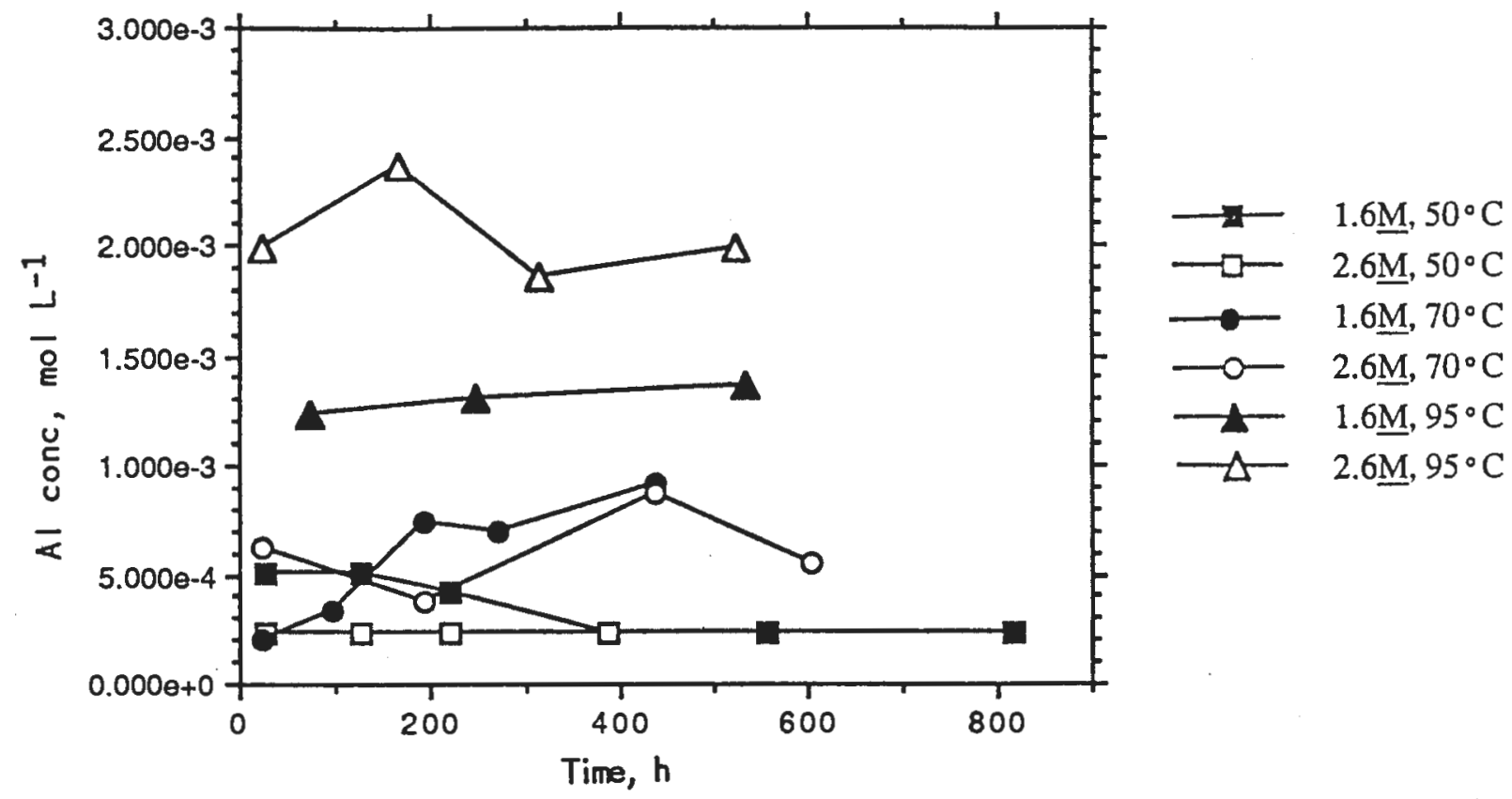

Fig. G-13. Concentration of Aluminum in TRUEX-NPH Solvent Degraded by Hydrolysis at 50,70 , or $95^{\circ} \mathrm{C}$ in Contact with Simulated CAW Containing 1.6 or $2.6 \underline{\mathrm{M}} \mathrm{H}^{+}$ 


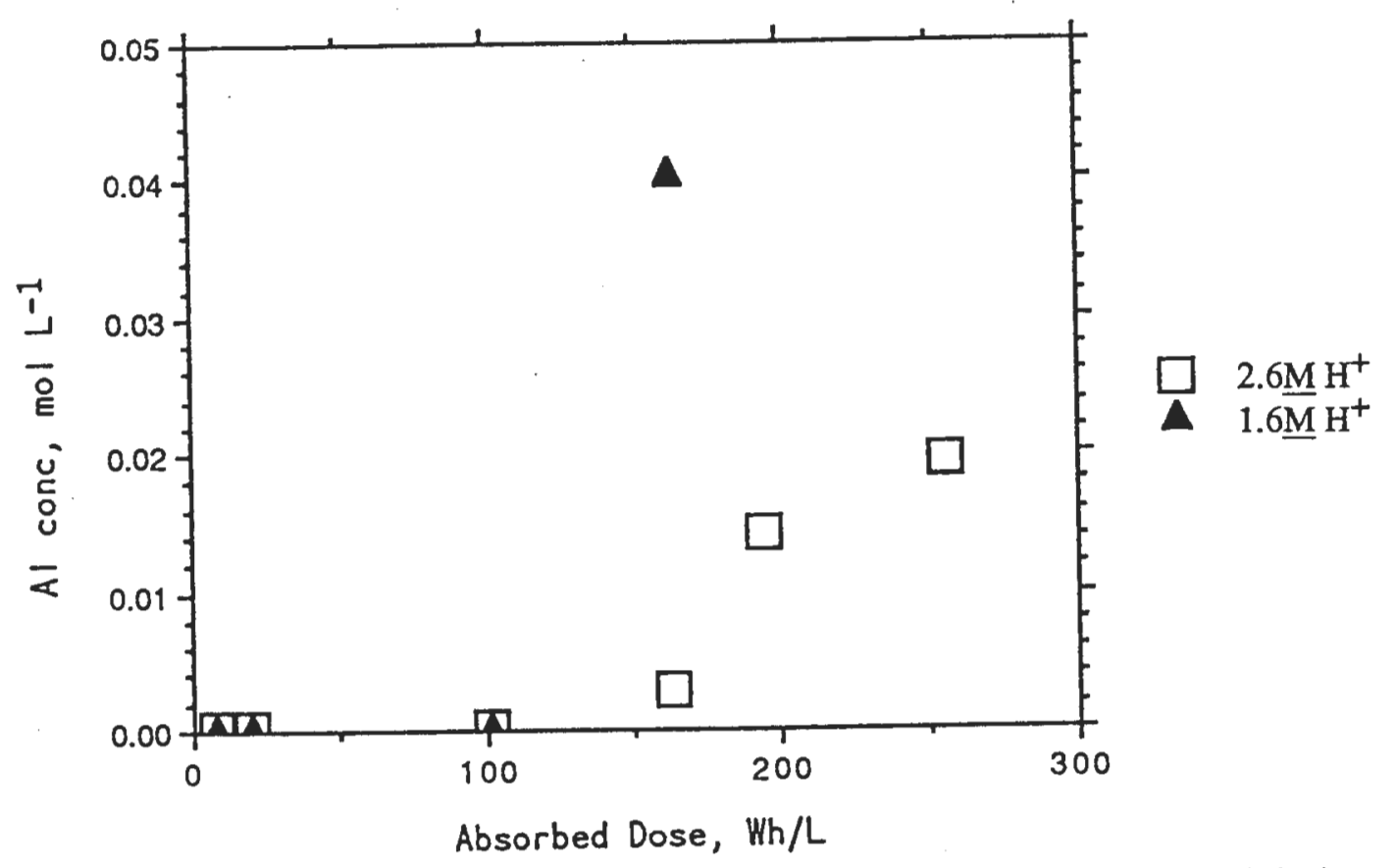

Fig. G-14. Concentration of Aluminum in TRUEX-NPH Solvent Degraded by Radiolysis at $50^{\circ} \mathrm{C}$ in Contact with Simulated CAW Containing 1.6 or $2.6 \underline{\mathrm{M}} \mathrm{H}^{+}$

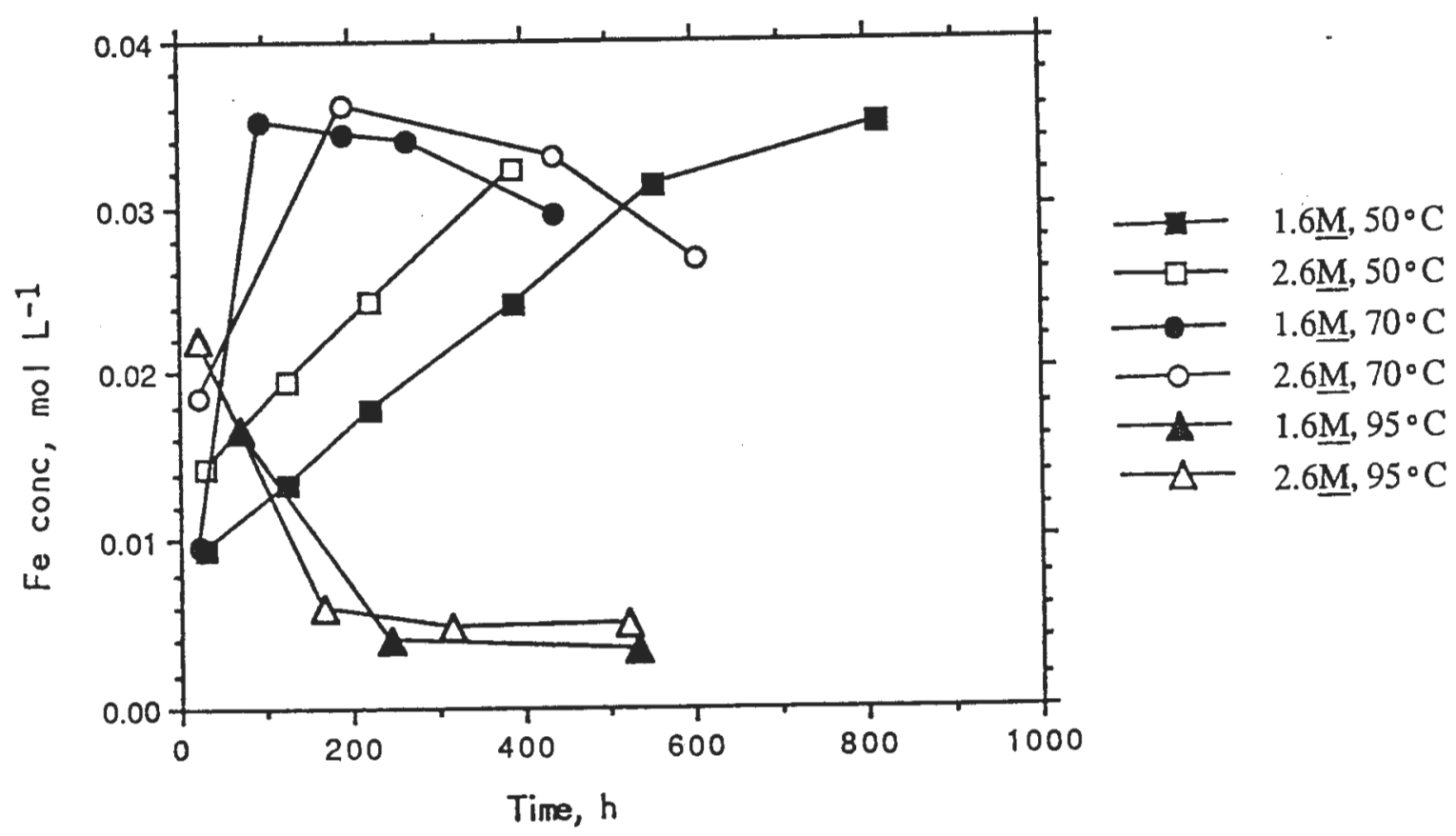

Fig. G-15. Concentration of Iron in TRUEX-NPH Solvent Degraded by Hydrolysis at 50,70 , or $95^{\circ} \mathrm{C}$ in Contact with Simulated CAW Containing 1.6 or $2.6 \underline{\mathrm{M} \mathrm{H}} \mathrm{H}^{+}$ 


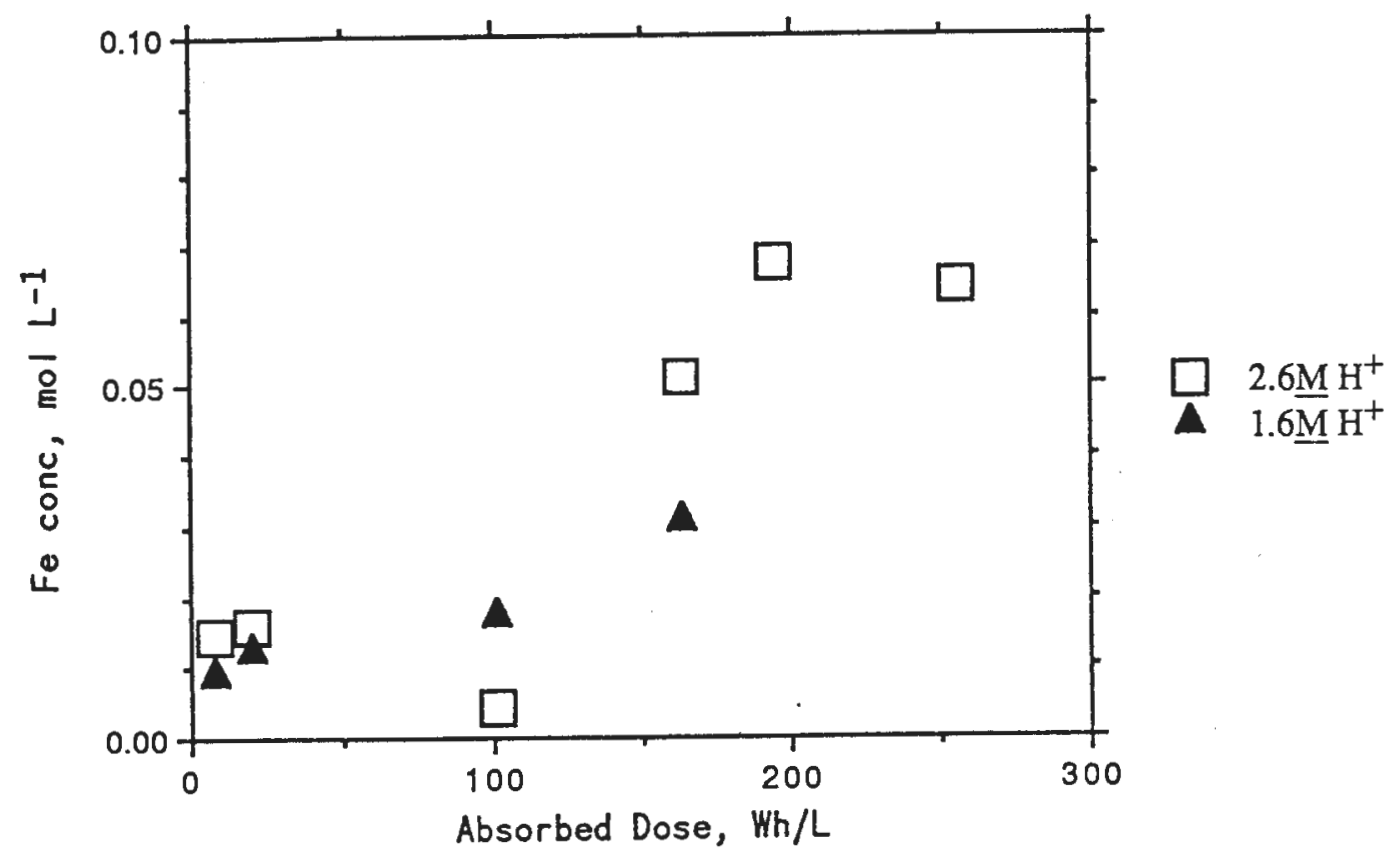

Fig. G-16. Concentration of Iron in TRUEX-NPH Solvent Degraded by Radiolysis at $50^{\circ} \mathrm{C}$ in Contact with Simulated CAW Containing 1.6 or $2.6 \underline{\mathrm{M} \mathrm{H}} \mathrm{H}^{+}$

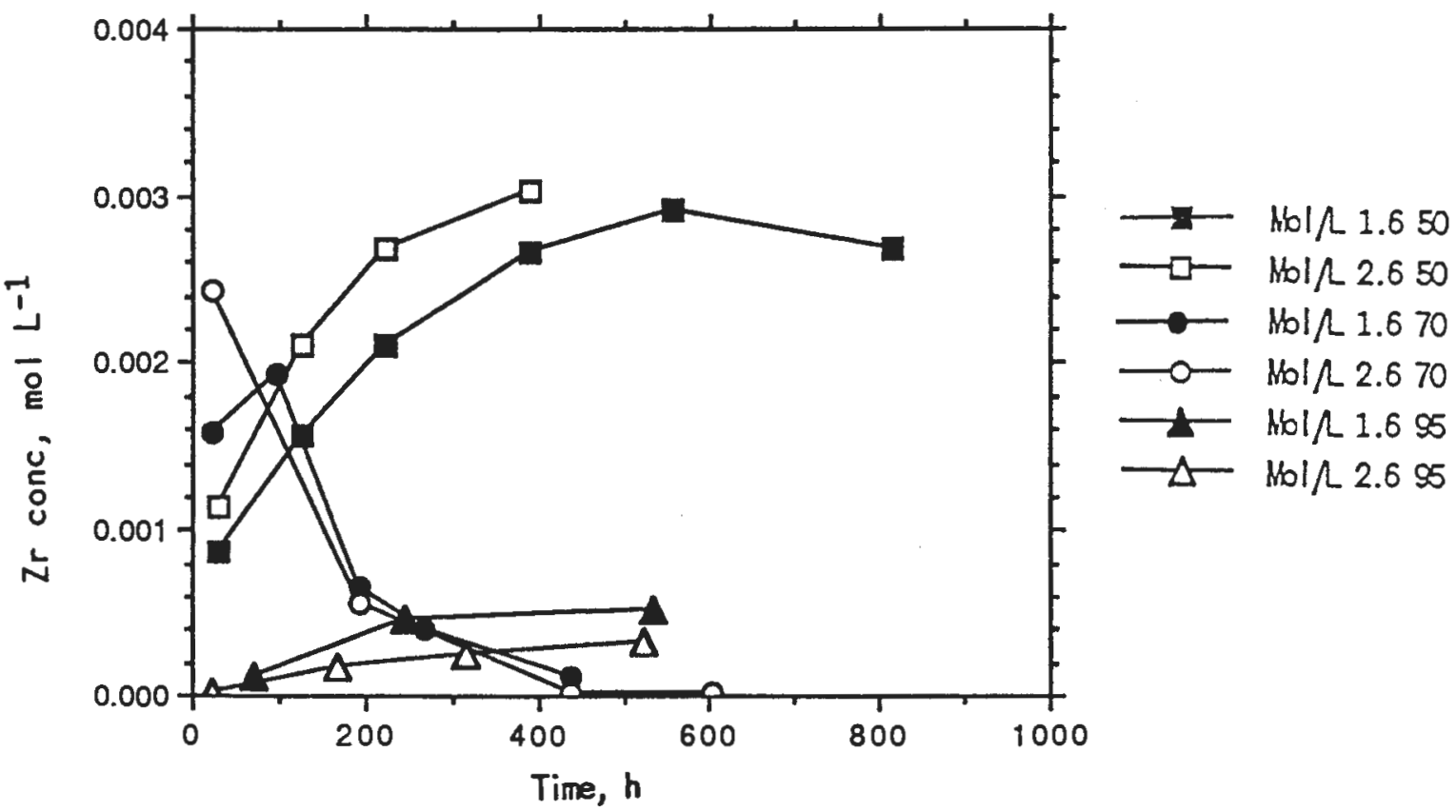

Fig. G-17. Concentration of Zirconium in TRUEX-NPH Solvent Degraded by Hydrolysis at 50,70 , or $95^{\circ} \mathrm{C}$ in Contact with Simulated CAW Containing 1.6 or $2.6 \mathrm{M} \mathrm{H}^{+}$ 


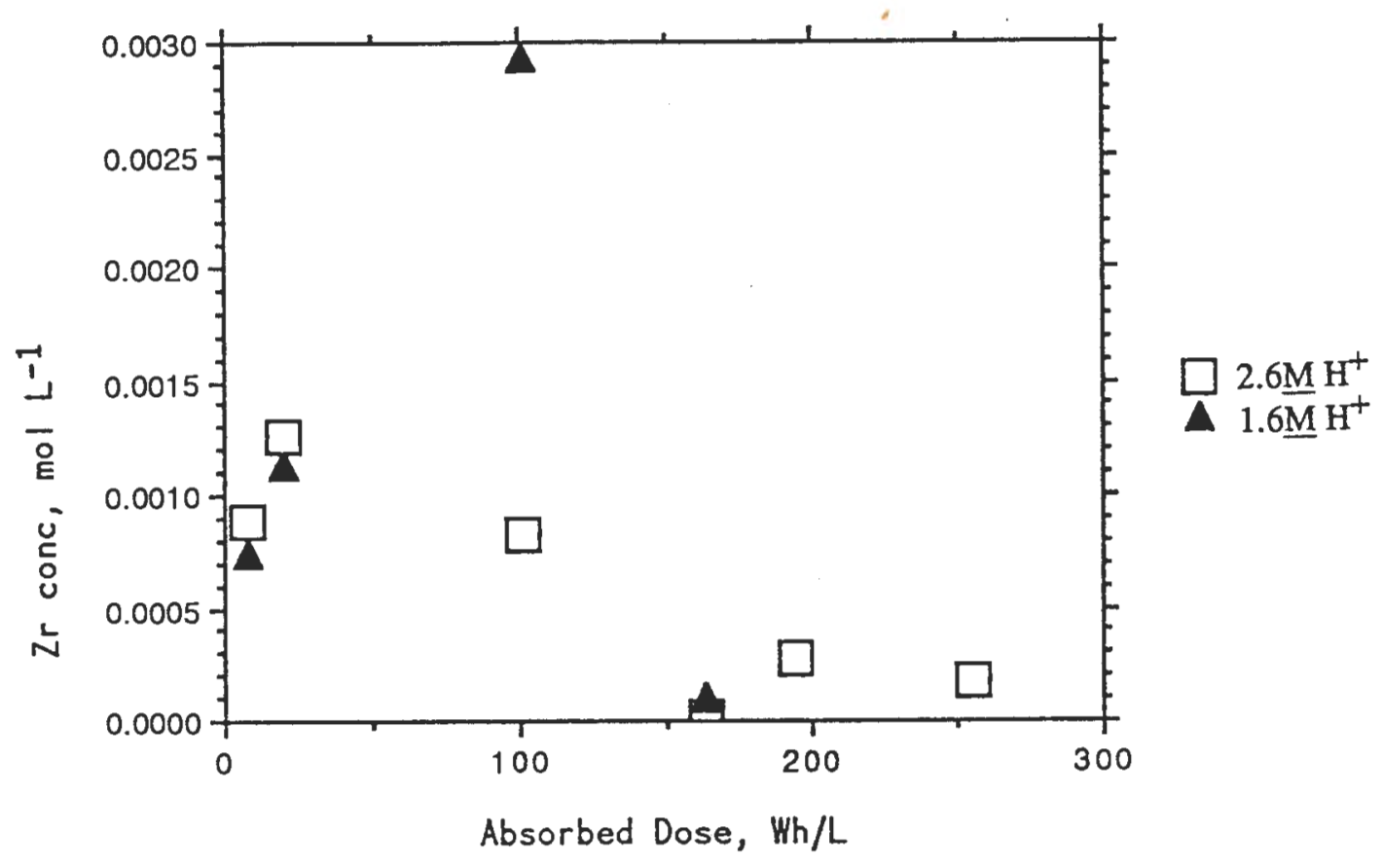

Fig. G-18. Concentration of Zirconium in TRUEX-NPH Solvent Degraded by Radiolysis at $50^{\circ} \mathrm{C}$ in Contact with Simulated CAW Containing 1.6 or $2.6 \mathrm{M} \mathrm{H}^{+}$

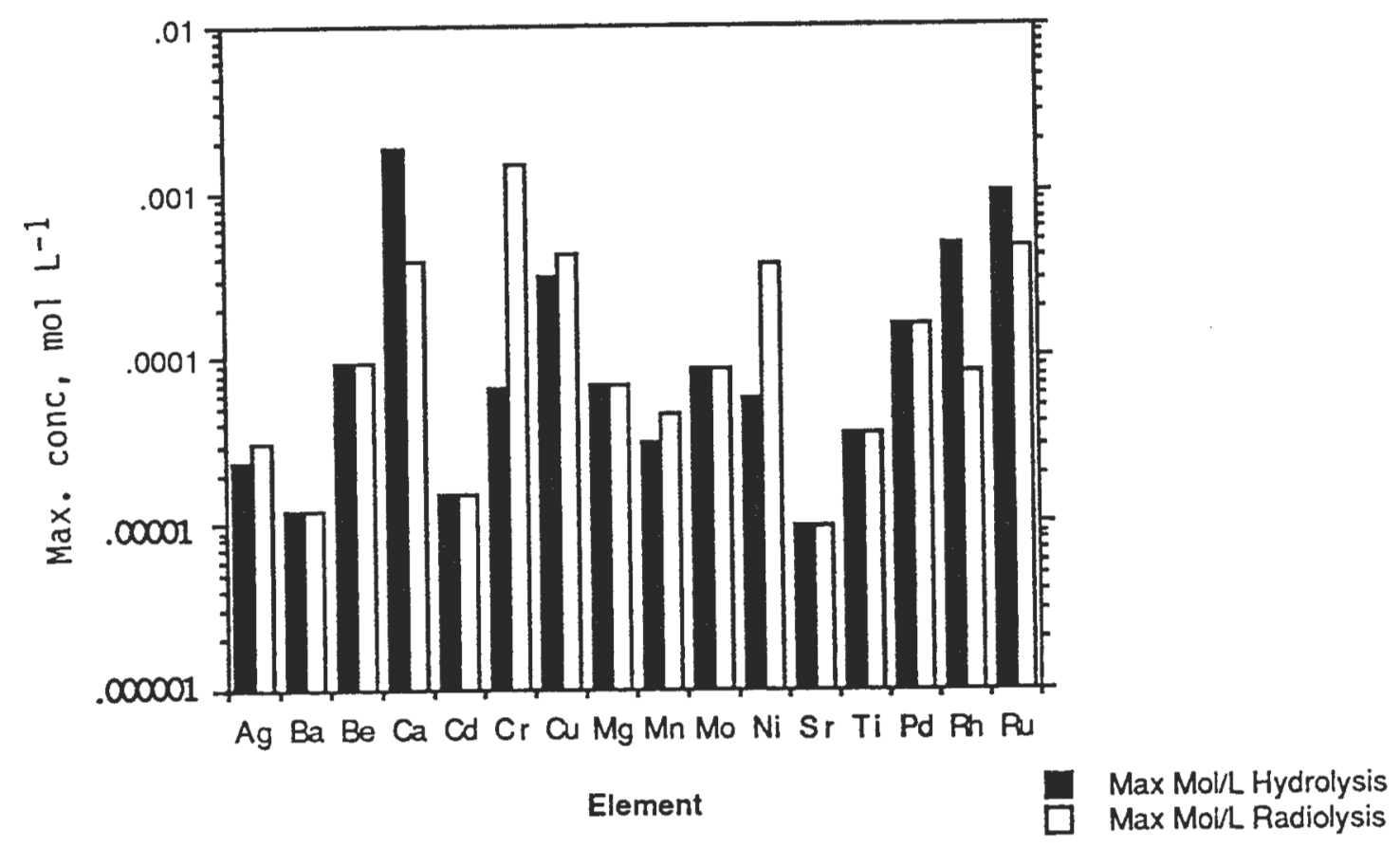

Fig. G-19. Maximum Concentration of NonTRU Elements in TRUEX-NPH Solvent Degraded in Contact with Simulated CAW by Hydrolysis at 50,70 , or $95^{\circ} \mathrm{C}$ and by Radiolysis at $50^{\circ} \mathrm{C}$ 
Distribution for ANL-90/14

Internal:
J. E. Battles
R. A. Leonard
L. E. Trevorrow (5)
D. L. Bowers
B. Misra
D. B. Chamberlain
M. C. Regalbuto
J. M. Copple
M. J. Steindler (2)
J. E. Harmon
C. E. Till
G. F. Vandegrift (20)
ANL Patent Dept.
ANL Contract File
J. C. Hutter

\section{External:}

DOE-OSTI (2)

ANL Library (2)

Manager, Chicago Operations Office, DOE

Chief, DOE-CH Patent Group

J. C. Haugen, DOE-CH

Chemical Technology Division Review Committee Members:

S. Baron, Brookhaven National Laboratory, Upton, NY

D. L. Douglas, Consultant, Bloomington, $\mathrm{MN}$

N. Jarrett, Noel Jarrett Associates, Lower Burrell, PA

J. G. Kay, Drexel University, Philadelphia, PA

J. Stringer, Electric Power Research Institute, Palo Alto, CA

J. B. Wagner, Arizona State University, Tempe, AZ

R. G. Wymer, Oak Ridge National Laboratory, Oak Ridge, TN

R. P. Anantatmula, Westinghouse Hanford Co., Richland, WA

J. A. Appel, Westinghouse Hanford Co., Richland, WA

M. Attrep, Jr., Los Alamos National Laboratory, Los Alamos, NM

S. Barker, Westinghouse Hanford Co., Richland, WA

G. S. Barney, Westinghouse Hanford Operations, Richland, WA

L. Beach, Rockwell International, Rocky Flats Plant, Golden, CO

J. T. Bell, Oak Ridge National Laboratory, Oak Ridge, TN

C. L. Bendixsen, Westinghouse Idaho Nuclear Co., Idaho Falls, ID

G. E. Benedict, Fluor Power Services, Irvine, CA

J. D. Berger, Westinghouse Hanford Co., Richland, WA

B. C. Blanke, USDOE-DA, Miamisburg, $\mathrm{OH}$

A. Bolt, Westinghouse Hanford Co., Richland, WA

W. D. Bond, Oak Ridge National Laboratory, Oak Ridge, TN

K. Boomer, Westinghouse Hanford Co., Richland, WA

D. F. Bowersox, Los Alamos National Laboratory, Los Alamos, NM

J. L. Burnett, USDOE, Office of Basic Energy Sciences, Germantown, MD

M. A. Cahill, Westinghouse Hanford Co., Richland, WA

D. Catlett, Los Alamos National Laboratory, Los Alamos, NM 
K. A. Chacey, USDOE, Office of Waste Management, Germantown, MD

C. E. Coffey, Westinghouse Savannah River Co., Aiken, SC

E. D. Collins, Oak Ridge National Laboratory, Oak Ridge, TN

P. Colton, Battelle Pacific Northwest Laboratory, Richland, WA

C. R. Cooley, USDOE, Office of Technology Development, Germantown, MD

M. S. Coops, Lawrence Livermore National Laboratory, Livermore, CA

J. T. D'Ambrosia, USDOE, Defense Waste and Transportation Management, Germantown, MD

M. Dinehart, Los Alamos National Laboratory, Los Alamos, NM

L. P. Duffy, USDOE, Environmental Restoration \& Waste Management, Washington, DC

W. R. Dworzak, Los Alamos National Laboratory, Los Alamos, NM

G. Escobar, Westinghouse Hanford Co., Richland, WA

C. W. Frank, USDOE, Office of Technology Development, Washington, DC

W. A. Freeby, Westinghouse Idaho Nuclear Co., Idaho Falls, ID

J. C. Fulton, Westinghouse Hanford Operations, Richland, WA

T. E. Gates, Westinghouse Hanford Co., Richland, WA

R. E. Gerton, USDOE, Richland Operations Office, Richland, WA

K. A. Giese, Westinghouse Hanford Co., Richland, WA

R. Gilchrist, Westinghouse Hanford Co., Richland, WA

A. P. Gouge, Westinghouse Savannah River Co., Aiken, SC

F. R. Graham, Westinghouse Savannah River Co., Aiken, SC

W. S. Groenier, Oak Ridge National Laboratory, Oak Ridge, TN

K. Hain, USDOE, Office of Technology Development, Germantown, MD

H. D. Harmon, Westinghouse Savannah River Co., Aiken, SC

J. M. Hennig, USDOE, Richland Operations Office, Richland, WA

M. E. Hodges, Westinghouse Savannah River Co., Aiken, SC

G. W. Hogg, Westinghouse Idaho Nuclear Co., Inc., Idaho Falls, ID

J. Holmes, Westinghouse Hanford Co., Richland, WA

J. O. Honeyman, Westinghouse Hanford Operations, Richland, WA

L. J. Jardine, Lawrence Livermore National Laboratory, Livermore, CA

J. J. Jicha, USDOE, New Production Department, Washington, DC

R. T. Jubin, Oak Ridge National Laboratory, Oak Ridge, TN

G. Kosiancic, Westinghouse Hanford Co., Richland, WA

D. Krenz, USDOE, Albuquerque Operations Office, Albuquerque, NM

C. M. Kronvall, Westinghouse Hanford Operations, Richland, WA

D. E. Kurath, Battelle Pacific Northwest Laboratory, Richland, WA

R. Lambert, Electric Power Research Institute, Palo Alto, CA

K. London, Rockwell International, Rocky Flats Plant, Golden, CO

Los Alamos National Laboratory, Director, Los Alamos, NM

R. Y. Lowrey, USDOE, Albuquerque Operations Office, Albuquerque, NM

G. Lumetta, Pacific Northwest Laboratory, Richland, WA

R. Maher, Westinghouse Savannah River Co., Aiken, SC

J. C. Mailen, Oak Ridge National Laboratory, Oak Ridge, TN

A. Malinauskas, Oak Ridge National Laboratory, Oak Ridge, TN

D. L. McIntosh, Westinghouse Savannah River Co., Aiken, SC

W. H. McVey, USDOE, Division of LMFBR Fuel Cycle Projects, Germantown, MD

G. A. Meyer, Westinghouse Hanford Co., Richland, WA 
E. Michaels, Mound Facility, Monsanto Research Corp., Miamisburg, $\mathrm{OH}$

A. C. Muscatello, Los Alamos National Laboratory, Los Alamos, NM

M. O'Hara, Martin Marietta Energy Systems, Oak Ridge, TN

Office of Basic Energy Sciences, USDOE, Washington, DC

A. L. Olson, Westinghouse Idaho Nuclear Co., Inc., Idaho Falls, ID

R. M. Orme, Westinghouse Hanford Co., Richland, WA

M. Palmer, Los Alamos National Laboratory, Los Alamos, NM

J. H. Pashley, Oak Ridge Gaseous Diffusion Plant, Oak Ridge, TN

G. Pfennigworth, Martin Marietta Energy Systems, Oak Ridge, TN

C. R. Reichmuth, Westinghouse Hanford Co., Richland, WA

D. J. Reif, Westinghouse Savannah River Co., Aiken, SC

G. W. Rosenwald, USDOE, Richland Operations Office, Richland, WA

W. G. Ruff, Westinghouse Hanford Co., Richland, WA

W. A. Rutherford, USDOE, Richland Operations Office, Richland, WA

P. S. Schaus, Westinghouse Hanford Co., Richland, WA

M. J. Schliebe, Westinghouse Hanford Operations, Richland, WA

P. Scott, Pacific Northwest Laboratory, Richland, WA

V. Sendelweck, Rockwell International, Golden, CO

E. Slaathug, Westinghouse Hanford Co., Richland, WA

J. P. Sloughter, Westinghouse Hanford Co., Richland, WA

W. H. Smith, Los Alamos National Laboratory, Los Alamos, NM

F. D. Stevenson, USDOE, Office of Basic Energy Sciences, Germantown, MD

J. Straalsund, Pacific Northwest Laboratory, Richland, WA

J. L. Swanson, Battelle Pacific Northwest Laboratory, Richland, WA

D. W. Tedder, Georgia Institute of Technology, Atlanta, GA

M. Thompson, Westinghouse Savannah River Co., Aiken, SC

T. A. Todd, Westinghouse Idaho Nuclear Co., Inc., Idaho Falls, ID

J. C. Tseng, USDOE, Office of Waste Operations, Germantown, MD

D. A. Turner, Westinghouse Hanford Co., Richland, WA

V. C. A. Vaughn, Oak Ridge National Laboratory, Oak Ridge, TN

J. Watson, Oak Ridge National Laboratory, Oak Ridge, TN

M. E. Whatley, Oak Ridge National Laboratory, Oak Ridge, TN

B. R. Wheeler, Westinghouse Idaho Nuclear Co., Inc., Idaho Falls, ID

A. K. Williams, Bechtel National Inc., San Francisco, CA

G. Wilson, Westinghouse Hanford Operations, Richland, WA

D. D. Wodrich, Westinghouse Hanford Co., Richland, WA

J. C. Womack, Westinghouse Hanford Co., Richland, WA

S. Yarbro, Los Alamos National Laboratory, Los Alamos, NM

D. Yearwood, Los Alamos National Laboratory, Los Alamos, NM 


ANL

TIS LIBRARIES

In|N|W.|.

00392076

ซึ

0

$\frac{0}{2}$ 